\title{
Conceptual Design of Oxygen-Based PC Boiler
}

\author{
Final Report
}

\author{
Andrew Seltzer \\ Zhen Fan
}

September 2005

DE-FC26-03NT41736

Foster Wheeler Power Group, Inc.

12 Peach Tree Hill Road

Livingston, New Jersey 07039 


\section{DISCLAIMER}

This report was prepared as an account of work sponsored by an agency of the United States Government. Neither the United States Government nor any agency thereof, nor any of their employees, makes any warranty, express or implied, or assumes any legal liability or responsibility for the accuracy, completeness, or usefulness of any information, apparatus, product, or process disclosed, or represents that its use would not infringe privately owned rights. Reference herein to any specific commercial product, process, or service by trade name, trademark, manufacturer, or otherwise does not necessarily constitute or imply its endorsement, recommendation, or favoring by the United States Government or any agency thereof. The views and opinions of authors expressed herein do not necessarily state or reflect those of the United States Government or any agency thereof. 


\section{ABSTRACT}

Coal is presently the world's primary fuel for generating electrical power and, being more abundant and less expensive than oil or natural gas, is expected to continue its dominance into the future. Coal, however, is more carbon intensive than natural gas and oil and consequently coal-fired power plants are large point source emitters of carbon dioxide $\left(\mathrm{CO}_{2}\right)$. Since $\mathrm{CO}_{2}$ is a greenhouse gas, which may have an adverse impact on the world's climate/weather patterns, studies have been conducted to determine the feasibility and economic impact of capturing power plant $\mathrm{CO}_{2}$ emissions for pipeline transport to a sequestration/storage site.

The stack gas that exhausts from a modern coal-fired power plant typically contains about 15 per cent $\mathrm{CO}_{2}$ on a dry volume basis. Although there are numerous processes available for removing $\mathrm{CO}_{2}$ from gas streams, gas scrubbing with amine solvent is best suited for this application because of the large gas volumes and low $\mathrm{CO}_{2}$ concentrations involved. Unfortunately the energy required to regenerate the solvent for continued use as a capturing agent is large and imposes a severe energy penalty on the plant. In addition this "back end" or post combustion cleanup requires the addition of large vessels, which, in retrofit applications, are difficult to accommodate.

As an alternative to post combustion scrubbing, Foster Wheeler (FW) has proposed that the combustion process be accomplished with oxygen rather than air. With all air nitrogen eliminated, a $\mathrm{CO}_{2}$-water vapor rich flue gas will be generated. After condensation of the water vapor, a portion of the flue gas will be recirculated back to the boiler to control the combustion temperature and the balance of the $\mathrm{CO}_{2}$ will be processed for pipeline transport. This proposed oxygen-carbon dioxide $\left(\mathrm{O}_{2} / \mathrm{CO}_{2}\right)$ combustion process eliminates the need for $\mathrm{CO}_{2}$ removal/separation and reduces the cost of supplying a $\mathrm{CO}_{2}$ rich stream for sequestration.

Under DOE Contract No DE-FC26-03NT41736 FW has developed a conceptual design of an $\mathrm{O}_{2}$ fired boiler to determine overall plant performance and economics. Five subtasks were conducted: 1) a literature review, 2) a system design and analysis, 3) a low NOx burner design and analysis, 4) a furnace and heat recovery area design analysis, and 5) an economic analysis.

The objective of the literature search is to locate any data/information relevant to the Oxygen-Based PC Boiler conceptual design.

The objective of the system design and analysis task is to optimize the PC boiler plant by maximizing system efficiency within practical considerations. Simulations of the oxygen-fired plant with $\mathrm{CO}_{2}$ sequestration were conducted using Aspen Plus and were compared to a reference air-fired $460 \mathrm{MW}$ plant. Flue gas recycle is used in the $\mathrm{O}_{2}$-fired $\mathrm{PC}$ to control the flame temperature. Parametric runs were made to determine the effect of flame temperature on system efficiency and required waterwall material and thickness. The degree of improvement on system efficiency of various modifications including hot gas recycle, purge gas recycle, flue gas feedwater recuperation, and 
recycle purge gas expansion were investigated. The selected $\mathrm{O}_{2}$-fired design case has a system efficiency of $30.6 \%$ compared to the air-fired system efficiency of $36.7 \%$. The design $\mathrm{O}_{2}$-fired case requires T91 waterwall material and has a waterwall surface area of only $65 \%$ of the air-fired reference case.

The objective of the low NOx burner design and analysis task is to optimize the burner design to ensure stable ignition, to provide safe operation, and to minimize pollutant formation. The burners were designed and analyzed using the Fluent CFD computer program. Four burner designs were developed: 1) with no OFG and $65 \%$ flue gas recycle, 2) with $20 \%$ OFG and $65 \%$ flue gas recycle, 3 ) with no OFG and $56 \%$ flue gas recycle and 4 ) with $20 \%$ OFG and $56 \%$ flue gas recycle. A 3-D Fluent simulation was made of a single wall-fired burner and horizontal portion of the furnace from the wall to the center. Without primary gas swirl, coal burnout was relatively small, due to the low oxygen content of the primary gas. Consequently, the burners were modified to include primary gas swirl to bring the coal particles in contact with the secondary gas. An optimal primary gas swirl was chosen to achieve sufficient burnout.

The objective of the furnace and heat recovery area design and analysis task is to optimize the location and design of the furnace, burners, over-fire gas ports, and internal radiant surfaces. The furnace is designed with opposed wall-firing burners and over-fire air ports. Water is circulated in the furnace by natural circulation to the waterwalls and divisional wall panels. Compared to the air-fired furnace, the oxygenfired furnace requires only $65 \%$ of the surface area and $45 \%$ of the volume. Two oxygen-fired designs were simulated: 1) without over-fire air and 2) with $20 \%$ over-fire air. The maximum wall heat flux in the oxygen-fired furnace is more than double that of the air-fired furnace due to the higher flame temperature and higher $\mathrm{H}_{2} \mathrm{O}$ and $\mathrm{CO}_{2}$ concentrations. The coal burnout for the oxygen-fired case is $100 \%$ due to a $500^{\circ} \mathrm{F}$ higher furnace temperature and higher concentration of $\mathrm{O}_{2}$. Because of the higher furnace wall temperature of the oxygen-fired case compared to the air-fired case, furnace water wall material was upgraded from carbon steel to T91. The total heat transfer surface required in the oxygen-fired heat recovery area is $25 \%$ less than the airfired HRA due to more heat being absorbed in the oxygen-fired furnace and the greater molecular weight of the oxygen-fired flue gas.

The objective of the economic analysis is to prepare a budgetary estimate of capital and operating costs of the $\mathrm{O}_{2}$-fired $\mathrm{PC}$ power plant as well as for the equivalent conventional PC-fired power plant. Capital and operating costs of conventional steam generation, steam heating, and power generation equipment are estimated based on Foster Wheeler's experience and database. Capital and operating costs of equipment, such as oxygen separation and $\mathrm{CO}_{2}$ liquefaction, are based on vendor supplied data and $\mathrm{FW}$ process plant experience. The levelized cost of electricity is determined for both the airfired and $\mathrm{O}_{2}$-fired power plants as well as the $\mathrm{CO}_{2}$ mitigation cost. An economic comparison between the $\mathrm{O}_{2}$-fired $\mathrm{PC}$ and other alternate technologies is presented. The levelized COE was calculated to be $4.61 \phi / \mathrm{kWh}$ for the reference air-fired plant and $6.41 \phi / \mathrm{kWh}$ for the $\mathrm{O}_{2} \mathrm{PC}$ plant. The $\mathrm{CO}_{2}$ mitigation cost of the $\mathrm{O}_{2}-\mathrm{PC}$ plant was calculated at 21.4 \$/tonne. 


\section{Table of Contents}

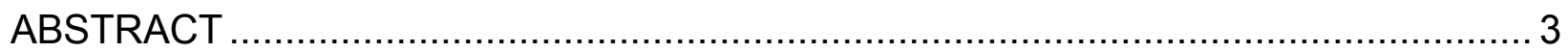

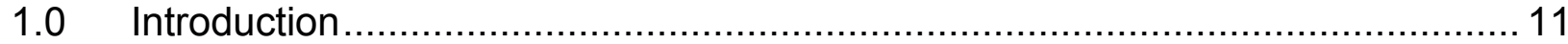

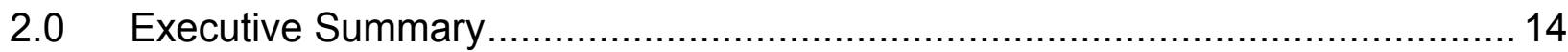

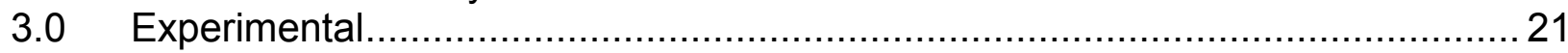

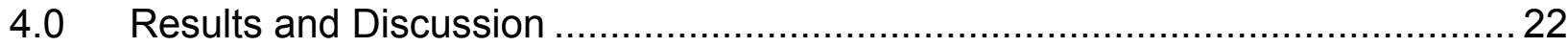

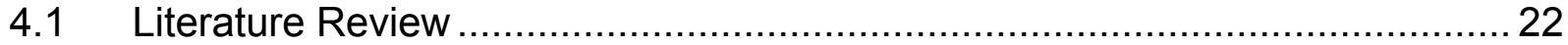

4.1.1 Combustion With Partial Oxygen Enhancement ............................... 22

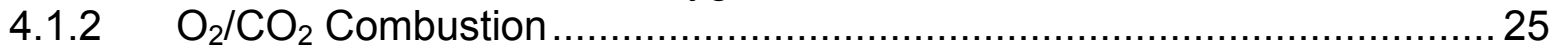

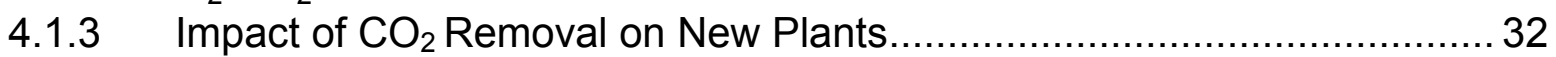

4.1.3.1 International Energy Agency Study …......................................... 32

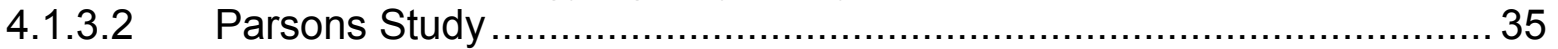

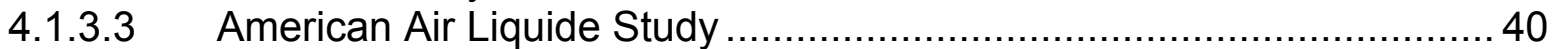

4.1.3.4 Summary of New Plant Studies...................................................... 42

4.1.4 Impact of $\mathrm{CO}_{2}$ Removal On Existing Plants ..................................... 44

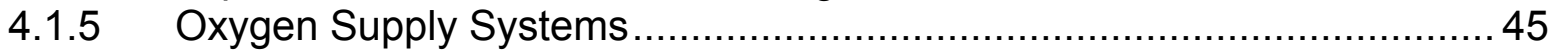

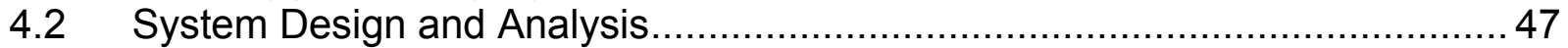

4.2.1 Reference Site and Fuel Conditions ................................................... 47

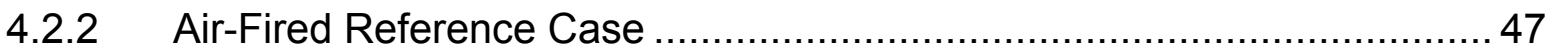

4.2.3 Oxygen-Based PC Plant ............................................................. 49

4.2.3.1 Boiler Plant Modifications .............................................................. 49

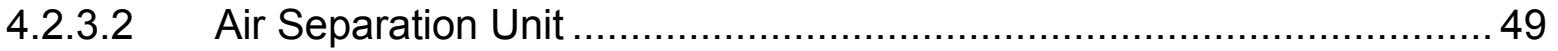

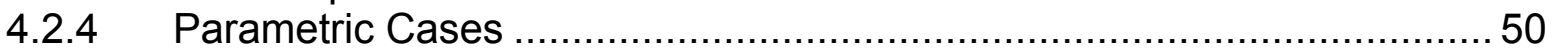

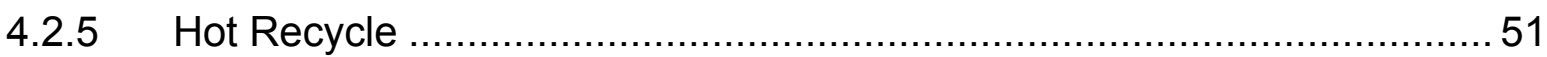

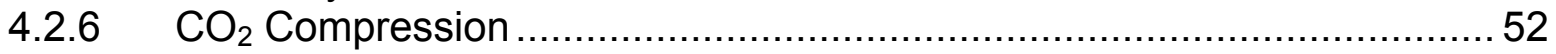

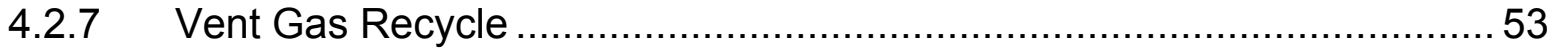

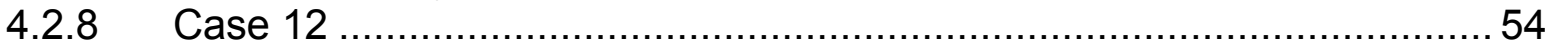

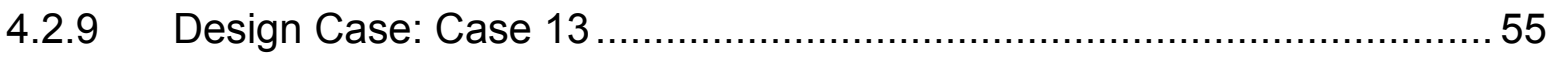

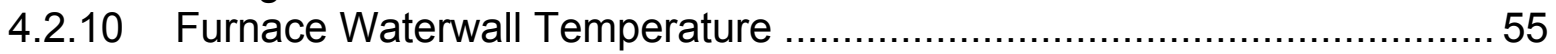

4.2.11 Comparison With Post $\mathrm{CO}_{2}$ Capture ................................................5 57

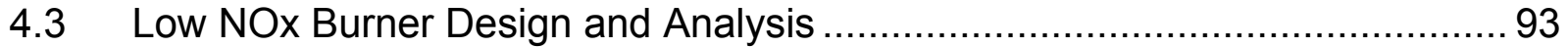

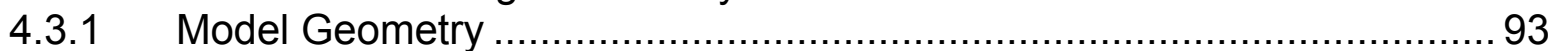

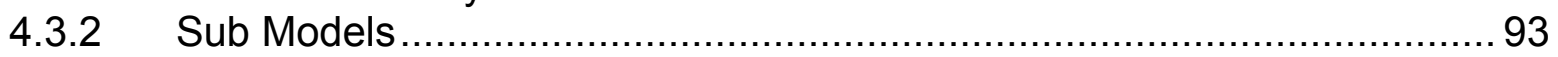

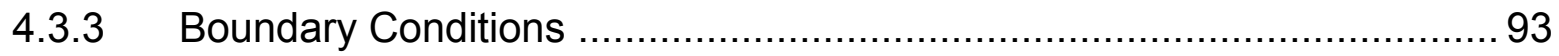

4.3.4 65\% Recycle Case With No OFG ..................................................... 94

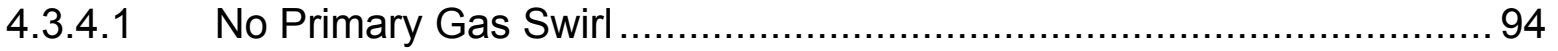

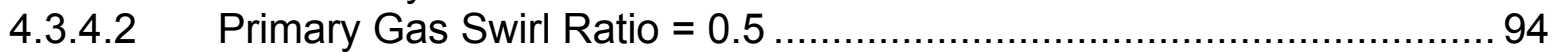

4.3.5 65\% Recycle Case With 20\% OFG ................................................. 94

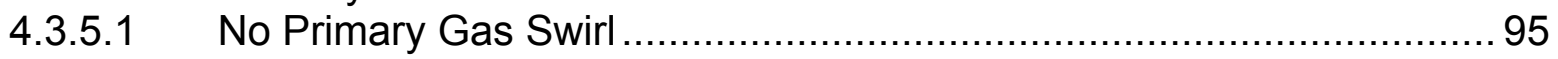

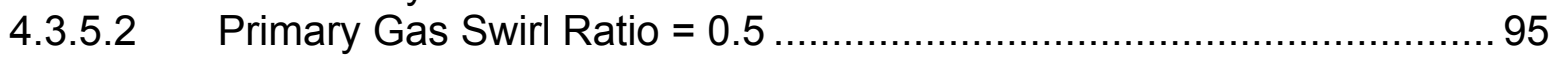

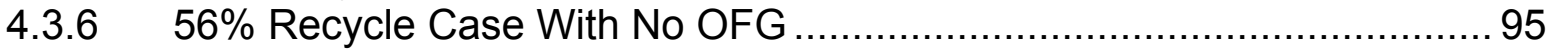

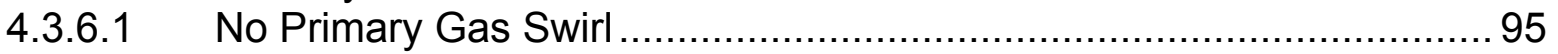

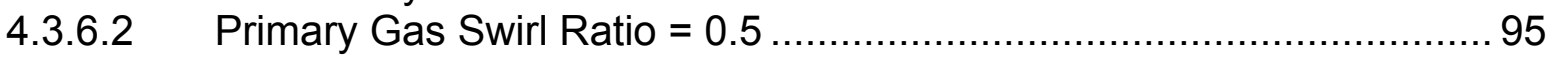

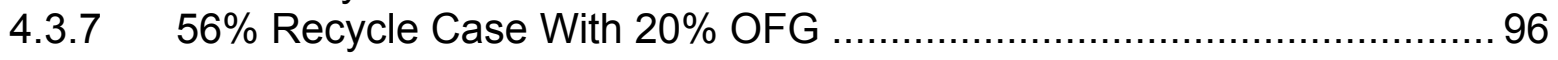

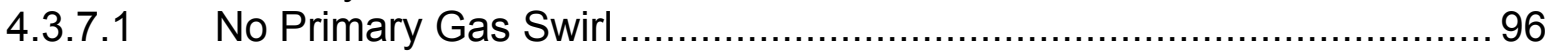




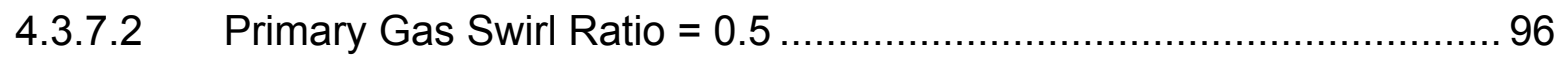

4.4 Furnace and HRA Design and Analysis ............................................... 144

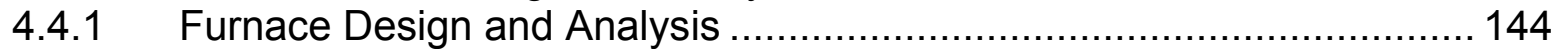

4.4.1.1 FW-FIRE Computer Program Description .................................... 144

4.4.1.2 Model Geometry.................................................................. 145

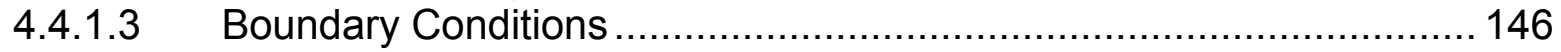

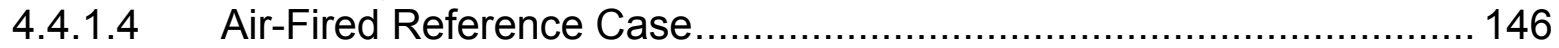

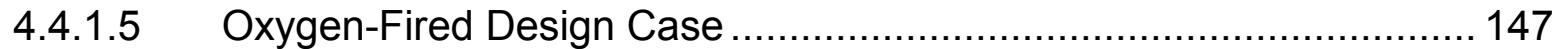

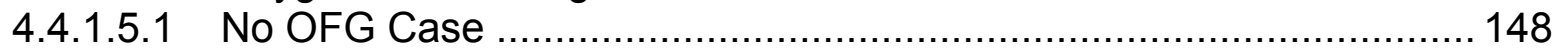

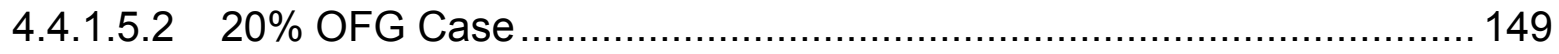

4.4.2 Heat Recovery Area Design and Analysis ........................................ 150

4.4.2.1 HEATEX Program Description .................................................. 150

4.4.2.2 Air-Fired Reference Case .......................................................... 150

4.4.2.3 Oxygen-Fired Case ..................................................................... 150

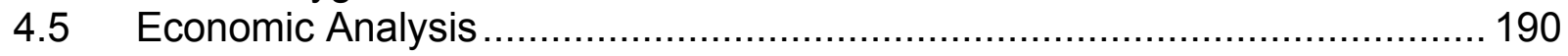

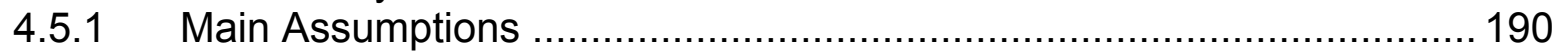

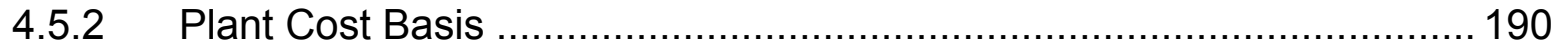

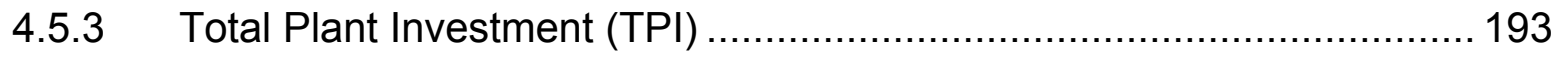

4.5.4 Total Capital Requirement (TCR) ……............................................. 193

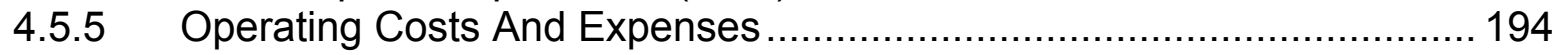

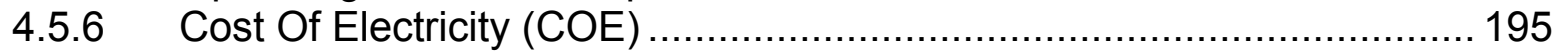

4.5.7 Comparison with Other Technologies ............................................ 196

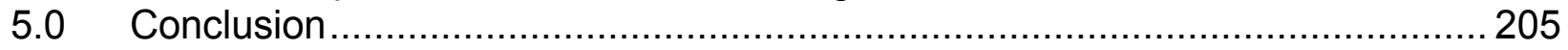

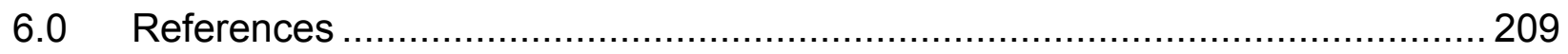

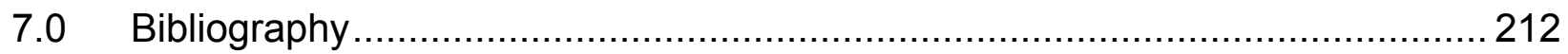

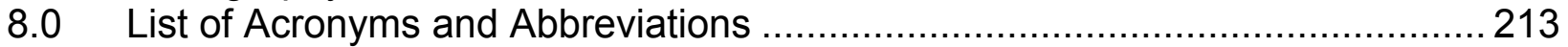




\section{LIST OF GRAPHICAL MATERIALS}

\section{Tables}

Table 4.1.1 CANMET Burner Operating Conditions ............................................ 28

Table 4.1.2 CANMET Burner Test Flow Rates............................................... 28

Table 4.1.3 CANMET Burner Performance ...................................................... 29

Table 4.1.4 Performance of Nominal 500 MWe Power Generating Technologies ........ 34

Table 4.1.5 Effect of $\mathrm{CO}_{2}$ Capture Technologies on a Nominal 500 MWe PC Fired Plant

Table 4.1.6 Effect of $\mathrm{CO}_{2}$ Absorption on Alternative Power Generating Technologies.. 35

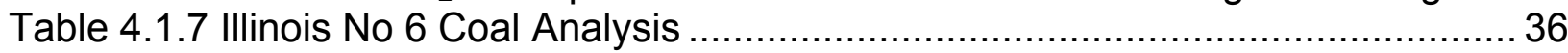

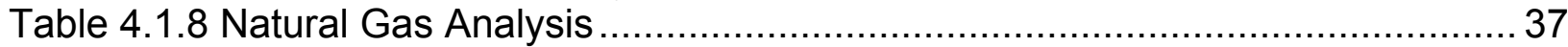

Table 4.1.9 NGCC and Illinois No 6 PC Plants Without $\mathrm{CO}_{2}$ Capture ...................... 38

Table 4.1.10 NGCC and Illinois No 6 PC Plants with 90 Per Cent $\mathrm{CO}_{2}$ Capture........... 39

Table 4.1.11 PRB Fueled PC Plant Performance With and Without $\mathrm{CO}_{2}$ Capture....... 41

Table 4.1.12 Summary of Plant $\mathrm{CO}_{2}$ Removal Studies ....................................... 43

Table 4.1.13 $\mathrm{CO}_{2}$ Removal Incorporated Into An Existing PC Plant......................... 45

Table 4.2.1 - Site Conditions and Coal Properties.......................................... 59

Table 4.2.2 - Case 1 (Air-Fired Reference) Boundary Conditions and Results ...........61 61

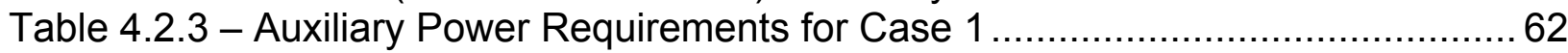

Table 4.2.4 - Parametric Cases Summary (Without $\mathrm{CO}_{2}$ Compression) .................... 71

Table 4.2 .5 - Parametric Cases Summary (With $\mathrm{CO}_{2}$ Compression) ....................... 82

Table 4.2.6 - Radiation Heat Flux and Water Wall Temperature ............................. 86

Table 4.3.1 - Coal Properties.................................................................. 99

Table 4.3.2 -Model Boundary Conditions .................................................. 100

Table 4.3.3 - Summary of Fluent Burner Modeling Results ................................ 101

Table 4.4.1 - Air-Fired Boundary Conditions .................................................. 155

Table 4.4.2 - Oxygen-Fired Boundary Conditions .......................................... 156

Table 4.4.3 - Summary of FW-FIRE Furnace Modeling Results.......................... 158

Table 4.4 .4 - HRA Tube Bank Design ........................................................ 188

Table 4.4.5 - HRA Tube Bank Performance .............................................. 189

Table 4.5.1 - Oxygen-Fired PC Plant Capital Cost Estimate ................................. 192

Table 4.5.2 - Operating, Maintenance and Fuel Costs for the $\mathrm{O}_{2} \mathrm{PC}$ and the Air-fired

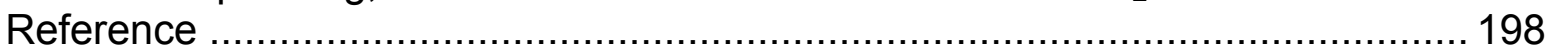

Table 4.5.3 - Estimate Basis/Financial Criteria for Revenue Requirement Calculations:

Air-fired Reference Plant ..................................................................... 199

Table 4.5.4 - Estimate Basis/Financial Criteria for Revenue Requirement Calculations:

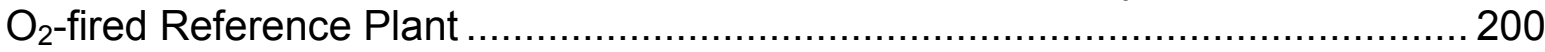

Table 4.5.5 - Capital Investment and Revenue Requirement Summary: Air-fired Reference Plant ................................................................................. 201

Table 4.5.6 - Capital Investment and Revenue Requirement Summary: $\mathrm{O}_{2}$-fired Plant 202 


\section{Figures}

Figure 4.1.1 Effect of OEC on Class C Bituminous Coal NOx Emissions .................... 24

Figure 4.1.2 Effect of OEC on Class A Bituminous Coal NOx Emissions......................2 24

Figure 4.1.3 Effect of Oxygen Ratio on Burner Combustion Efficiency ........................26

Figure 4.1.4 Effect of Primary to Secondary $\mathrm{O}_{2}$ Ratio on Burner Combustion Efficiency

Figure 4.1.5 CANMET Burner

Figure 4.1.6 Centerline Temperatures Downstream of Burner ................................ 30

Figure 4.1.7 Centerline NOx Emission Rates ……............................................ 30

Figure 4.1.8 Centerline $\mathrm{SO}_{2}$ Emission Rates ..................................................... 31

Figure 4.1.9 PRB Fired PC Plant Capital Costs With and Without $\mathrm{CO}_{2}$ Capture........... 42

Figure 4.1.10 PRB Fired PC Plant COE and $\mathrm{CO}_{2}$ Avoided Costs ............................ 42

Figure 4.2.1 - Cycle Analysis of Case 1 (Air-Fired Reference Case) ..........................60

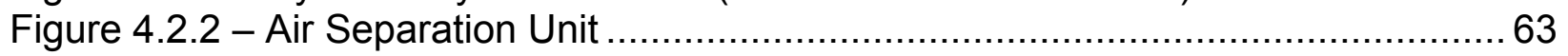

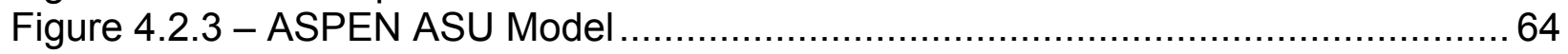

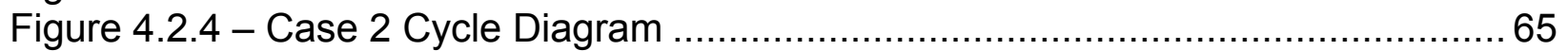

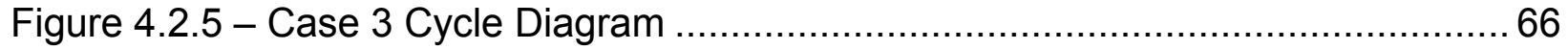

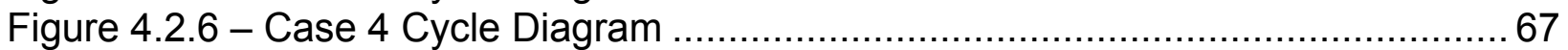

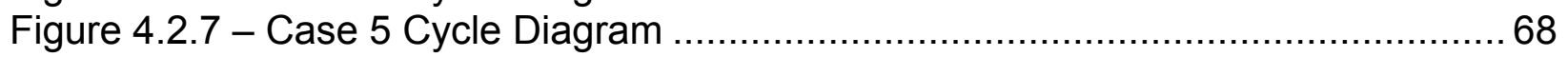

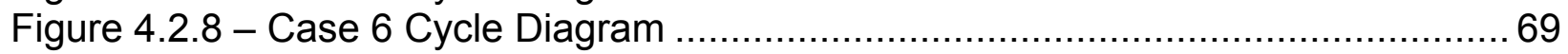

Figure 4.2.9 - Case 7 Cycle Diagram ............................................................ 70

Figure 4.2.10 - Net Efficiency (without $\mathrm{CO}_{2}$ compression) Versus Adiabatic

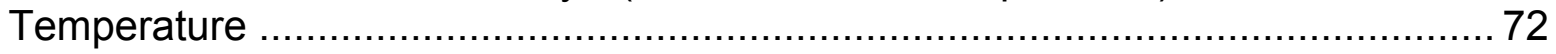

Figure 4.2.11 - ASU and Auxiliary Power Requirements Versus Adiabatic Temperature

.

Figure 4.2.12 - Recycled Gas Mass Flow Rate Versus Adiabatic Temperature ............74

Figure 4.2.13 - Recycled Gas Volumetric Flow Rate Versus Adiabatic Temperature... 75

Figure 4.2.14 - Flue Gas Cooling Curve ........................................................ 76

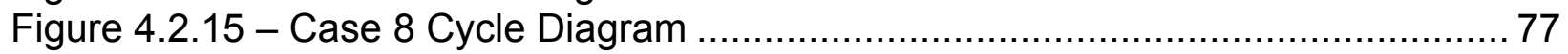

Figure 4.2.16 - Case 9 Cycle Diagram ......................................................... 78

Figure 4.2.17 - Net Cycle Efficiency Vs. Flue Gas Recycle Flow ..............................79

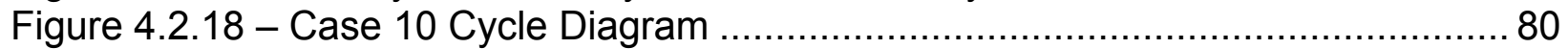

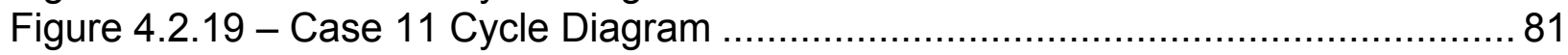

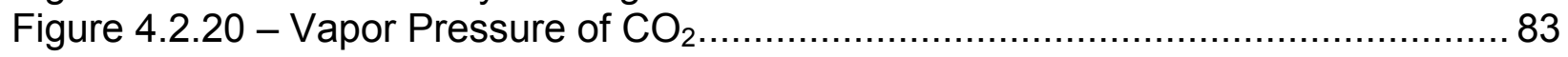

Figure 4.2.21 - Equilibrium CO and CO2 Versus Flue Gas Recycle Flow ................... 84

Figure 4.2.22 - Adiabatic and Equilibrium Temperatures Versus Flue Gas Recycle Flow

.

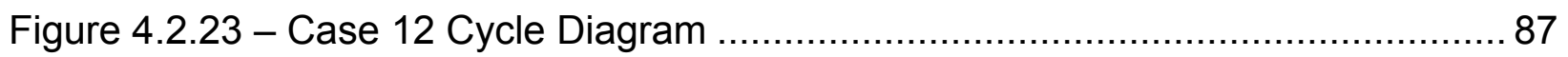

Figure 4.2.24 - Wet End Economizer Temperature Vs. Heat Duty ............................. 88

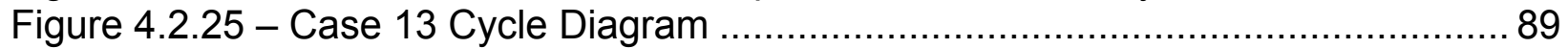

Figure 4.2.26 - Efficiency of Saved Extraction Steam Versus Stage ............................ 90

Figure 4.2.27 - Comparison of Power Consumption of $\mathrm{CO}_{2}$ Removal of Different

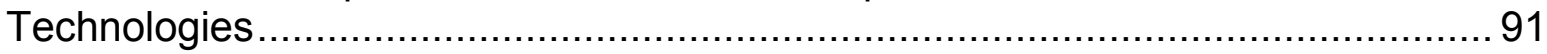

Figure 4.2.28 - Comparison of Overall Cycle Efficiency Point of $\mathrm{CO}_{2}$ Removal of

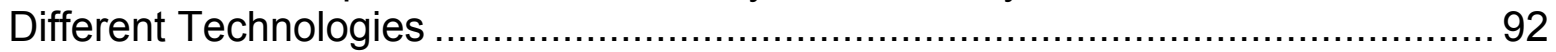


Figure 4.3.1 - Oxygen-Fired Burner Geometry ........................................................ 97

Figure 4.3.2 - Computational Model of Oxygen-Fired Burner ................................... 98

Figure 4.3.3 - Burnout and NOx/burnout vs. Primary gas Swirl for $65 \%$ Recycle, No OFG 102

Figure 4.3.4 - Gas Velocity for 65\% Recycle, No OFG, 0.0 PG Swirl ....................... 103

Figure 4.3.5 - Gas Temperature for 65\% Recycle, No OFG, 0.0 PG Swirl .................. 104

Figure 4.3.6 - $\mathrm{O}_{2}$ Mole Fraction for 65\% Recycle, No OFG, 0.0 PG Swirl .................. 105

Figure 4.3.7 - Burnout of $69 \mu$ Particles for 65\% Recycle, No OFG, 0.0 PG Swirl....... 106

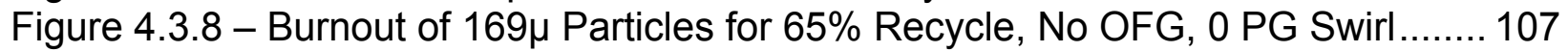

Figure 4.3.9 - Gas Velocity for 65\% Recycle, No OFG, 0.5 PG Swirl ........................ 108

Figure 4.3.10 - Gas Temperature for 65\% Recycle, No OFG, 0.5 PG Swirl ............... 109

Figure 4.3.11 - $\mathrm{O}_{2}$ Mole Fraction for 65\% Recycle, No OFG, 0.5 PG Swirl ................ 110

Figure 4.3.12 - Velocity Vectors Colored by Axial Velocity (ft/sec) for $65 \%$ Recycle, No

OFG, 0.5 PG Swirl .............................................................................. 111

Figure 4.3.13 - Burnout of 69 $\mu$ Particles for 65\% Recycle, No OFG, 0.0 PG Swirl..... 112

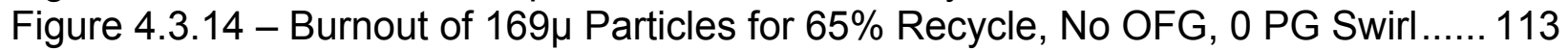

Figure 4.3.15 - Gas Velocity for 65\% Recycle, 20\% OFG, 0.0 PG Swirl .................... 114

Figure 4.3.16 - Gas Temperature for 65\% Recycle, 20\% OFG, 0.0 PG Swirl ............ 115

Figure 4.3.17 - O2 Mole Fraction for 65\% Recycle, 20\% OFG, 0.0PG Swirl .............. 116

Figure 4.3.18 - Burnout of $69 \mu$ Particles for 65\% Recycle, 20\% OFG, 0 PG Swirl ..... 117

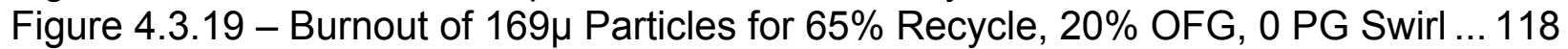

Figure 4.3.20 - Gas Velocity for 65\% Recycle, 20\% OFG, 0.5 PG Swirl .................... 119

Figure 4.3.21 - Gas Temperature for 65\% Recycle, 20\% OFG, 0.5 PG Swirl ............ 120

Figure 4.3.22 - O2 Mole Fraction for 65\% Recycle, 20\% OFG, 0.5 PG Swirl ............. 121

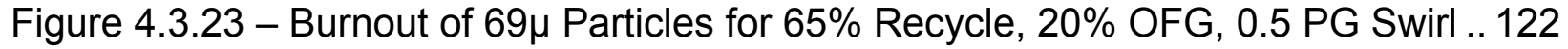

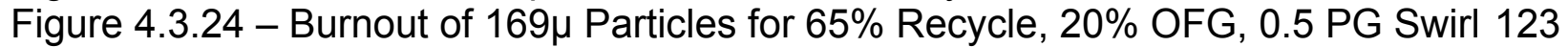

Figure 4.3.25 - Gas Velocity for 56\% Recycle, 0\% OFG, 0.0 PG Swirl ...................... 124

Figure 4.3.26 - Gas Temperature for 56\% Recycle, 0\% OFG, 0.0 PG Swirl .............. 125

Figure 4.3.27 - O2 Mole Fraction for 56\% Recycle, 0\% OFG, 0.0 PG Swirl ............... 126

Figure 4.3.28 - Burnout of $69 \mu$ Particles for 56\% Recycle, 0\% OFG, 0 PG Swirl ........ 127

Figure 4.3.29 - Burnout of $169 \mu$ Particles for 56\% Recycle, 0\% OFG, 0 PG Swirl ..... 128

Figure 4.3.30 - Gas Velocity for 56\% Recycle, 0\% OFG, 0.5 PG Swirl ...................... 129

Figure 4.3.31 - Gas Temperature for 56\% Recycle, 0\% OFG, 0.5 PG Swirl .............. 130

Figure 4.3.32 - O2 Mole Fraction for 56\% Recycle, 0\% OFG, 0.5 PG Swirl .............. 131

Figure 4.3.33 - Burnout of $69 \mu$ Particles for 56\% Recycle, 0\% OFG, 0.5 PG Swirl .... 132

Figure 4.3.34 - Burnout of $169 \mu$ Particles for 56\% Recycle, 0\% OFG, 0.5 PG Swirl .. 133

Figure 4.3.35 - Gas Velocity for 56\% Recycle, 20\% OFG, 0. PG Swirl ...................... 134

Figure 4.3.36 - Gas Temperature for 56\% Recycle, 20\% OFG, 0. PG Swirl .............. 135

Figure 4.3.37 - O2 Mole Fraction for 56\% Recycle, 20\% OFG, 0. PG Swirl ................ 136

Figure 4.3.38 - Burnout of $69 \mu$ Particles for 56\% Recycle, 20\% OFG, 0. PG Swirl .... 137

Figure 4.3.39 - Burnout of $169 \mu$ Particles for 56\% Recycle, 20\% OFG, 0. PG Swirl .. 138

Figure 4.3.40 - Gas Velocity for 56\% Recycle, 20\% OFG, 0.5 PG Swirl .................... 139

Figure 4.3.41 - Gas Temperature for 56\% Recycle, 20\% OFG, 0.5 PG Swirl ............. 140

Figure 4.3.42 - O2 Mole Fraction for 56\% Recycle, 20\% OFG, 0.5 PG Swirl ............. 141

Figure 4.3.43 - Burnout of $69 \mu$ Particles for 56\% Recycle, 20\% OFG, 0.5 PG Swirl .. 142

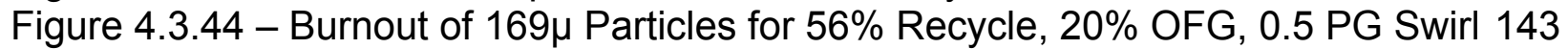


Figure 4.4.1- Computational Model of Air-Fired Furnace (with right side wall removed)

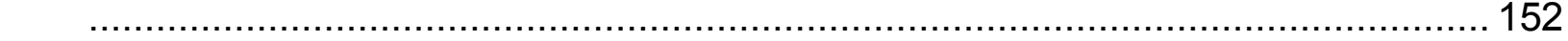

Figure 4.4.2 - Computational Model of Oxygen-Fired Furnace Without OFG............ 153

Figure 4.4.3 - Computational Model of Oxygen-Fired Furnace With OFG .................. 154

Figure 4.4.4 - Air-Fired Boiler Design .......................................................... 157

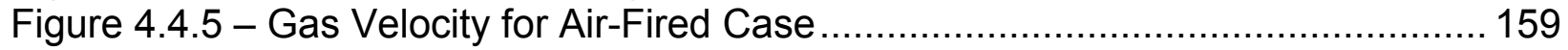

Figure 4.4.6 - Gas Temperature for Air-Fired Case ............................................. 160

Figure 4.4.7 - $\mathrm{O}_{2}$ Mole Fraction for Air-Fired Case ............................................ 161

Figure 4.4.8 - Wall Heat Flux for Air-Fired Case .................................................... 162

Figure 4.4.9 - Wall Temperature for Air-Fired Case ................................................ 163

Figure 4.4.10 - Wall CO for Air-Fired Case ......................................................... 164

Figure 4.4.11 - Char Mass Fraction (72 microns) for Air-Fired Case ......................... 165

Figure 4.4.12 - Char Mass Fraction (176 microns) for Air-Fired Case ........................ 166

Figure 4.4.13 - Outlet NOx Versus OFA Flow Rate for Air-Fired Furnace .................. 167

Figure 4.4.14 - Coal Burnout Versus OFA Flow Rate for Air-Fired Furnace ............... 167

Figure 4.4.15 - Air-Fired and Oxygen-Fired Boiler Outlines.................................... 168

Figure 4.4.16 - Oxygen-Fired Boiler Design ................................................... 169

Figure 4.4.17 - Gas Velocity for $\mathrm{O}_{2}$-Fired Case Without OFG .............................. 170

Figure 4.4.18 - Gas Temperature for $\mathrm{O}_{2}$-Fired Case Without OFG ......................... 171

Figure 4.4.19- $\mathrm{O}_{2}$ Mole Fraction for $\mathrm{O}_{2}$-Fired Case Without OFG.......................... 172

Figure 4.4.20 - Wall Heat Flux for $\mathrm{O}_{2}$-Fired Case Without OFG .............................173

Figure 4.4.21 - Wall Temperature for $\mathrm{O}_{2}$-Fired Case Without OFG ......................... 174

Figure 4.4.22 - Wall CO for $\mathrm{O}_{2}$-Fired Case Without OFG .................................... 175

Figure 4.4.23 - Char Mass Fraction (69 micron) for $\mathrm{O}_{2}$-Fired Case, No OFG............. 176

Figure 4.4.24 - Char Mass Fraction (169 micron) for $\mathrm{O}_{2}$-Fired Case, No OFG........... 177

Figure 4.4.25 - Char Mass Fraction (169 micron) for $\mathrm{O}_{2}$-Fired Case, No OFG, Without

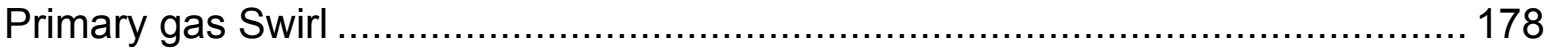

Figure 4.4.26 - Gas Velocity for $\mathrm{O}_{2}$-Fired Case With 20\% OFG ............................ 179

Figure 4.4.27 - Gas Temperature for $\mathrm{O}_{2}$-Fired Case With 20\% OFG …................... 180

Figure 4.4.28 $-\mathrm{O}_{2}$ Mole Fraction for $\mathrm{O}_{2}$-Fired Case With 20\% OFG ....................... 181

Figure 4.4.29 - Wall Heat Flux for $\mathrm{O}_{2}$-Fired Case With 20\% OFG .......................... 182

Figure 4.4.30 - Wall Temperature for $\mathrm{O}_{2}$-Fired Case With 20\% OFG ....................... 183

Figure 4.4.31 - Wall CO for $\mathrm{O}_{2}$-Fired Case With 20\% OFG.................................. 184

Figure 4.4.32 - Char Mass Fraction (69 micron) for $\mathrm{O}_{2}$-Fired Case, 20\% OFG .......... 185

Figure 4.4.33 - Char Mass Fraction (169 micron) for $\mathrm{O}_{2}$-Fired Case, 20\% OFG ........ 186

Figure 4.4.34 - Char Mass Fraction (169 micron) for $\mathrm{O}_{2}$-Fired Case, 20\% OFG, Without

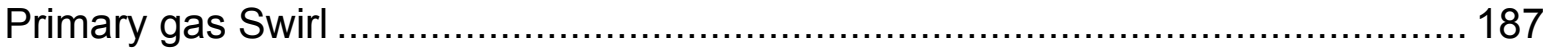

Figure 4.5.1- Comparison of Levelized Cost of Electricity Among Alternative

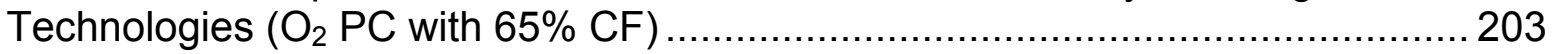

Figure 4.5.2 - Comparison of Mitigation Costs Among Alternative Technologies $\left(\mathrm{O}_{2} \mathrm{PC}\right.$

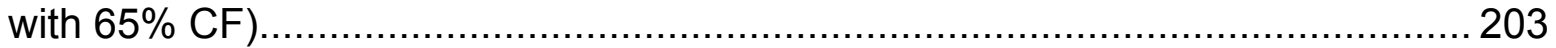

Figure 4.5.3 - Comparison of Levelized Cost of Electricity Among Alternative

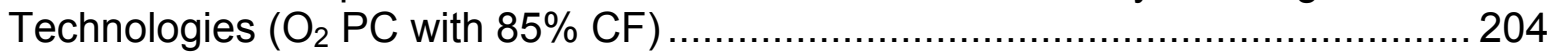

Figure 4.5.4 - Comparison of Mitigation Costs Among Alternative Technologies $\left(\mathrm{O}_{2} \mathrm{PC}\right.$

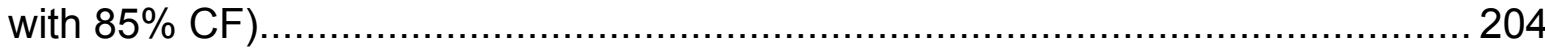




\subsection{Introduction}

The carbon dioxide $\left(\mathrm{CO}_{2}\right)$ content of the earth's atmosphere has increased by approximately 35 per cent since the early 1800s [1]. In the last 50 years, however, the rate of accumulation of $\mathrm{CO}_{2}$ has increased relatively rapidly going from about $310 \mathrm{ppmv}$ in 1950 to about 370 ppmv in 2000. Since $\mathrm{CO}_{2}$ is a greenhouse gas, there is increasing concern that its accumulation in the atmosphere will adversely impact the world's climate/weather patterns. Desiring that actions be taken, representatives from more than 160 countries met in Kyoto Japan in December 1997 and established goals for reducing greenhouse gas emissions.

Coal is presently the world's primary fuel for generating electrical power. In 2001 coal generated approximately 39 per cent of the world's electricity compared with 18 and 8 per cent for natural gas and oil, respectively [2]. Compared with natural gas and oil, coal also represents the world's largest reserve of energy and those reserves are more widely distributed throughout the world. Unfortunately coal is also the more carbon intensive fuel releasing roughly 70 and 30 per cent more $\mathrm{CO}_{2}$ per unit of heat release than natural gas and oil respectively.

In the United States (U.S.) coal generates more than half of the nation's electric power (approximately 55 per cent in 2002 [3]); it is much less expensive than oil or natural gas and domestic reserves are large enough to meet the nation's energy needs for the next 300 years. Because of its relatively low cost and strategic security, coal is expected to continue to be a major source of future U.S. electric power generation; it is estimated that it will also generate approximately 55 per cent of the nation's power in 2025 [3]. To address growing $\mathrm{CO}_{2}$ greenhouse gas concerns several states have passed legislation requiring their electric utilities to reduce $\mathrm{CO}_{2}$ emissions; New Hampshire is requiring generators to reduce their $\mathrm{CO}_{2}$ emissions to 1990 values by 2010 , Massachusetts is requiring their six largest generators to reduce $\mathrm{CO}_{2}$ emission rates to $1,800 \mathrm{lbs} / \mathrm{MWh}$ by 2006, etc. [4]. As a result advanced concepts are being proposed and studies undertaken to determine the performance and economic impacts of capturing power plant $\mathrm{CO}_{2}$ emissions for sequestration/storage. The captured $\mathrm{CO}_{2}$ could be transported by pipeline to a variety of sites for alternative uses some of which are:

1.) Injection into depleted oil fields for enhanced oil recovery (EOR)

2.) Injection into old coal mines to release/produce methane

3.) Injection into underground geologic formations and aquifers for storage

4.) Injection into the ocean for storage

Since coal-fired power plants are large point source emitters of $\mathrm{CO}_{2}$, their centralized location and "economy of scale" make them a focal point for controlling $\mathrm{CO}_{2}$ emissions. There are numerous, commercially proven processes for removing $\mathrm{CO}_{2}$ from gas streams. Some are best suited for streams containing relatively low $\mathrm{CO}_{2}$ concentrations whereas others require high $\mathrm{CO}_{2}$ partial pressures ( $>75 \mathrm{psig}$ ). The stack gas that exhausts from coal-fired power plants is typically at atmospheric pressure, has a temperature of less than $300^{\circ} \mathrm{F}$, and contains approximately 15 per cent $\mathrm{CO}_{2}$ on a dry 
volume basis. The low concentration of $\mathrm{CO}_{2}$ in the flue gas is best suited for chemical absorption. The chemical absorption process occurs in a conventional packed bed tower wherein the gas, after being cooled to approximately $100^{\circ} \mathrm{F}$, is admitted at the bottom, flows vertically up to the exit at the top, while it is contacted/scrubbed by a counter flowing liquid solvent such as monoethanolamine (MEA). The solvent chemically reacts (chemical absorption) with the $\mathrm{CO}_{2}$ and, after exiting the absorption tower, is fed to the stripping tower, and heated with steam to approximately $250^{\circ} \mathrm{F}$ to drive off the $\mathrm{CO}_{2}$ (steam stripping); the steam stripped or regenerated solvent is then, after cooling, recirculated back to the absorption tower for $\mathrm{CO}_{2}$ capture. The released $\mathrm{CO}_{2}$ is cooled, dried, and compressed to about 1200 psig or higher for pipeline transport.

Unfortunately the energy required to break the $\mathrm{CO}_{2}$-solvent chemical bond and to strip out the $\mathrm{CO}_{2}$ is large (typically $2,000 \mathrm{Btu} / \mathrm{lb}_{\mathrm{CO}}$ ). As a result a large amount of steam must be extracted from the steam turbine to the stripping tower thereby causing a significant loss in steam turbine power output. In addition the flue gas contains impurities, i.e. SOx, $\mathrm{NOx}, \mathrm{O}_{2}$, hydrocarbons, etc. that can dissolve in the solvent and cause a reduction in the solvent absorption capability, lead to operating difficulties (corrosion, deposits, etc.), and require the addition of "inhibitors", cleaning steps, and continuous feed of fresh solvent. Although this "back end" or post combustion $\mathrm{CO}_{2}$ removal approach requires no modifications to the boiler, it requires the addition of adsorption-regeneration system with large vessels and imposes harsh performance and economic penalties.

Aside from compression to pipeline pressure, the bulk of the penalties associated with $\mathrm{CO}_{2}$ sequestration are due to selectively removing $\mathrm{CO}_{2}$ from the nitrogen rich flue gas and releasing it by steam stripping. As an alternative, Foster Wheeler (FW) has proposed that the coal be burned with oxygen rather than air. With air nitrogen eliminated, a $\mathrm{CO}_{2}$ rich flue gas is generated that does not require $\mathrm{CO}_{2}$ capture and stripping. Instead, the flue gas can be fed directly to the $\mathrm{CO}_{2}$ processing unit for cooling/water condensation, drying, and compression. Elimination of air nitrogen from the coal combustion zone can result in excessively high flame temperatures that can be detrimental to a conventional boiler. To limit flame temperatures and thereby enable commercial boiler design practices to be used, a portion of the $\mathrm{CO}_{2}$ rich flue gas is recirculated back to the boiler yielding an $\mathrm{O}_{2} / \mathrm{CO}_{2}$ combustion medium.

It is anticipated that the oxygen required by the $\mathrm{O}_{2} / \mathrm{CO}_{2}$ combustion process would be supplied by a conventional cryogenic air separation unit (ASU). Although ASU system costs and power requirements are significant, they are expected to be less than those associated with chemical absorption and stripping. Under DOE Contract Number, DEFC26-03NT41736, FW is:

1.) Preparing a conceptual design of a pulverized coal (PC) fired $\mathrm{O}_{2}$ boiler

2.) Determining the performance and economics of the $\mathrm{O}_{2}$ power plant

3.) Evaluating the commercial viability of the plant by comparison to similar sized plants incorporating other $\mathrm{CO}_{2}$ sequestration technologies 
As part of the above, FW has conducted a review of published literature to locate data that is relevant to the conceptual design of the $\mathrm{O}_{2}$-fired PC power plant. Included in this review is identification of the performance and economics of plants incorporating other $\mathrm{CO}_{2}$ sequestering technologies.

The system design and analysis task, which was performed using the Aspen Plus computer program, is aimed at optimizing the PC boiler plant operating parameters to minimize the overall power plant heat rate. The flow rates and other properties of individual streams of the power plant were calculated as the results of the Aspen Plus simulations. The required performance characteristics of such operating components as pulverized coal-fired furnace, heat recovery area, flue gas recuperator, and economizer were determined. Two plant configurations were simulated: 1) a conventional air-fired PC power plant and 2) the proposed oxygen-based PC plant. In order to compare the performance of the oxygen-based plant with that of the conventional plant, the power output of the steam turbine in both plants was kept constant.

The low NOx burner design and analysis, which was performed using the Fluent CFD computer program, is aimed at optimizing the burner design to ensure stable ignition, to provide safe operation, and to minimize pollutant formation. Design conditions were based on the results of the system analysis and design task. Four burner designs were developed: 1) with no OFG and $65 \%$ flue gas recycle, 2) with $20 \%$ OFG and $65 \%$ flue gas recycle, 3) with no OFG and $56 \%$ flue gas recycle, and 4 ) with $20 \%$ OFG and $56 \%$ flue gas recycle.

The furnace and heat recovery area design and analysis task, which was performed using the FW-FIRE and HEATEX computer programs, is aimed at optimizing the location and design of the furnace, burners, over-fire gas ports, and internal radiant surfaces. Design conditions were based on the results of the system analysis and design task. Burner design was based on the burner design task. Two furnace and HRA designs were developed: 1) a conventional air-fired PC power plant and 2) the proposed oxygen-based PC plant.

The economic analysis is based on the results of the system analysis and design task and the furnace design and analysis task. The basis of the economic analysis is a conventional air-fired power plant that Foster Wheeler is currently designing and constructing. 


\subsection{Executive Summary}

Coal is presently the primary fuel for generating electrical power in the U.S. and the world. Even though coal is relatively inexpensive and abundant in the U.S. there is growing concern over its continued use. Compared with oil and natural gas, coal is carbon intensive, releasing roughly 70 and 30 per cent more $\mathrm{CO}_{2}$ per unit of heat release. Since $\mathrm{CO}_{2}$ is a greenhouse gas, there is increasing concern that its accumulation in the atmosphere will adversely impact the world's climate/weather patterns.

Coal-fired power plants are large point source emitters of $\mathrm{CO}_{2}$ and studies have been conducted to determine the impact of capturing their $\mathrm{CO}_{2}$ for pipeline transport to a sequestration/storage site. Although there are numerous processes available for removing $\mathrm{CO}_{2}$ from gas streams, the large gas volumes and dilute $\mathrm{CO}_{2}$ concentrations involved are best suited for a liquid-gas scrubbing process. In this process the gas is scrubbed with a liquid solvent designed to remove a specific gaseous component. Some solvents are best suited for streams containing relatively low $\mathrm{CO}_{2}$ concentrations (chemical absorption) whereas others (physical absorption) require high $\mathrm{CO}_{2}$ partial pressures (>75 psig). Since power plant flue gas $\mathrm{CO}_{2}$ concentrations are relatively low, a chemical absorption type solvent is best suited for this application. After being cooled to about $100^{\circ} \mathrm{F}$, the flue gas enters the bottom of a conventional packed bed tower, flows vertically up to exit from the top, while it is contacted by a counter flowing liquid solvent such as monoethanolamine (MEA). The solvent chemically reacts with/absorbs the $\mathrm{CO}_{2}$ in the absorption tower, and, after exiting, the solvent is fed to stripping tower, and heated with steam to approximately $250^{\circ} \mathrm{F}$; this heating releases the $\mathrm{CO}_{2}$ (steam stripping) and allows the regenerated solvent to be returned, after cooling, to the absorber tower for $\mathrm{CO}_{2}$ capture. The $\mathrm{CO}_{2}$ released from the solvent is cooled, dried, and compressed for pipeline transport.

Unfortunately the energy required to break the $\mathrm{CO}_{2}$-solvent chemical bond and to strip out the $\mathrm{CO}_{2}$ is large (typically $2,000 \mathrm{Btu} / \mathrm{lb}_{\mathrm{CO}}$ ). As a result a large amount of steam must be extracted from the steam turbine to the stripping tower thereby causing a significant loss in steam turbine power output. In addition, the flue gas contains impurities, i.e. SOx, NOx, $\mathrm{O}_{2}$, hydrocarbons, etc. that can dissolve in the solvent and cause a reduction in the solvent absorption capability, lead to operating difficulties (corrosion, deposits, etc.), and require the addition of "inhibitors", cleaning steps, and continuous feed of fresh solvent. Although this "back end" or post combustion $\mathrm{CO}_{2}$ removal approach requires no modifications to the boiler, it requires the addition of large vessels and imposes harsh performance and economic penalties; $\mathrm{CO}_{2}$ capture by chemical absorption, excluding $\mathrm{CO}_{2}$ cooling, drying, and compression to pipeline pressure, has been estimated to decrease the plant efficiency by approximately 8 percentage points and increase the cost of electricity by 59 per cent [9].

As an alternative to post combustion scrubbing, FW has proposed that the combustion process be accomplished with oxygen rather than air. With air nitrogen eliminated, a 
$\mathrm{CO}_{2}$-water vapor rich flue gas will be generated. After partial removal of the water vapor, a portion of the flue gas is recirculated back to the boiler to control the combustion temperature and the balance of the $\mathrm{CO}_{2}$ is processed for pipeline transport. This proposed oxygen-carbon dioxide $\left(\mathrm{O}_{2} / \mathrm{CO}_{2}\right)$ combustion process eliminates the need for the $\mathrm{CO}_{2}$ removal/separation process and, despite the expense and power consumption of cryogenic air separation, reduces the cost of $\mathrm{CO}_{2}$ capture. Excluding $\mathrm{CO}_{2}$ cooling, drying, and compression to pipeline pressure, the $\mathrm{O}_{2} / \mathrm{CO}_{2}$ process increases the cost of electricity of a PC plant by 27 per cent but yields a value that is 20 per cent less than that of a plant incorporating amine scrubbing [9].

Under DOE Contract No DE-FC26-03NT41736, FW is developing a conceptual design of an $\mathrm{O}_{2}$ fired boiler to determine overall plant performance and economics. In support of this effort a literature search was undertaken to locate any data/information relevant to this effort. This search has revealed that:

1.) Pilot scale $\mathrm{O}_{2} / \mathrm{CO}_{2}$ combustion tests have been conducted by two different investigators/teams. One used eastern bituminous coal in a $0.2 \mathrm{MWt}$ test unit whereas the other used subbituminous coal in a $1.5 \mathrm{MWt}$ unit. Both test programs showed that by the use of $\mathrm{O}_{2}$ with flue gas $/ \mathrm{CO}_{2}$ recirculation:

a. Flame temperatures can be kept within safe limits.

b. Flue gas can be produced with a 90 to 95 per cent $\mathrm{CO}_{2}$ content.

c. Air-fired boiler temperature profiles and flow patterns can be maintained.

d. Flame stability and combustion efficiency can be enhanced.

e. NOx emissions can be reduced significantly.

2.) Several studies have been conducted on pulverized coal-fired plants to determine the performance and economic impact of capturing 90 per cent of their $\mathrm{CO}_{2}$ for pipeline transport to a sequestration site. An International Energy Agency (IEA) study analyzed several different technologies for this separation/providing a $\mathrm{CO}_{2}$ rich gas for pipeline transport and found the two most cost effective approaches to be: a) scrubbing post combustion flue gas with an amine solvent and b) using $\mathrm{O}_{2}$ combustion. For a new plant, scrubbing with Monoethanolamine (MEA) to supply an uncompressed, concentrated $\mathrm{CO}_{2}$ stream can reduce the plant efficiency by 8 to 11 percentage points and increase its cost of electricity by about 50 to 60 per cent. $\mathrm{O}_{2}$ combustion, in contrast, has a smaller effect in that it is projected to reduce the plant efficiency by 6 to 7 percentage points and increase its cost of electricity by 27 to 58 per cent. Furthermore, for application to an existing plant, $\mathrm{O}_{2}$ combustion retrofit also offers a lower loss in plant efficiency.

Based on the published literature it is possible to design a pulverized coal burner to operate with an oxygen-carbon dioxide gas mixture rather than air; a properly designed $\mathrm{O}_{2} / \mathrm{CO}_{2}$ burner can yield flame temperatures and thermal profiles similar to those of an air-fired boiler while also providing improved flame stability, increased combustion efficiency, and reduced NOx emissions. Plant conceptual designs and cost estimates, 
although differing in absolute values, indicate an $\mathrm{O}_{2}$ combustion based plant should be technically feasible and, when compared to alternative commercial technologies, appears to be the lowest cost way of providing a concentrated $\mathrm{CO}_{2}$ stream for sequestration. It is also expected that when applied to a new plant, $\mathrm{O}_{2}$ combustion can result in a more compact, less expensive boiler. Depending upon the $\mathrm{SO}_{2}$ and $\mathrm{NOx}$ levels that can be recirculated back to the boiler, as well as tolerated at the sequestration site, $\mathrm{O}_{2}$ combustion can result in reduced flue gas cleanup costs. Since $\mathrm{O}_{2}$ combustion eliminates the need for large, back-end, amine based scrubbers and, in essence, "saves the boiler" (requires minimal if any boiler modification), it is especially attractive for retrofit applications.

$\mathrm{O}_{2}$ based $\mathrm{PC}$ plants require large amounts of oxygen and cryogenic air separation is presently the best available oxygen supply technology for large-scale applications. Cryogenic units, however, are expensive and consume large amounts of power. It is noted that ceramic membranes are under development that are projected to be a lower cost, lower power consuming way to produce large quantities of oxygen. When commercial, those membranes should further enhance the performance and cost effectiveness of $\mathrm{O}_{2}$ based plants.

The objective of the Conceptual Design of Oxygen-Based PC Boiler study is to develop a conceptual pulverized coal-fired power plant, which facilitates the practical capture of carbon dioxide capture for subsequent sequestration.

The system design and analysis task, which was performed using the Aspen Plus computer program, is aimed at optimizing the PC boiler plant operating parameters to minimize the overall power plant heat rate. The reference plant is a subcritical pressure, natural circulation boiler firing high-volatile bituminous coal (Illinois \#6) generating $460 \mathrm{MWe}$ (gross). A conventional air-fired case was simulated as the comparison basis. The air-fired plant has a boiler efficiency of $88.2 \%$ and a net plant efficiency of $36.7 \%$.

The oxygen-based plant system model contains all the components in the conventional plant model (with the exception of the FGD) plus the addition of an air separation unit and a flue gas cooler. Flue gas is recycled to control the flame temperature inside the PC-fired boiler to minimize NOx formation, minimize ash slagging in the furnace combustion zone, and avoid the application of exotic materials.

Parametric runs were made varying the amount of recycled flue gas (which directly affects the flame temperature) while maintaining the same boiler outlet $\mathrm{O}_{2}$ concentration as the air-fired case. The results show that by reducing the recycled flue gas flow rate by $33 \%$, the adiabatic temperature increases from $3574^{\circ} \mathrm{F}$ to $4337^{\circ} \mathrm{F}$, increasing the system efficiency (without $\mathrm{CO}_{2}$ compression) from $31.2 \%$ to $31.9 \%$. The system efficiency was further increased to $32.1 \%$ by raising the temperature of the recycled flue gas from $96^{\circ} \mathrm{F}$ to $148^{\circ} \mathrm{F}$. 
Equipment to compress and liquefy the $\mathrm{CO}_{2}$ effluent to 2000 psia and to reduce the moisture to $50 \mathrm{ppm}$ (to avoid transport pipe corrosion) was added to the system model. This equipment reduces the system efficiency of the $3574^{\circ} \mathrm{F}$ adiabatic temperature case from $31.2 \%$ to $27.9 \%$. Recycling the residual $\mathrm{O}_{2}$ before $\mathrm{CO}_{2}$ compression increases the system efficiency with $\mathrm{CO}_{2}$ compression to $28.3 \%$. For the high temperature case $\left(3574^{\circ} \mathrm{F}\right)$ recycling of the purge gases results in a system efficiency of $29.5 \%$. A further enhancement of this high adiabatic temperature case was simulated by adding a flue gas feedwater heater prior to $\mathrm{CO}_{2}$ separation and a turbine expander to recover power from the recycled purge gas pressure reduction. The addition of this equipment raised the system efficiency to $29.8 \%$ with a conservative $1 \%$ unburned carbon loss and an efficiency of $30.1 \%$ with negligible unburned carbon loss. To further reduce the required furnace surface area while increase the net cycle efficiency the flue gas recycle flow rate was reduced from $65 \%$ to $56 \%$ raising the net cycle efficiency to $30.6 \%$.

Calculations were made using the computer program, EMISS, to determine the furnace waterwall temperature and required material and tube wall thickness for the various cases run. For the air-fired reference case, the waterwalls are carbon steel with a 0.285 " wall thickness. For the maximum temperature $\mathrm{O}_{2}$-fired case, the maximum wall temperature is $961^{\circ} \mathrm{F}$ for which 0.24 " thick T91 material is required. Furthermore, due to the greater temperature and greater concentrations of radiating gas species $\left(\mathrm{H}_{2} \mathrm{O}\right.$ and $\mathrm{CO}_{2}$ ), the required waterwall surface area is only $65 \%$ of the air-fired reference case.

The efficiency of carbon sequestration in oxygen-firing boilers even can rival competing gasification plants. The power consumption of $\mathrm{CO}_{2}$ removal for $\mathrm{O}_{2}$-fired $\mathrm{PC}$ plants is about one-third of natural gas combined cycles, about one-half of post $\mathrm{CO}_{2}$ removal $\mathrm{PCs}$ and slightly less than integrated gasification combined cycles. The reduction in power plant efficiency of $\mathrm{CO}_{2}$ removal for $\mathrm{O}_{2}$-fired $\mathrm{PC}$ plants is nearly half of either natural gas combined cycles or post $\mathrm{CO}_{2}$ removal $\mathrm{PCs}$ and nearly the same as integrated gasification combined cycles.

The oxygen-based PC boiler incorporates cryogenic $\mathrm{O}_{2}$ separation, which can produce very pure oxygen; but it requires substantial capital and operating costs. Membrane separation of $\mathrm{O}_{2}$ has been demonstrated at small scale employing very thin membrane fibers, which preferentially allow $\mathrm{O}_{2}$ to permeate, but not $\mathrm{N}_{2}$. Although the purity of $\mathrm{O}_{2}$ from membranes may not be as high as in the cryogenic separation, lower purity oxygen may be sufficient for the oxygen-based PC boiler power cycle. Membrane separation has the potential to use less power at a lower capital cost.

The low NOx burner design and analysis, which was performed using the 3-D Fluent computer program, is aimed at optimizing the burner design to ensure stable ignition, to provide safe operation, and to minimize pollutant formation.

Four burner designs were developed: 1) with no OFG and $65 \%$ flue gas recycle, 2) with $20 \%$ OFG and $65 \%$ flue gas recycle, 3 ) with no OFG and $56 \%$ flue gas recycle, and 4 ) with $20 \%$ OFG and $56 \%$ flue gas recycle. Boundary conditions are based on ASPEN simulations of the power plant. A 3-D Fluent simulation was made of a single wall-fired 
burner and horizontal portion of the furnace from the wall to the center. Burner geometry is based upon FW low NOx burner experience adapted for $\mathrm{O}_{2}$ firing.

Without primary gas swirl, coal burnout was relatively small, due to the low oxygen content of the primary gas. Consequently, the burners were modified to include primary gas swirl to bring the coal particles in contact with the secondary gas. An optimal primary gas swirl was chosen to achieve sufficient burnout $(>70 \%$ by the center of the furnace), but not to produce substantial NOx.

The wall-fired burner design conditions selected were as follows:

1. $100 \mathrm{ft} / \mathrm{sec}$ primary gas exit axial velocity with a tangential swirl ratio of 0.5 .

2. 60-70 ft/sec inner secondary gas exit velocity for combustion air staging to minimize NOx formation.

3. 120-135 ft/sec outer secondary gas exit axial velocity with a tangential swirl ratio of 1.0 to induce hot flue gas recirculation to the flame ignition point.

The furnace and heat recovery area design and analysis task, which was performed using the FW-FIRE and HEATEX computer programs, is aimed at optimizing the location and design of the furnace, burners, over-fire gas ports, and internal radiant surfaces.

A simulation was made for both the reference air-fired case and for the oxygen-fired case. Two oxygen-fired models were constructed: one with no OFA ports and the second with OFA ports. Boundary conditions are based on ASPEN simulations of the power plant.

The furnace is designed with opposed wall-firing burners and over-fire ports located at one burner pitch above the top burner row. Water is circulated in the furnace by natural circulation to the waterwalls at the periphery and divisional wall panels within the furnace.

For the air-fired furnace simulation, the maximum flue gas temperature is approximately $3300^{\circ} \mathrm{F}$. The maximum heat flux is approximately $70,000 \mathrm{Btu} / \mathrm{hr}-\mathrm{ft}^{2}$ and is located on the side wall at the top of the burner zone. The total heat absorbed by the furnace walls before the furnace exit is $1880 \mathrm{MM} \mathrm{Btu/hr}$. The maximum temperature of the waterwalls is approximately $800^{\circ} \mathrm{F}$ and of the division walls is approximately $875^{\circ} \mathrm{F}$. Total burnout of all particle sizes is $99.7 \%$. Average NOx concentration at the furnace outlet is 227 ppmvw (0.34 lb/MMBtu).

Compared to the air-fired furnace, the oxygen furnace requires only $65 \%$ of the surface area and $45 \%$ of the volume. Two oxygen-fired designs were simulated: 1) without overfire air and 2) with $20 \%$ over-fire air. The mixed primary/secondary gas $\mathrm{O}_{2}$ content (before combustion) is $42 \%$. 
In the oxygen-fired furnace, the maximum flue gas temperature is approximately $3900^{\circ} \mathrm{F}$ for $0 \%$ OFG and $3750^{\circ} \mathrm{F}$ for $20 \%$ OFG. The maximum heat flux is $175,000 \mathrm{Btu} / \mathrm{hr}-\mathrm{ft}^{2}$ (top of the burner zone on the side wall) for 0\% OFG and 165,000 Btu/hr- $\mathrm{ft}^{2}$ (above the overfire ports on the side wall) for $20 \%$ OFG. The maximum wall heat flux in the oxygenfired furnace is more than double that of the air-fired furnace due to the higher flame temperature and higher $\mathrm{H}_{2} \mathrm{O}$ and $\mathrm{CO}_{2}$ concentrations. The total heat absorbed by the furnace walls before the furnace exit is approximately $2200 \mathrm{MM} \mathrm{Btu/hr}$. The coal burnout for the oxygen-fired case is $100 \%$ due to the high furnace temperature and high concentration of $\mathrm{O}_{2}$. NOx concentration at the furnace outlet is 333 ppmvw for the $0 \%$ OFG case and 257 ppmvw for the 20\% OFG case. Although the average NOx concentration at the furnace outlet is similar on a volume basis for both air-fired and $\mathrm{O}_{2-}$ fired PC, it is substantially less on a mass basis for the $\mathrm{O}_{2}$-fired PC due to the substantially lower volumetric flue gas flow rate of the $\mathrm{O}_{2}$-fired PC.

The maximum temperature of the oxygen-fired furnace waterwalls is approximately $935^{\circ} \mathrm{F}$ and of the division walls is approximately $945^{\circ} \mathrm{F}$. Because of the higher temperature of the oxygen-fired case compared to the air-fired case, furnace water wall material was upgraded from carbon steel to T91.

HEATEX was used to determine the heat recovery area (HRA) design of the convective tube banks between the furnace exit and the SCR/air heater. These tube banks include the finishing superheater, finishing reheater, primary superheater, primary reheater, upper economizer, and lower economizer.

For the air-fired design, total surface area of all convective banks is $294,111 \mathrm{ft}^{2}$. The total heat transferred to the water/steam is $1354 \mathrm{MM} \mathrm{Btu} / \mathrm{hr}$ as $3.88 \mathrm{MM} \mathrm{Ib/hr}$ of flue gas is cooled from $2135^{\circ} \mathrm{F}$ to $720^{\circ} \mathrm{F}$.

For the oxygen-fired design, total surface area of all convective banks is $215,700 \mathrm{ft}^{2}$. The total heat transferred to the water/steam is $1096 \mathrm{MM} \mathrm{Btu} / \mathrm{hr}$ as $2.20 \mathrm{MM} \mathrm{lb/hr}$ of flue gas is cooled from $2350^{\circ} \mathrm{F}$ to $650^{\circ} \mathrm{F}$. The total heat transfer surface required in the oxygen-fired HRA is $25 \%$ less than the air-fired HRA due to more heat being absorbed in the oxygen-fired furnace, the greater molecular weight of the oxygen-fired flue gas, and lower flue gas mass flow rate in the HRA.

The HRA tube materials and wall thickness are practically the same for the air-fired and oxygen-fired design since the flue gas and water/steam temperature profiles encountered by the heat transfer banks are very similar.

The objective of the economic analysis is to prepare a budgetary estimate of capital and operating costs of the $\mathrm{O}_{2}$-fired PC power plant as well as for the equivalent conventional PC-fired power plant. 
The reference plant is a subcritical pressure, natural circulation boiler firing high-volatile bituminous coal generating $450 \mathrm{MWe}$. A conventional air-fired case was simulated as the comparison basis.

The economic analysis was performed based on the EPRI Technical Assessment Guide (TAG) methodology. Plant capital costs were compiled under the Code of Accounts developed by EPRI. The estimate basis is 2004 dollars, 20 -year life, and $85 \%$ capacity factor.

The major changes to the reference plant were boiler redesign, SCR system removal, FGD removal, ASU addition, and $\mathrm{CO}_{2}$ compression addition. The estimated cost of the reference plant is $\$ 585,000,000(1300 \$ / \mathrm{kW})$ and of the $\mathrm{O}_{2}$-fired plant is $\$ 668,673,700$ $(2106 \$ / \mathrm{kW})$. A substantial part of this cost increase is caused by $\mathrm{CO}_{2}$ compression equipment, which must be included for any $\mathrm{CO}_{2}$ removal systems. Note that he energy stored in the compressed $\mathrm{CO}_{2}$ fluid is a net loss of energy to the power plant, which is about $8 \%$ of gross power, or 3.0 points in efficiency percentage.

The levelized cost of electricity (COE) was calculated for both the reference plant and the $\mathrm{O}_{2}$-fired plant. The COE value is made up of contributions from the capital cost, operating and maintenance costs, consumables, and fuel costs. The levelized COE was calculated to be $4.61 \phi / \mathrm{kWh}$ for the reference plant and $6.41 \phi / \mathrm{kWh}$ for the $\mathrm{O}_{2} \mathrm{PC}$ plant. The $\mathrm{CO}_{2}$ mitigation cost (MC) of the $\mathrm{O}_{2}-\mathrm{PC}$ plant was calculated at $21.4 \$$ tonne.

Compared to the COE of the $\mathrm{O}_{2} \mathrm{PC}$, the COE for the other technologies is $45 \%$ higher for Air PC, 40\% higher for NGCC, and 6\% higher for IGCC. Compared to the MC of the $\mathrm{O}_{2} \mathrm{PC}$, the MC for the other technologies is $250 \%$ higher for NGCC, $160 \%$ higher for Air PC, and $17 \%$ higher for IGCC. 


\subsection{Experimental}

This work performed for this report was performed utilizing computer program simulations. No experimental equipment was used. 


\subsection{Results and Discussion}

\subsection{Literature Review}

A review was conducted of published literature to locate data/information relevant to the design and cost estimating of $\mathrm{O}_{2}$ based coal-fired power generating plants. The collected material has been divided into four sections and leads to the conclusion that $\mathrm{O}_{2}$ combustion should be feasible and should have a $\mathrm{CO}_{2}$ avoided cost that is lower than that of competing commercially available systems. The four sections are:

a.) coal combustion with air-oxygen mixtures (oxygen enhanced combustion)

b.) coal combustion with pure oxygen or oxygen- $\mathrm{CO}_{2}$ mixtures

c.) impact of $\mathrm{CO}_{2}$ removal on new coal-fired plant performance and economics

d.) impact of $\mathrm{CO}_{2}$ removal on existing coal-fired plant performance

e.) oxygen supply systems

Sections 4.1 .1 to 4.1 .5 identify/summarize the findings of the literature on each of the above topics.

\subsubsection{Combustion With Partial Oxygen Enhancement}

Nitrous oxides (NOx) are nitrogen-containing compounds that react in the atmosphere to cause acid rain and smog (ground level ozone). Since acid rain and smog can damage the environment and public health, environmental regulations have been established at both the Federal and state level that limit, among other things, power plant NOx emissions. In a typical pulverized coal-fired boiler approximately 70 to 80 per cent of the NOx emitted comes from the fuel itself (from the nitrogen species contained in the volatile matter released during the heating of the fuel and from the remaining char residue that is eventually combusted). The conversion of fuel bound nitrogen (especially volatiles) to NOx involves numerous reactions and intermediate species that compete to form either NOx or nitrogen $\left(\mathrm{N}_{2}\right)$. Reducing or fuel rich conditions favor the transformation of fuel bound nitrogen to $\mathrm{N}_{2}$, whereas, oxidizing or fuel lean conditions favor transformations to NOx.

Numerous techniques have been developed to reduce the NOx emissions from coalfired boilers. One of them is the use of low NOx burners that stage the introduction and mixing of the combustion air with the coal. By limiting the amount of air (primary air) that first contacts the coal, a fuel rich zone is created close to the burner. Coal exiting the burner, enters this region, undergoes devolatilization and, because of the reducing conditions, the conversion of volatile nitrogen species to $N_{2}$ is favored. The balance of the combustion air can be admitted via an outer concentric annulus and the streams mix to form a downstream oxidizing zone wherein the combustion process is completed. By staging the introduction and mixing of the air and coal, the flame can be stretched out, a lower flame temperature can be achieved, and the formation of both fuel bound and 
thermal NOx can be minimized. However, there are limits to combustion staging. If the flame temperature is too low, devolatilization may continue into the oxidizing zone and the combustion process may not go to completion, thus resulting in higher levels of NOx and higher levels of unburned carbon in the coal ash. Experience has shown that an optimized low NOx burner can reduce NOx emissions to approximately 30 to 50 per cent of the "unstaged" values.

Another method of NOx reduction that is a generally less expensive than low NOx burners, is to divert air flow from the burner to an over-fire air (OFA) port above it. Typically flame stability considerations limit the burner stoichiometry to a minimum of about 0.8 resulting in an over fire arrangement which produces about a 10 to 30 per cent reduction in NOx emissions from "unstaged" values.

A recent approach to improving the performance of low NOx burners is to enrich the combustion air with a small amount of oxygen. This approach, named oxygen enhanced combustion (OEC), typically introduces less than 10 per cent of the stoichiometric oxygen requirement and raises the overall combustion air oxygen level from 21 per cent to 22 to 23 per cent. By replacing a portion of the primary air with this oxygen, less nitrogen is present and the flame temperature can be increased without changing the combustion stoichiometry. The higher temperature increases the coal devolatilization rate and yield and drives transformations/reactions to produce $\mathrm{N}_{2}$ rather than NOx. With devolatilization increased, less carbon is left in the char, and unburned carbon levels are reduced. This approach can also be applied to the burners of an over fire air arrangement or even a combined low NOx burner-over fire air arrangement.

Praxair Inc. has taken OEC from bench scale to commercial scale demonstrations [5]. Their first demonstration of OEC was performed in a $44 \mathrm{MWe}$ wall fired boiler at City Utilities in Springfield, Missouri. The demonstration successfully reduced NOx emissions by up to 40 per cent and work proceeded to a larger scale at the $125 \mathrm{MWe}$ Mt. Tom Generation Station in Holyoke, Massachusetts. The latter possesses 16 burners in a 4 by 4 wall arrangement and 6 over fire air ports are provided in a single row above the topmost row of burners. Although oxygen was injected into each of the burners, the authors do not reveal the actual amount used or the unit operating condition; they do indicate, however, that the maximum operating load was 24 per cent over the name plate rating and that the resulting higher gas temperatures and reduced gas residence times limited the potential of the demonstration. Tests were conducted with three different bituminous coals: two were Class $C$ the other was Class $A$. The NOx data presented in Figure 4.1.1 and Figure 4.1.2 show that the reductions provided by OEC varied with load; the reduction was about 17 per cent at maximum load versus about 35 per cent at minimum load. With the load points not being identified, the inference is made that the minimum load test points are more representative of a normal boiler and that OEC can reduce NOx emissions to less than $0.15 \mathrm{lbs} / \mathrm{MMBtu}$. In addition flame stability was improved and unburned carbon losses were reduced. 


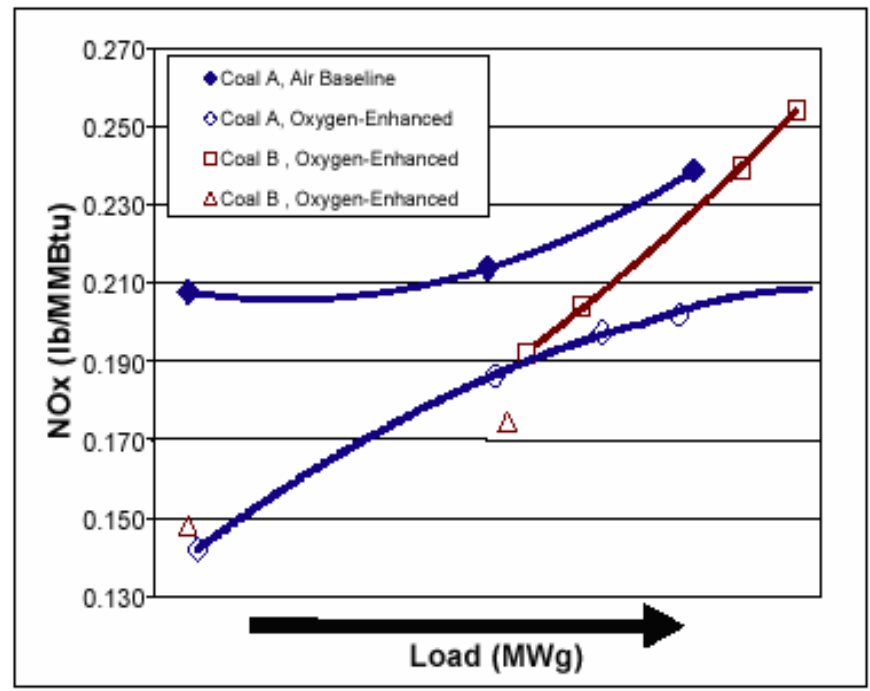

Figure 4.1.1 Effect of OEC on Class C Bituminous Coal NOx Emissions

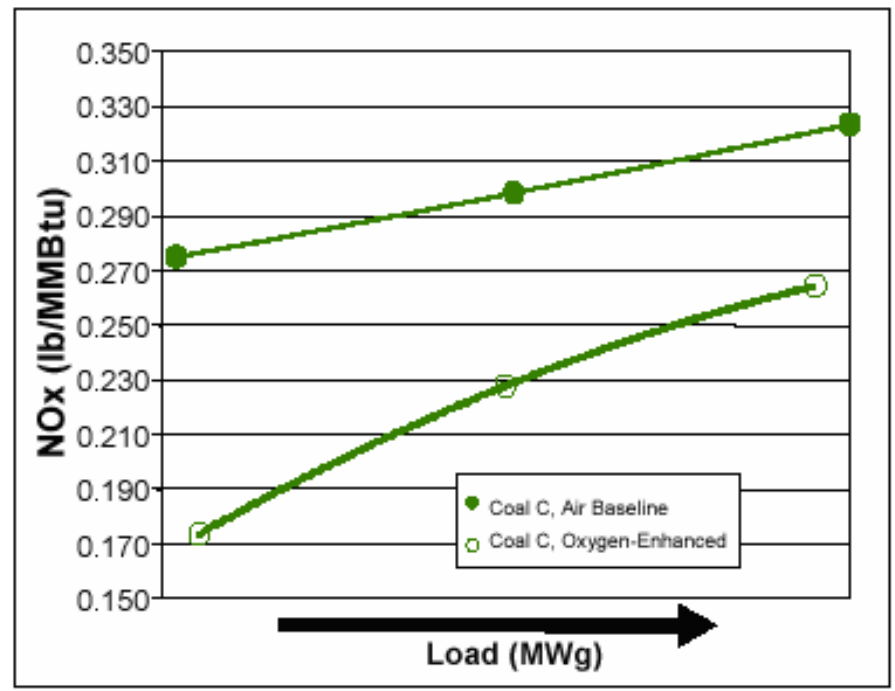

Figure 4.1.2 Effect of OEC on Class A Bituminous Coal NOx Emissions

The tests performed by Praxair show that a relatively small amount of oxygen can be safely injected into pulverized coal-fired burners for reductions in both NOx emission and unburned carbon losses. For plants designed to remove and sequester $\mathrm{CO}_{2}$, much 
higher levels of oxygen injection are envisioned and Section 4.1.2 reports on experimental work in this area.

\subsection{2 $\mathrm{O}_{2} / \mathrm{CO}_{2}$ Combustion}

The electric utility tests discussed in Section 4.1.1 indicate that the addition of small amounts of oxygen to the combustion air can improve plant performance, i.e. reduce NOx emissions, reduce unburned carbon, increase ash utilization, and may also improve economics. Further increases in oxygen injection can reach the extreme at which all air flow can be eliminated. At this condition the flue gas is virtually nitrogenfree and it can be cooled, dried, and compressed for pipeline transport to a sequestering site without the need for $\mathrm{CO}_{2}$ capture or stripping. Since the nitrogen in the combustion air absorbs heat, flame temperatures will increase causing concern that metal temperatures may reach unacceptably high levels and slagging problems may develop.

Two teams of experimenters have conducted pulverized coal combustion tests using oxygen instead of air. In [6] the tests were conducted in a bench scale, down-fired, cylindrical, $145 \mathrm{KW}$ furnace. The furnace roof and walls were water cooled and covered by a $50 \mathrm{~mm}$ thick layer of refractory that yielded a $100 \mathrm{~mm}$ diameter and a $2300 \mathrm{~mm}$ length. A total of five burner configurations were tested with Indonesian subbituminous coal pulverized to a minus 63 micron size. To protect the unit from high temperature flame impingement, testing began without any swirl; the coal and oxygen were admitted as a downward flowing mixture on the centerline. Three different configurations were tested and despite high flame temperatures, combustion efficiencies were less than expected; with Reynolds Numbers being low it was hypothesized that a $\mathrm{CO}_{2}$ layer was forming on the surface of the coal particles that was preventing oxygen from reaching the coal surface. In the fourth and fifth burner configurations a portion of the oxygen was moved to an outer annulus that surrounded the central primary stream and $\mathrm{CO}_{2}$ was added to the latter. Vanes located in the annulus imparted 60 degree and 75 degree swirl angles respectively. The authors report the fifth or strong swirl burner did not achieve a stable flame and the fourth burner with its weaker level of swirl was selected for more extensive testing over the following conditions:

$\begin{array}{ll}\text { Coal Flow Rate, } \mathrm{kg} / \mathrm{h} & 6.7 \\ \text { Primary } \mathrm{O}_{2} \text { Flow Rate, } \mathrm{m}^{3} / \mathrm{h} & 3.6 \\ \text { Secondary } \mathrm{O}_{2} \text { Flow Rate, } \mathrm{m}^{3} / \mathrm{h} & 4.8-7.2 \\ \text { Diluting } \mathrm{CO}_{2} \text { Flow Rate, } \mathrm{m}^{3} / \mathrm{h} & 1.5\end{array}$

Figure 4.1.3 shows that a peak combustion efficiency of 99.5 per cent was achieved at an excess oxygen level of 12.5 per cent. The ratio of primary oxygen (O2-1) to secondary oxygen (O2-2) was also varied and the referenced peak efficiency was achieved at a ratio of 0.63 (see Figure 4.1.4) along with a furnace exit $\mathrm{CO}_{2}$ concentration of 90.4 per cent. 


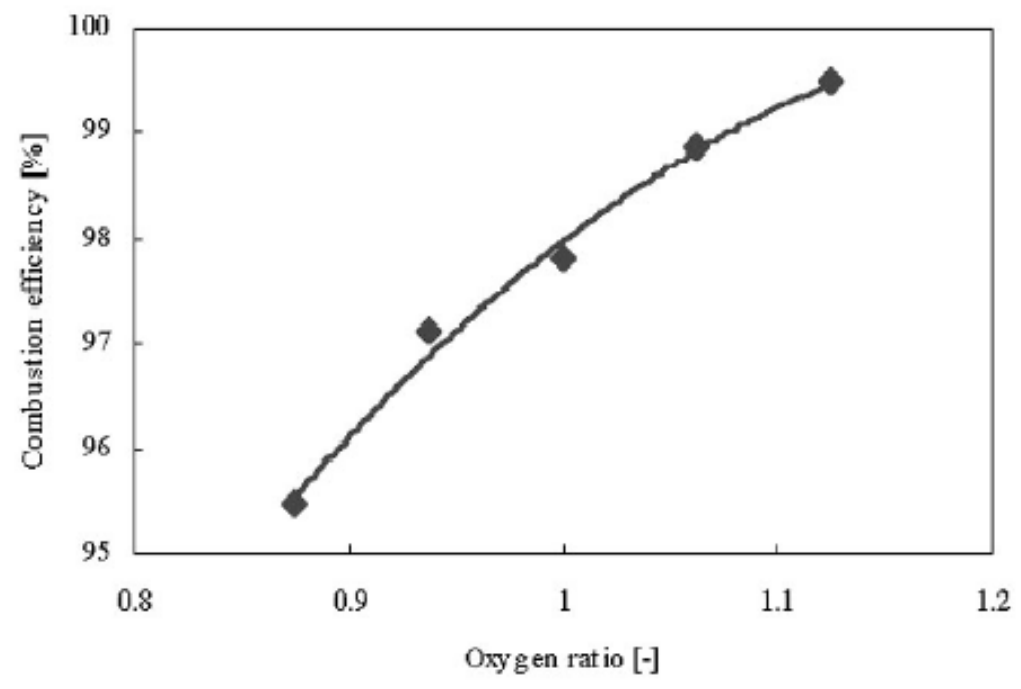

Figure 4.1.3 Effect of Oxygen Ratio on Burner Combustion Efficiency

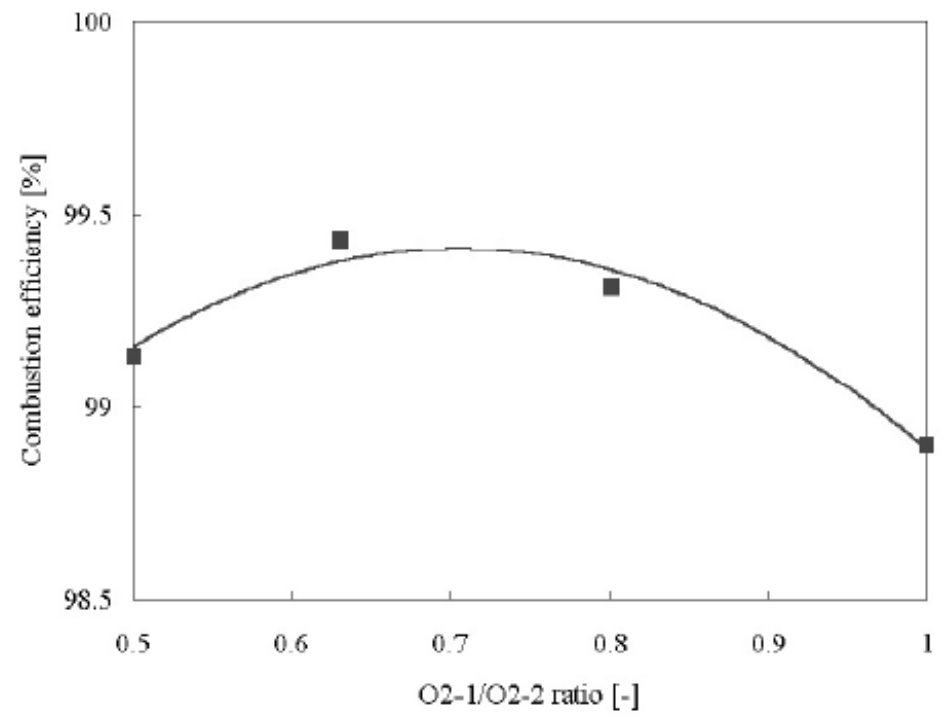

Figure 4.1.4 Effect of Primary to Secondary $\mathrm{O}_{2}$ Ratio on Burner Combustion Efficiency 
Oxygen combustion tests were also conducted at the CANMET Vertical Combustor Research Facility in an $8.3 \mathrm{~m}$ tall, down-fired unit possessing a $0.3 \mathrm{MWt}$ maximum heat input rating [7]. The unit was refractory lined to a $600 \mathrm{~mm}$ diameter and, together with water-cooled panels, provided a realistic time-temperature history for burning coal particles. A single register, swirl stabilized burner developed by CANMET was located on the centerline of the unit. As shown in Figure 4.1.5 the burner possessed a centrally located natural gas-fired igniter surrounded by four concentric flow annuli. During the tests a variety of secondary gases, e.g. air, oxygen, $\mathrm{CO}_{2}, \mathrm{~N}_{2}$, and recycled flue gas, were admitted through the swirl inducing outermost annulus. This outermost annulus enclosed the primary coal-air-oxygen stream annulus, which in turn enclosed an annulus that injected oxygen into the primary stream via radial holes. The oxygen annulus in turn enclosed a small tertiary stream that admitted air, $\mathrm{N}_{2}$, and/or $\mathrm{O}_{2}$ for the natural gas igniter and also served as a buffer that protected the burner front from excessive flame temperatures.

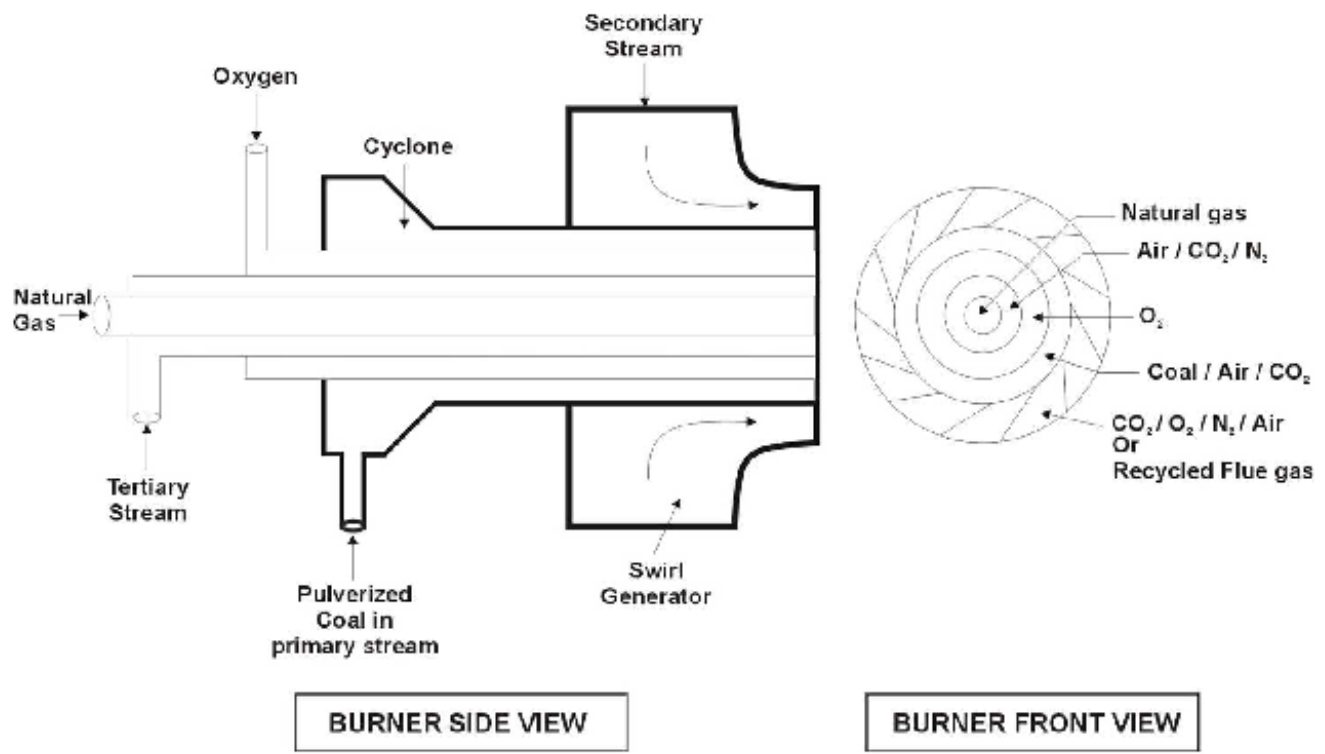

Figure 4.1.5 CANMET Burner

Table 4.1.1 and Table 4.1.2 summarize the burner test conditions. Each test was conducted with pulverized subbituminous coal using a target value of 2 per cent excess oxygen (dry volume basis) and secondary swirl set at 8 for a calculated swirl number of approximately 1.05 . Test WS-1 was conducted with air to establish a performance baseline, WS-4 added oxygen to the secondary stream to demonstrate oxygen enriched combustion, and in WS-5, 7, and 3 the air was gradually backed out and replaced with $\mathrm{CO}_{2}$ and recycled flue gas that had been cooled in a condensing heat exchanger. By using the $\mathrm{CO}_{2}$ and recycled flue gas the flame temperature was controlled (approximated the air baseline value -- see Table 4.1.3) and a $\mathrm{CO}_{2}$ rich flue gas was produced that was amenable, after moisture removal, for sequestration. As expected, 
with the $\mathrm{CO}_{2}$ specific heat being higher than that of nitrogen, Test WS-3 required a slightly larger oxygen flow than WS-7 to achieve the same flame temperature. Similarly as the $\mathrm{CO}_{2}$ or recycled flue gas flow is increased, the nitrogen transported to the flame zone by air is reduced and the NOx emission is reduced. The recycled flue gas also contains NOx, which can potentially be reduced to $N_{2}$ in the fuel rich regions of the flame. Although the authors present no direct combustion efficiency data, the $\mathrm{CO}$ emissions are observed to be relatively low.

\section{Table 4.1.1 CANMET Burner Operating Conditions}

\begin{tabular}{|c|c|c|c|c|c|c|c|c|}
\hline \multirow[t]{2}{*}{$\begin{array}{l}\text { Trial } \\
\text { Ref }\end{array}$} & \multirow{2}{*}{$\begin{array}{c}\text { Target } \\
\text { Flue Gas } \\
\mathrm{CO}_{2} \\
\text { Content } \\
\text { (dry vol. \%) }\end{array}$} & \multirow[t]{2}{*}{$\begin{array}{c}\text { Primary } \\
\text { Gas }\end{array}$} & \multirow[t]{2}{*}{$\begin{array}{c}\text { Secondary } \\
\text { Gas }\end{array}$} & \multirow{2}{*}{$\begin{array}{l}\text { Excess } \\
\mathrm{CO}_{2}{ }^{(1)} \\
\text { (wt. \%) }\end{array}$} & \multirow{2}{*}{$\begin{array}{c}\text { Total } \\
\text { Flue } \\
\text { Gas }{ }^{(2)} \\
(\mathrm{kg} / \mathrm{hr})\end{array}$} & \multicolumn{3}{|c|}{$\begin{array}{c}\text { Target } \\
\text { Feed Gas } \\
\text { Composition } \\
\text { (dry vol. \%) }\end{array}$} \\
\hline & & & & & & $\mathrm{O}_{2}$ & $\mathrm{~N}_{2}$ & $\mathrm{CO}_{2}$ \\
\hline WS-1 & 17 & Air & Air & 0 & 292 & 21 & 79 & 0 \\
\hline WS-4 & 25 & Air & $\mathrm{Air}+\mathrm{O}_{2}$ & 0 & 224 & 28 & 72 & 0 \\
\hline WS-5 & 30 & Air & $\mathrm{Air}+\mathrm{O}_{2}+\mathrm{CO}_{2}$ & 22 & 229 & 28 & 66 & 5 \\
\hline WS-7 & 70 & Air & $\mathrm{Air}+\mathrm{O}_{2}+\mathrm{CO}_{2}$ & 184 & 271 & 28 & 27 & 45 \\
\hline WS-3 & 98 & $\mathrm{CO}_{2}$ & Flue gas $+\mathrm{O}_{2}$ & 211 & 238 & 35 & 0 & 65 \\
\hline
\end{tabular}

Notes:

1) "excess $\mathrm{CO}_{2}$ " is defined as the mass of excess $\mathrm{CO}_{2}$ leaving the combustion process relative to the mass of $\mathrm{CO}_{2}$ produced in the combustion process.

2) "total flue gas" is defined as the total mass of flue gas exiting the combustion process.

3) "target feed gas" composition refers to the bulk gas mixture entering the burner.

Table 4.1.2 CANMET Burner Test Flow Rates

\begin{tabular}{|c|c|c|c|c|c|c|c|c|}
\hline \multirow{2}{*}{$\begin{array}{l}\text { Trial } \\
\text { Ref }\end{array}$} & \multirow{2}{*}{$\begin{array}{c}\text { Coal Flow } \\
(\mathrm{kg} / \mathrm{hr})\end{array}$} & \multicolumn{2}{|c|}{ Pri. Gas (kg/hr) } & \multirow{2}{*}{$\begin{array}{c}\text { Direct } \mathrm{O}_{2} \\
(\mathrm{~kg} / \mathrm{hr})\end{array}$} & \multicolumn{4}{|c|}{ Secondary Gas $(\mathrm{kg} / \mathrm{hr})$} \\
\hline & & Air & $\mathrm{CO}_{2}$ & & $\mathrm{O}_{2}$ & Air & $\mathrm{CO}_{2}$ & Flue Gas \\
\hline WS-1 & 35.5 & 59.0 & - & - & - & 209.5 & - & - \\
\hline WS-4 & 35.5 & 59.3 & & 6.4 & 10.4 & 123.6 & - & - \\
\hline WS-5 & 35.5 & 59.0 & - & 9.6 & 11.9 & 107.8 & 16.3 & - \\
\hline WS-7 & 35.5 & 60.3 & - & 10.9 & 32.8 & 17.9 & 133.2 & - \\
\hline WS-3 & 35.5 & - & 59.0 & 32.5 & 24.4 & - & $20^{(1)}$ & 94.9 \\
\hline
\end{tabular}

Notes:

1) This $\mathrm{CO}_{2}$ was used for sealing/purging and was not injected through the burner 
Table 4.1.3 CANMET Burner Performance

\begin{tabular}{|c|c|c|c|c|c|}
\hline \multirow{2}{*}{$\begin{array}{c}\text { Trial } \\
\text { ID }\end{array}$} & $\begin{array}{c}\text { Calculated Adiabatic } \\
\text { Flame Temperature } \\
(1)\end{array}$ & $\begin{array}{c}\text { Measured Peak } \\
\text { Flame Temperature } \\
\left({ }^{\circ} \mathrm{C}\right)\end{array}$ & \multicolumn{2}{|c|}{$\begin{array}{c}\text { Measured } \\
\text { Emissions } \\
\left({ }^{(2)}\right.\end{array}$} & $\begin{array}{c}\text { Estimated } \\
\text { Emissions } \\
\left({ }^{(}\right)\end{array}$ \\
\cline { 4 - 6 } & & & $\mathrm{CO}$, dry basis $)$ & NO & NO \\
\hline WS-1 & 2100 & 1380 & $<10$ & 710 & 236 \\
\hline WS-4 & $>2750$ & 1565 & 35 & 1750 & 482 \\
\hline WS-5 & 2650 & 1565 & 35 & 1550 & 352 \\
\hline WS-7 & 2120 & 1440 & 60 & 1100 & 144 \\
\hline WS-3 & 2230 & 1440 & 75 & 1090 & 78 \\
\hline
\end{tabular}

Notes:

1) calculated using HYSYS

2) measured using a proprietary shielded high velocity thermocouple probe

3) values shown are the average taken over the duration of each experiment and were measured in the flue gas leaving the combustion process.

4) values show were corrected to account for the reduced gas flow to the stack assuming that the "excess $\mathrm{CO}_{2}$ " would be provided by recycling flue gases

The CANMET Vertical Combustor was also tested with an eastern bituminous coal [8]. The tests were conducted at a $0.2 \mathrm{MWt}$ firing rate with 5 per cent excess oxygen ( 5 per cent dry volume basis $\mathrm{O}_{2}$ in the flue gas). During these tests the combustion air was enriched to 28 and 35 per cent oxygen by varying amounts of oxygen and or recycled dry flue gas. Flame temperatures were measured starting from about $75 \mathrm{~cm}$ from the burner and, as expected, they increased (see Figure 4.1.6) when the oxygen concentration in the feed gas increased both with and without flue gas recycle. Since the specific heat of $\mathrm{CO}_{2}$ is greater than that of $\mathrm{N}_{2}$, the gas temperatures observed with dry flue gas recycle were lower than those observed with air at equivalent oxygen concentrations. NOx measurements were also taken and, as shown in Figure 4.1.7, oxygen enrichment reduced the NOx emission and values observed with dry flue gas recycle were lower than those observed without recycle at the same equivalent oxygen concentrations; the lower values were possibly caused by part of the recycled NOx reducing to $\mathrm{N}_{2}$ in the flame zone and or part of the NOx dissolving in the water condensed out of the recycled flue gas. Figure 4.1.8 shows no effect of $\mathrm{O}_{2}$ or $\mathrm{CO}_{2}$ concentration on $\mathrm{SO}_{2}$ emissions over the range tested but dry flue gas recycle yields lower values, again, possibly caused by $\mathrm{SO}_{2}$ dissolving in the water condensed out of the recycle flue gas. 


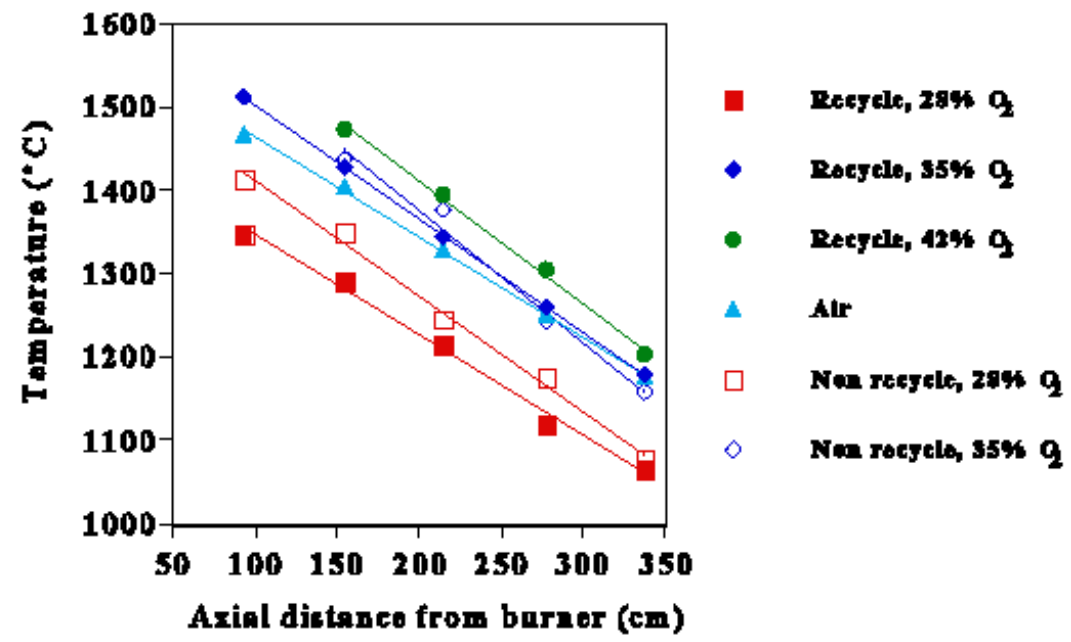

Figure 4.1.6 Centerline Temperatures Downstream of Burner

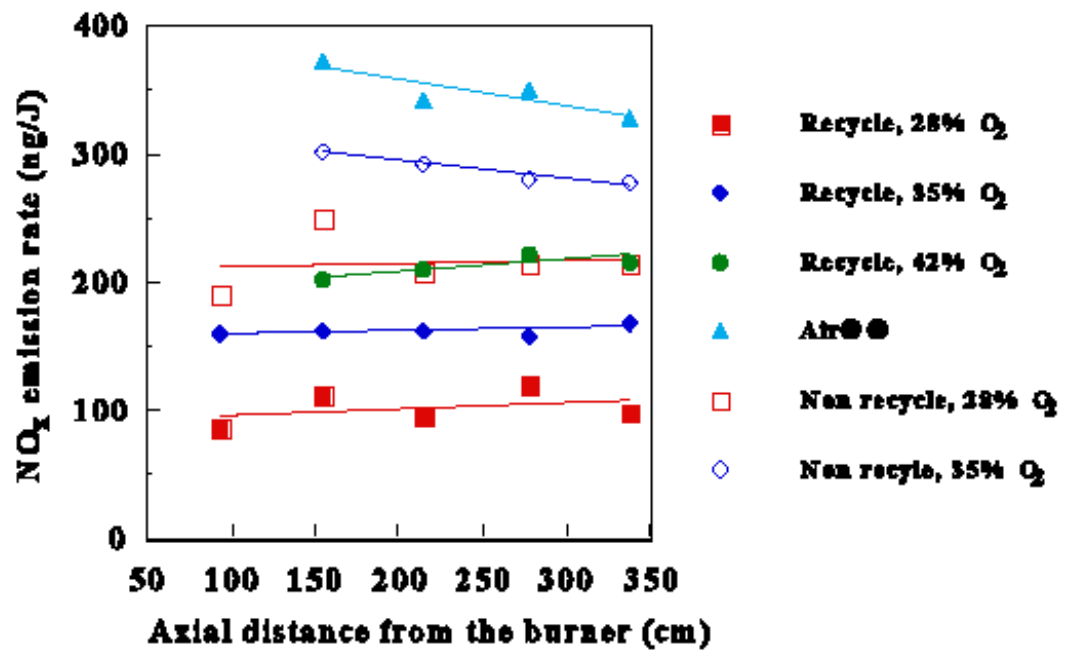

Figure 4.1.7 Centerline NOx Emission Rates 


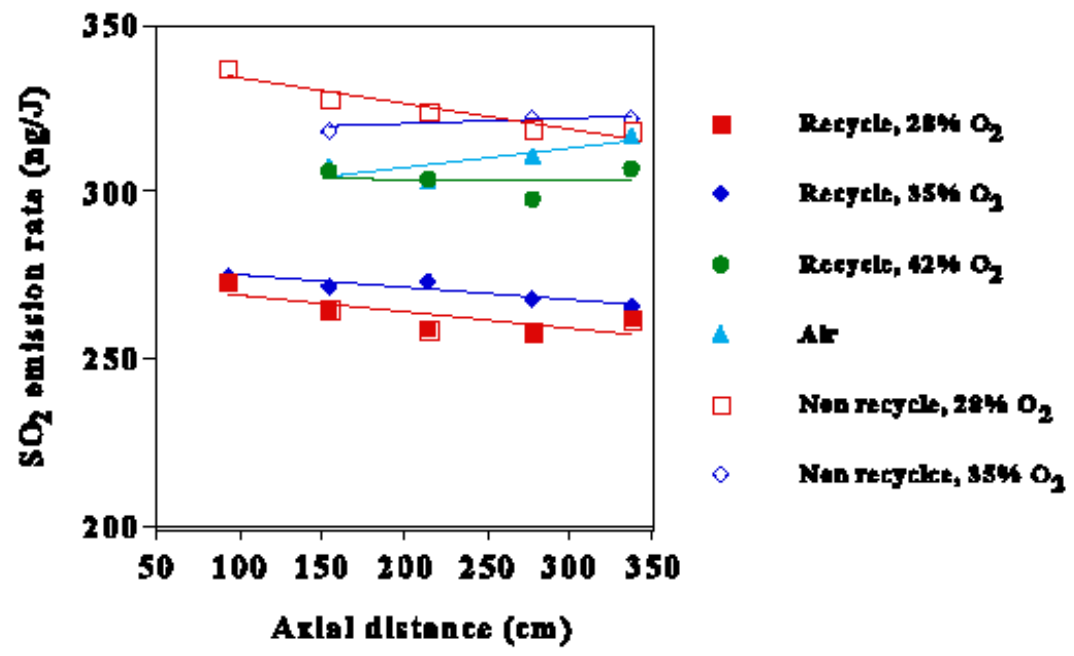

Figure 4.1.8 Centerline $\mathrm{SO}_{2}$ Emission Rates

$\mathrm{O}_{2}$ combustion tests were also conducted by The Babcock and Wilcox Company in a 1.5 MWt pilot scale, small boiler simulator test rig [9]. The tests were conducted with subbituminous coal and, by recirculating 75 to 80 per cent of the $\mathrm{CO}_{2}$ rich flue gas back to the unit, the flow rates, fluid dynamics, and temperature profiles observed were similar to those experienced with air-only operation. The flue gas volumetric flow exiting the stack was about 80 per cent lower than air-fired operation and the gas volumetric concentration was about 80 per cent $\mathrm{CO}_{2}, 3$ per cent $\mathrm{O}_{2}$, and 17 per cent nitrogen, the latter was attributed to air infiltration into the system most probably at the scrubber, baghouse, and induced draft fan. Although overall combustion characteristics were similar to air-fired operation, NOx emissions were about 70 per cent lower; rather than 0.22 to 0.26 , the NOx level dropped to 0.07 to $0.08 \mathrm{lbs} / \mathrm{MMBtu}$.

The data collected by the above investigators show that by replacing combustion air with $\mathrm{O}_{2}$ and by using flue gas recycle, flue gases containing 90 to 95 per cent $\mathrm{CO}_{2}$ can be produced without excessively high flame temperatures. In addition flame stability and combustion efficiency can be enhanced and NOx emissions can be reduced significantly. 


\subsubsection{Impact of $\mathrm{CO}_{2}$ Removal on New Plants}

\subsubsection{International Energy Agency Study}

Under the IEA Greenhouse Gas R\&D Program the performance and cost impacts of incorporating $\mathrm{CO}_{2}$ removal on four different power generation options was studied. The options covered the spectrum of fossil fueled power generation and for each plant attempts were made to apply the following four different technologies to remove/separate their $\mathrm{CO}_{2}$ for eventual sequestration:
a.) absorption
b.) adsorption
c.) cryogenics
d.) membranes

The study was conducted in two phases. In the first phase [10] a baseline plant configuration/conceptual design was established for each power generation option to identify performance, emissions, and economics, and then limited sensitivity studies were performed. In the second phase [11] the four $\mathrm{CO}_{2}$ capturing options were applied separately to each baseline plant. The studies involved the participation of four different organizations in Phase 1 (each developed one of the baseline plant designs) and seven different organizations in Phase 2. Since the objective of the studies was to provide a relative ranking of technologies, attempts were made to design the plants for the same conditions and to estimate their costs using a consistent set of criteria. The plants were assumed to be located at a coastal western European site where $59^{\circ} \mathrm{F}\left(15^{\circ} \mathrm{C}\right)$ sea water cooling was available. Each plant was designed for a 500 MWe net output and a 35 year operating life, and costs were determined in 1992 U.S. dollars. Although attempts were made to apply a consistent set of design and economic criteria, because so many different organizations were involved, it is suggested that results be viewed on a relative basis rather than based on absolute values. The fuels used were 0.86 per cent sulfur (as received) Australian bituminous coal or North Sea "Brent" natural gas.

The four different power generation options studied, together with identification of their designer and a brief description of their base line plant, are as follows:

Pulverized Coal-Fired Boiler with Wet Flue Gas Desulfurization (PC+FGD)

This plant was conceptually designed by the Coal Research Establishment of British Coal Corporation. The plant utilized a conventional subcritical pressure steam cycle and a natural circulation boiler with conventional burners, an electrostatic precipitator, and wet flue gas desulfurization for 90 per cent $\mathrm{SO}_{2}$ capture.

Natural Gas-Fired Combined Cycle (NGCC)

This plant was conceptually designed by the Norwegian Institute of Technology. The plant was conventional in configuration and used conventional components, i.e. two combustion turbines, two heat recovery steam generators (HRSGs), one steam turbine, 
etc. The combustion turbines utilized pre-mix/hybrid burners to achieve a NOx level of 25 ppmv.

Integrated Gasification Combined Cycle (IGCC)

This plant was conceptually designed by the Netherlands Research Foundation. The plant incorporated two high pressure Texaco gasifiers with syngas cooling, two expanders, two combustion turbines (Siemens Model V94.2), one heat recovery steam generator, one steam turbine, and two elevated pressure air separation units with their nitrogen being used for combustion turbine NOx control. Selexol cold gas cleanup, together with tail gas incineration, enabled the plant to operate with 99 per cent sulfur capture efficiency.

Oxygen Fired $\mathrm{PC}$ with $\mathrm{CO}_{2}$ recycle $\left(\mathrm{O}_{2}\right.$ Combustion)

This plant was conceptually designed by the Centre for Energy Research in Northern Ireland. The plant incorporated cryogenic air separation, a pulverized coal-fired boiler with low NOx burners, an electrostatic precipitator, and an air heater; the plant was not provided with an FGD or selective catalytic reduction (SCR) system to minimize flue gas $\mathrm{SO}_{2}$ and NOx levels. Oxygen from the air separation unit served as the boiler oxidant and produced a $\mathrm{CO}_{2}$ rich flue gas. After particulate removal and cooling, a portion of the $\mathrm{CO}_{2}$ flue gas was recycled back to the furnace for temperature control and the balance was exhausted to atmosphere. According to the authors the beneficial feature of this plant is that, compared to a normal air fired plant, the $\mathrm{CO}_{2}$ content of the flue gas is increased from 14 to 63 mole per cent (the majority of the balance is moisture) and the stack gas flow rate is reduced by approximately 67 per cent. Hence this plant is more amenable to sequestration.

Table 4.1.4 summarizes the performance, economics, and $\mathrm{CO}_{2}$ emissions of the four plants. The NGCC plant is the most efficient and, with natural gas being primarily a hydrogen-based fuel, it has the lowest $\mathrm{CO}_{2}$ emission per unit of power output-hence, the reason for interest in fuel switching. The NGCC plant, however, operates with high excess air and, as a result, it has one of the highest flue gas flow rates and the lowest $\mathrm{CO}_{2}$ volume contents (4 per cent versus 14 per cent for the PC plant, on a dry volume basis); high volume flows and low $\mathrm{CO}_{2}$ contents increase the cost of $\mathrm{CO}_{2}$ removal. The $\mathrm{O}_{2}$ PC plant, in contrast, has the lowest flue gas flow rate and, with its $\mathrm{CO}_{2}$ content already at 91 per cent on a dry volume basis, does not require a $\mathrm{CO}_{2}$ capture step. Depending upon the amount of $\mathrm{SO}_{2}$ and $\mathrm{NOx}$ that can be tolerated by the sequestration site and the transport pipeline, the $\mathrm{CO}_{2}$ rich flue gas may need further cleanup before it is dried and compressed to pipeline pressure.

In [11] a team of seven organizations conducted analyses to determine the impact of applying the above $\mathrm{CO}_{2}$ capturing options to each baseline plant to remove/capture 90 per cent of its $\mathrm{CO}_{2}$. Each of the processes had an associated parasitic power loss that reduced the plant output and, after integration into the plant, each plant was scaled up in size to maintain a 500 MWe net output. Table 4.1.5 shows the effects of the different 
$\mathrm{CO}_{2}$ separation technologies on the conventional PC plant with $\mathrm{FGD}$. Of the technologies shown, absorption/amine stack gas scrubbing resulted in both the lowest power cost and the lowest $\mathrm{CO}_{2}$ avoided cost. The plant efficiency, however, reduced from 40 per cent (LHV basis) to 29 per cent and the cost of power increased by approximately 50 per cent. Since amine scrubbing is commercially proven and is the technology most frequently used for large-scale applications, only the absorption results are presented in Table 4.1.6 for the other plants; for information on the alternative processes the reader is referred to [11].

In the $\mathrm{CO}_{2}$ absorption process the gas is washed with a liquid solvent whose selection depends, among other things, on the $\mathrm{CO}_{2}$ concentration level. When $\mathrm{CO}_{2}$ levels are relatively low, chemical absorption type solvents are used $\left(\mathrm{CO}_{2}\right.$ chemically reacts with the solvent) and steam stripping is employed to release the $\mathrm{CO}_{2} /$ regenerate the solvent. When $\mathrm{CO}_{2}$ concentrations are relatively high, physical absorption type solvents are used $\left(\mathrm{CO}_{2}\right.$ dissolves in the solvent) and depressuring/flashing is employed to release the $\mathrm{CO}_{2} /$ regenerate the solvent. The air based plants (PC+FGD and NGCC) used chemical absorption applied after combustion, whereas the oxygen-blown IGCC pressurized plant used physical absorption. In the $\mathrm{O}_{2} / \mathrm{CO}_{2} \mathrm{PC}$ plant the $\mathrm{CO}_{2}$ removal occurred after combustion and raised the $\mathrm{CO}_{2}$ removal level to 99 per cent. For the IGCC plant its coal-derived syngas was water gas shifted and the $\mathrm{CO}_{2}$ was removed prior to combustion (the combustion turbine, in essence, became fueled with hydrogen).

Recognizing that the data presented in Table 4.1.4 through Table 4.1.6 were prepared by several different organizations and, even though attempts were made to assure a consistent set of design and economic assumptions (costing accuracy is estimated to be plus or minus 30 per cent), it is suggested the data only be used for relative comparison. It is noted the $\mathrm{O}_{2} / \mathrm{CO}_{2} \mathrm{PC}$ plant with scrubbing added to it can provide up to 99 per cent $\mathrm{CO}_{2}$ removal and when designed for 91 per cent removal (no scrubbing) its cost of electricity is similar to that of a PC plant with 90 per cent $\mathrm{CO}_{2}$ removal via amine scrubbing (78 versus 74 mills/kWh).

Table 4.1.4 Performance of Nominal 500 MWe Power Generating Technologies

Plant Efficiency, \% (LHV)

Specific Plant Cost, $\$ / K W$

$\mathrm{COE}$, mills/kWh

$\mathrm{CO} 2$

$\begin{array}{rrrr}\text { PC+FGD } & \text { NGCC } & \text { IGCC } & \text { PC with O2/CO2 } \\ 40 & 52 & 42 & 33 \\ 1058 & 702 & 1561 & 2044 \\ 49 & 35 & 53 & 78 \\ 0.23 & & & \\ 13 & 0.11 & 0.21 & 0.28 \\ 14 & 3 & 7 & 63 \\ & 4 & 7 & 91\end{array}$




\section{Table 4.1.5 Effect of $\mathrm{CO}_{2}$ Capture Technologies on a Nominal $500 \mathrm{MWe}$ PC Fired Plant}

$\begin{array}{cccc}\text { Plant Efficiency } & \text { Power Cost } & \text { CO2 Avoided Cost } & \text { CO2 Emission Rate } \\ \% \text { (LHV basis) } & \text { mills/kWh } & \$ / \text { tonne } & \mathrm{g} / \mathrm{kWh}\end{array}$

Plant with $\mathrm{CO} 2$ Capture by:

Absorption

\section{Table 4.1.6 Effect of $\mathrm{CO}_{2}$ Absorption on Alternative Power Generating Technologies}

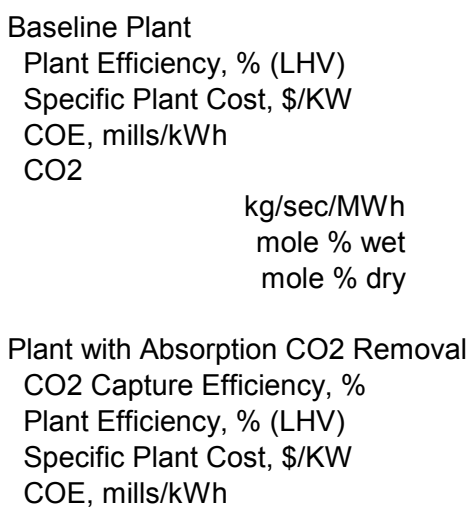

$\begin{array}{rr}P C+F G D & N G C C \\ 40 & 52 \\ 1058 & 702 \\ 49 & 35 \\ & \\ 0.23 & 0.11 \\ 13 & 3 \\ 14 & 4 \\ & \\ & \\ 90 & 85 \\ 29 & 42 \\ 1842 & 1367 \\ 74 & 53 \\ 35 & 55\end{array}$

IGCC PC with $\mathrm{O} 2 / \mathrm{CO} 2$

$\begin{array}{rr}42 & 33 \\ 1561 & 2044 \\ 53 & 78 \\ & \\ 0.21 & 0.28 \\ 7 & 63 \\ 7 & 91\end{array}$

$\begin{array}{rr}82 & 99 \\ 36 & 30 \\ 2400 & 3102 \\ 63 & 94 \\ 23 & 16\end{array}$

\subsubsection{Parsons Study}

Parsons Energy and Chemical Group Inc. [12], working under a contract jointly funded by the Electric Power Research Institute and the U.S. DOE, determined the performance and cost impacts of applying $\mathrm{CO}_{2}$ removal via amine scrubbing on three different power generation technologies. The power plants studied were:

1.) Pulverized Coal-Fired with Wet Flue Gas Desulfurization

2.) Natural Gas Combined Cycle

3.) Integrated Coal Gasification Combined Cycle 
In the PC and NGCC cases $\mathrm{CO}_{2}$ removal was performed after combustion at the back end of the plant where gas temperatures are a minimum. Since these cycles use air as their oxidant their flue gas $\mathrm{CO}_{2}$ concentration is relatively low and a chemical absorption type solvent (MEA) was used. In the IGCC plant oxygen is used as the oxidant and the syngas is cooled to approximately $100^{\circ} \mathrm{F}$ to allow acid gas removal prior to combustion. With the syngas at elevated pressure at this point and $\mathrm{CO}_{2}$ partial pressures relatively high, physical absorption was utilized.

The plants were fueled with either Illinois No 6 coal costing $\$ 1.26 / \mathrm{MMBtu}$ or natural gas costing $\$ 2.70 / \mathrm{MMBtu}$ (both on HHV basis); the compositions of these fuels are given in Table 4.1.7 and Table 4.1.8. A mid-western site with a $63^{\circ} \mathrm{F}$ (dry bulb) and 14.4 psia ambient was assumed and each plant separated and compressed their $\mathrm{CO}_{2}$ to 1200 psig for pipeline transport to a sequestering site. The $\mathrm{CO}_{2}$ specification called for a $40^{\circ} \mathrm{F}$ dew point, a hydrogen limit of 1.25 per cent, and sulfur limits of 100 and $50 \mathrm{ppm}$ for $\mathrm{SO}_{2}$ and $\mathrm{H}_{2} \mathrm{~S}$ respectively. All plants operated with a 1 psia steam condenser back pressure and utilized mechanical draft evaporative cooling towers. The following is a brief description of the plants (more detailed information is presented in [12]):

Table 4.1.7 Illinois No 6 Coal Analysis

\begin{tabular}{lc} 
& $\begin{array}{c}\text { Per Cent by Weight } \\
\text { (As Received) }\end{array}$ \\
Ultimate Analysis & \\
Moisture & 11.12 \\
Carbon & 63.75 \\
Hydrogen & 4.5 \\
Nitrogen & 1.25 \\
Chlorine & 0.29 \\
Sulfur & 2.52 \\
Ash & 9.7 \\
Oxygen (by difference) & 6.88 \\
\multicolumn{2}{r}{ Total } \\
Higher Heating Value & 100.00 \\
Btu/lb & 11,666 \\
MJ/kg & 27.12
\end{tabular}




\section{Table 4.1.8 Natural Gas Analysis}

$\begin{array}{lcc}\text { Component } & & \text { Per Cent by Volume } \\ \mathrm{CH} 4 & & 90 \\ \mathrm{C} 2 \mathrm{H} 6 & & 5 \\ \text { Inerts/N2 } & & 5 \\ & \text { Total } & 100 \\ \text { Higher Heating Value } & \\ & \text { Btu/lb } & 21,824 \\ & \text { Btu/SCF } & 1,002 \\ & \mathrm{MJ} / \mathrm{kg} & 50.75\end{array}$

\section{Pulverized Coal-Fired Plant}

The PC plant was conventional in configuration incorporating a PC fired boiler with low NOx burners, air staging, and SCR to minimize NOx emissions. An electrostatic precipitator was provided for particulate control and a wet limestone flue gas desulfurization system controlled $\mathrm{SO}_{2}$ emissions. A regenerative feedwater heating system was utilized and two different steam pressures were investigated. The first utilized a supercritical pressure (SC) double reheat steam cycle with steam turbine conditions of $3500 \mathrm{psig} / 1050^{\circ} \mathrm{F} / 1050^{\circ} \mathrm{F} / 1050^{\circ} \mathrm{F}$. In the second case ultra super critical pressure, double reheat steam conditions of $5000 \mathrm{psig} / 1200^{\circ} \mathrm{F} / 1200^{\circ} \mathrm{F} / 1200^{\circ} \mathrm{F}$ were utilized and both cases were investigated with and without $\mathrm{CO}_{2}$ capture. For $\mathrm{CO}_{2}$ capture inhibited aqueous MEA was used for chemical absorption.

\section{Natural Gas Combined Cycle Plant}

Two NGCC plant configurations were investigated. The first utilized two General Electric (GE) Company 7FA combustion turbines, each with its own heat recovery steam generator (HRSG) that supplied steam to a single steam turbine, whereas, the second case utilized a single GE H Class combustion turbine with one HRSG and one steam turbine. Both cases utilized a triple pressure HRSG, an $1800 \mathrm{psig} / 1050^{\circ} \mathrm{F} / 1050^{\circ} \mathrm{F}$ steam turbine, a 1 psia steam condenser back pressure, dry low NOx burners, and were investigated with and without $\mathrm{CO}_{2}$ capture. For $\mathrm{CO}_{2}$ capture, inhibited aqueous MEA was used for chemical absorption and only the $\mathrm{H}$ Class data is presented herein.

\section{Integrated Coal Gasification Combined Cycle Plant}

The IGCC plant utilized E-Gas ${ }^{T M}$ type gasification technology to produce a syngas that was cooled in a fire-tube type boiler and cleaned of particulate via a porous metal candle filter. When operated without $\mathrm{CO}_{2}$ capture, gasification occurred at approximately 500 psig and the filtered syngas underwent further cooling, water scrubbing, reheating, COS hydrolysis, cooling, removal of $\mathrm{H}_{2} \mathrm{~S}$ in absorption tower using Selexol solvent, reheating, and humidification for delivery to the combustion turbine burners. When designed for $\mathrm{CO}_{2}$ capture, gasification occurred at approximately 800 psig (increases $\mathrm{CO}_{2}$ partial pressure) and the filtered syngas underwent two stages of sour gas shifting, cooling, removal of $\mathrm{H}_{2} \mathrm{~S}$ in a first absorption stage tower, removal of $\mathrm{CO}_{2}$ in a second 
absorption stage tower, reheating, humidification, and expansion to 385 psia in a turbine expander. The gas was then reheated and delivered to the combustion turbine burners. Selexol solvent was used in both absorption stages. $\mathrm{H}_{2} \mathrm{~S}$ was stripped from the first stage solvent by flashing and processed by a Claus Plant with a tail gas treating unit for recovery of elemental sulfur. $\mathrm{CO}_{2}$ was stripped from the second stage solvent by flashing and was cooled, dried, and compressed to 1200 psig yielding a virtually moisture-free, supercritical pressure $\mathrm{CO}_{2}$ stream for pipeline transport.

Both the $\mathrm{F}$ and $\mathrm{H}$ Class plants utilized two 50 per cent capacity, cryogenic air separation units, and three 50 per cent capacity, 65 per cent coal/35 per cent water slurry preparation/feeding systems that fed their gasifiers with oxygen and fuel. The $\mathrm{F}$ Class plant incorporated two 50 per cent capacity gasifier equipment trains with each delivering syngas to its dedicated combustion turbine. The $\mathrm{H}$ Class plant incorporated three 33 per cent capacity gasifier equipment trains that delivered their syngas to the plant's single expander and single combustion turbine.

Table 4.1.9 presents the performance, economics, and emissions of the plants operating without $\mathrm{CO}_{2}$ capture and assuming an 80 per cent plant capacity factor. The plant net power outputs ranged from 384 MWe for the NGCC to 506 MWe for the USC PC plant. With the H Class NGCC plant fueled with natural gas (essentially a hydrogen based fuel) and operating with a 53.6 per cent efficiency (HHV basis), it has the lowest total plant cost (TPC), the lowest cost of electricity (COE), and the lowest $\mathrm{CO}_{2}$ emission rate of $0.75 \mathrm{lbs} / \mathrm{kWh}$. The IGCC and USC PC plants both have efficiencies of about 43 per cent and $\mathrm{CO}_{2}$ emissions of about $1.6 \mathrm{lbs} / \mathrm{kWh}$, a value more than double that of the NGCC plant.

\section{Table 4.1.9 NGCC and Illinois No 6 PC Plants Without $\mathrm{CO}_{2}$ Capture}

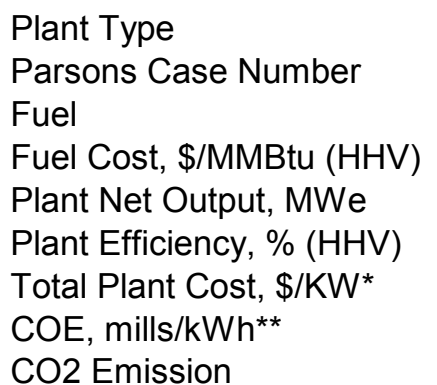

Plant Type

Parsons Case Number

Fue

Plant Net Output, MWe

Plant Efficiency, \% (HHV)

COE, mills $/ \mathrm{kWh}^{* *}$

$\mathrm{CO} 2$ Emission

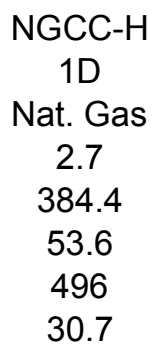

$\mathrm{lb} / \mathrm{kWh}$
$\mathrm{kg} / \mathrm{kWh}$
0.745

0.338

IGCC-H
3B
Illinois No 6
1.26
424.5
43.1
1263
45.1

1.582

0.718

SC-PC
$7 C$
Illinois No 6
1.26
462.1
40.5
1143
45.0

1.707

0.774
USC-PC

7D Illinois No 6

1.26

506.2

42.7

1161

44.3

1.618

0.734

${ }^{*}$ Year 2000 U.S. Dollars $\quad{ }^{* *} 20$ year levelized values with $80 \%$ capacity factor 
Table 4.1.10 shows the impact of 90 per cent $\mathrm{CO}_{2}$ removal on the $\mathrm{H}$ Class combustion turbine and the supercritical pressure PC plants (for the lower performing $\mathrm{F}$ Class plants the reader is referred to [12]). With the NGCC and PC plants using chemical absorption to remove $\mathrm{CO}_{2}$ after combustion, they experience about a 10 to 12 percentage point drop in efficiency; the IGCC plant, which removes $\mathrm{CO}_{2}$ from its shifted syngas before combustion and at about 800 psig, experiences about half the efficiency loss (6 percentage points). In summary 90 per cent $\mathrm{CO}_{2}$ removal:

a.) USC PC: decreases efficiency by 12 points and increases COE by 62 per cent to $71.6 \mathrm{mills} / \mathrm{kWh}$

b.) IGCC H: decreases efficiency by 6 points and increases COE by 25 per cent to $56.4 \mathrm{mills} / \mathrm{kWh}$

c.) NGCC H: decreases efficiency by 10 points and increases COE by 59 per cent to $48.8 \mathrm{mills} / \mathrm{kWh}$

The cost of $\mathrm{CO}_{2}$ removed or the $\mathrm{CO}_{2}$ avoided cost can be calculated by a comparison of plants with and without removal; the $\mathrm{CO}_{2}$ avoided cost is defined as the difference in plant $\mathrm{COE}$ in mills/kWh divided by the difference in plant $\mathrm{CO}_{2}$ emissions in $\mathrm{lbs} / \mathrm{kWh}$. With NGCC plants operating at high excess air and low stack gas $\mathrm{CO}_{2}$ concentrations, Table 4.1.10 shows that the NGCC plant has the highest $\mathrm{CO}_{2}$ avoided cost of $\$ 66.9 /$ ton versus about $\$ 48 /$ ton for the super critical pressure PC plants.

Recognizing that the NGCC plant both starts with and ends with a much lower $\mathrm{CO}_{2}$ emission rate than the coal based plants, its 90 per cent $\mathrm{CO}_{2}$ removal requirement could be relaxed and the plants compared on an equal emission rate basis. For such an analysis the reader is referred to [12].

\section{Table 4.1.10 NGCC and Illinois No 6 PC Plants with 90 Per Cent $\mathrm{CO}_{2}$ Capture}

\begin{tabular}{|c|c|c|c|c|}
\hline Plant Type+ & NGCC-H & IGCC-H & SC-PC & USC-PC \\
\hline Parsons Case Number & 1B & $3 A$ & $7 A$ & 7B \\
\hline Fuel & Nat. Gas & Illinois No 6 & Illinois No 6 & Illinois No 6 \\
\hline Fuel Cost, \$/MMBtu (HHV) & 2.7 & 1.26 & 1.26 & 1.26 \\
\hline Plant Net Output, MWe & 310.8 & 403.5 & 329.3 & 367.4 \\
\hline Plant Efficiency, \% (HHV) & 43.3 & 37 & 28.9 & 31.0 \\
\hline Total Plant Cost, $\$ / \mathrm{KW}^{*}$ & 943 & 1642 & 1981 & 1943 \\
\hline $\mathrm{COE}, \mathrm{mills} / \mathrm{kWh} \mathrm{h}^{* *}$ & 48.8 & 56.4 & 74.4 & 71.6 \\
\hline $\begin{array}{l}\text { CO2 Removal Location } \\
\text { Plant CO2 Emission }\end{array}$ & Post Combustion & Pre-Combustion & Post Combustion & Post Combustion \\
\hline $\mathrm{lb} / \mathrm{kWh}$ & 0.088 & 0.162 & 0.238 & 0.222 \\
\hline $\mathrm{kg} / \mathrm{kWh}$ & 0.040 & 0.073 & 0.108 & 0.101 \\
\hline CO2 Avoided Cost, \$/ton & 66.9 & 19.3 & 48.6 & 47.5 \\
\hline
\end{tabular}


The changes in plant efficiency and COE reported by Parsons are similar to those identified in the IEA Table 4.1.6. From the standpoint of absolute values, Parsons work is recommended as the IEA work is a compilation of work performed by different organizations. Parsons economic analyses was based on a natural gas price of \$2.70/MMBtu; they report that with $\mathrm{CO}_{2}$ capture the NGCC and IGCC COEs become equal at a gas price of $\$ 3.72 / \mathrm{MMBtu}$ and that NGCC and USC PC COEs become equal at a gas price of $\$ 5.75 / \mathrm{MMBtu}$.

During the 1994 to 1997 time period, four coal fueled, power producing IGCC demonstration plants were commissioned (Buggenum, Wabash, Polk County, and Puertollano). Each had a single, high temperature, entrained flow gasifier supplied by a different manufacturer. Despite several years of operation, modifications, and improvements, the availability of these units, when fueled with coal, remains disappointingly low (in the 70s) and there is a growing consensus that future plants will require at least a spare gasifier, if not a spare gasification equipment train, to achieve high availability [13 and 14]. The IGCC demonstration plants conceptually designed by Parsons and the Netherlands Research Foundation, however, do not include spares. As a result their IGCC plant costs can be expected to increase.

\subsubsection{American Air Liquide Study}

In [9] the impact of incorporating 90 per cent $\mathrm{CO}_{2}$ removal on a new PC plant via two different technologies/approaches was studied. Although the removed $\mathrm{CO}_{2}$ was to be sequestered at a distant site, no pipeline conditions were identified and so the study did not include the effects of $\mathrm{CO}_{2}$ cooling, drying, and compression to pipeline pressure. The plant was fueled with Powder River Basin (PRB) subbituminous coal and, in its baseline configuration (no $\mathrm{CO}_{2}$ capture), it produced $501 \mathrm{MWe}$ of power with an efficiency of 37 per cent HHV basis. The plant incorporated low NOx burners with SCR for NOx control, a limestone spray dryer for $\mathrm{SO}_{2}$ control (LSD), an activated carbon injection system for mercury control (ACl), an ESP for particulate removal, and a subcritical pressure steam cycle for power generation. In the first approach at $\mathrm{CO}_{2}$ removal an amine/MEA scrubbing system that removed 90 per cent of the $\mathrm{CO}_{2}$ was installed downstream of the ESP; the plant net output and efficiency decreased to 388 MWe and 28.6 per cent respectively. In the second approach, the boiler was fired with a mixture of oxygen and recirculated flue gas to form an $\mathrm{O}_{2} / \mathrm{CO}_{2}$ combustion system. With air nitrogen eliminated there was a five fold reduction in flue gas volume which led to reduced flue gas treatment costs including elimination of the SCR The oxygen was supplied at a 99 per cent purity level by a cryogenic air separation unit and, even though the cryogenic system introduced a $100 \mathrm{MWe}$ auxiliary power loss, a higher net plant output was obtained: $405 \mathrm{MWe}$ if the recirculated flue gas was cooled to condense its moisture (Dry OC) versus 408 MWe if it wasn't dried (Wet OC). 
Table 4.1.11 identifies the plant outputs and efficiencies, Figure 4.1.9 presents plant capital costs, and Figure 4.1.10 identifies the plant costs of electricity and $\mathrm{CO}_{2}$ avoided costs. In addition to imposing a smaller efficiency penalty, $\mathrm{O}_{2}$ combustion also imposes a smaller cost penalty on the plant. Compared to the baseline, the MEA absorption process increased the plant capital costs per KW of net power by 48 per cent whereas with $\mathrm{O}_{2}$ combustion the increase was only 23 per cent. From a cost of electricity standpoint, the increase from the baseline was approximately 59 per cent for amine scrubbing ( 10 versus 6.3 cents $/ \mathrm{kWh}$ ) versus 27 per cent for the $\mathrm{O}_{2}$ combustion plant ( 8 versus 6.3 cents $/ \mathrm{kWh}$ ) plus the latter's $\mathrm{CO}_{2}$ avoided cost was less than half that of scrubbing ( $\$ 20 /$ ton versus $\$ 47 /$ ton).

Despite its large requirement for oxygen, the greatly reduced flue gas flow rate associated with $\mathrm{O}_{2}$ combustion allows for a more compact, less expensive boiler design and reduced flue gas cleanup costs; all of these make $\mathrm{O}_{2}$ combustion a more cost effective technology for $\mathrm{CO}_{2}$ removal and, should emerging technologies reduce oxygen production costs (see Section 4.1.4), its economics will become even more attractive, especially for retrofit applications.

\section{Table 4.1.11 PRB Fueled PC Plant Performance With and Without $\mathrm{CO}_{2}$ Capture}

Boiler Oxidant

Flue Gas Recycle

CO2 Concentrated*

Technique Used

Steam Turbine Power, MWe

Plant Auxiliary Power, MWe

ASU

Other

Total

Plant Net Power, MWe

Plant Net Efficiency, \% (HHV)

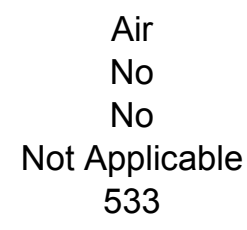

31

31

501

37.0
Air

No

Yes

MEA Scrubbing

434

47

47

388

28.6

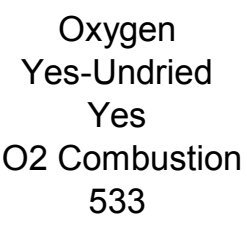

100

24

124

408

31.4
Oxygen

Yes-Dried

Yes

O2 Combustion

533

104

24

128

405

29.9

* Plant does not include CO2 processing or compression for pipeline transport

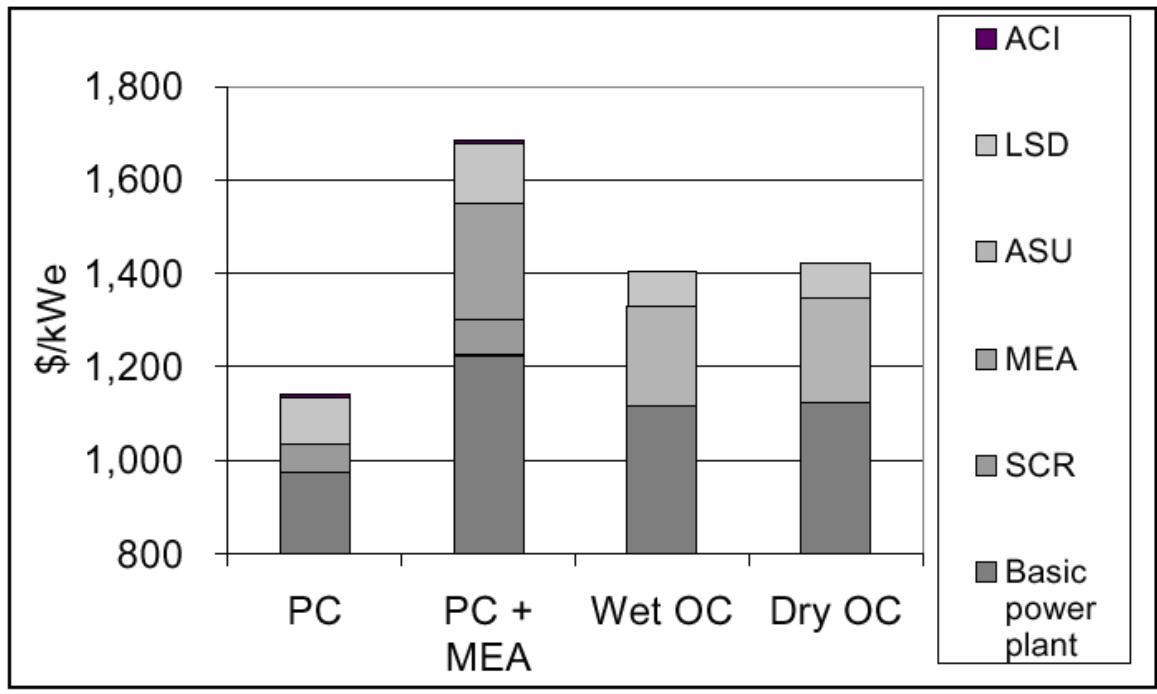


Figure 4.1.9 PRB Fired PC Plant Capital Costs With and Without $\mathrm{CO}_{2}$ Capture

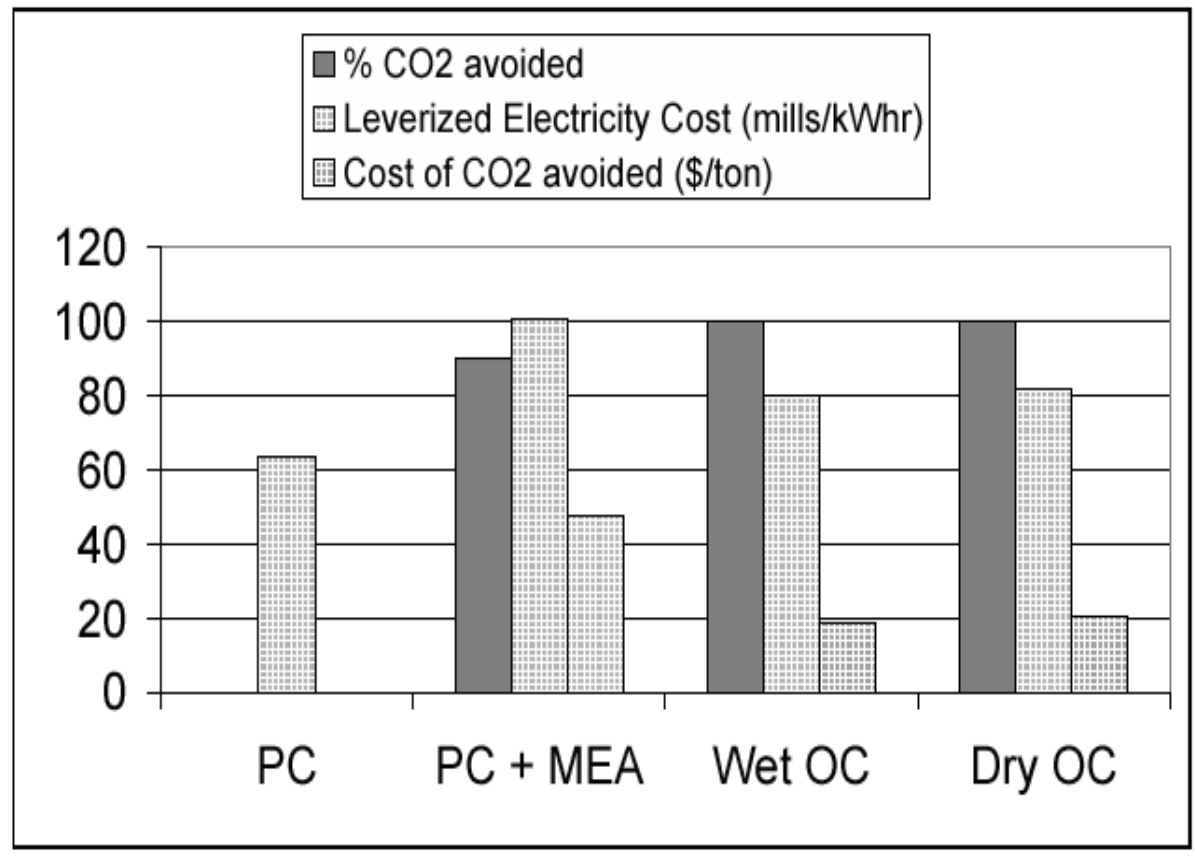

Figure 4.1.10 PRB Fired PC Plant COE and $\mathrm{CO}_{2}$ Avoided Costs

\subsubsection{Summary of New Plant Studies}

The new plant studies described above were conducted with different coals, different steam cycles, different site conditions, different scopes of supply, different economic assumptions, etc, and some included $\mathrm{CO}_{2}$ pipeline compression. In Table 4.1.12 the known key features of these studies have been summarized along with study results. Despite the differences between the studies, they indicate that $\mathrm{O}_{2}$ combustion, when compared to MEA scrubbing, can provide a $\mathrm{CO}_{2}$ rich stream for sequestration at a lower cost and at a lower efficiency penalty to the plant. 
Table 4.1.12 Summary of Plant $\mathrm{CO}_{2}$ Removal Studies

\begin{tabular}{|c|c|c|c|c|c|c|c|c|}
\hline \multirow{2}{*}{ Study } & \multicolumn{6}{|c|}{ Now Plants } & \multicolumn{2}{|c|}{--------------Repowering-------_. } \\
\hline & IEA & Parsons & Parsons & Air Liquide & IEA & Air Liquide & Alstom & Alstom \\
\hline \multicolumn{9}{|l|}{ Coal } \\
\hline Type & Bit & Bit & Bit & SubBit & Bit & SubBit & Bit & Bit \\
\hline Sulfur Content, \% & 0.86 & 2.5 & 2.5 & & 0.86 & & & \\
\hline $\mathrm{HHV}, \mathrm{Btu} / \mathrm{lb}$ & & 11,666 & 11,666 & & & & & \\
\hline LHV, Btu/lb & 11,114 & & & & 11,114 & & & \\
\hline Cost, $\$ / M M B t u$ & 2.64 & 1.26 & 1.26 & & 2.64 & & & \\
\hline Steam Cycle & SubC & SC & USC & SubC & SubC & SubC & SubC & SubC \\
\hline \multicolumn{9}{|l|}{ Gas Clean Up } \\
\hline Low NOx Burners & No & Yes & Yes & Yes & Yes & Yes & No & No \\
\hline SCR & No & Yes & Yes & Yes & No & Yes & No & No \\
\hline Sulfur Removal & FGD & FGD & FGD & LSD & No & LSD & FGD & FGD \\
\hline Mercury Removal & No & No & No & $\mathrm{ACl}$ & No & $\mathrm{ACl}$ & No & No \\
\hline Particulate Removal & ESP & ESP & ESP & ESP & ESP & ESP & ESP & ESP \\
\hline \multicolumn{9}{|l|}{ Plant Without/With CO2 Capture } \\
\hline \multicolumn{9}{|l|}{ Performance } \\
\hline $\begin{array}{r}\text { Plant Net Power, MWe } \\
\text { Plant Efficiency, \% }\end{array}$ & $500 / 500^{*}$ & $462.1 / 329.3$ & $506.2 / 367.4$ & $501 / 388$ & $500 / 500^{*}$ & $501 / 408$ & $433.8 / 260.8$ & $433.8 / 279.7$ \\
\hline LHV & $40 / 29$ & & & & $40 / 33$ & & & \\
\hline $\mathrm{HHV}$ & & $40.5 / 28.9$ & $42.7 / 31.0$ & $37.0 / 28.6$ & & $37.0 / 31.4$ & $35.0 / 21.0$ & $35.0 / 23.1$ \\
\hline \multicolumn{9}{|l|}{ Economics } \\
\hline Year & 1992 & 2000 & 2000 & 1999 & 1992 & 1999 & & \\
\hline Specific Cost,\$/KW & $1058 / 1842$ & & & & $1058 / 2040$ & & & \\
\hline Total Plant Cost, $\$ / \mathrm{KW}$ & & $1143 / 1981$ & $1161 / 1943$ & $1140 / 1690$ & & $1140 / 1400$ & & \\
\hline Plant Capacity Factor, \% & & 80 & 80 & 70 & & 70 & & \\
\hline $\mathrm{COE}, \mathrm{mills} / \mathrm{kWh}$ & $49.0 / 74.0$ & $45.0 / 74.4$ & $44.3 / 71.6$ & $63 / 100$ & $49.0 / 77.5$ & $63 / 80$ & & \\
\hline \multicolumn{9}{|l|}{ Effects of CO2 Capture/Separation } \\
\hline Technology Used & MEA & MEA & MEA & MEA & $\mathrm{O} 2 / \mathrm{CO} 2$ & $\mathrm{O} 2 / \mathrm{CO} 2$ & MEA & $\mathrm{O} 2 / \mathrm{CO} 2$ \\
\hline CO2 Compression, psig & Not Inclu & 1200 & 1200 & Not Inclu & Not Inclu & Not Inclu & 2000 & 2000 \\
\hline Decrease in Net Power, MWe & & 132.8 & 138.8 & 113 & & 93 & 173 & 154.1 \\
\hline Points Lost in Efficiency & 11 & 11.6 & 11.7 & 8.4 & 7 & 5.6 & 14 & 11.9 \\
\hline Increase in Plant Costs, \% & 74 & 73 & 67 & 48 & 93 & 23 & & \\
\hline Increase in $\mathrm{COE}, \%$ & 51 & 65 & 62 & 59 & 58 & 27 & & \\
\hline
\end{tabular}

*Size increased to maintain output 


\subsubsection{Impact of $\mathrm{CO}_{2}$ Removal On Existing Plants}

In [16] Alstom Power Incorporated conducted a study to determine the impact of incorporating $\mathrm{CO}_{2}$ removal into an existing pulverized coal-fired power plant via two different technologies/approaches. The plant selected was American Electric Power's bituminous coal fired Unit Number 2 at Conesville Ohio. It utilized a tangentially fired boiler together with a $2400 \mathrm{psig} / 1000^{\circ} \mathrm{F} / 1000^{\circ} \mathrm{F}$ steam turbine, an $\mathrm{ESP}$, and a wet FGD system; prior to $\mathrm{CO}_{2}$ removal it produced $433.8 \mathrm{MWe}$ of net power with an efficiency of 35 per cent and a $\mathrm{CO}_{2}$ emission rate of $866.2 \mathrm{klb} / \mathrm{h}(1.997 \mathrm{lb} / \mathrm{kWh})$.

The first case studied employed an MEA scrubber system to remove $\mathrm{CO}_{2}$ from the unit's flue gas. The MEA system had a flue gas $\mathrm{SO}_{2}$ limit of $10 \mathrm{ppm}$ dry volume basis; to accommodate this limit, the sulfur removal efficiency of the FGD system was increased by the addition of a second absorber and the MEA system was installed at its outlet. Approximately 79 per cent of the intermediate pressure steam turbine exhaust was required to regenerate the MEA solvent and the released $\mathrm{CO}_{2}$ was cooled, dried, and compressed to 2000 psig for delivery to a pipeline. The system removed 96 per cent of the plant $\mathrm{CO}_{2}$ and in doing so the plant net power output and efficiency decreased by $173 \mathrm{MWe}$ and 14 percentage points. It was also noted that a plot plan area of 5 acres was required to accommodate the MEA system.

In the second case $\mathrm{O}_{2}$ combustion was used. Three trains of conventional cryogenic air separation units were used to supply 99 per cent pure oxygen to the boiler at a total rate of approximately 8924 tons per day. About $2 / 3$ rds of the flue gas was recirculated to the boiler to maintain its air-fired temperature and gas flow profiles and an air in-leakage rate of one per cent of the total oxygen requirement was assumed. Although the steam turbine power was maintained, the cryogenic system consumed approximately $96 \mathrm{MWe}$ and the plant net output and efficiency decreased by $154 \mathrm{MWe}$ and 12 percentage points. The $\mathrm{O}_{2} / \mathrm{CO}_{2}$ system was calculated to remove 94 per cent of the plant $\mathrm{CO}_{2}$ and required half as much plot plan area ( $21 / 2$ acres) as the MEA system for its equipment.

Results of the two cases are summarized in Table 4.1.13. An $\mathrm{O}_{2}$ combustion retrofit, based on conventional cryogenic air separation, yields an efficiency about 2 percentages points higher than an MEA retrofit, requires half the real estate, and its efficiency, according to the authors, might be increased by another 20 per cent if advanced oxygen separating ceramic membranes (see Section 4.1.5) were used instead of cryogenic air separation. The retrofit study results have been added to Table 4.1.12 and the referenced two percentage point efficiency advantage shown for $\mathrm{O}_{2}$ combustion is similar to that predicted by American Air Liquide [9] for a new PRB coalfired plant application. Although Table 4.1.13 does not present economic data, [9] also analyzed an MEA versus $\mathrm{O}_{2}$ combustion retrofit and concluded that $\mathrm{O}_{2}$ combustion involved significantly lower capital costs and significantly lower operating and maintenance costs. 


\section{Table 4.1.13 $\mathrm{CO}_{2}$ Removal Incorporated Into An Existing PC Plant}

\begin{tabular}{|c|c|c|c|}
\hline Boiler Oxidant & Air & Air & Oxygen \\
\hline Flue Gas Recycle & No & No & Yes-Dried \\
\hline CO2 Concentrated* & No & Yes & Yes \\
\hline Technique Used & Not Applicable & MEA Scrubbing & O2 Combustion \\
\hline Steam Turbine Power, MWe & 463.5 & 331.5 & 463.1 \\
\hline \multicolumn{4}{|l|}{ Plant Auxiliary Power, MWe } \\
\hline ASU & & & 95.9 \\
\hline Other & 29.7 & 70.7 & 87.5 \\
\hline Total & 29.7 & 70.7 & 183.4 \\
\hline Plant Net Power, MWe & 433.8 & 260.8 & 279.7 \\
\hline \multicolumn{4}{|l|}{ Plant Net Efficiency, \% } \\
\hline HHV Basis & 35.0 & 21.0 & 23.0 \\
\hline LHV Basis & 36.7 & 22.0 & 24.1 \\
\hline \multicolumn{4}{|l|}{ Plant CO2 Emission } \\
\hline $\mathrm{KIb} / \mathrm{h}$ & 866.2 & 31.0 & 51.7 \\
\hline $\mathrm{lb} / \mathrm{kWh}$ & 1.997 & 0.119 & 0.185 \\
\hline $\mathrm{kg} / \mathrm{h}$ & 0.906 & 0.054 & 0.084 \\
\hline Plant CO2 Removal, \% & & 96.4 & 94.0 \\
\hline
\end{tabular}

\subsubsection{Oxygen Supply Systems}

There are currently three major commercial methods for producing oxygen from air; they are cryogenic air separation, pressure swing adsorption, and membrane separation. When large quantities or very high purity levels of oxygen are required, cryogenic air separation is the most cost effective technology. In addition it is the only one that can produce liquid oxygen which is an attractive feature in that tank storage can be provided that allows the oxygen user to continue to operate even though the ASU may be down for short term repairs. As a result, cryogenic air separation has been used at numerous IGCC plants, i.e. Buggenum, Wabash, Polk County, Puertollano, etc. Unfortunately cryogenic units are both expensive and high power consumers; they represent 12 to 15 per cent of IGCC plant capital costs, consume upwards of 10 per cent of the plant gross power output, and provide oxygen at a cost of about \$15/ton [15].

With cryogenic air separation being a mature technology, many people feel it offers very limited opportunities for significant reductions in cost or power consumption. As a result the DOE is funding research on emerging technologies that can hopefully provide "break through" advances to improve the economics of IGCC plants. The oxygen requirement of $\mathrm{O}_{2}$ based plants, based on tons of $\mathrm{O}_{2}$ per MWh of power generated, is estimated to be more than three times larger than that of IGCC plants [17] and, hence, it too will greatly benefit from such reductions. 
Air Products and Chemicals Inc. (Air Products) and Praxair Inc. are working under separate DOE contracts to develop oxygen transport membranes that hopefully will achieve a significant reduction in both oxygen production costs as well as power requirements. The Air Products technology is based on a ceramic membrane which, when operated at high temperature (typically 1500 to $1650^{\circ} \mathrm{F}$ ), will selectively transport oxygen ions. When subjected to an oxygen partialpressure driving force at this temperature the membrane will produce high-purity oxygen at a high flux rate. Air Products has named their air separation technology lon Transport Membrane (ITM) Oxygen. When applied to a single train IGCC plant incorporating a Texaco high-pressure quench gasifier and a Siemens Westinghouse 501G gas turbine, ITM Oxygen, when compared with cryogenic ASU, is projected to cost 35 per cent less. In addition it requires 37 per cent less power yielding a 7 per cent reduction in IGCC capital costs and a one percentage point increase in plant efficiency [18]. Air Products is pursuing a planar membrane system, has successfully manufactured and tested commercial scale wafers, and hopes to have a commercial scale unit with an oxygen capacity in the hundreds of tons per day in the year 2007-2008 time frame.

Praxair [19] reports similar success with the ceramic oxygen transport membrane (OTM) system it is developing. A ceramic material composed of synthetic inorganic compounds in an architecture suitable for a 10 year life appears feasible and a multi OTM element system, capable of delivering $>99$ per cent purity oxygen, has been successfully tested for 1000 hours at $1650^{\circ} \mathrm{F}$ and 275 psia; the multi element system is next undergoing cycle testing involving heating, oxygen production, and cool down to prove its integrity.

Although the ceramic membranes being pursued by both Air Products and Praxair are aimed at reducing the costs and increasing the efficiency of IGCC plants, they can also be applied to and will improve the performance and economics of $\mathrm{O}_{2}$ combustion plants. 


\subsection{System Design and Analysis}

\subsubsection{Reference Site and Fuel Conditions}

In December, 2000 Parsons published a study of the cost of electricity of several case studies in $\mathrm{CO}_{2}$ sequestration from a PC boiler by post capture (Ref. 12). To provide a consistent comparison with the cases analyzed in the Parsons report, the same site conditions $\left(59^{\circ} \mathrm{F}, 14.7 \mathrm{psia}, 60 \% \mathrm{RH}\right)$ and the same fuel (Illinois \#6) are used in the analysis presented herein. Site Conditions and fuel properties are presented in Table 4.2.1. Fuel HHV and LHV were estimated by a DuLong's method and the stoichiometric air ratio of $867 \mathrm{lb}_{\text {air }} / \mathrm{lb}_{\text {coal }}$ was calculated based on the fuel ultimate analysis.

The liquid $\mathrm{CO}_{2}$ produced from the oxygen-based PC power plant is not chemically pure, but can readily sequestered in geologic formations (depleted oil and gas reservoirs, unmineable coal seams, saline formations, and shale formations). The liquid $\mathrm{CO}_{2}$ exits the plant at 2000 psia (Parsons study used 1200 psia). The other gases in the delivered $\mathrm{CO}_{2}$ are limited to $\mathrm{H}_{2} \mathrm{O}<50 \mathrm{ppm}$ (to avoid acid corrosion), and $\mathrm{Ar}+\mathrm{N}_{2}<3 \%$ (to avoid phase separation). The excess gases in $\mathrm{CO}_{2}$ stream either have to be purged or recycled. However, since $\mathrm{SO}_{2}$, as an acid gas, similar to $\mathrm{CO}_{2}$, it can be sent to pipeline directly, and as mentioned in literature, it does not need to be separated out from $\mathrm{CO}_{2}$ product. Furthermore, it is also not necessary to remove the small concentration of NOx in the $\mathrm{CO}_{2}$ effluent since it can be sequestered along with the $\mathrm{CO}_{2}$.

\subsubsection{Air-Fired Reference Case}

To study the effects of $\mathrm{CO}_{2}$ removal on the performance of power plant, an airfired PC boiler was been simulated in detail as a reference case. This model was used as the base, which was then extended to include the air separation unit (ASU) and $\mathrm{CO}_{2}$ compression for $\mathrm{O}_{2}$-fired PC cases.

The reference plant employs a subcritical pressure, natural circulation boiler firing high-volatile bituminous coal producing 2400 psig steam at $1000^{\circ} \mathrm{F}$ and reheat steam at $1000^{\circ} \mathrm{F}$ to generate $460 \mathrm{MWe}$ (gross). A condenser pressure of $2.5^{\prime \prime} \mathrm{Hg}$ was applied along with seven feedwater heaters, which raise the feedwater temperature to $494^{\circ} \mathrm{F}$.

Case 1 is the reference air-fired PC boiler case and the model and results are shown in Figure 4.2.1.

The Aspen Plus model includes coal mills, flue gas heater, pulverized coal-fired furnace, steam generator, superheater, reheater, economizer, ash-removal unit, nitrogen oxides (NOx) selective catalytic reactor (SCR), flue gas de-sulfurization reactor (FGD), air blower, induced draft (ID) fan, feed water pump, cooling water 
pump, feed water heaters, and a single reheat steam turbine. A coal drying function has been modeled and added into mill module to result in the proper correct mill exit gas temperature. The furnace was simulated by a zero dimensional model. However, all key tube banks of the heat recovery area (HRA) were individually modeled. The furnace roof heat absorption is also simulated. The high pressure steam temperature is controlled by water spray for desuperheat. The simulation also included heat losses from boiler and HRA sides, as well as steam pipes. Some user-defined models are included to perform emission calculations. User built-in calculations were added to determine boiler efficiency, system net efficiency, and net power. The heat carried by exhaust streams was automatically calculated by program.

For a given steam turbine output and a fuel, ASPEN PLUS iterates to determine the feed rates of air, coal, etc., based on specified temperature approaches and the excess air requirement.

The system configuration, detailed setup parameters and summary of results for the case 1 reference case are shown in Figure 4.2.1 and Table 4.2.2. This system has a steam turbine cycle efficiency (generator power divided by heat transferred to the steam cycle) of $45.78 \%$, a boiler efficiency (heat to steam cycle divided by heat input from fuel to boiler) of $88.2 \%$, an unburned carbon loss (UBC) of $1.0 \%$, and a net plant efficiency of $36.68 \%$ (net plant heat rate of 9302 $\mathrm{Btu} / \mathrm{kWh}$ ). It has a gross power as $460 \mathrm{MWe}$ at generator, an auxiliary power of $42 \mathrm{MWe}$, and a net power of $418 \mathrm{MWe}$. Total heat input from fuel is $3890 \mathrm{MM}$ Btu/hr.

The temperature of the flue gas exhausted to the stack is $292^{\circ} \mathrm{F}$. The flue gas exiting the boiler contains $3.0 \%$, vol., wet $\mathrm{O}_{2}(18 \%$ excess air) and contains 773 $\mathrm{klb} / \mathrm{hr}(1.95 \mathrm{lb} / \mathrm{kwh})$ of $\mathrm{CO}_{2}$. This $3.0 \% \mathrm{O}_{2}$ level is kept constant for all of the $\mathrm{O}_{2}$ fired cases. An SCR is applied to control $\mathrm{NOx}$ with $\mathrm{NH}_{3} / \mathrm{NOx}=1.0$, while an FGD is used to control $\mathrm{SO}$ by lime solution with $\mathrm{Ca} / \mathrm{S}=1.05, \mathrm{~L} / \mathrm{G}=10$, and $85 \%$ excess air for aeration (Table 4.2.2)

The breakdown of auxiliary power for case 1 is listed in Table 4.2.3. Most of these power consumptions were simulated directly by the ASPEN module. Some required user Fortran for those processes lacking ASPEN modules, such as solids handling. The power consumption was based on stream flows and design data. Fan power consumption was simulated based on the pressure drops from both air side and gas side. The total auxiliary power consumption, including FGD, for case 1 is approximately $9.2 \%$ of the gross power. 


\subsubsection{Oxygen-Based PC Plant}

\subsubsection{Boiler Plant Modifications}

The oxygen-based (or oxygen-fired) plant model contains essentially all the components in the conventional plant model. In addition, it also includes an air separation unit (ASU) and a flue gas cooler. In the $\mathrm{O}_{2}$-fired plant, the FGD is not needed because the $\mathrm{SO}_{2}$ is acid gas similar to $\mathrm{CO}_{2}$ and can thus be sent to pipeline together with the $\mathrm{CO}_{2}$. A substantial portion of the $\mathrm{SOx}$ and $\mathrm{H}_{2} \mathrm{~S}$ will be removed as the flue gas is cooled down in the $\mathrm{CO}_{2}$ cooling and compression equipment.

The steam side components remain very similar to the air-fired case with only some changes in heat bundle duties in the heat recover area (HRA).

In $\mathrm{O}_{2}$-fired cases, flue gas is recycled is to control the flame temperature inside the PC-fired boiler to minimize NOx formation, minimize ash slagging in the furnace combustion zone, and avoid the application of exotic materials.

Before the flue gas is separated into a recycled and effluent stream (to the pipeline), it is cooled to $90^{\circ} \mathrm{F}$. Since this is below the acid/moisture dew point a heat exchanger containing acid-resistant materials must be used. The recycled gas is then reheated, before the forced draft (FD) fan, by mixing it with a bypassed hot gas to avoid reaching the dew point. After the $\mathrm{O}_{2}$ from ASU plant is mixed with recycled flue gas, it is heated by the flue gas exiting the boiler in a gas-gas heat exchanger, which acts as a recuperator to improve cycle efficiency and reduce fan power requirements.

It is assumed in this study that there is no tramp air ingress through the sealed boiler.

\subsubsection{Air Separation Unit}

For an $\mathrm{O}_{2}$-fired $\mathrm{PC}, \mathrm{O}_{2}$ purity is a key parameter for system performance and economics. A high purity $\mathrm{O}_{2}$ will produce a high purity of product $\mathrm{CO}_{2}$ gas that will reduce $\mathrm{CO}_{2}$ purification and compression power. However, producing high purity $\mathrm{O}_{2}$ requires high ASU plant operational and equipment costs. Furthermore, too high $\mathrm{O}_{2}$ purity is not necessary because the fuel combustion itself will generate some gases, such as $\mathrm{N}_{2}$ and some excess $\mathrm{O}_{2}$ is required for complete combustion, in additional to $\mathrm{CO}_{2}$ as flue gas. Therefore there is a balance point to give an optimum. After literature review and some trade studies, it was determined to use a complete ASU to separate air to $\mathrm{O}_{2}$ and $\mathrm{N}_{2} / \mathrm{Ar}$, ( $\mathrm{Ar}$ is separated out from the $\mathrm{O}_{2}$ by additional column) to maintain an $\mathrm{O}_{2}$ purity between 99.0 and $99.5 \%$. 
The method of air separation chosen for this study is the commercially available large-scale cryogenic air separation technique. A traditional cryogenic ASU plant, shown in Figure 4.2.2, was simplified in the simulation to include the power consumption, but without details of distillation columns and cold heat exchangers. The ASPEN simplified ASU model is shown in Figure 4.2.3. The ASPEN model does not include the air purifier, which removes moisture, hydrocarbons, $\mathrm{CO}_{2}$, and $\mathrm{NOx}$ in an adsorber and is located between the cold box and air compressor. Although the separated $\mathrm{N}_{2} / \mathrm{Ar}$ gases could potentially be sold as byproducts, no economic credit for this is taken in this study. No heat recovery from the ASU air compressor inter-stage coolers is included, because recovery of this low-grade heat recovery is very inefficient.

Power consumption is $23.6 \mathrm{kw} / \mathrm{klb}_{\text {air }}$ [12] for $95 \% \mathrm{O}_{2}$ purity under 67 psia ASU pressure. From Ref. 20, the power increases by $4 \%$ when $\mathrm{O}_{2}$ purity is increased from $95 \%$ to $99.5 \%$. Thus, for the $\mathrm{O}_{2}$ purity of $99.5 \%$ used in this study a power consumption of $24.5 \mathrm{kw} / \mathrm{klb}_{\text {air }}$ was applied. For a $460 \mathrm{MW}$ steam turbine generation, the ASU plant consumes about $70 \mathrm{MW}$, or $15 \%$ of generated power.

\subsubsection{Parametric Cases}

There were five $\mathrm{O}_{2}$-fired parametric cases studied as follows:

1. Case 1: air fired reference case

2. Case 2: with ASU \& gas recycle, the same mass flows of air and flue gas as case 1

3. Case 3: with ASU, reduced air, the same flue gas flow and $\mathrm{O}_{2} \%$ as case 1

4. Case 4: reduced recycle gas flow, the same adiabatic temperature and $\mathrm{O}_{2} \%$ as case 1

5. Case 5: reduced recycle gas flow, high adiabatic temperature and the same $\mathrm{O}_{2} \%$ as case 1

6. Case 6: reduced recycle gas flow, higher adiabatic temperature and the same $\mathrm{O}_{2} \%$ as case 1

Case 2 has the same system net excess air (exit plant $\mathrm{O}_{2}$ flow rate divided by stoichiometric $\mathrm{O}_{2}$ flow rate) as case 1 , but because of gas recycle, more $\mathrm{O}_{2}$ is carried by recycled gas back into boiler, which raised boiler excess air (boiler exit $\mathrm{O}_{2}$ flow rate divided by stoichiometric $\mathrm{O}_{2}$ flow rate) to a very high number of $69 \%$, and a very high oxygen content of the flue gas of $15.3 \%$. The cycle diagram for case 2 is shown in Figure 4.2.4.

In Case 3 the air flow rate was reduced to produce a $3 \%$, vol. $\mathrm{O}_{2}$ concentration at the boiler exit (similar to case 1). This corresponds to a boiler excess of $13.5 \%$ and a net excess of $3.1 \%$. Compared to case 2 the air flow rate of case 3 was reduced by $13 \%$ from $3422 \mathrm{klb} / \mathrm{hr}$ to $2981 \mathrm{klb} / \mathrm{hr}$. $\mathrm{O}_{2}$ concentration in the boiler is $26.9 \%$, compared to $20.4 \%$ for the air-fired case, and yields a higher combustion 
efficiency. Flue gas flow to the sequestration plant is reduced from $927 \mathrm{klb} / \mathrm{hr}$ in case 2 to $820 \mathrm{klb} / \mathrm{hr}$ in case 3 , which results in less $\mathrm{CO}_{2}$ compression duty. Case 3 maintains the same flue gas flow rate as cases 1 and 2 . The cycle diagram for case 3 is shown in Figure 4.2.5. In cases 4 to 6 the amount of flue gas recycled was reduced to increase the $\mathrm{O}_{2}$ level in the boiler. This increase in boiler $\mathrm{O}_{2}$ creates a higher adiabatic temperature, which reduces the size of the furnace and increases the overall cycle efficiency. The adiabatic temperature (used as the abscissa in Figure 4.2.10 to Figure 4.2.13) is the maximum theoretical temperature that can be reached by the products of combustion with no loss of heat and no dissociation. Actual flame temperature is lower than the adiabatic temperature especially at adiabatic temperatures greater than $3600^{\circ} \mathrm{F}$ due to flue gas dissociation of $\mathrm{CO}_{2}$ to $\mathrm{CO}$ and $\mathrm{H}_{2} \mathrm{O}$. The effect of adiabatic temperature on cycle efficiency is shown in Table 4.2.4 and Figure 4.2.10. Case 4 has the same adiabatic temperature as air-fired reference case, while cases 5 and 6 have higher adiabatic temperatures. Although there is little change in gas exhaust flow to the $\mathrm{CO}_{2}$ compressor among cases 3-6 (listed as gas exit system in Table 4.2.4), the decreasing recycle gas flow results in reduced auxiliary power consumption for both the FD and ID fans. The reduction in FD and ID fan auxiliary power requirements is presented in Figure 4.2.11 (approximately 2.5 $\mathrm{MW}$ from case 3 to case 6 ) along with the reduction in ASU power requirements (approximately $1 \mathrm{MW}$ from case 3 to case 6 )

Figure 4.2.12 shows the relationship of flue gas flow to boiler adiabatic temperature. Figure 4.2.13 is a similar plot to Figure 4.2.12, but it uses volumetric flow rate as the ordinate instead of mass flow rate. Both figures show the air-fired data for comparison. It can be observed that the $\mathrm{O}_{2}$-fired $\mathrm{PC}$ has a lower volume flow rate than does the air-fired PC due to the higher molecular weight of the flue gas (i.e. $\mathrm{CO}_{2}$ versus $\mathrm{N}_{2}$ ). From case 3 to case 6 the ratio of the $\mathrm{O}_{2}$-fired $\mathrm{PC}$ volume flow rate to the air-fired PC volume flow rate drops from $75 \%$ to $57 \%$, which means for a constant flue gas velocity, boiler size is reduced.

Another advantage from decreasing the quantity of recycle gas is to increase the $\mathrm{O}_{2}$ content in the boiler (from $27 \%$ to $34 \%$ by vol. from case 3 to case 6 ), which improves the fuel combustion and reduces the required height of the furnace. This credit has not been simulated in this system study, but was modeled in the 3-D CFD boiler simulation study (Section 4.4.1).

\subsubsection{Hot Recycle}

A case with hot gas recycle (case 7, Figure 4.2.9) was run to evaluate its effect on the system performance. A hot gas recycle brings more energy back into boiler, reduces fuel and $\mathrm{O}_{2}$ feed rates, and reduces ASU duty, but it requires more power to the fan because of the increased recycle gas volume flow.

Table 4.2.4 shows that increasing the recycle gas temperature from $95^{\circ} \mathrm{F}$ to $148^{\circ} \mathrm{F}$ increases the boiler efficiency from $89.60 \%$ to $90.94 \%$ and net efficiency 
from $31.90 \%$ to $32.12 \%$. The additional fan power increase of $0.3 \mathrm{MW}$ was more than made up by a reduction in ASU power of $0.5 \mathrm{MW}$. The resultant fuel saving is approximately $0.7 \%$. The size of the gas-gas heat exchanger increases due to the reduction in LMTD (fluid temperature difference is reduced from $213^{\circ} \mathrm{F}$ to $176^{\circ} \mathrm{F}$ for the hot end, and from $104^{\circ} \mathrm{F}$ to $74^{\circ} \mathrm{F}$ for the cold end).

There is a limit to increasing the recycle gas temperature without increasing the stack gas temperature, which will reduce efficiency and increase cooling duty. One option mentioned in literature is to raise both stack gas and recycle gas temperatures, and then recover heat from stack gas to replace part of the feedwater heaters. The merits of this approach are questionable because the efficiency improvement will be very small from replacing the low pressure feedwater heater.

Figure 4.2.14 shows the cooling curve for flue gas cooling before compressor. Part of the heat can be recovered to preheat the condensate. If $90 \mathrm{MMBtu} / \mathrm{hr}$ of heat is recovered (exit temperature $=142^{\circ} \mathrm{F}$ ), the steam saved from extraction will generate an additional $2.2 \mathrm{MW}$, or an efficiency increase of $0.2 \%$ point. If 150 $\mathrm{MMBtu} / \mathrm{hr}$ of heat is recovered (exit temperature $=133^{\circ} \mathrm{F}$ ), the steam saved from extraction will generate an additional $3.4 \mathrm{MW}$, or an efficiency increase of $0.3 \%$ point. This potential energy savings will be further explored in Section 4.2.8.

\subsection{6 $\mathrm{CO}_{2}$ Compression}

The flue gas effluent stream (mainly $\mathrm{CO}_{2}$ ) has to be compressed to the high pipeline pressure of 1200 to 2000 psia. Using case 3 as a basis, case 8 is simulated in which the $\mathrm{CO}_{2}$ sequestration equipment is added to the system and the effluent is conservatively compressed to 2000 psia. The dominant moisture in flue gas is condensed out first during flue gas cooling before the first stage compression. The condensed water contains acid gases and has to be treated before recycle or discharge.

The flue gas dry composition before the first stage $\mathrm{CO}_{2}$ compressor from case 8 is:

\begin{tabular}{lllll}
$\mathrm{CO}_{2}$ & $\mathrm{O}_{2}$ & \multicolumn{2}{c}{$\mathrm{N}_{2}+$ Ar SOx } & $\mathrm{H}_{2} \mathrm{O}$ \\
90.9 & 2.9 & 1.3 & 1.3 & 3.6
\end{tabular}

In literature, a $\mathrm{O}_{2}$ concentration as low as $1.3 \%$ was used. Reducing $\mathrm{O}_{2}$ content, such as from $3.0 \%$ to $2.0 \%$ by reducing excess air, would be helpful in reducing $\mathrm{CO}_{2}$ compression power, but it is judged that and oxygen content of approximately $3.0 \%$ is required for good combustion efficiency. Both $\mathrm{CO}_{2}$ and $\mathrm{SO}_{\mathrm{x}}$ are acid gases. They combine with moisture to form acid, which causes a corrosion problem along $\mathrm{CO}_{2}$ pipeline. Therefore, after the $2^{\text {nd }}$ stage, a chemical method of active dehydration with TEG (Triethyleneglycol), retarding hydrate formation and corrosion, has been applied to reduce the moisture to a very low 
level of less than $50 \mathrm{ppm}$, where the TEG can be regenerated by heating. In the model, the TEG dehydration was simulated, but the TEG itself was not simulated.

A four-stage compression with inter-stage cooling was applied in case 8. To reduce power, an equal compression pressure ratio of approximately 3.4 was applied. The results are shown in Figure 4.2.15 and Table 4.2.5. The effects of the addition of the ASU and the $\mathrm{CO}_{2}$ sequestration plant can be seen in Table 4.2.5 as follows:

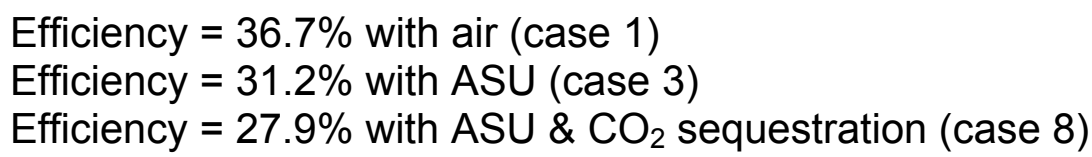

\subsubsection{Vent Gas Recycle}

Because of limitation of the other gases in $\mathrm{CO}_{2}$ pipeline (i.e., $\mathrm{H}_{2} \mathrm{O}<50 \mathrm{ppm}$ and $\mathrm{Ar}+\mathrm{N}_{2}<3 \%$ ), the excess gases have to be purged. A novel idea applied in this study is to recycle this $\mathrm{O}_{2}$-rich purge gas back to system and to reduce ASU duty and to recover power. The vent gas recycle has been simulated in case 9 (Figure 4.2.16). To effectively separate out the non- $\mathrm{CO}_{2}$ gases, the compressed $\mathrm{CO}_{2}$ stream from the $3^{\text {rd }}$ stage is cooled down to its dew point (Figure 4.2.20) and condensed out by phase separation by a stripper tower (not simulated in this study). Instead of using a compressor for the $4^{\text {th }}$ stage $\mathrm{CO}_{2}$ of compression as in case 8, a $\mathrm{CO}_{2}$ liquid pump is used in case 9 to save power and cost.

The composition of the purge gas is as follows:

$\begin{array}{llll} & \mathrm{O}_{2} & \mathrm{~N}_{2}+\text { Ar others } \\ \text { Case } 9 & 71.6 & 28.1 & 0.3\end{array}$

Although the flue gas flow discharged to $\mathrm{CO}_{2}$ plant is nearly identical for both cases 8 and 9 as shown in Table 4.2.5, the net excess $\mathrm{O}_{2}$ reduces to near zero when vent gas recycle is applied, and consequently the air flow rate to system is reduced from 2981 to $2905 \mathrm{klb} / \mathrm{hr}$. However since the boiler is still operated at $27.5 \% \mathrm{O}_{2}$ inlet, and a $3 \% \mathrm{O}_{2}$ outlet, the boiler combustion performance will not be affected.

The addition of vent gas recycle (compare case 8 to case 9 in Table 4.2.5) increases the net efficiency from $27.9 \%$ to $28.3 \%$, increases the net power from 317.3 to $321.8 \mathrm{MW}$, and decreases the auxiliary power from 143.1 to $138.6 \mathrm{MW}$ (a net 4.5 MW saving). Gas recycle will also reduce NOx in the effluent since the majority of the NOx will be separated out with the purge gas and removed by the gas adsorber in ASU plant.

Since the vent gas from the $\mathrm{CO}_{2}$ compression plant is at 920 psia and the ASU is at 67 psia, the vent gas can be sent to an expander to generate power and 
reduce its pressure and temperature. This power generation is not included in case 9 , but is added in a subsequent case (see Section 4.2.8). Furthermore, the low temperature expanded recycled gas could be used as extra coolant for the ASU distillation column. However, this energy savings has not been accounted at present time because the model does not include the details for ASU plant.

In cases 10 and 11 the amount of flue gas recycled was reduced to increase the $\mathrm{O}_{2}$ level in the boiler (similar to cases 4 to 6 ). This increase in boiler $\mathrm{O}_{2}$ creates a higher adiabatic temperature, which reduces the size of the furnace and increases the overall cycle efficiency. The effect of adiabatic temperature on cycle efficiency is shown in Table 4.2.5, which demonstrates that raising the adiabatic temperature from $3575^{\circ} \mathrm{F}$ to $4343^{\circ} \mathrm{F}$ increases the net efficiency from $28.3 \%$ to $29.5 \%$ (boiler efficiency is also increased from $88.3 \%$ to $90.8 \%$ ). Figure 4.2.17 presents the net cycle efficiency versus the recycle flow rate. Cycle diagrams for cases 10 and 11 are shown in Figure 4.2.18 and Figure 4.2.19, respectively.

\subsubsection{Case 12}

Based on the results of the parametric cases, cases 12 is modeled

Since all processes that capture $\mathrm{CO}_{2}$ must include some kind of wet gas cooler, due to the low temperature to which the flue gas is cooled, case 12 utilizes a wetend economizer to recover as much of this heat as practical. In case 12 a heat exchanger is added to recover the flue gas sensible energy prior to separation into recycle and outlet streams. The heat exchanger cools the flue gas to $142^{\circ} \mathrm{F}$ and removes $90 \mathrm{MM} \mathrm{Btu/hr}$. This significantly increases the boiler efficiency by reducing the energy content of the flue gas effluent. The LMTD of the heat exchanger is $34^{\circ} \mathrm{F}$ and it is judged that reducing the flue gas temperature further (below $142^{\circ} \mathrm{F}$ ) could be uneconomical since the required heat exchanger would be too large. Figure 4.2.24 shows that reducing the flue gas temperature from $142^{\circ} \mathrm{F}$ to $139^{\circ} \mathrm{F}$ (increasing the heat exchanger absorption from $90 \mathrm{MM}$ Btu/hr to $100 \mathrm{MM} \mathrm{Btu} / \mathrm{hr}$ ) reduces the LMTD from $34^{\circ} \mathrm{F}$ to $26^{\circ} \mathrm{F}$.

Although the flue gas outlet temperature of this additional heat exchanger is nominally at the moisture condensation temperature, the presence of SOx in the flue gas raises the dew point of gas such that sulfuric acid solutions will condense below $300^{\circ} \mathrm{F}$. Consequently the heat exchanger must be constructed from acid-resistant materials.

There are two possible applications for this wet-end economizer: 1) replace the first stage FWH1 or 2) heat up a split stream from the condensate pump. The second option results in a higher thermal efficiency since it reduces the higher pressure steam extractions. This is demonstrated in Figure 4.2.26, which shows that the efficiency (work/steam thermal energy) of the steam, if it is not extracted, 
increases with increasing pressure (stage). Therefore the split stream method yields higher efficiency and is applied in the design case (Figure 4.2.23).

Case 12 also incorporates a turbine expander to recover power from the recycled purge gas pressure reduction. The turbine generates $0.41 \mathrm{MW}$ of power as the pressure is reduced from 925 psia to 67 psia. The expanded gas is quite cold $\left(-183^{\circ} \mathrm{F}\right)$ and could potentially be used as a coolant for distillation operation. However, since the ASU was not modeled in detail in this study no credit for this cooling effect is taken.

Due to the possible danger of pre-combustion in the mill and primary gas stream, a modification is made to the cycle to use the vitiated air $\left(3.0 \% \mathrm{O}_{2}\right)$ as the coalcarrying primary gas stream. The recycled flue gas is mixed with the secondary gas stream after the primary gas take-off.

Figure 4.2.23 shows the cycle diagram for case 12 . The boiler efficiency is $93.2 \%$ and the overall cycle efficiency is $29.8 \%$ (Table 4.2 .5 ). The $4.7 \%$ losses in the boiler efficiency is comprised of $17 \%$ sensible heat, $66 \%$ latent heat $\left(\mathrm{H}_{2} \mathrm{O}\right), 14 \%$ unburned carbon, $3 \%$ radiation. Since it is likely that with $\mathrm{O}_{2}$-fired combustion and a high flame temperature, the unburned carbon loss will be nearly zero (confirmed in Section 4.4.1.5), the boiler efficiency would be $94.1 \%$ and the overall cycle efficiency would be $30.1 \%$.

\subsubsection{Design Case: Case 13}

To further reduce the required furnace surface area while increasing the net cycle efficiency, the flue gas recycle flow rate was reduced from $65 \%$ (case 12) to $56 \%$ (case 13). All features of case 12 are incorporated in case 13. In addition part of the $\mathrm{CO}_{2}$ compressor inter-stage cooling is used to replace part of the economizer duty in the feed water heating train.

Figure 4.2 .25 shows the cycle diagram for case 13 . The boiler efficiency is $93.5 \%$ and the overall cycle efficiency is $30.3 \%$ (Table 4.2 .5 ). The $4.7 \%$ losses in the boiler efficiency is comprised of $15 \%$ sensible heat, $67 \%$ latent heat $\left(\mathrm{H}_{2} \mathrm{O}\right), 14 \%$ unburned carbon, $3 \%$ radiation. Since it is likely that with $\mathrm{O}_{2}$-fired combustion and a high flame temperature, the unburned carbon loss will be nearly zero (confirmed in Section 4.4.1.5), the boiler efficiency would be $94.5 \%$ and the overall cycle efficiency would be $30.6 \%$.

\subsubsection{Furnace Waterwall Temperature}

The level of radiation in the $\mathrm{O}_{2}$-fired boiler is significantly higher than an air-fired boiler due to greater concentrations of radiating gas species $\left(\mathrm{CO}_{2}\right.$ and $\left.\mathrm{H}_{2} \mathrm{O}\right)$ and higher flame temperature. Consequently, it is important to select the proper 
amount of recycled flue gas to limit the water wall temperature such that a reasonable waterwall material can be used.

The maximum waterwall temperature and furnace heat flux was calculated from the ASPEN results using the Foster Wheeler computer program, EMISS. The EMISS computer program calculates radiative heat flux of $\mathrm{CO}_{2}$ and $\mathrm{H}_{2} \mathrm{O}$ gases as follows:

$$
\begin{aligned}
& Q / A=\left(\frac{\varepsilon_{\text {wall }}+1}{2}\right) \sigma\left(\varepsilon_{g} T_{g}^{4}-\alpha_{g} T_{w}^{4}\right) \\
& Q / A=U_{O}\left(T_{W}-T_{f}\right)
\end{aligned}
$$

where,

$\varepsilon=\varepsilon_{\mathrm{CO} 2}+\varepsilon_{\mathrm{H} 2 \mathrm{O}}-\Delta \varepsilon$

$\Delta \varepsilon \quad=$ Correction factor due to spectral overlap

$\varepsilon_{\mathrm{CO} 2}=$ Emissivity of $\mathrm{CO}_{2}$ (function of temperature, mean beam length, and partial pressure of $\mathrm{CO}_{2}$ )

$\varepsilon_{\mathrm{H} 2 \mathrm{O}}=$ Emissivity of $\mathrm{H}_{2} \mathrm{O}$ (function of temperature, mean beam length, and partial pressure of $\mathrm{H}_{2} \mathrm{O}$ )

$\varepsilon_{\mathrm{g}} \quad=$ Emissivity of gas at gas temperature

$\alpha_{\mathrm{g}} \quad=$ Absorptivity of gas at wall temperature (equal to emissivity)

$\varepsilon_{\text {wall }}=$ Tube wall emissivity (assumed to be 0.7 )

$\sigma \quad=$ Stefan-Boltzmann constant $=1.714 \times 10^{-9} \mathrm{Btu} / \mathrm{hr}-\mathrm{ft}^{2}-\mathrm{R}^{4}$

$\mathrm{Q} / \mathrm{A}=$ Heat Flux (Btu/hr-ft $\left.{ }^{2}\right)$

$\mathrm{T}_{\mathrm{f}} \quad$ = Water/Steam fluid temperature $\left({ }^{\circ} \mathrm{R}\right)$

$\mathrm{T}_{\mathrm{g}} \quad=$ Gas temperature $\left({ }^{\circ} \mathrm{R}\right)$

$\mathrm{T}_{\mathrm{w}} \quad=$ Wall temperature $\left({ }^{\circ} \mathrm{R}\right)$

$\mathrm{U}_{\mathrm{o}} \quad=$ Heat transfer coefficient from outside of wall to steam/water $\left(\mathrm{Btu} / \mathrm{hr}-\mathrm{ft}^{2}-\mathrm{F}\right)$

Table 4.2.6 presents the calculated furnace heat flux for cases 1 to 13 . Both the maximum heat flux (based on the maximum furnace gas temperature) and the average heat flux (based on the average furnace gas temperature) are presented. Based on the maximum heat flux, the maximum water wall temperature is computed. From this maximum wall temperature and the selected material, the minimum tube wall thickness is computed using stress allowables from the ASME Boiler and Pressure Vessel Code.

Due to $\mathrm{CO}_{2}$ dissociation into $\mathrm{CO}$ and $\mathrm{O}_{2}$, the equilibrium flame temperature is lower than the adiabatic temperature. Figure 4.2.21 presents the equilibrium values of $\mathrm{CO}_{2}$ and $\mathrm{CO}$ concentration versus flue gas recycle flow. The effect of $\mathrm{CO}_{2}$ dissociation is shown in Figure 4.2.22, which presents the adiabatic temperature (without $\mathrm{CO}_{2}$ dissociation) and equilibrium temperature (with $\mathrm{CO}_{2}$ dissociation) versus flue gas recycle flow. The maximum flame temperature applied for furnace wall temperature calculations is based on a temperature 
slightly lower than the equilibrium temperature to account for heat loss by the flame.

Table 4.2.6 shows that for the air-fired reference case (case 1), the waterwalls are carbon steel with a 0.30 " wall thickness. Even though the $\mathrm{O}_{2}$-fired cases 2 and 3 have similar furnace gas temperatures than case 1 , the substantially greater concentrations of $\mathrm{CO}_{2}$ and $\mathrm{H}_{2} \mathrm{O}$ results in a radiative heat flux of approximately $50 \%$ higher. Thus, to maintain the same wall thickness requires an upgrade in the material to the T2 alloy. As the flame temperature is increased in cases 4 to 6 and cases 9 to 11, the heat flux and wall temperature increases requiring further material upgrades. For case, the maximum wall temperature is $960^{\circ} \mathrm{F}$ for which 0.24 " thick T91 material is required.

The ratio of the average furnace heat flux of the $\mathrm{O}_{2}$-fired furnace to the average furnace heat flux of the air-fired furnace is also presented in Table 4.2.6. For case 13 this ratio is 0.53 , which means that case 13 requires only approximately $53 \%$ of the case 1 heating surface area. This can be used as a preliminary estimate of the $\mathrm{O}_{2}$-fired furnace size. Table 4.2.6 shows that the air-fired furnace dimensions of 36' $\times 51^{\prime} \times 207^{\prime}(\mathrm{D} \times \mathrm{W} \times \mathrm{H})$ are substantially reduced to $30^{\prime} \times 43^{\prime} \times$ $142^{\prime}(\mathrm{D} \times \mathrm{W} \times \mathrm{H})$ in case 12 and $27^{\prime} \times 38^{\prime} \times 134^{\prime}(\mathrm{D} \times \mathrm{W} \times \mathrm{H})$ in case 13. Section 4.4.1.5 conducted a detailed design of the $\mathrm{O}_{2}$-fired boiler in detail by performing a three-dimensional CFD simulation.

\subsubsection{Comparison With Post $\mathrm{CO}_{2}$ Capture}

$\mathrm{CO}_{2}$ cannot be free captured and sequestrated without reducing both the plant power and efficiency because of a potential energy stored in the pressurized liquid $\mathrm{CO}_{2}$. A minimum of $40 \mathrm{kw} / \mathrm{klb} \mathrm{b}_{\mathrm{CO}}$ additional auxiliary power is required for $\mathrm{CO}_{2}$ compression. The difference between technologies lies in the difference in power requirements of the different $\mathrm{CO}_{2}$ or $\mathrm{O}_{2}$ separation techniques.

Parsons [12] performed some studies on $\mathrm{CO}_{2}$ removal by a post capture method for a conventional PC boiler. The plant efficiency drops from $40.5 \%$ to $28.9 \%$ for a supercritical $\left(3500 \mathrm{psia} / 1050^{\circ} \mathrm{F} / 1050^{\circ} \mathrm{F} / 1050^{\circ} \mathrm{F} / 2.0^{\prime \prime} \mathrm{Hg}\right)$ boiler, and from $42.7 \%$ to $31.0 \%$ for an ultra supercritical $\left(5000\right.$ psia/ $1200^{\circ} \mathrm{F} / 1200^{\circ} \mathrm{F} / 1200^{\circ} \mathrm{F} / 2.0^{\prime \prime} \mathrm{Hg}$ ) boiler. In the study presented herein, the $\mathrm{CO}_{2}$ removal using an $\mathrm{O}_{2}$-fired $\mathrm{PC}$ is used, which relies on an ASU. The efficiency drops from $36.7 \%$ (case 1) to $30.6 \%$ (case 13 with minimal UBC loss) for a subcritical (2415 psia/ $1000^{\circ} \mathrm{F} / 1000^{\circ} \mathrm{F} / 2.5^{\prime \prime} \mathrm{Hg}$ ) boiler. Since the Parsons study compressed the effluent $\mathrm{CO}_{2}$ to 1200 psia, whereas this study herein compressed the $\mathrm{CO}_{2}$ to 2000 psia, the 1200 psia pressure is used as comparison basis, which increases the case 13 efficiency to $30.8 \%$. The net efficiency drops for these cases are

$11.7 \%$ points for supercritical, post combustion $\mathrm{CO}_{2}$ removal

$11.7 \%$ points for ultra supercritical, post combustion $\mathrm{CO}_{2}$ removal

$5.9 \%$ point for subcritical, $\mathrm{O}_{2}$ fired 
Based on the Parson's study it appears that the efficiency reduction is independent of steam cycle. However, there is a big difference between the efficiency reductions for post capture and $\mathrm{O}_{2}$-fired. Furthermore, the $\mathrm{O}_{2}$-fired method gives near $100 \% \mathrm{CO}_{2}$ removal, while the post capture is practically limited to about $90 \%$ (limited by a vapor-liquid equilibrium from absorptionregeneration cycle).

Another comparison basis is the $\mathrm{kw} / \mathrm{b}_{\mathrm{CO} 2}$ removal, where the $\mathrm{kw}$ is power generation difference between cases with and without $\mathrm{CO}_{2}$ removal. Comparing the post $\mathrm{CO}_{2}$ capture to the $\mathrm{O}_{2}$-fired case:

$187 \mathrm{kwh} / \mathrm{lb} \mathrm{b}_{\mathrm{CO} 2}$ for supercritical, $90 \%$ post combustion $\mathrm{CO}_{2}$ removal

$188 \mathrm{kwh} / \mathrm{lb} \mathrm{b}_{\mathrm{CO} 2}$ for ultra supercritical, $90 \%$ post combustion $\mathrm{CO}_{2}$ removal

$80 \mathrm{kwh} / \mathrm{lb}_{\mathrm{CO} 2}$ for subcritical, $\mathrm{O}_{2}$ fired $100 \%$ removal

Again, the change in power penalty for $\mathrm{CO}_{2}$ removal appears independent of steam cycle. From above data, it is very clear that the $\mathrm{O}_{2}-\mathrm{PC}$ has advantages over the post $\mathrm{CO}_{2}$ capture.

The efficiency of carbon sequestration in oxygen-firing boilers even can rival competing gasification plants. Figure 4.2.27 compares the power consumption of adding $\mathrm{CO}_{2}$ removal equipment to various competing technologies. Figure 4.2.27 shows that the power consumption of $\mathrm{CO}_{2}$ removal for $\mathrm{O}_{2}$-fired $\mathrm{PC}$ plants is less than one-third of natural gas combined cycles (NGCC), less than one-half of post $\mathrm{CO}_{2}$ removal PCs and $80 \%$ of integrated gasification combined cycles (IGCC). Figure 4.2.28 compares the reduction in power plant efficiency of adding $\mathrm{CO}_{2}$ removal equipment to various competing technologies. Figure 4.2.28 shows that the reduction in power plant efficiency of $\mathrm{CO}_{2}$ removal for $\mathrm{O}_{2}$-fired $\mathrm{PC}$ plants is nearly half of either natural gas combined cycles (NGCC) or post $\mathrm{CO}_{2}$ removal PCs and slightly less than integrated gasification combined cycles (IGCC). And once again note that the $\mathrm{O}_{2}$-firing $\mathrm{PC}$ is the only technology that removes $100 \%$ of the $\mathrm{CO}_{2}$. 
Table 4.2.1 - Site Conditions and Coal Properties

\begin{tabular}{|c|c|c|c|}
\hline Elevation & $\mathrm{ft}$ & 0 & \\
\hline Ambient pressure & psia & 14.70 & \\
\hline Ambient Temperature & $\mathrm{F}$ & 59.0 & \\
\hline Ambient Temperature, wet & $\mathrm{F}$ & 51.5 & \\
\hline Relative Humidity & $\%$ & 60.0 & \\
\hline $\mathrm{P}-\mathrm{H} 2 \mathrm{O}$ & psia & 0.247 & \\
\hline $\mathrm{Y}-\mathrm{H} 2 \mathrm{O}$ & $\%$, vol & 1.010 & \\
\hline Condenser Pressure & " $\mathrm{Hg}$ & 2.50 & \\
\hline Air Composition & & Dry & Wet \\
\hline N2 & $\%$, vol & 78.085 & 77.297 \\
\hline $\mathrm{O} 2$ & $\%$, vol & 20.947 & 20.735 \\
\hline $\mathrm{Ar}$ & $\%$, vol & 0.935 & 0.926 \\
\hline $\mathrm{CO} 2$ & $\%$, vol & 0.033 & 0.033 \\
\hline $\mathrm{H} 2 \mathrm{O}$ & $\%$, vol & 0.000 & 1.010 \\
\hline Total & $\%, \mathrm{vol}$ & 100.000 & 100.000 \\
\hline
\end{tabular}

\begin{tabular}{|r|c|r|}
\hline Illinois No. 6 Coal & & \\
\hline $\mathrm{C}$ & $\%$ & $63.75 \%$ \\
\hline $\mathrm{H}$ & $\%$ & $4.50 \%$ \\
\hline $\mathrm{O}$ & $\%$ & $6.88 \%$ \\
\hline $\mathrm{N}$ & $\%$ & $1.25 \%$ \\
\hline $\mathrm{Cl}$ & $\%$ & $0.29 \%$ \\
\hline $\mathrm{S}$ & $\%$ & $2.51 \%$ \\
\hline $\mathrm{Ash}$ & $\%$ & $9.70 \%$ \\
\hline $\mathrm{H} 2 \mathrm{O}$ & $\%$ & $11.12 \%$ \\
\hline Total & $\%$ & $100.00 \%$ \\
\hline & & \\
\hline $\mathrm{LHV}$ & $\mathrm{Btu} / \mathrm{lb}$ & 11,283 \\
\hline $\mathrm{HHV}$ & $\mathrm{Btu} / \mathrm{lb}$ & 11,631 \\
\hline
\end{tabular}


Figure 4.2.1 - Cycle Analysis of Case 1 (Air-Fired Reference Case)

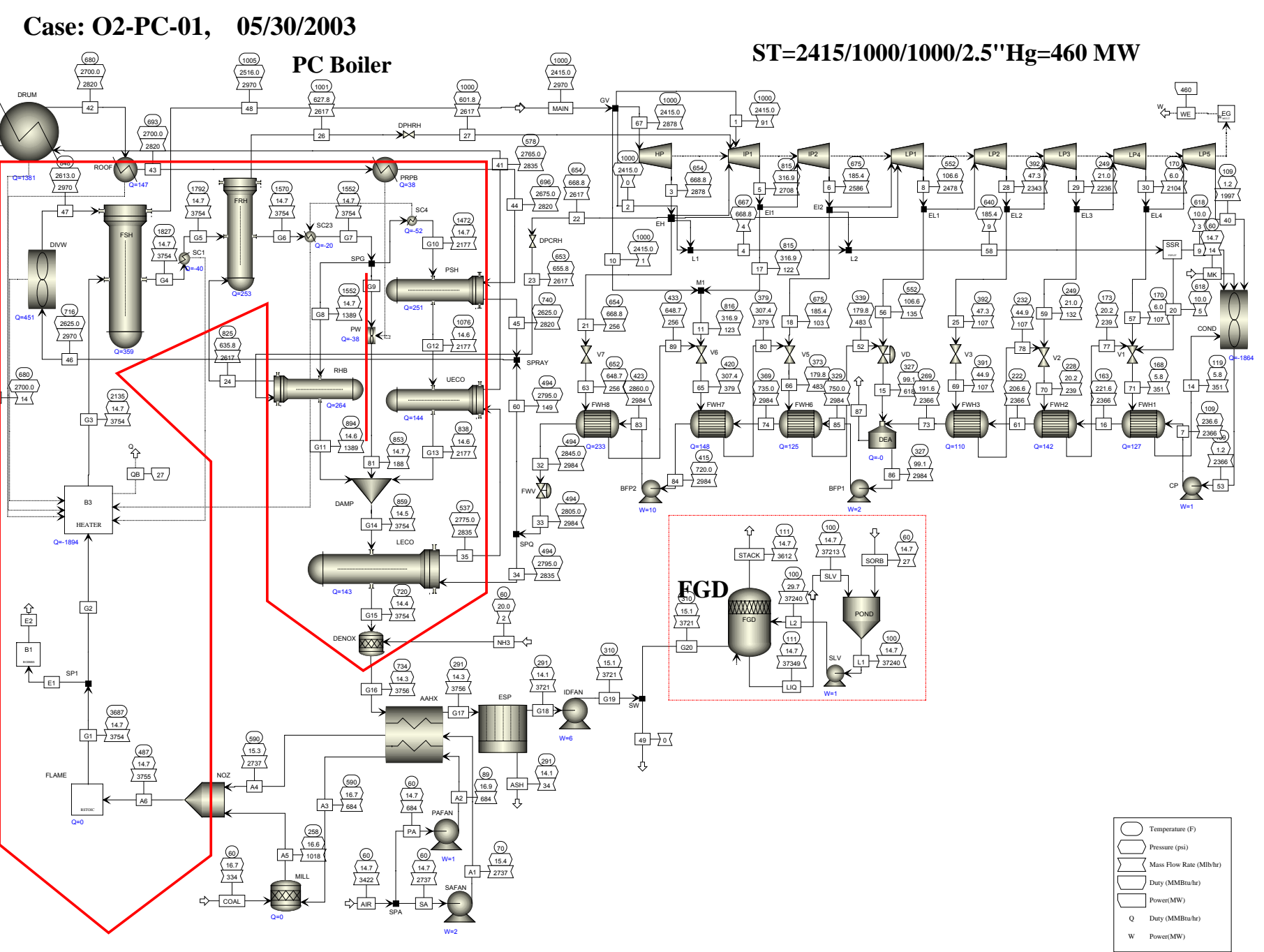


Table 4.2.2 - Case 1 (Air-Fired Reference) Boundary Conditions and Results

\begin{tabular}{|c|c|c|c|c|c|c|c|}
\hline \multicolumn{8}{|c|}{ SETUPS \& RESULTS } \\
\hline amb & & dP-air & "H2O & ST & & result & \\
\hline elevation, ft & 0 & $\mathrm{AAHX}$ & 4.0 & main P, psia & 2415 & net power, MWe & 418 \\
\hline amb T, F & 60 & duct & 6.0 & main $\mathrm{T}, \mathrm{F}$ & 1000 & net eff, \% & 36.68 \\
\hline amb $P$, psia & 14.7 & nozzle & 10.0 & RH P, psia & 602 & gross @ST, MW & 460 \\
\hline \multirow[t]{2}{*}{$\mathrm{RH}, \%$} & 60 & sum & 20.0 & $\mathrm{RH} \mathrm{T}, \mathrm{F}$ & 1000 & aux power, MW & 42.1 \\
\hline & & & & FWHs & 7 & as $\%$ & 9.2 \\
\hline air & $\% \mathrm{v}$ & dp-gas & "H2O & end wet, \% & 9.9 & & \\
\hline $\mathrm{O} 2$ & 20.74 & FSH & 0.5 & end $\mathrm{P}, \mathrm{Hg}$ & 2.5 & $\mathrm{HHV}$ in, mmbtu & 3890 \\
\hline $\mathrm{N} 2$ & 77.3 & $\mathrm{FRH}$ & 0.5 & & & $\mathrm{Q}$ to ST, mmbtu & 3431 \\
\hline $\mathrm{Ar}$ & 0.93 & $\mathrm{RH}$ & 1.0 & FWH & $\mathrm{F}$ & $\mathrm{Q}$, cond, mmbtu & 1864 \\
\hline $\mathrm{CO} 2$ & 0.03 & $\mathrm{PSH}$ & 0.7 & TD & 5 & boiler eff, \% & 88.2 \\
\hline $\mathrm{H} 2 \mathrm{O}$ & 1.01 & UECO & 0.3 & DC & 10 & ST cycle eff, \% & 45.78 \\
\hline \multirow[t]{2}{*}{ sum } & 100.0 & ECO & 2.0 & FW T & 494 & Generator eff, \% & 98.3 \\
\hline & & $\mathrm{AAHX}$ & 1.6 & & & & \\
\hline coal & \%w & Damper & 4.3 & DeSuperheat & & air, klb & 3422 \\
\hline $\mathrm{C}$ & 63.75 & $\mathrm{BHG}$ & 5.5 & $\mathrm{SH}, \%$ & 5 & coal, klb & 334 \\
\hline $\mathrm{H}$ & 4.5 & FGD & 12.0 & water T, F & 494 & sorb, klb & 26 \\
\hline $\mathrm{O}$ & 6.88 & sum & 28.4 & & & flue gas, klb & 3721 \\
\hline $\mathrm{N}$ & 1.25 & & & Boiler & & $\mathrm{O} 2, \%$ & 3.0 \\
\hline$S$ & 2.51 & dP & "H2O & UBC, $\%$ & 1.0 & $\mathrm{H} 2 \mathrm{O}, \%$ & 8.5 \\
\hline A & 9.99 & PAFan & 60 & margin, \% & 0.5 & $\mathrm{CO}, \mathrm{ppmv}$ & 71 \\
\hline $\mathrm{M}$ & 11.12 & IDFan & 28 & radiation, \% & 0.22 & NOx, ppmv & 733 \\
\hline $\mathrm{V}$ & 34.99 & SAFan & 20 & Exa, \% & 18 & SOx, ppmv & 2082 \\
\hline$F$ & 44.19 & & & flame T, F & 3839 & after FGD & 42 \\
\hline \multirow[t]{2}{*}{ sum } & 100.0 & eff & $\%$ & stack T, F & 292 & Ash, klb & 34 \\
\hline & & FDFan & 75 & blowdown, \% & 0.5 & C, $\%$ & 6.0 \\
\hline fuel HHV & btu/lb & IDFan & 70 & miller exit T, $\mathrm{F}$ & 258 & & \\
\hline given & 11666 & CWPump & 80 & & & main st flow, klb & 2970 \\
\hline \multirow[t]{2}{*}{ aspen } & 11631 & BFPump & 80 & FGD \& SCR & & RH st flow, klb & 2878 \\
\hline & & Motor/mechanic & 95 & L/G & 10 & end st flow, klb & 1997 \\
\hline sorb & $\% w$ & & & $\mathrm{Ca} / \mathrm{S}$ & 1.05 & & \\
\hline \multirow[t]{2}{*}{$\mathrm{CaCO} 3$} & 100 & air & $\%$ & Excess air, \% & 85 & DeSOx, \% & 98 \\
\hline & & PA & 20 & NH3/NOx & 1.0 & DeNOx, \% & 90 \\
\hline
\end{tabular}


Table 4.2.3 - Auxiliary Power Requirements for Case 1

\begin{tabular}{|l|r|}
\hline Aux power & MWe \\
\hline condensed water pump & 0.6 \\
\hline LP feed water pump & 2.5 \\
\hline HP feed water pump & 9.8 \\
\hline circulating water pump & 3.9 \\
\hline FGD pump & 0.7 \\
\hline PA Fan & 1.5 \\
\hline SA Fan & 2.0 \\
\hline ID Fan & 5.6 \\
\hline FGD Fan & 4.1 \\
\hline cooling tower Fan & 2.1 \\
\hline coal handling & 2.1 \\
\hline sorb handling & 0.8 \\
\hline ash handling + ESP & 1.8 \\
\hline others (=1\%) & 4.6 \\
\hline total & 42.1 \\
\hline
\end{tabular}


Figure 4.2.2 - Air Separation Unit

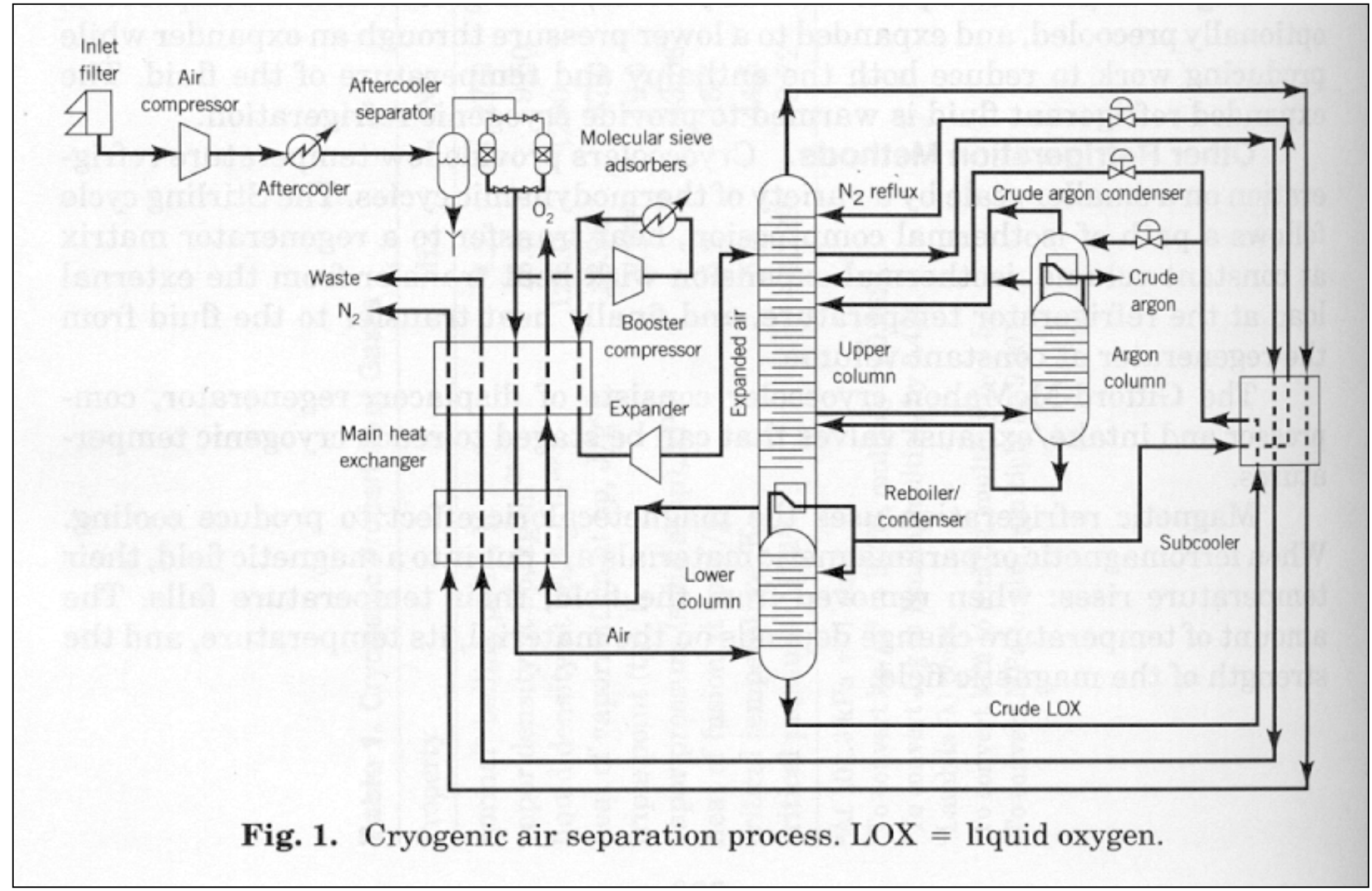


Figure 4.2.3 - ASPEN ASU Model

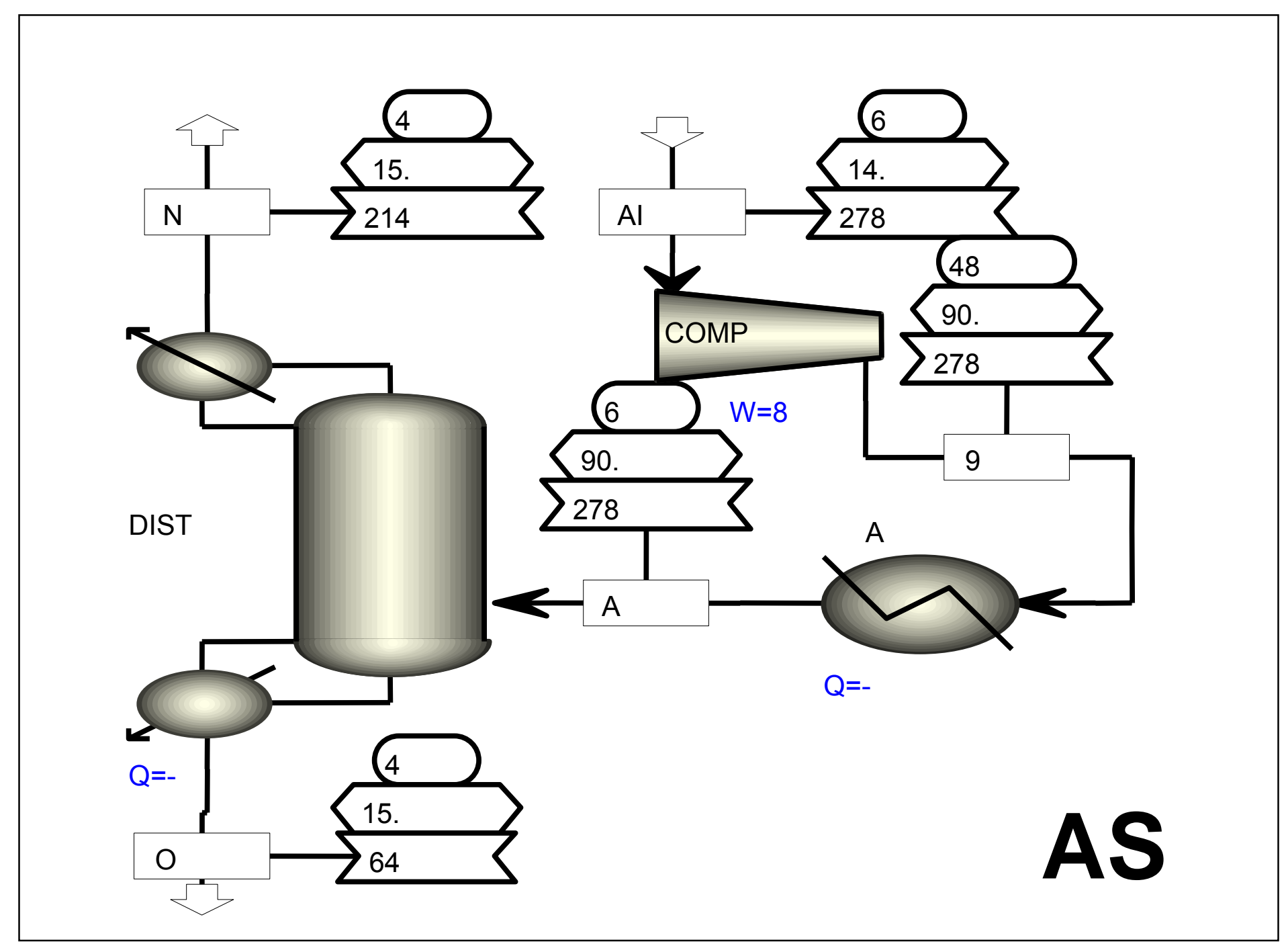


Figure 4.2.4 - Case 2 Cycle Diagram

\section{Case: Q2-PC-02, 06/05/2003}

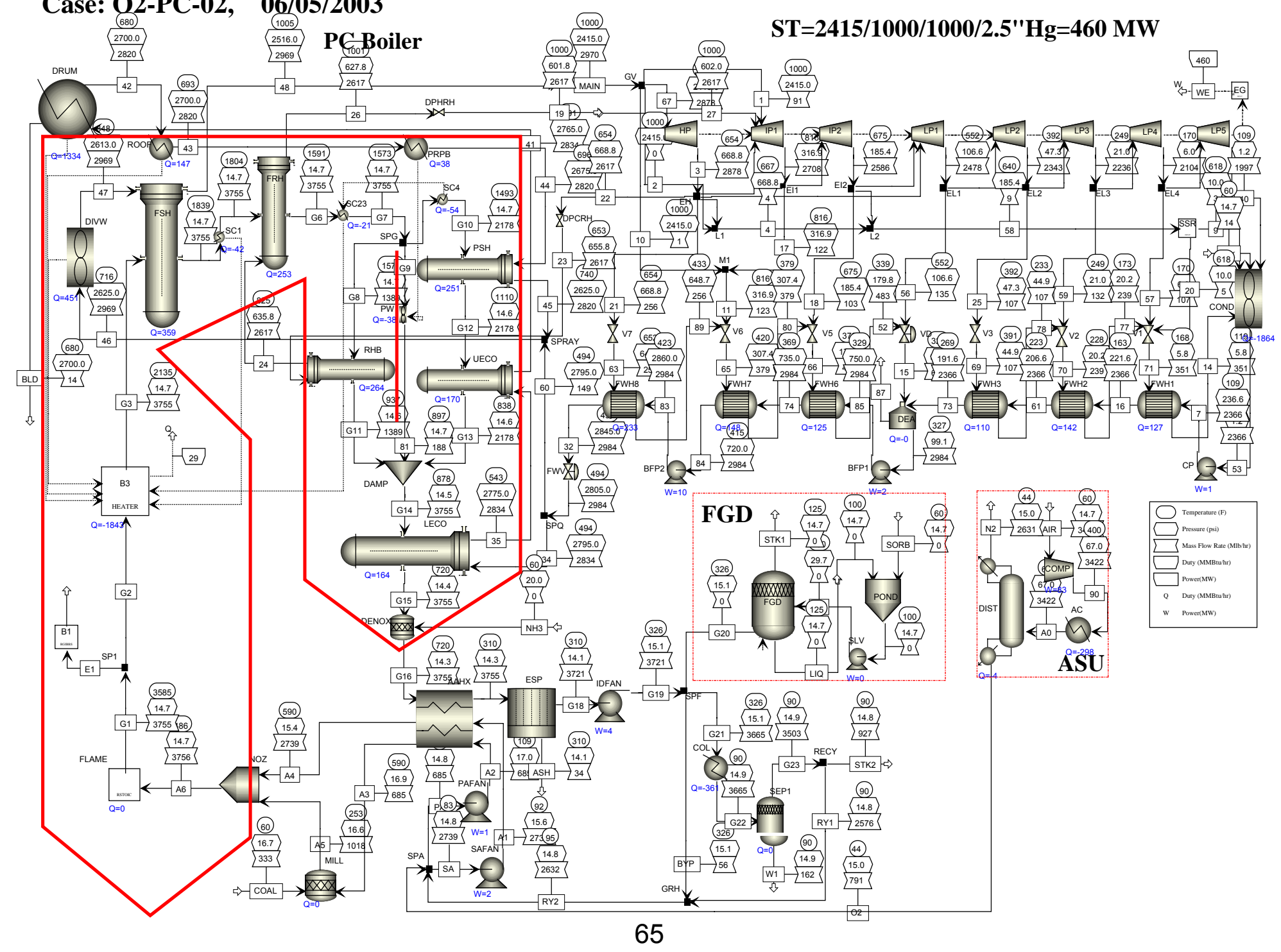


Figure 4.2.5 - Case 3 Cycle Diagram

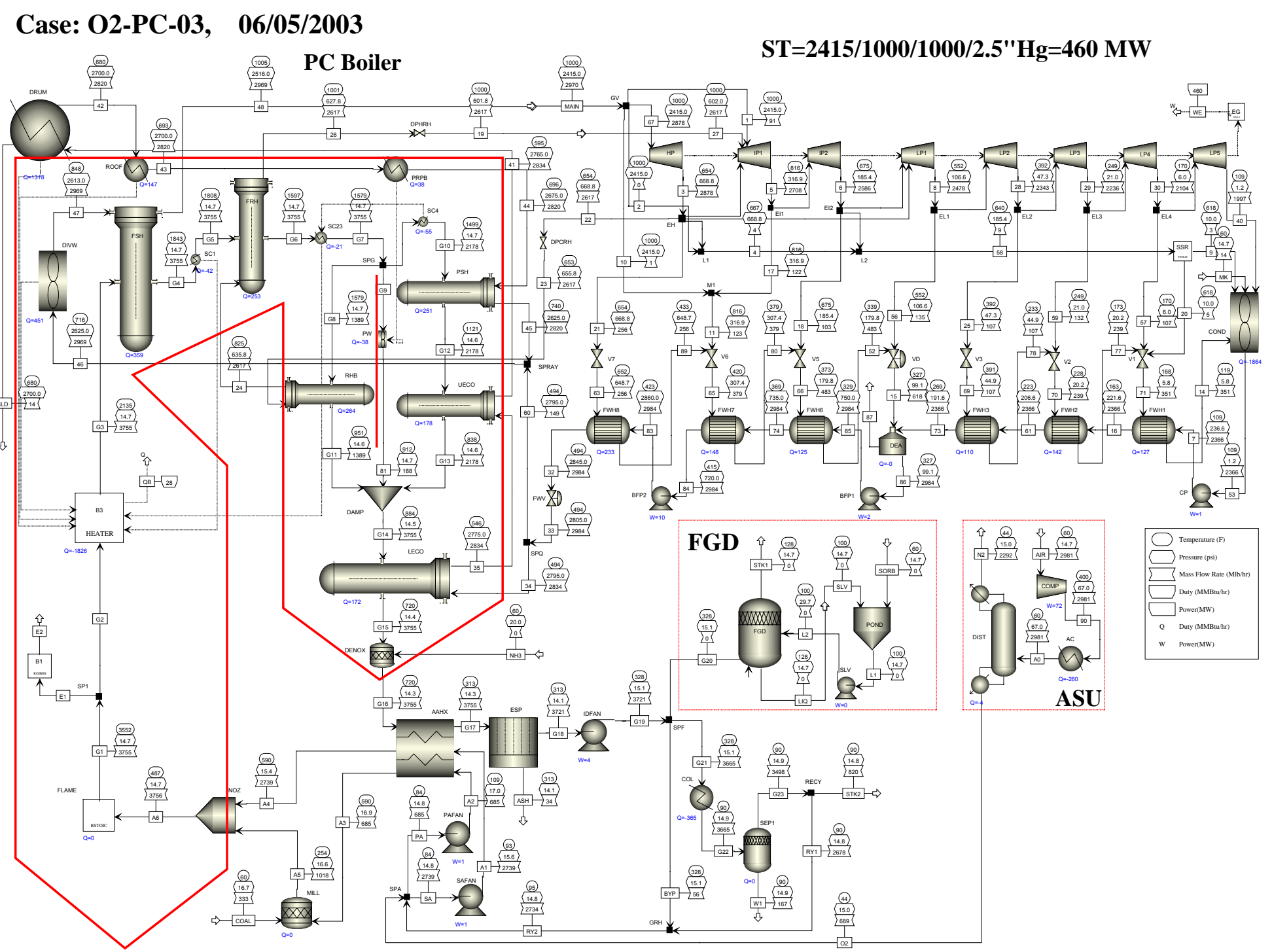


Figure 4.2.6 - Case 4 Cycle Diagram

Case: O2-PC-04, 06/05/2003

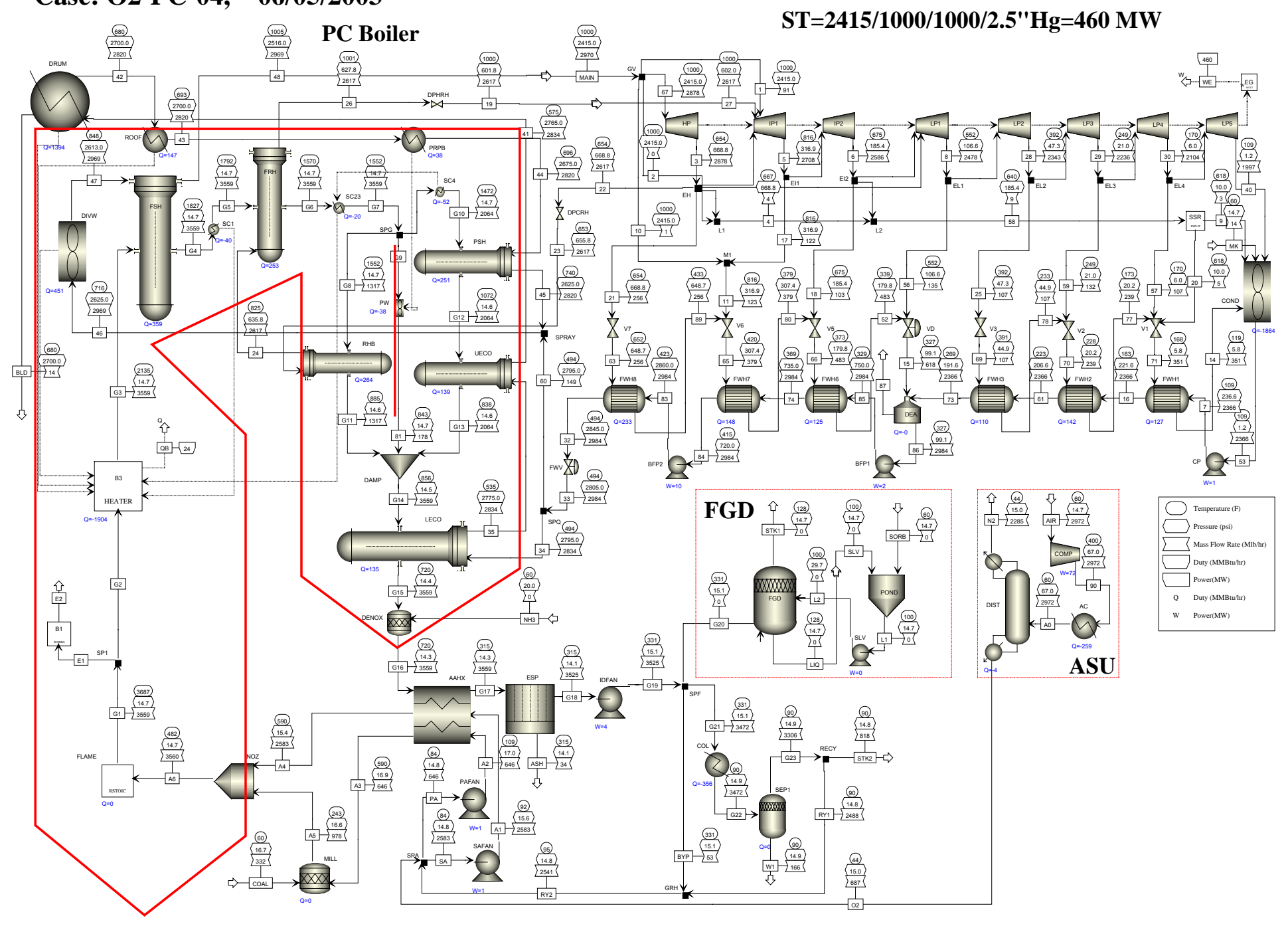




\section{Figure 4.2.7 - Case 5 Cycle Diagram}

Case: O2-PC-05， 06/05/2003

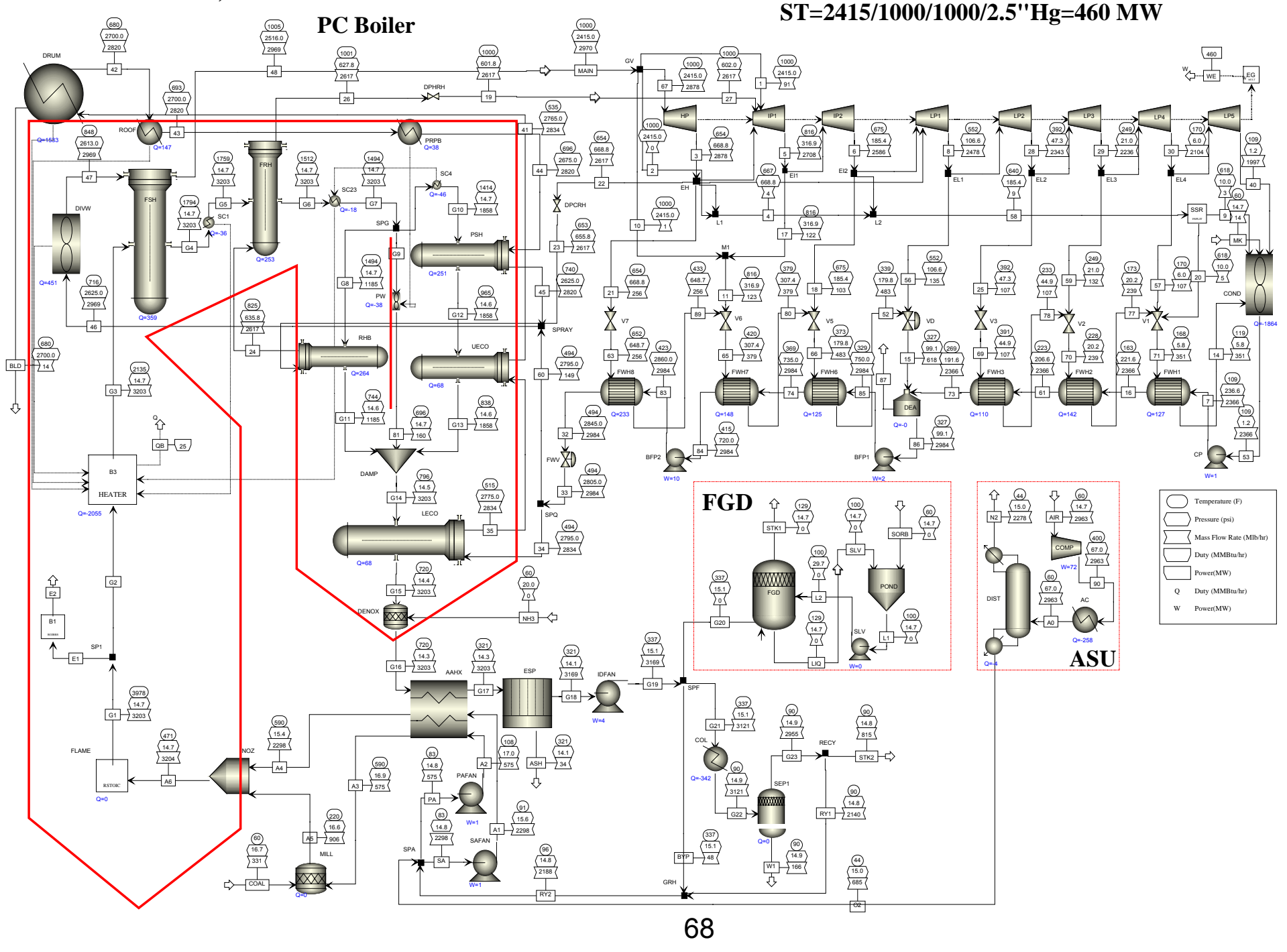


Figure 4.2.8 - Case 6 Cycle Diagram

Case: O2-PC-06, 06/05/2003

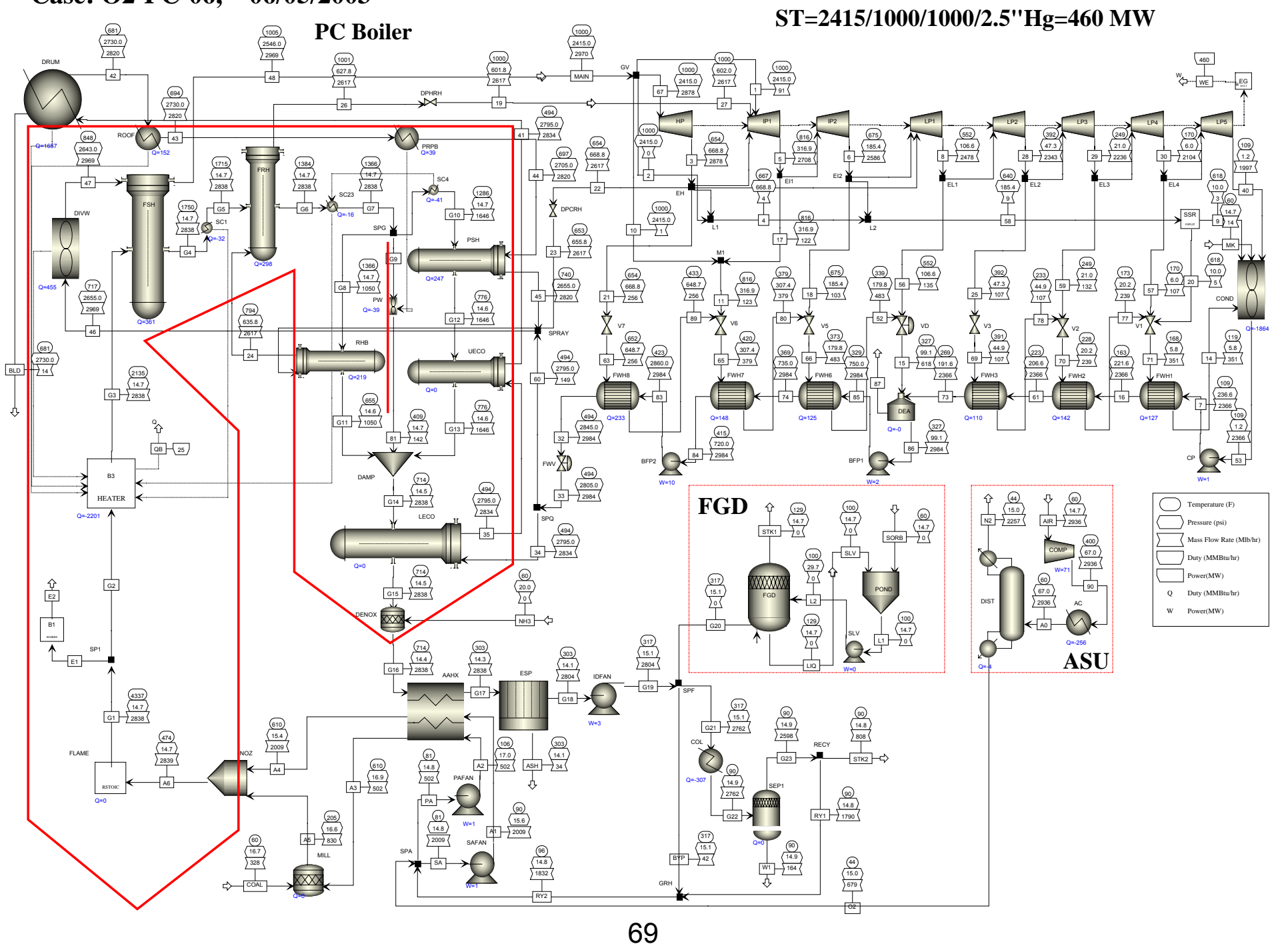


Figure 4.2.9 - Case 7 Cycle Diagram

Case: O2-PC-07， 06/05/2003

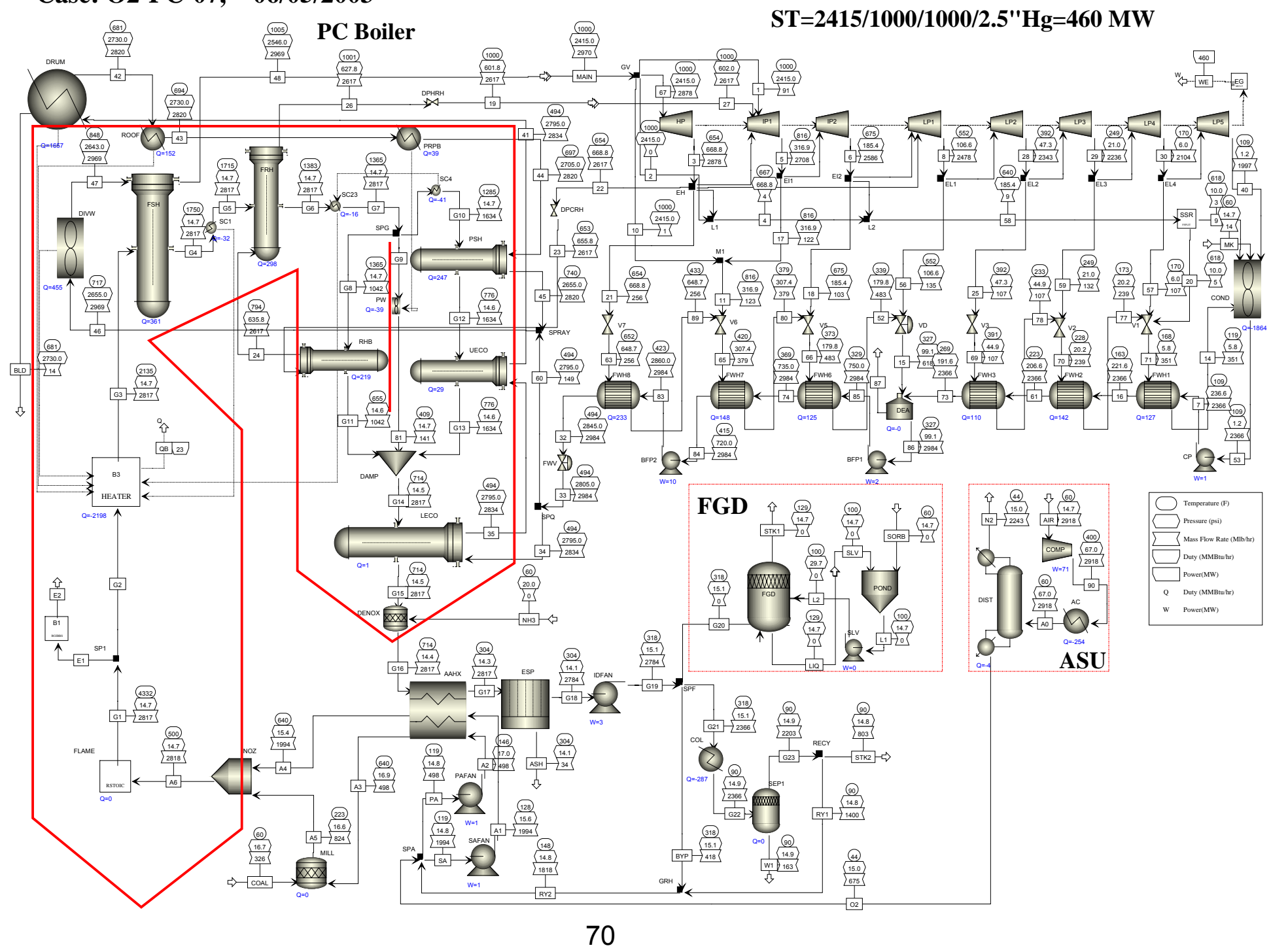


Table 4.2.4 - Parametric Cases Summary (Without $\mathrm{CO}_{2}$ Compression)

\begin{tabular}{|l|c|c|c|c|c|c|c|}
\hline \multicolumn{1}{r|}{ case } & $\mathbf{1}$ & $\mathbf{2}$ & $\mathbf{3}$ & $\mathbf{4}$ & $\mathbf{5}$ & $\mathbf{6}$ & $\mathbf{7}$ \\
\hline ASU & no & yes & yes & yes & yes & yes & yes \\
\hline coal to boiler, klb/h & 334 & 333 & 333 & 332 & 331 & 328 & 326 \\
\hline air to plant, klb/h & 3422 & 3422 & 2981 & 2972 & 2963 & 2936 & 2918 \\
\hline O2 purity, \% & 20.7 & 99.6 & 99.6 & 99.6 & 99.6 & 99.6 & 99.6 \\
\hline O2 level to boiler, \% & 20.4 & 39.7 & 26.9 & 28.1 & 30.9 & 34.1 & 33.7 \\
\hline O2 level exit boiler, \% & 3.0 & 15.3 & 3.0 & 3.0 & 3.0 & 3.0 & 3.0 \\
\hline Net EXA, \% & 18.0 & 18.0 & 3.1 & 3.1 & 3.0 & 3.2 & 3.2 \\
\hline Boiler EXA, \% & 18.0 & 69.1 & 13.6 & 12.5 & 11.2 & 10.4 & 10.4 \\
\hline adiabatic temperature, F & 3687 & 3608 & 3574 & 3687 & 3978 & 4337 & 4332 \\
\hline gas to boiler exit, klb/h & 3721 & 3721 & 3721 & 3525 & 3169 & 2804 & 2784 \\
\hline gas to boiler exit, mmcft/h & 237 & 181 & 175 & 167 & 151 & 134 & 135 \\
\hline gas recycle to boiler, klb/h & 0 & 2632 & 2734 & 2541 & 2188 & 1832 & 1818 \\
\hline gas T before IDFan, F & 291 & 307 & 309 & 315 & 321 & 303 & 304 \\
\hline Recycled gas T, F & - & 95 & 95 & 95 & 95 & 96 & 148 \\
\hline gas exit system, klb/h & 3721 & 927 & 820 & 818 & 815 & 808 & 803 \\
\hline CO2, \%v & 14.0 & 76.4 & 89.6 & 89.6 & 89.6 & 89.6 & 89.6 \\
\hline ASU plant power, MW & 0 & 83.0 & 72.3 & 72.1 & 71.8 & 71.2 & 70.7 \\
\hline Aux power, MW & 42.1 & 116.7 & 105.8 & 105.3 & 104.4 & 102.7 & 102.5 \\
\hline Boiler eff, \% & 88.2 & 88.3 & 88.3 & 88.6 & 88.9 & 89.60 & 90.94 \\
\hline Net eff (w/o CO2), \% & 36.68 & 30.19 & 31.15 & 31.29 & 31.46 & 31.90 & 32.12 \\
\hline
\end{tabular}


Figure 4.2.10 - Net Efficiency (without $\mathrm{CO}_{2}$ compression) Versus Adiabatic Temperature

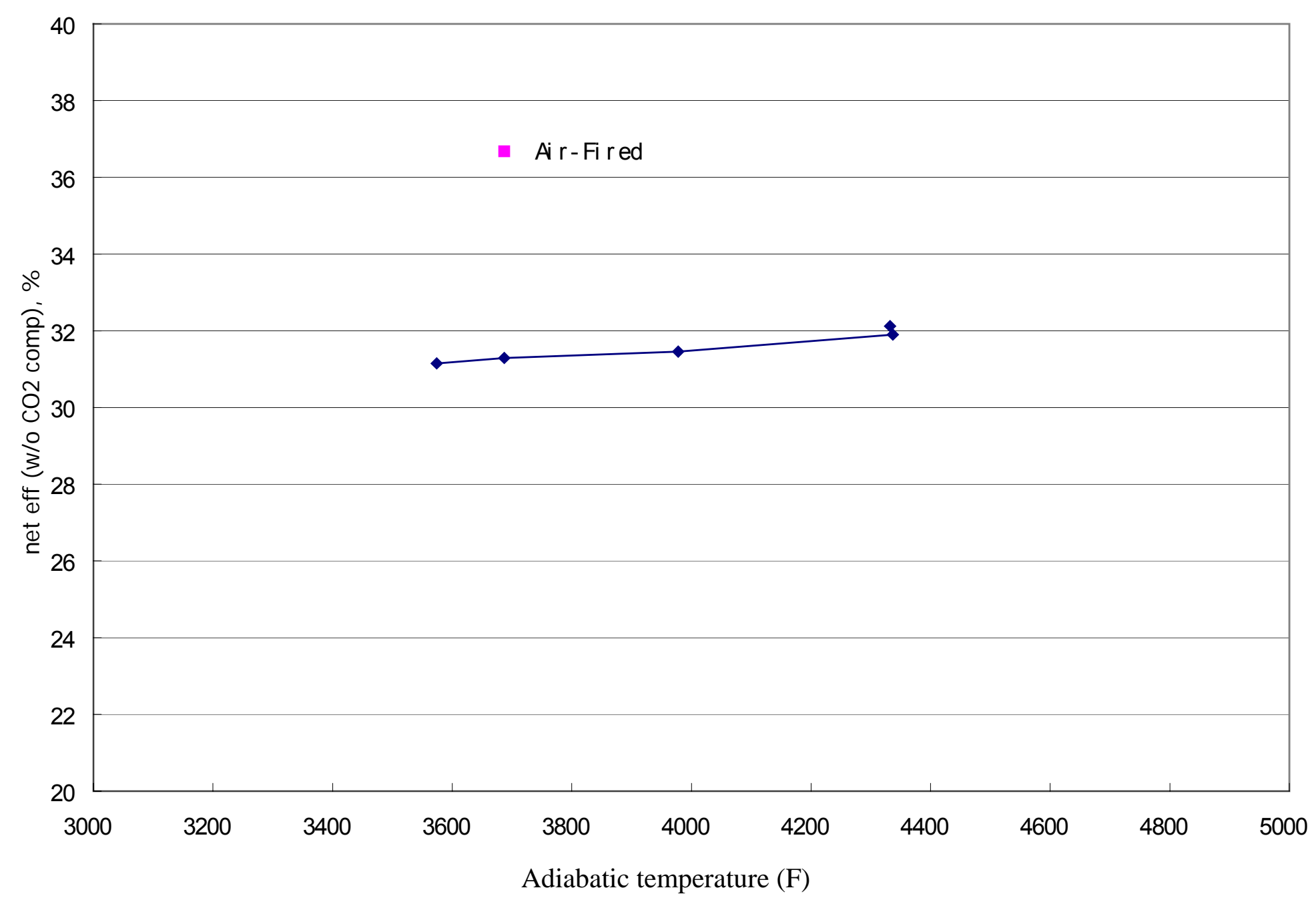


Figure 4.2.11 - ASU and Auxiliary Power Requirements Versus Adiabatic Temperature

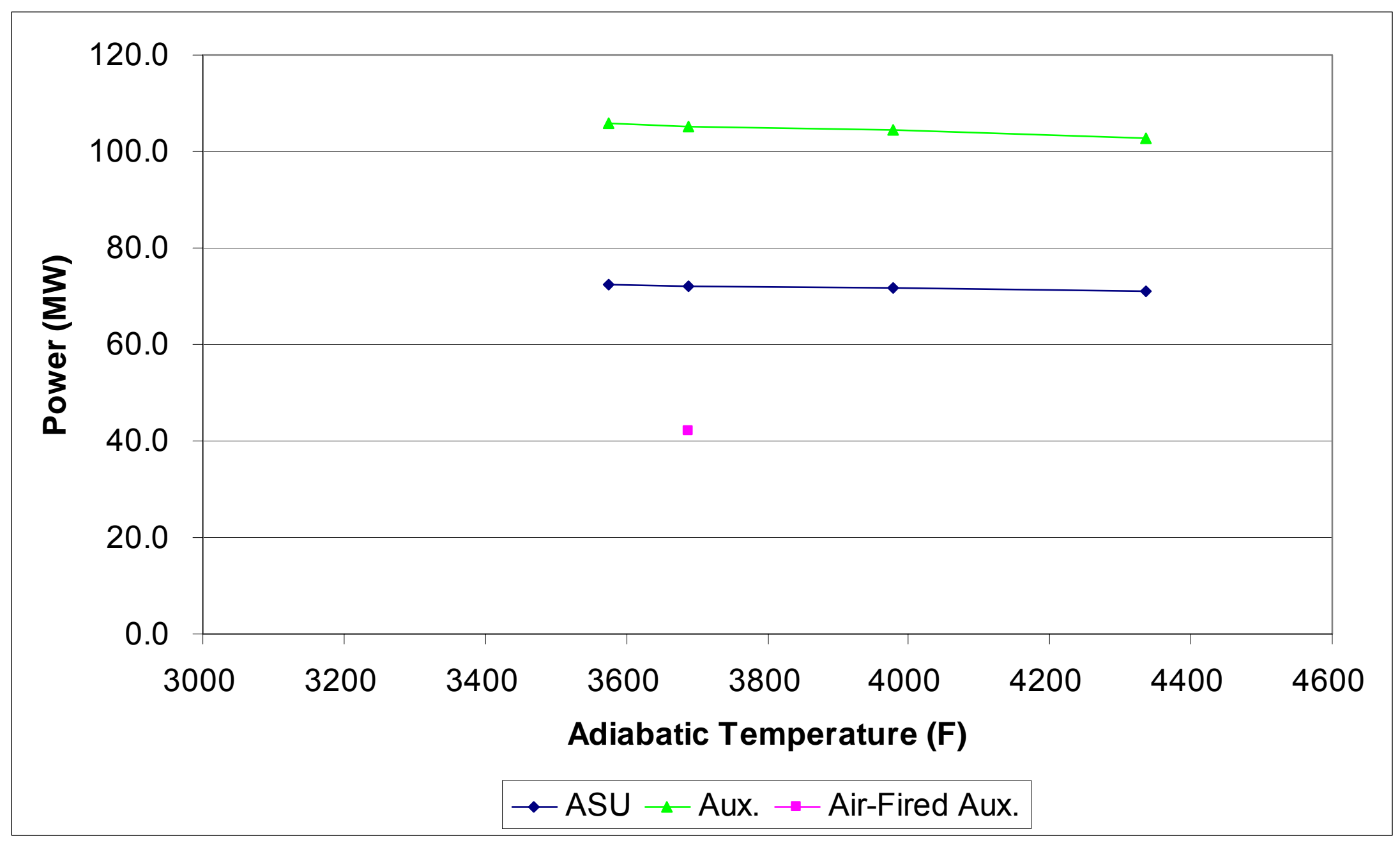


Figure 4.2.12 - Recycled Gas Mass Flow Rate Versus Adiabatic Temperature

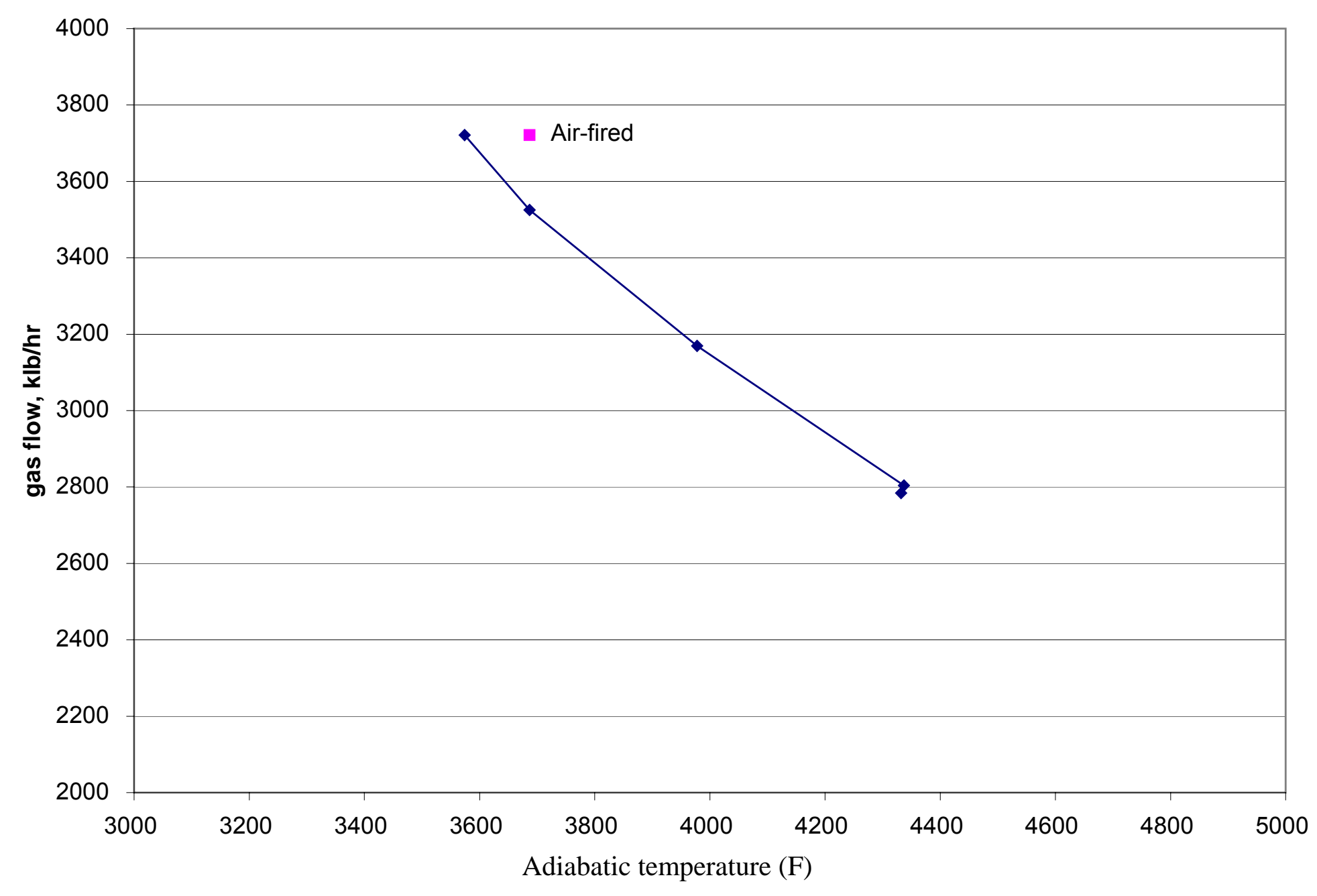

74 
Figure 4.2.13 - Recycled Gas Volumetric Flow Rate Versus Adiabatic Temperature

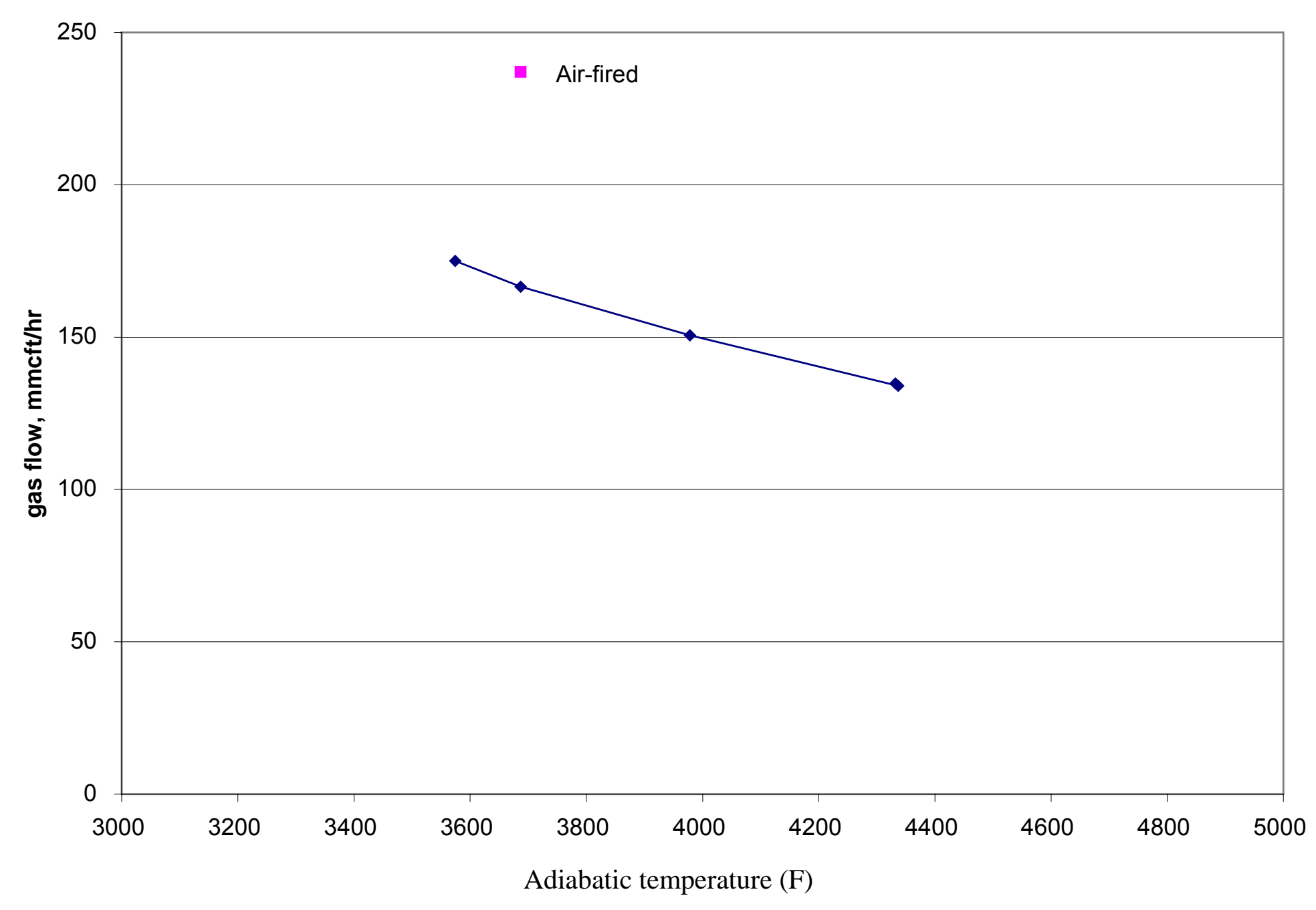


Figure 4.2.14 - Flue Gas Cooling Curve

\section{Cooling Curve}

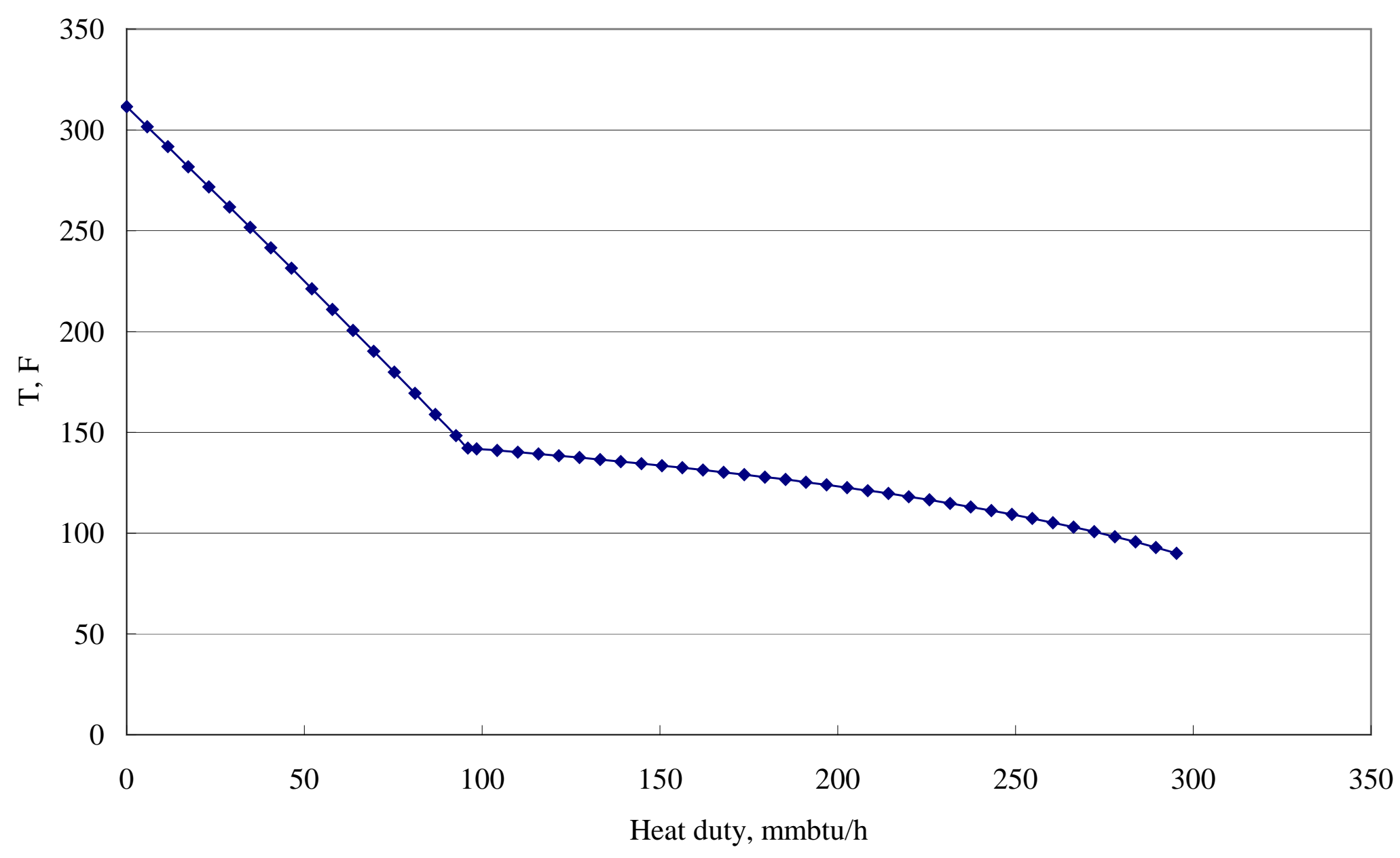


Figure 4.2.15 - Case 8 Cycle Diagram

Case: 02-PC-11, 08/04/2003

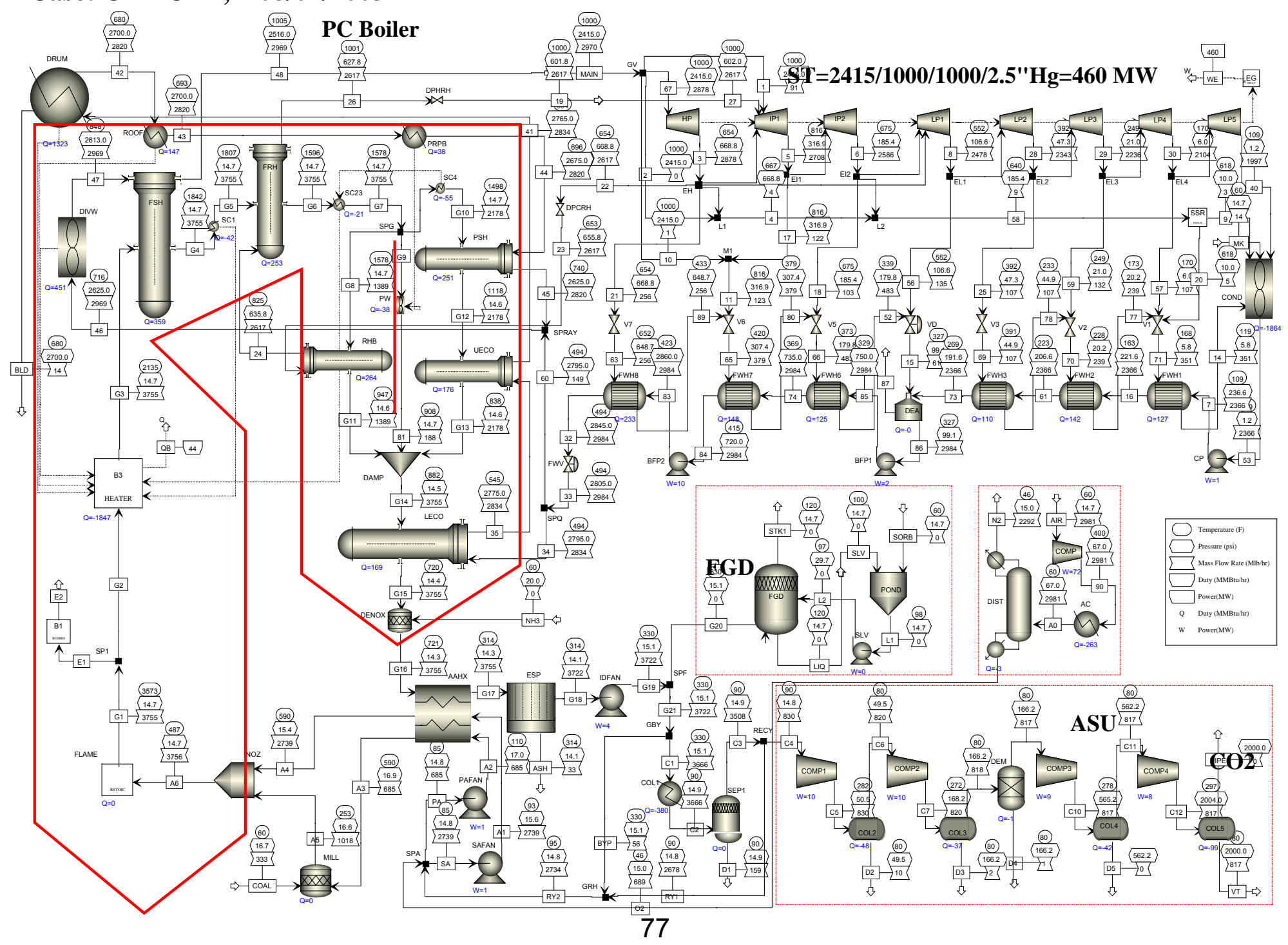


Figure 4.2.16 - Case 9 Cycle Diagram

Case: O2-PC-12, 08/07/2003

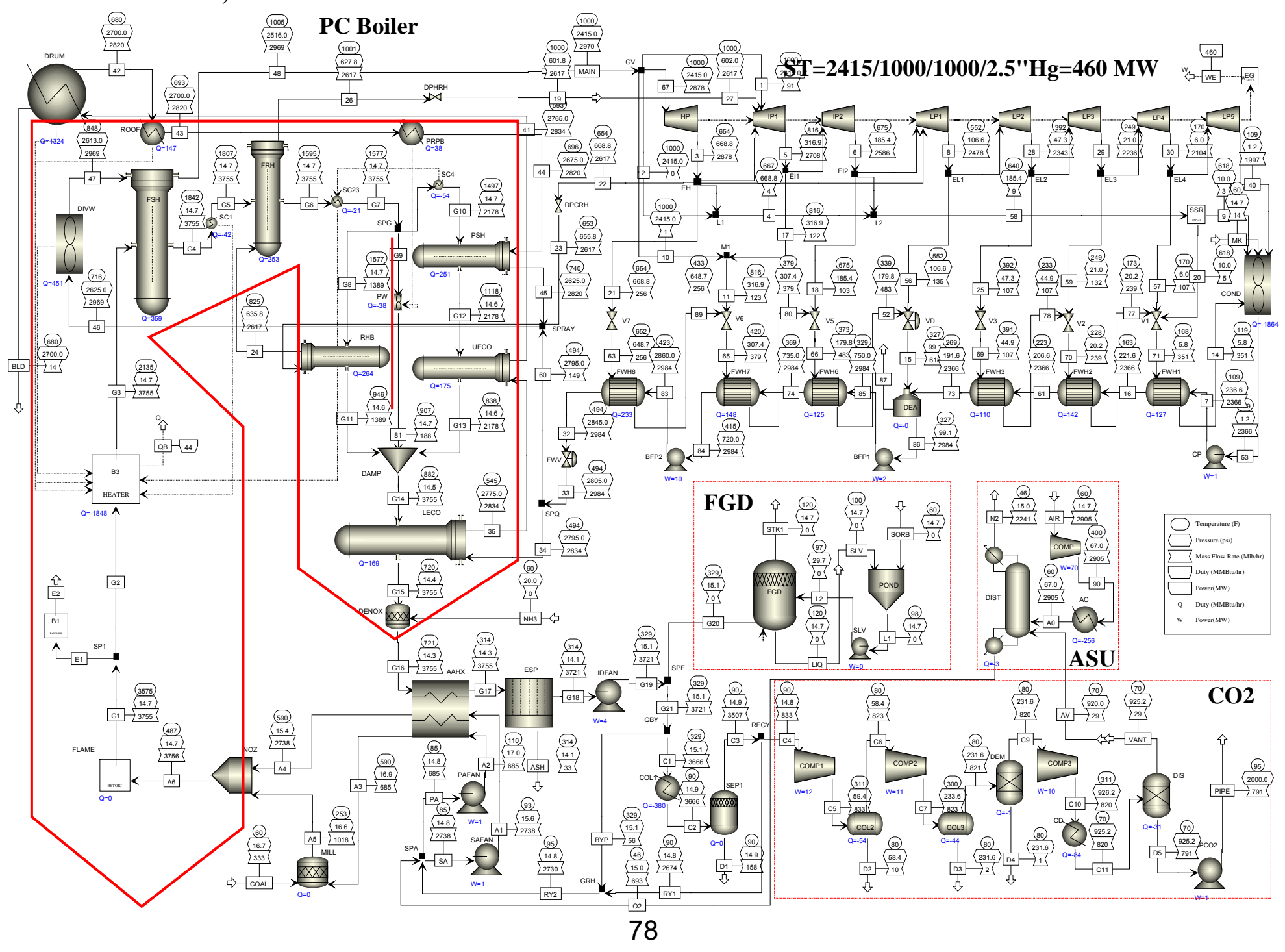


Figure 4.2.17 - Net Cycle Efficiency Vs. Flue Gas Recycle Flow

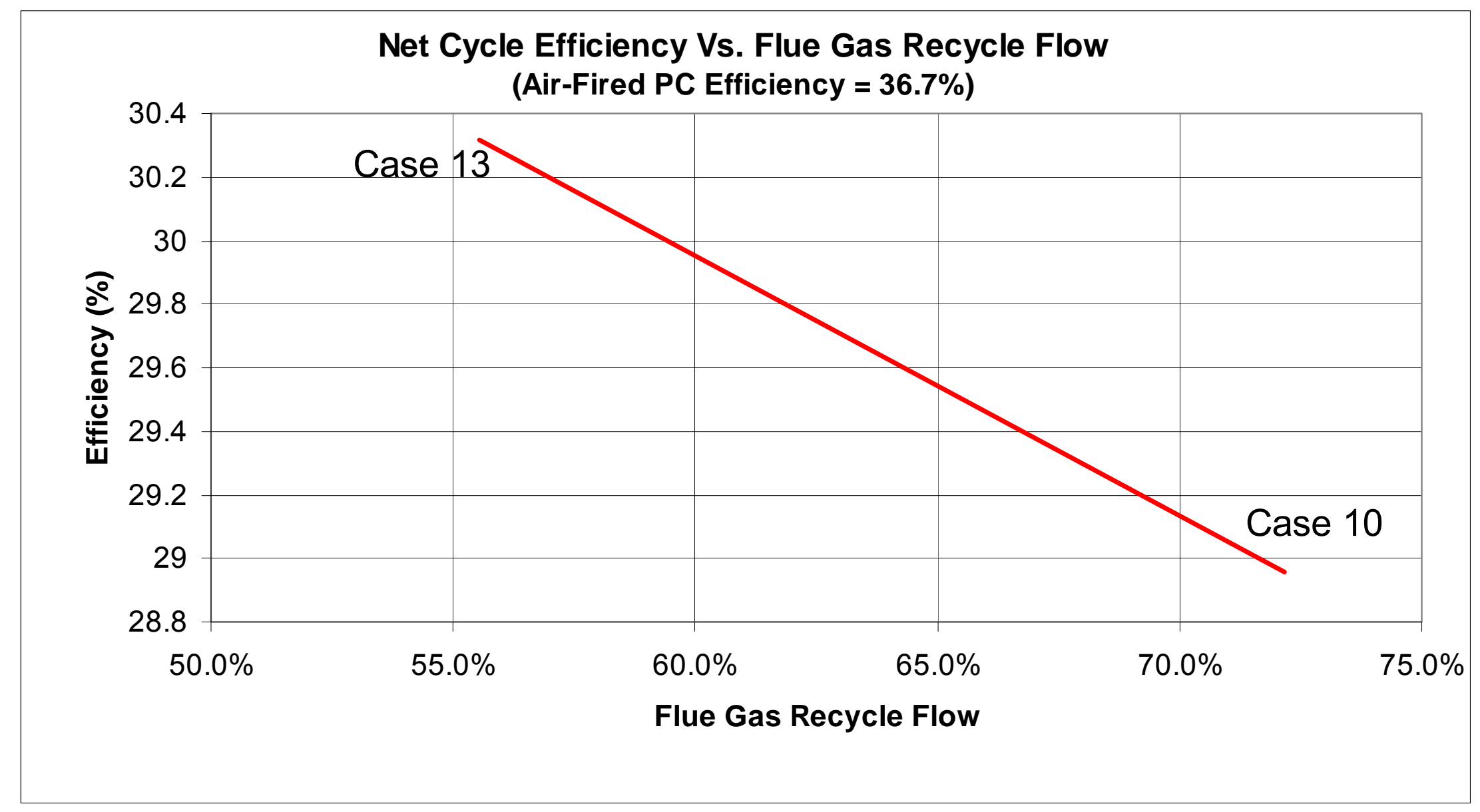


Figure 4.2.18 - Case 10 Cycle Diagram

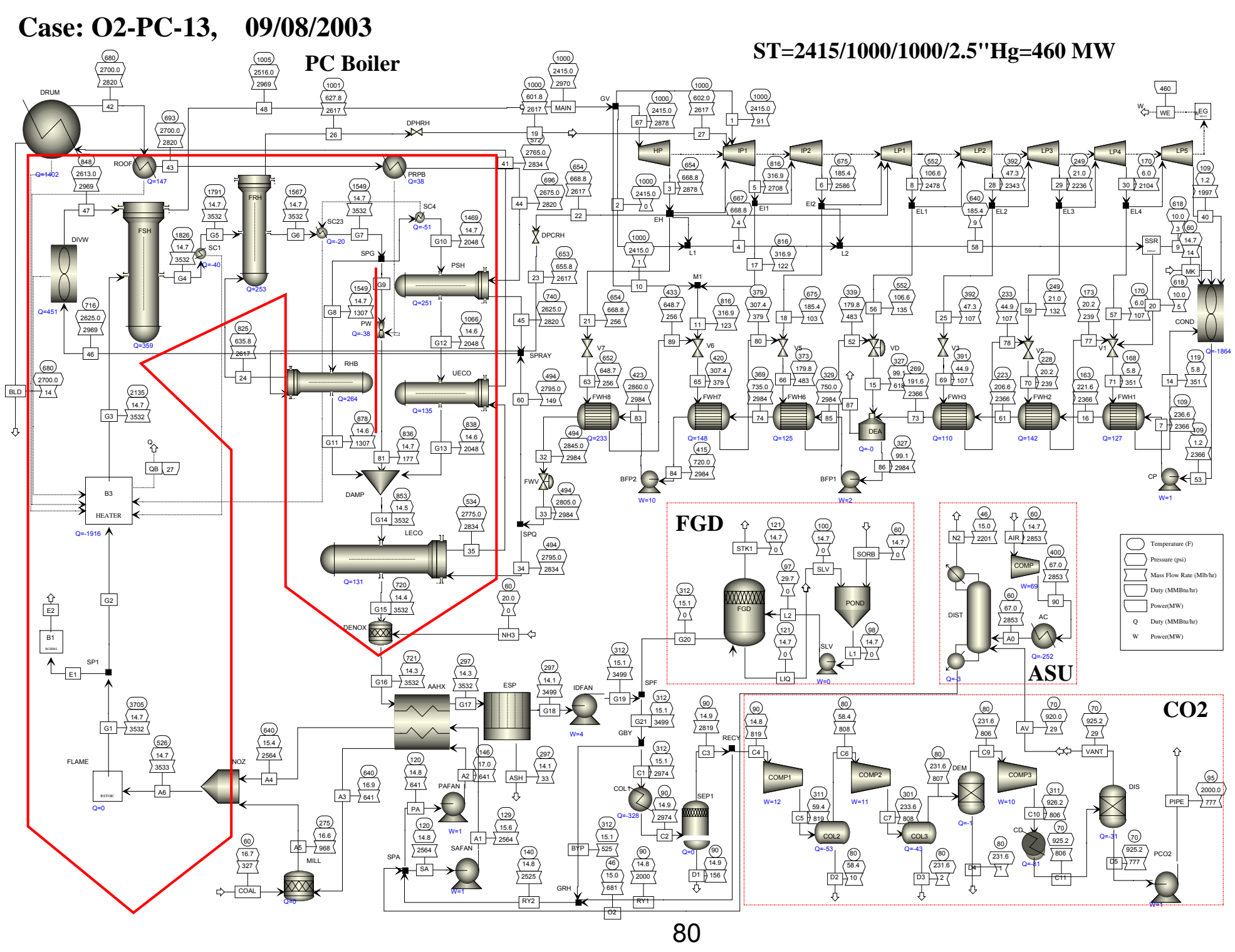




\section{Figure 4.2.19 - Case 11 Cycle Diagram}

Case: O2-PC-14, 10/22/2003

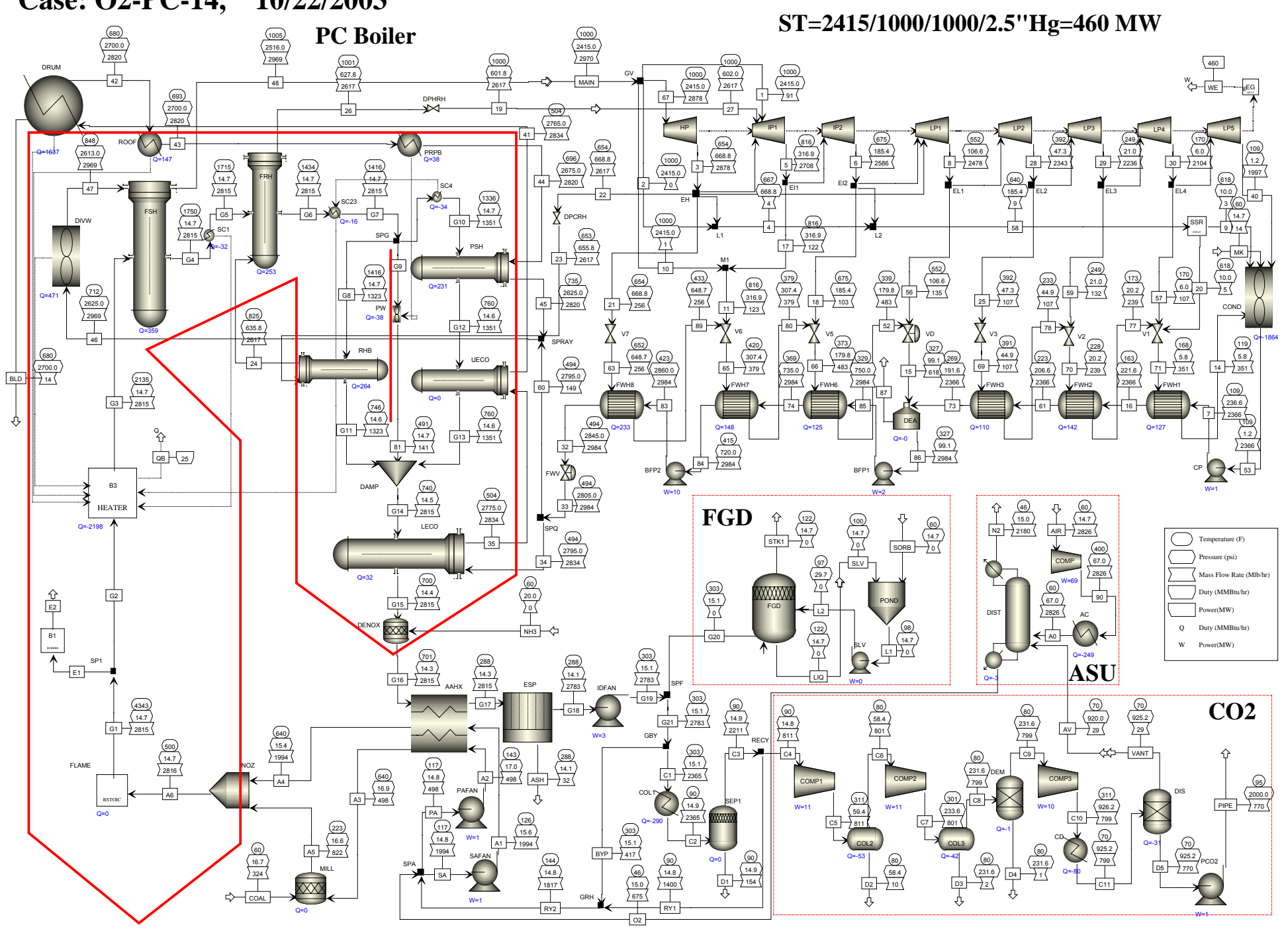


Table 4.2.5 - Parametric Cases Summary (With $\mathrm{CO}_{2}$ Compression)

\begin{tabular}{|c|c|c|c|c|c|c|c|c|}
\hline case & 1 & 3 & 8 & 9 & 10 & 11 & 12 & 13 \\
\hline ASU & no & yes & yes & yes & yes & yes & yes & yes \\
\hline CO2 Sequestration & no & no & yes & yes & yes & yes & yes & yes \\
\hline Vent gas recover & no & no & no & yes & yes & yes & yes & yes \\
\hline Wet-end economizer & no & no & no & no & no & no & yes & yes \\
\hline coal to boiler, klb/h & 334 & 333 & 333 & 333 & 327 & 324 & 324 & 324 \\
\hline air to plant, klb/h & 3422 & 2981 & 2981 & 2905 & 2853 & 2826 & 2826 & 2817 \\
\hline O2 purity, \% & 20.7 & 99.6 & 99.6 & 99.5 & 99.5 & 99.5 & 99.5 & 99.5 \\
\hline O2 level to boiler, \% & 20.4 & 26.9 & 26.7 & 27.1 & 28.0 & 33.9 & 33.9 & 42.4 \\
\hline O2 level exit boiler, \% & 3.0 & 3.0 & 3.0 & 3.0 & 3.0 & 3.0 & 3.0 & 3.0 \\
\hline Excess Air, \% & 18.0 & 3.1 & 3.1 & 0.3 & 0.3 & 0.3 & 0.3 & 0.3 \\
\hline adiabatic temperature, $\mathrm{F}$ & 3687 & 3574 & 3573 & 3575 & 3705 & 4343 & 4343 & 5164 \\
\hline gas to boiler exit, klb/h & 3721 & 3721 & 3722 & 3721 & 3499 & 2783 & 2783 & 2169 \\
\hline gas to boiler exit, mmcft/h & 237 & 175 & 175 & 174 & 166 & 134 & 134 & 104 \\
\hline gas recycle to boiler, $\mathrm{klb} / \mathrm{h}$ & 0 & 2734 & 2734 & 2730 & 2525 & 1817 & 1817 & 1205 \\
\hline gas exit system, klb/h & 3721 & 820 & 820 & 833 & 819 & 811 & 811 & 810 \\
\hline ASU plant power, MW & 0 & 72.3 & 72.3 & 70.5 & 69.2 & 68.6 & 68.6 & 68.6 \\
\hline CO2 compression power, MW & 0 & 0 & 37.2 & 34.6 & 34.0 & 33.7 & 33.7 & 32.0 \\
\hline Gross power, MW & 460 & 460 & 460.0 & 460.0 & 460.0 & 460.0 & 464 & 468 \\
\hline Aux power, MW & 42.1 & 105.8 & 143.1 & 138.6 & 136.4 & 133.9 & 134.6 & 132 \\
\hline Net Power, MW & 417.9 & 354.2 & 317.3 & 321.8 & 324.0 & 326.5 & 329.6 & 336.0 \\
\hline Boiler efficiency, \% & 88.2 & 88.3 & 88.3 & 88.3 & 89.9 & 90.8 & 93.2 & 93.4 \\
\hline Net efficiency, \% & 36.68 & 31.15 & 27.87 & 28.27 & 28.98 & 29.48 & 29.75 & 30.33 \\
\hline
\end{tabular}


Figure 4.2.20 - Vapor Pressure of $\mathrm{CO}_{2}$

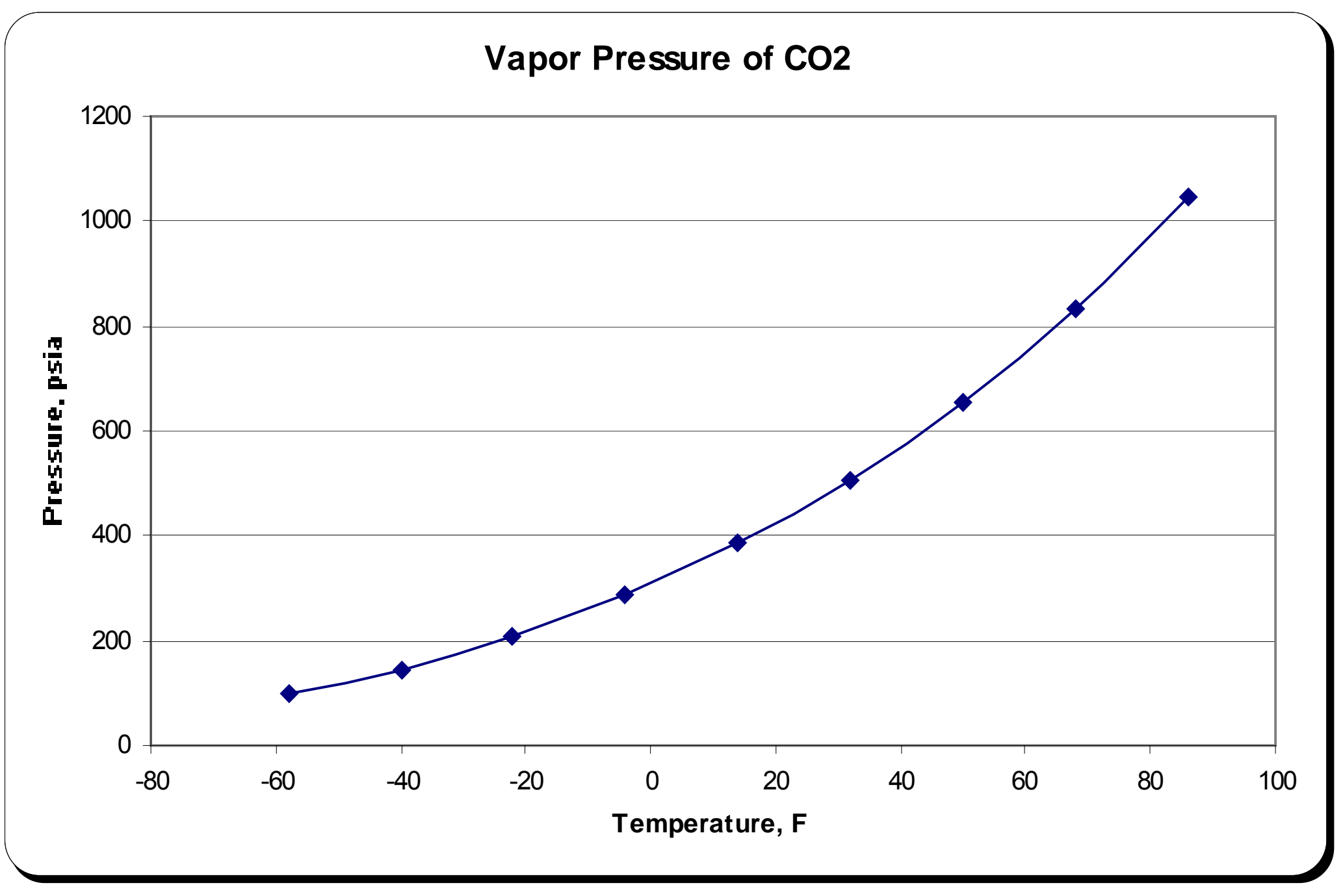


Figure 4.2.21 - Equilibrium $\mathrm{CO}$ and $\mathrm{CO} 2$ Versus Flue Gas Recycle Flow

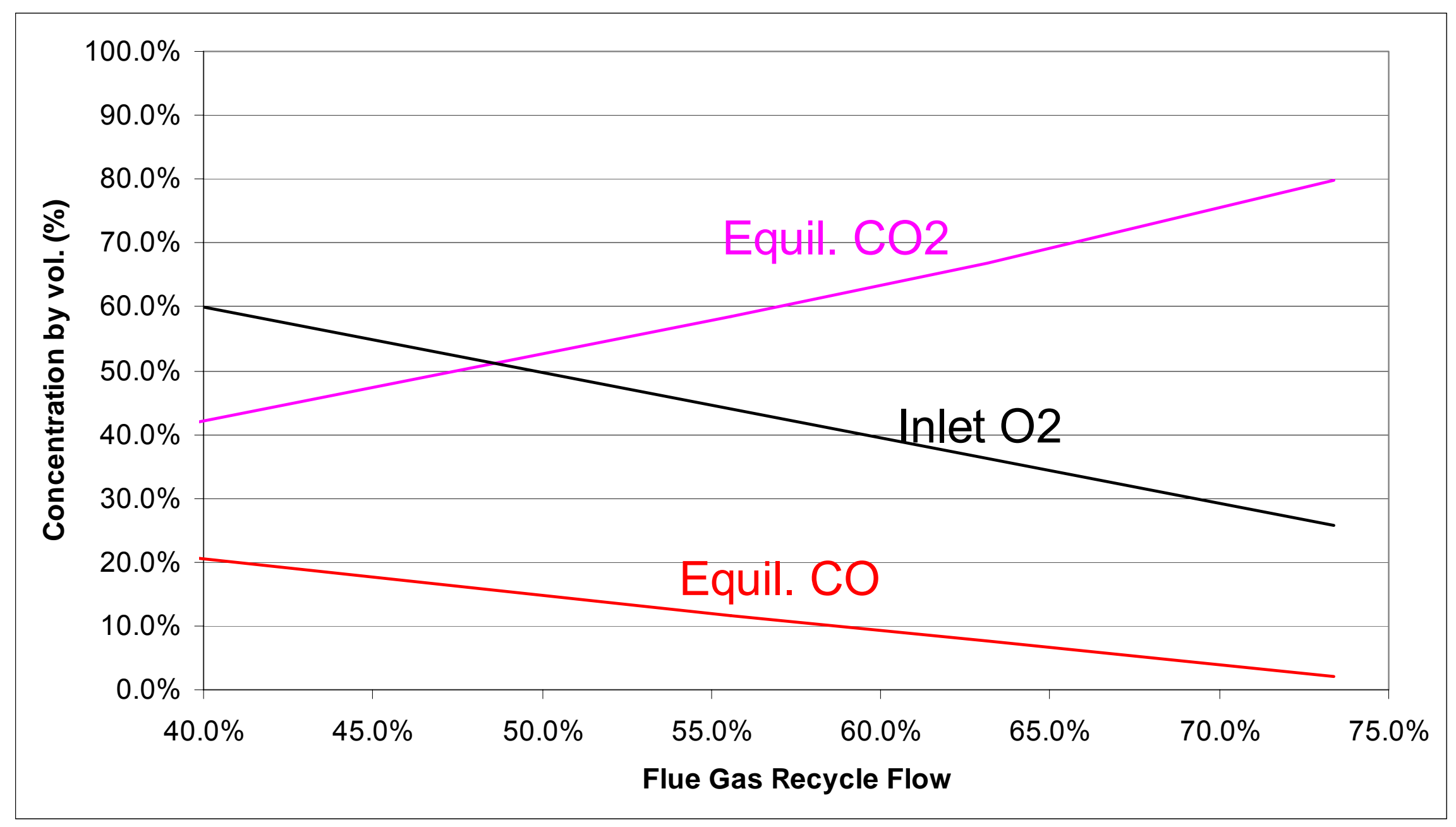


Figure 4.2.22 - Adiabatic and Equilibrium Temperatures Versus Flue Gas Recycle Flow

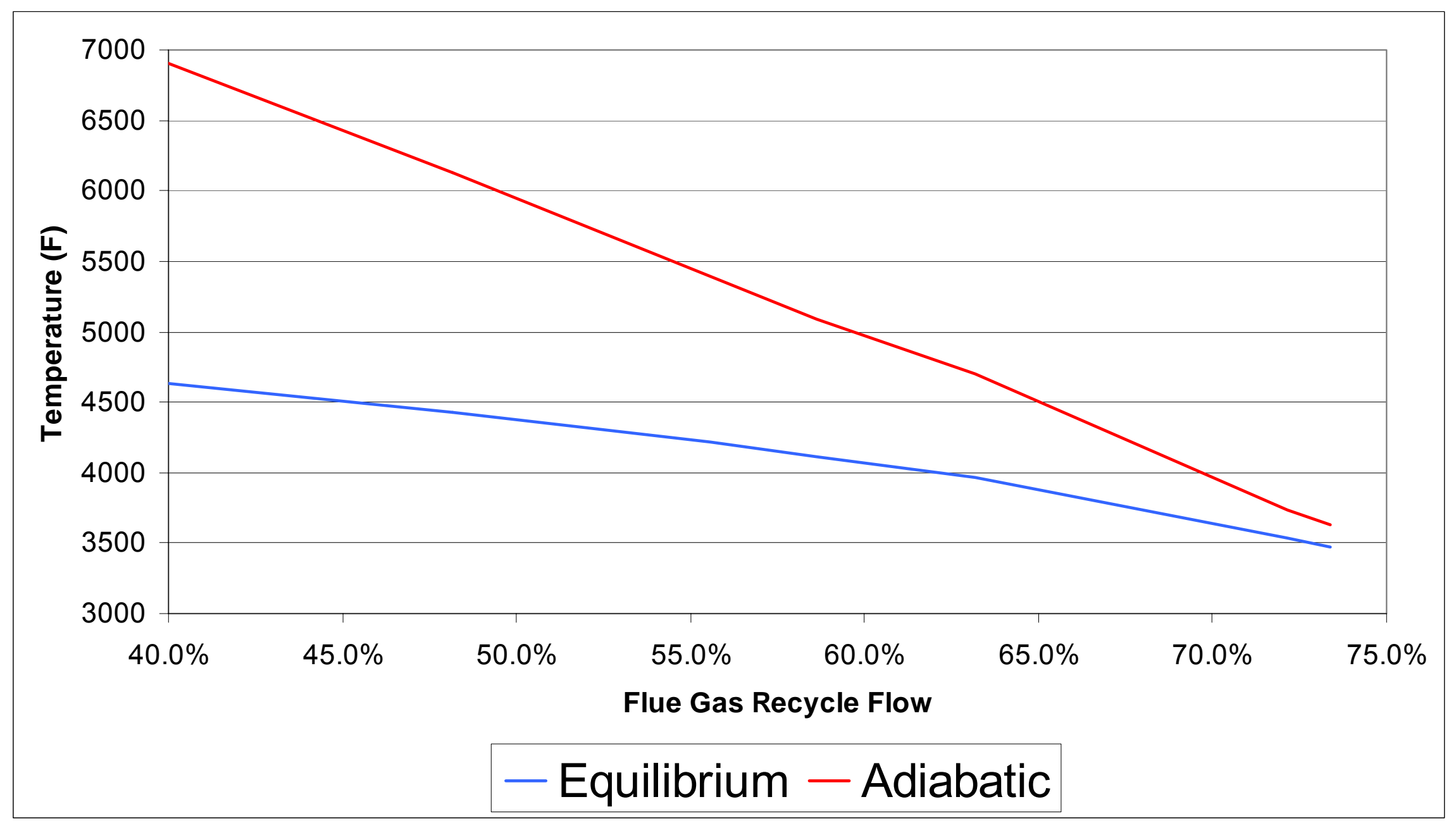


Table 4.2.6 - Radiation Heat Flux and Water Wall Temperature

\begin{tabular}{|c|c|c|c|c|c|c|c|c|c|c|c|c|c|}
\hline & & 1 & 2 & 3 & 4 & 5 & 6 & 7 & 8 & 9 & 10 & 11,12 & 13 \\
\hline Gas Flow Rate & $\mathrm{MM} \mathrm{ft} 3 / \mathrm{hr}$ & 320.8 & 223.1 & 222.7 & 212.1 & 193.3 & 174.3 & 173.0 & 219.9 & 219.9 & 208.7 & 173.7 & 173.7 \\
\hline Furnace Heat Duty & MM Btu/hr & 1894 & 1848 & 1826 & 1904 & 2055 & 2201 & 2198 & 1847 & 1848 & 1916 & 2198 & 2198 \\
\hline Furnace $\mathrm{H} 2 \mathrm{O}$ & $\%$ & 5.0 & 11.1 & 11.6 & 11.9 & 12.8 & 13.8 & 15.2 & 11.1 & 11.0 & 12.6 & 14.7 & 17.6 \\
\hline Furnace $\mathrm{CO} 2$ & $\%$ & 7.0 & 59.2 & 68.9 & 68.6 & 67.8 & 66.9 & 65.5 & 69.8 & 69.4 & 67.8 & 65.9 & 63.0 \\
\hline Depth & $\mathrm{ft}$ & 39.6 & 33.0 & 33.0 & 32.2 & 30.7 & 29.2 & 29.1 & 32.8 & 32.8 & 31.9 & 30.2 & 27.0 \\
\hline Width & $\mathrm{ft}$ & 56.3 & 46.9 & 46.9 & 45.8 & 43.7 & 41.5 & 41.3 & 46.6 & 46.6 & 45.4 & 42.9 & 38.0 \\
\hline Height & $\mathrm{ft}$ & 176.5 & 150.3 & 144.2 & 152.7 & 166.0 & 174.9 & 172.6 & 155.2 & 155.4 & 158.5 & 141.9 & 133.7 \\
\hline Mean Beam Length & $\mathrm{ft}$ & 32.9 & 27.2 & 27.0 & 26.7 & 26.0 & 25.0 & 24.9 & 27.2 & 27.2 & 26.7 & 24.9 & 22.2 \\
\hline Tube wall Properties & & & & & & & & & & & & & \\
\hline Outside Diameter & in & 2.75 & 2.75 & 2.75 & 2.75 & 2.75 & 2.75 & 2.75 & 2.75 & 2.75 & 2.75 & 2.75 & 2.75 \\
\hline Wall Thickness & in & 0.3 & 0.285 & 0.285 & 0.285 & 0.285 & 0.23 & 0.23 & 0.285 & 0.285 & 0.285 & 0.23 & 0.24 \\
\hline Inside Diameter & in & 2.15 & 2.18 & 2.18 & 2.18 & 2.18 & 2.29 & 2.29 & 2.18 & 2.18 & 2.18 & 2.29 & 2.27 \\
\hline inside H.T.C. & Btu/hr-ft2-F & 2500 & 2500 & 2500 & 2500 & 2500 & 2500 & 2500 & 2500 & 2500 & 2500 & 2500 & 2500 \\
\hline Material & & SA-210C & SA-213-T2 & SA-213-T2 & SA-213-T2 & SA-213-T22 & SA-213-T91 & SA-213-T91 & SA-213-T2 & SA-213-T2 & SA-213-T2 & SA-213-T91 & SA-213-T91 \\
\hline Wall Therm. Cond. & Btu/hr-ft-F & 22.0 & 21.8 & 22.2 & 22.2 & 20.0 & 16.1 & 16.1 & 22.2 & 22.2 & 22.2 & 16.1 & 16.1 \\
\hline Overall U & Btu/hr-ft2-F & 557.5 & 579.6 & 587.0 & 587.0 & 544.9 & 560.8 & 560.8 & 587.0 & 587.0 & 587.0 & 560.8 & 540.6 \\
\hline Stress Allowable & psi & 12,362 & 14,502 & 14,482 & 14,439 & 14,753 & 19,435 & 19,292 & 14,492 & 14,492 & 14,404 & 19,129 & 17,463 \\
\hline Min. Wall & in & 0.30 & 0.26 & 0.26 & 0.26 & 0.26 & 0.20 & 0.20 & 0.26 & 0.26 & 0.26 & 0.21 & 0.22 \\
\hline Max. Furnace Temp. & $\mathrm{F}$ & 3492 & 3467 & 3456 & 3492 & 3584 & 3710 & 3710 & 3372 & 3372 & 3433 & 3640 & 4013 \\
\hline Max. Heat Flux & Btu/hr-ft2 & 63,300 & 98,408 & 100,700 & 102,800 & 109,400 & 115,550 & 118,900 & 100,210 & 100,210 & 104,500 & 122,700 & 152,040 \\
\hline Max. Wall Temp. & $\mathrm{F}$ & 794 & 850 & 852 & 855 & 881 & 886 & 892 & 851 & 851 & 858 & 899 & 961 \\
\hline Ave. Furnace Temp. & $F$ & 3128 & 2989 & 2981 & 3008 & 3076 & 3171 & 3171 & 2920 & 2920 & 2964 & 3118 & 3404 \\
\hline Ave. Wall Flux & Btu/hr-ft2 & 49,460 & 68,140 & 69,900 & 71,150 & 75,028 & 81,100 & 82,320 & 66,684 & 66,684 & 69,900 & 78,410 & 93,901 \\
\hline flux/flux(case1) & & 1.00 & 0.73 & 0.71 & 0.70 & 0.66 & 0.61 & 0.60 & 0.74 & 0.74 & 0.71 & 0.63 & 0.53 \\
\hline
\end{tabular}




\section{Figure 4.2.23 - Case 12 Cycle Diagram}

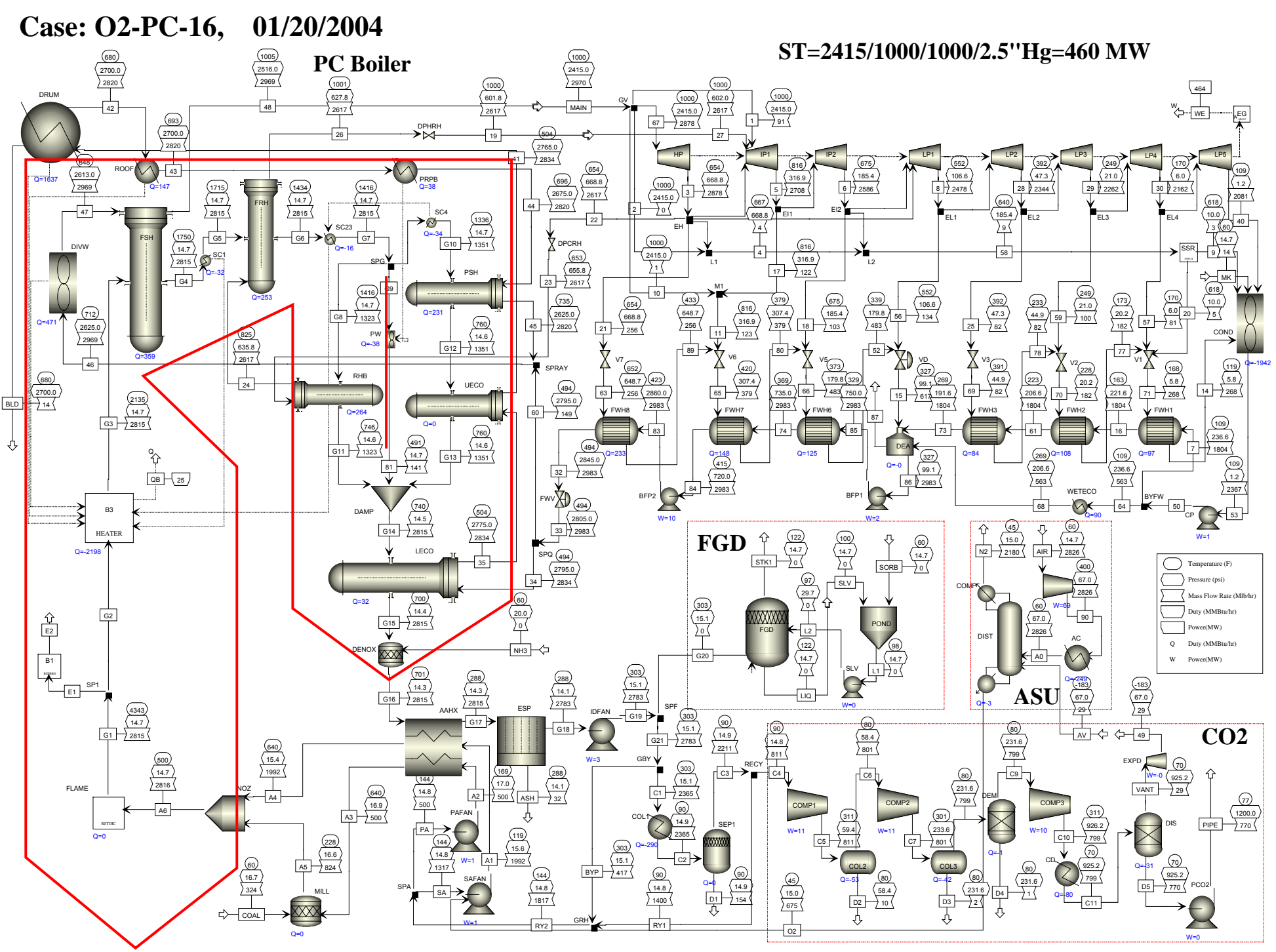


Figure 4.2.24 - Wet End Economizer Temperature Vs. Heat Duty

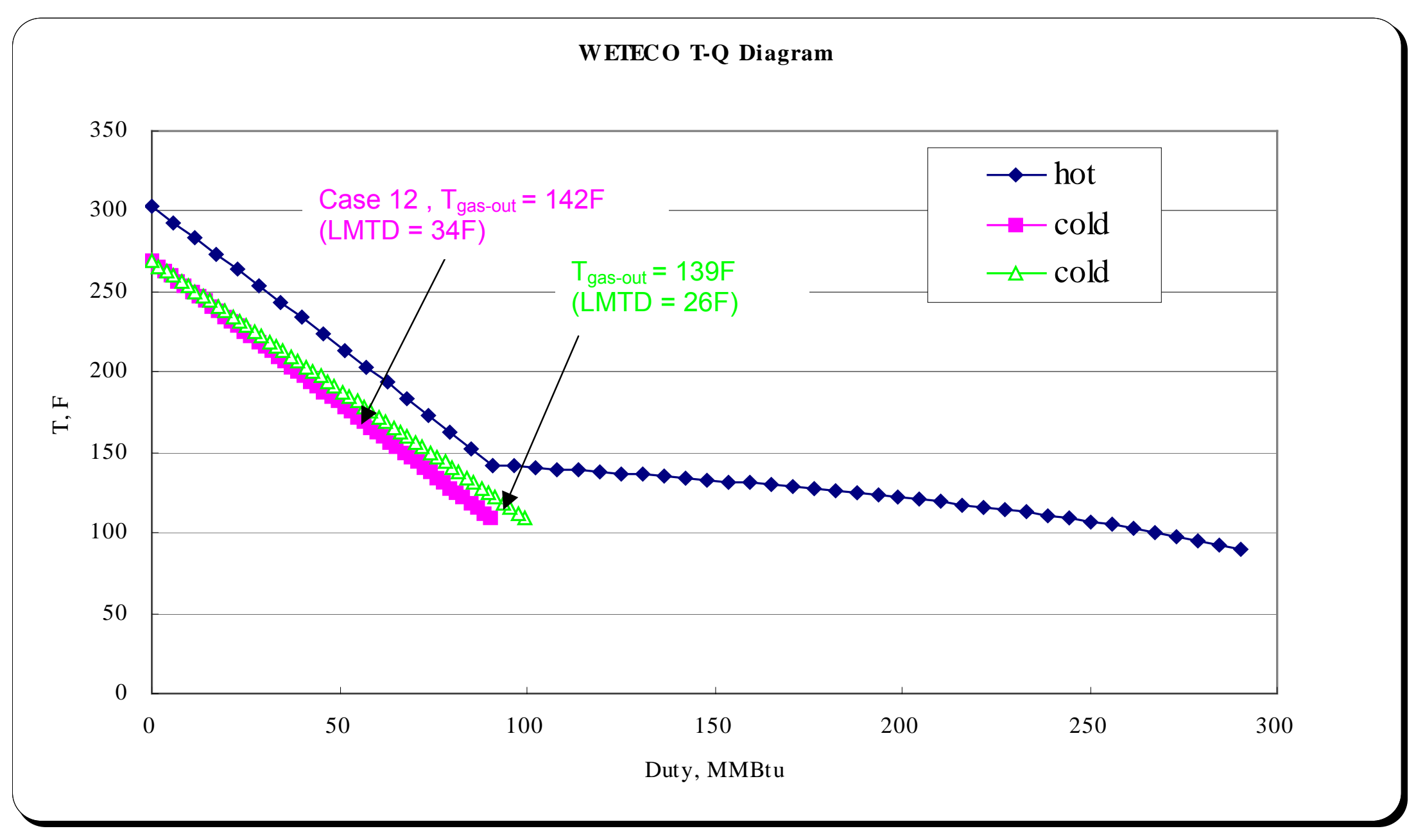


Figure 4.2.25 - Case 13 Cycle Diagram

Case: 02-PC-18， 09/07/2004

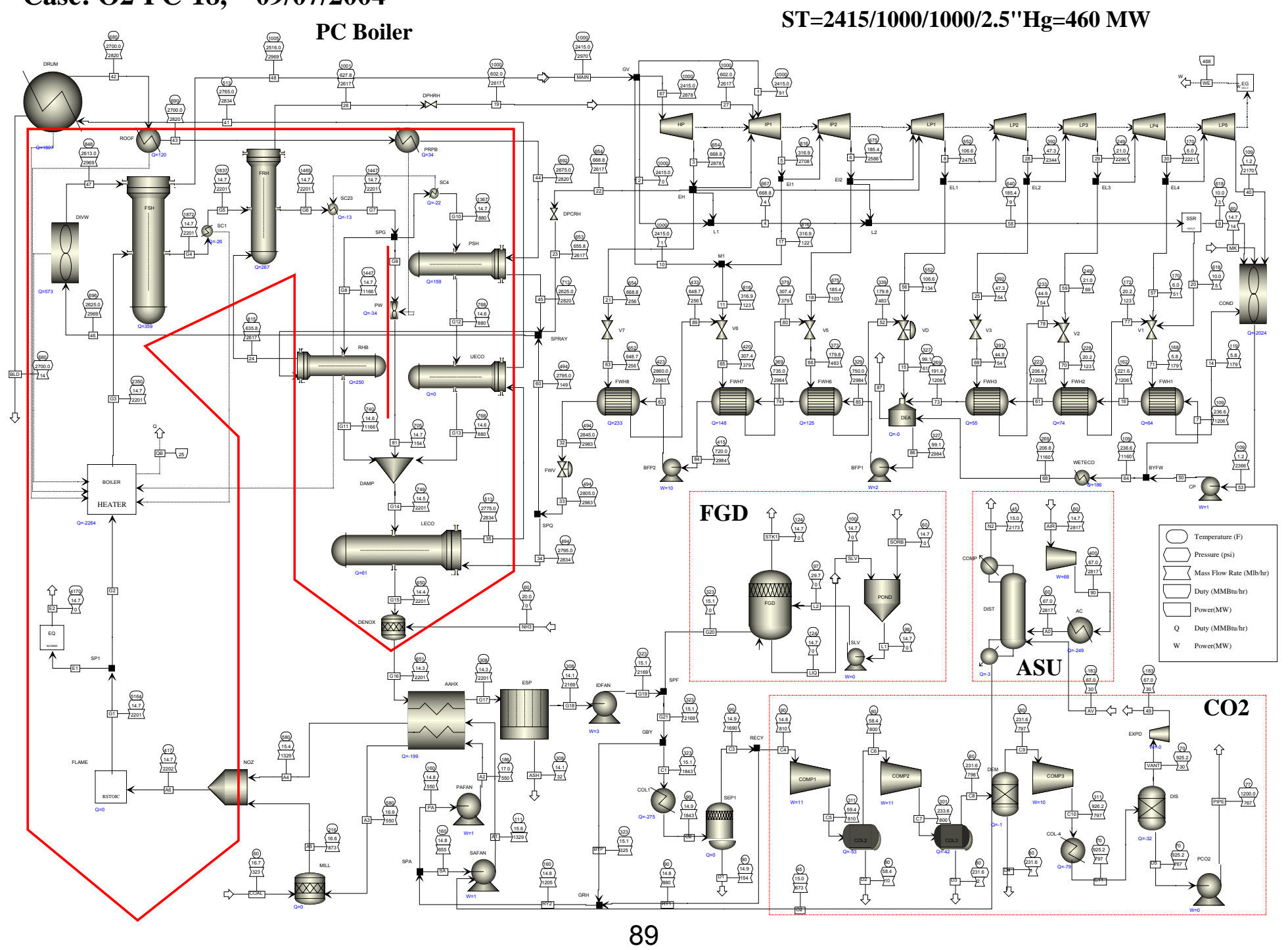


Figure 4.2.26 - Efficiency of Saved Extraction Steam Versus Stage

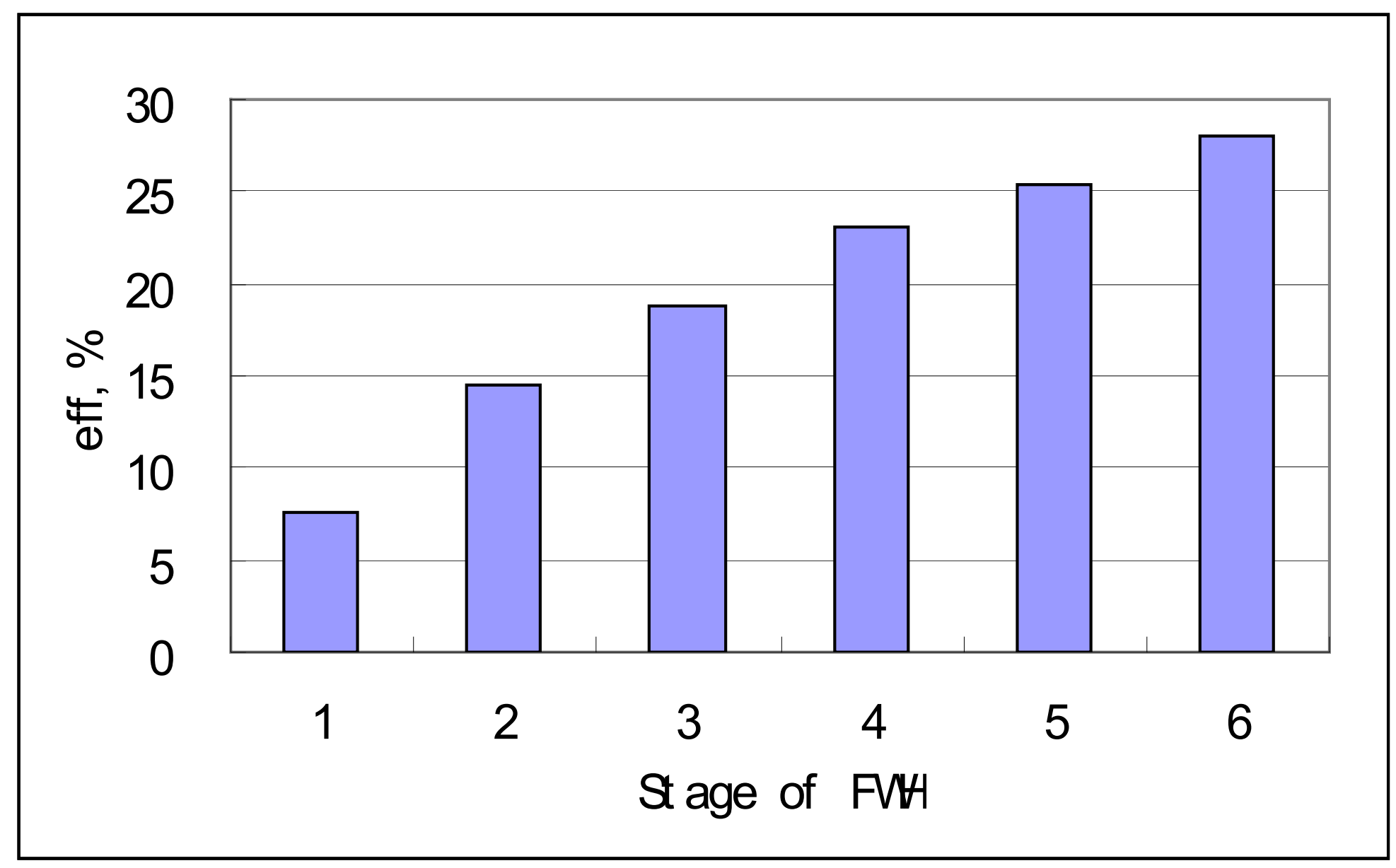


Figure 4.2.27 - Comparison of Power Consumption of $\mathrm{CO}_{2}$ Removal of Different Technologies

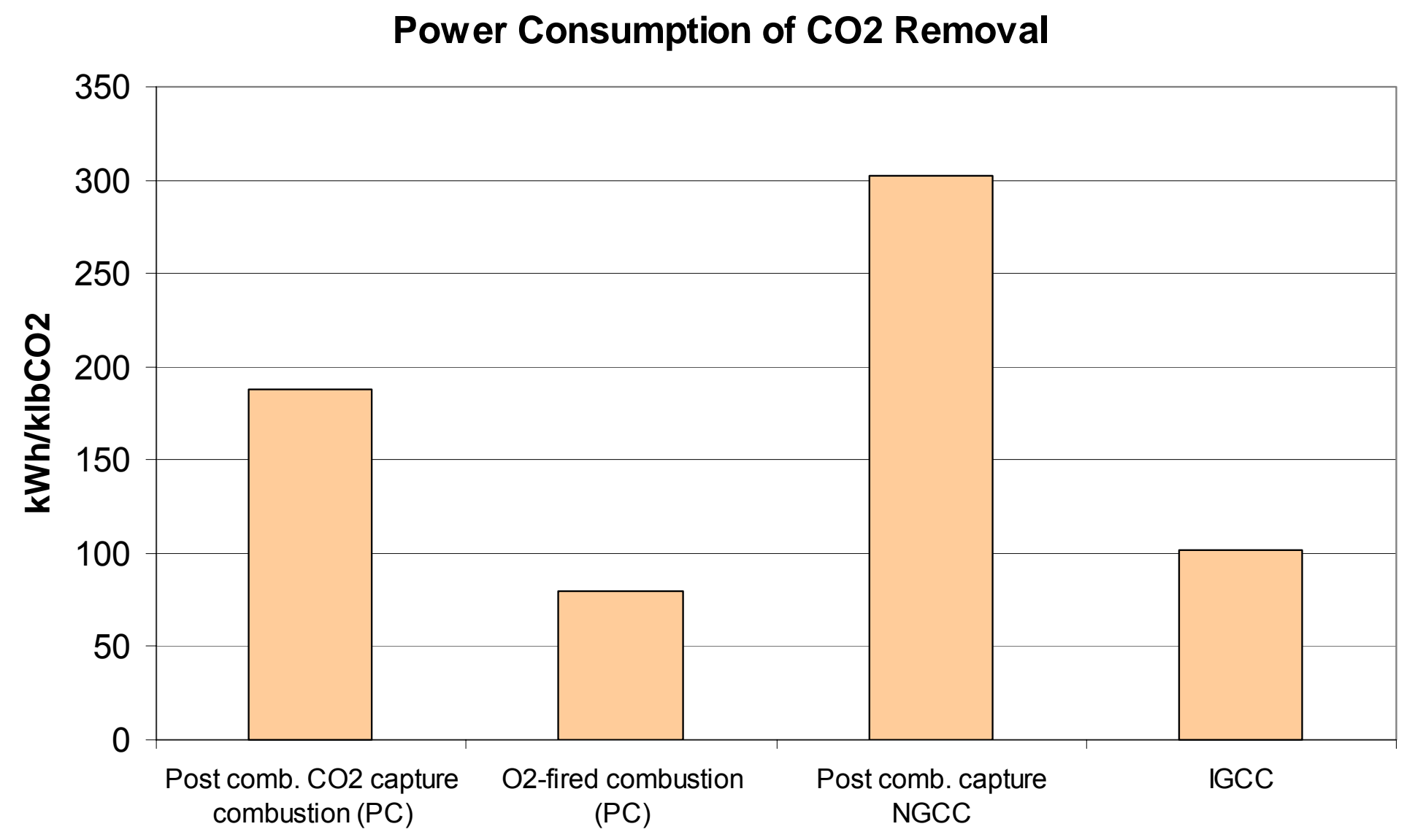


Figure 4.2.28 - Comparison of Overall Cycle Efficiency Point of $\mathrm{CO}_{2}$ Removal of Different Technologies

\section{Efficency Point Reduction of CO2 Removal}

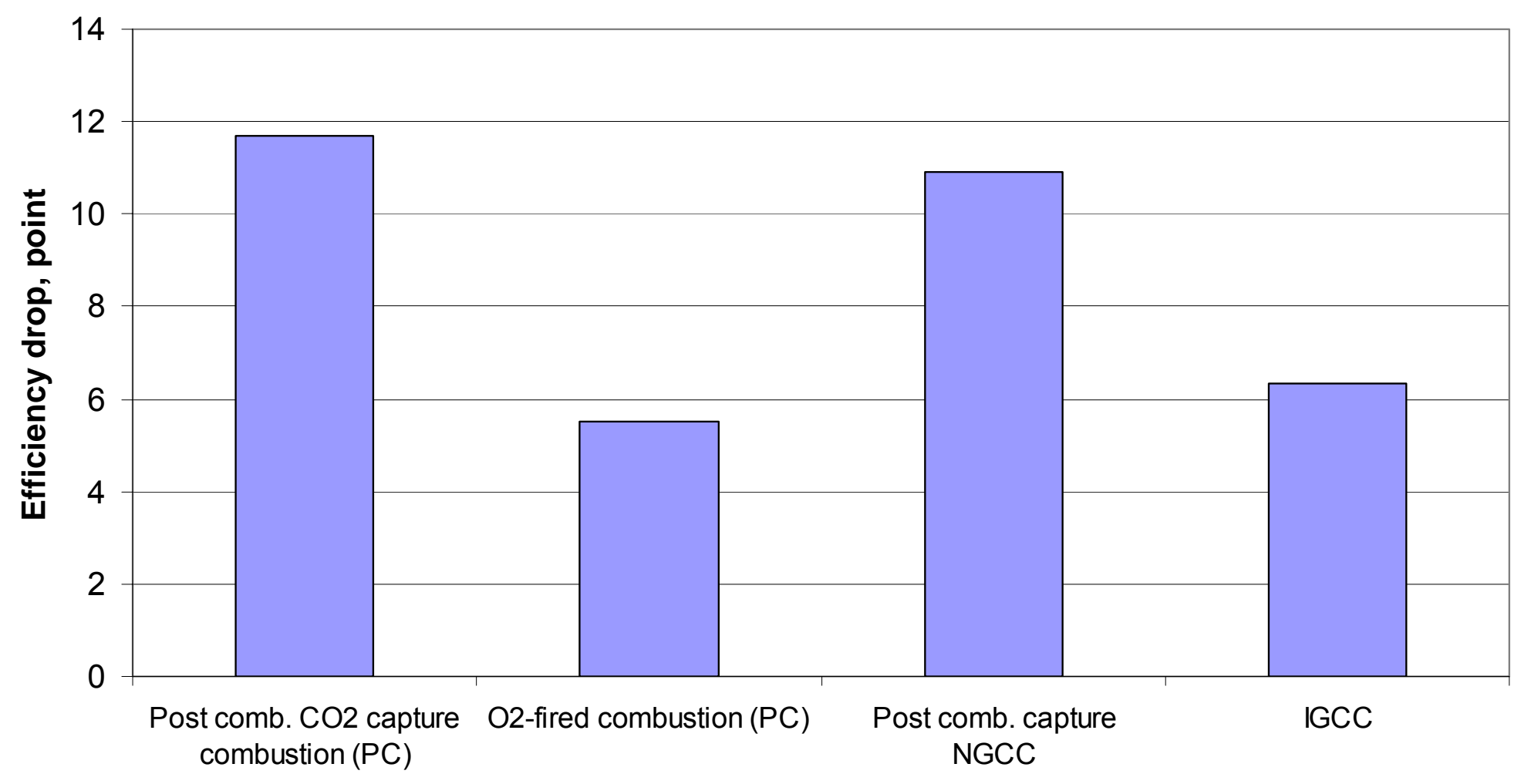




\subsection{Low NOx Burner Design and Analysis}

\subsubsection{Model Geometry}

A 3-D simulation was made of a single wall-fired burner and horizontal portion of the furnace from the wall to the center. Burner geometry is based upon FW low NOx burner experience adapted for $\mathrm{O}_{2}$ firing. Figure 4.3.1 presents the burner geometry and dimensions for the four models. Figure 4.3.2 presents a 3-D view of the CFD model near the burner outlet. The CFD model contains 60,254 cells and is shown in Figure 4.3.1.

\subsubsection{Sub Models}

The following fluent sub-models were utilized:

$\begin{array}{ll}\text { Turbulence: } & \text { standard two-equation k- } \varepsilon \text { model. } \\ \text { Radiation: } & \text { discrete ordinate } \\ \text { Species Transport: } & \text { Non-premixed combustion (pdf) } \\ \text { Gaseous radiation emissivity: domain based } \\ \text { Solver: } & \text { Segregated with SIMPLE pressure-velocity } \\ & \text { coupling and PRESTO! pressure discretation } \\ \text { Char devolatilization: } & \text { two competing rates } \\ \text { Char oxidation: } & \text { kinetics/diffusion limited }\end{array}$

\subsubsection{Boundary Conditions}

Boundary conditions are based on ASPEN simulations of the power plant (Section 4.2). The oxygen-fired ASPEN reference cycle diagrams are presented in Figure 4.2.23 (case 12) and Figure 4.2.25 (case 13), respectively The input data required by Fluent include fuel analysis, coal particle size distribution (mass percentage for each size bin), and the velocities, flow rates and temperatures of primary and secondary gas streams. Coal properties are presented in Table 4.3.1 and boundary conditions are detailed in Table 4.3.2.

For the front wall (waterwall) of the furnace an emissivity of 0.7 and temperature of $980^{\circ} \mathrm{F}$ were applied. For the tunnel, emissivity of 0.7 and a temperature of approximately $2700^{\circ} \mathrm{F}$ corresponding to the average burner heat absorption were applied.

For coal devolatilization kinetic properties, Ubhayakar rate parameters were employed for bituminous coal. For bituminous char oxidation, high volatile bituminous first order reaction coefficients were applied. 


\subsubsection{5\% Recycle Case With No OFG}

The boundary conditions were applied to the computational model (Figure 4.3.1) and Fluent was run until steady state conditions were achieved. The modeling results are summarized in Table 4.3.3. The coal burnout shown in the table is the percentage of dry ash-free based coal burned.

\subsubsection{No Primary Gas Swirl}

Figure 4.3.4 presents the velocity distribution and Figure 4.3.5 presents the temperature distribution. The $\mathrm{O}_{2}$ mole fraction is shown in Figure 4.3.6. The trajectories and burnout of the 69 micron and 169 micron coal particles are shown in Figure 4.3.7 and Figure 4.3.8. Due to the low oxygen content of the primary gas $(3.0 \%$, by vol.), coal burnout is relatively small, especially for the larger particles as can be seen in Figure 4.3.8. Consequently, it is necessary to add swirl to the primary gas to bring the coal particles (especially the larger sizes) in contact with the secondary gas. However, as the primary gas swirl is increased the NOx generally increases since the combustion staging is reduced. Figure 4.3.3 shows the effect of primary gas swirl ratio on burnout and NOx. Note that the NOx at the burner outlet can be significantly lower than the NOx at the furnace outlet, which is predicted in Section 4.4.1.5. Based on Figure 4.3.3 a primary gas swirl ratio of 0.5 was chosen as optimal.

\subsubsection{Primary Gas Swirl Ratio $=0.5$}

Figure 4.3.9 presents the velocity distribution and Figure 4.3 .10 presents the temperature distribution. Comparing Figure 4.3.5 with Figure 4.3.10 demonstrates that the addition of the 0.5 PG swirl increases the maximum flame temperature by $450^{\circ} \mathrm{F}$ and also increases the flame core temperature. Increasing the core temperature creates a more stable flame since the secondary gas swirl recirculates the hot flue gas back to the flame ignition point as shown in Figure 4.3.12. The $\mathrm{O}_{2}$ mole fraction is shown in Figure 4.3.11. The trajectories and burnout of the 69 micron and 169 micron coal particles are shown in Figure 4.3.13 and Figure 4.3.14. Note that with the 0.5 PG swirl ratio approximately $55 \%$ of the larger coal particles are burned (Figure 4.3.14) as compared to only about $25 \%$ for a zero PG swirl ratio (Figure 4.3.8).

\subsubsection{5\% Recycle Case With 20\% OFG}

The boundary conditions were applied to the computational model (Figure 4.3.1) and Fluent was run until steady state conditions were achieved. The modeling results are summarized in Table 4.3.3. 


\subsubsection{No Primary Gas Swirl}

Figure 4.3.15 presents the velocity distribution and Figure 4.3 .16 presents the temperature distribution. The $\mathrm{O}_{2}$ mole fraction is shown in Figure 4.3.17. The trajectories and burnout of the 69 micron and 169 micron coal particles are shown in Figure 4.3.18 and Figure 4.3.19. Due to the low oxygen content of the primary gas $(3.0 \%$, by vol.), coal burnout is relatively small, especially for the larger particles as can be seen in Figure 4.3.19. Consequently, it is necessary to add swirl to the primary gas to bring the coal particles (especially the larger sizes) in contact with the secondary gas.

\subsubsection{Primary Gas Swirl Ratio $=0.5$}

Figure 4.3.20 presents the velocity distribution and Figure 4.3 .21 presents the temperature distribution. Comparing Figure 4.3.16 with Figure 4.3.21 demonstrates that the addition of the 0.5 PG swirl increases the maximum flame temperature by $160^{\circ} \mathrm{F}$ and also increases the flame core temperature. Increasing the core temperature creates a more stable flame since the secondary gas swirl recirculates the hot flue gas back to the flame ignition point. The $\mathrm{O}_{2}$ mole fraction is shown in Figure 4.3.22. The trajectories and burnout of the 69 micron and 169 micron coal particles are shown in Figure 4.3.23 and Figure 4.3.24. Note that with the $0.5 \mathrm{PG}$ swirl ratio approximately $45 \%$ of the larger coal particles are burned (Figure 4.3.24) as compared to only about 33\% for a zero PG swirl ratio (Figure 4.3.19).

\subsubsection{6\% Recycle Case With No OFG}

The boundary conditions were applied to the computational model (Figure 4.3.1) and Fluent was run until steady state conditions were achieved. The modeling results are summarized in Table 4.3.3.

\subsubsection{No Primary Gas Swirl}

Figure 4.3.25 presents the velocity distribution Figure 4.3.26 presents the temperature distribution. The $\mathrm{O}_{2}$ mole fraction is shown in Figure 4.3.27. The trajectories and burnout of the 69 micron and 169 micron coal particles are shown in Figure 4.3.28 and Figure 4.3.29. Due to the low oxygen content of the primary gas $(3.0 \%$, by vol.), coal burnout is relatively small, especially for the larger particles as can be seen in Figure 4.3.29. Consequently, it is necessary to add swirl to the primary gas to bring the coal particles (especially the larger sizes) in contact with the secondary gas.

\subsubsection{Primary Gas Swirl Ratio $=0.5$}

Figure 4.3.30 presents the velocity distribution and Figure 4.3.31presents the temperature distribution. Comparing with Figure 4.3.26 with Figure 4.3.31 
demonstrates that the addition of the 0.5 PG swirl increases the maximum flame temperature by $100^{\circ} \mathrm{F}$ and also increases the flame core temperature. Increasing the core temperature creates a more stable flame since the secondary gas swirl recirculates the hot flue gas back to the flame ignition point. The $\mathrm{O}_{2}$ mole fraction is shown in Figure 4.3.32. The trajectories and burnout of the 69 micron and 169 micron coal particles are shown in Figure 4.3.33 and Figure 4.3.34. Note that with the 0.5 PG swirl ratio approximately $47 \%$ of the $169 \mu$ coal particles are burned (Figure 4.3.34) as compared to only about $44 \%$ for a zero PG swirl ratio (Figure 4.3 .29 ) and $85 \%$ of the $69 \mu$ coal particles are burned (Figure 4.3.33) as compared to only about $52 \%$ for a zero PG swirl ratio (Figure 4.3.28)

\subsubsection{6\% Recycle Case With 20\% OFG}

The boundary conditions were applied to the computational model (Figure 4.3.1) and Fluent was run until steady state conditions were achieved. The modeling results are summarized in Table 4.3.3.

\subsubsection{No Primary Gas Swirl}

Figure 4.3.35 presents the velocity distribution and Figure 4.3 .36 presents the temperature distribution. The $\mathrm{O}_{2}$ mole fraction is shown in Figure 4.3.37. The trajectories and burnout of the 69 micron and 169 micron coal particles are shown in Figure 4.3.38 and Figure 4.3.39. Due to the low oxygen content of the primary gas $(3.0 \%$, by vol.), coal burnout is relatively small, especially for the larger particles as can be seen in Figure 4.3.39. Consequently, it is necessary to add swirl to the primary gas to bring the coal particles (especially the larger sizes) in contact with the secondary gas.

\subsubsection{Primary Gas Swirl Ratio $=0.5$}

Figure 4.3.40 presents the velocity distribution and Figure 4.3 .41 presents the temperature distribution. Comparing Figure 4.3.36 with Figure 4.3.41 demonstrates that the addition of the 0.5 PG swirl increases the maximum flame temperature by $220^{\circ} \mathrm{F}$ and also increases the flame core temperature. Increasing the core temperature creates a more stable flame since the secondary gas swirl recirculates the hot flue gas back to the flame ignition point. The $\mathrm{O}_{2}$ mole fraction is shown in Figure 4.3.42. The trajectories and burnout of the 69 micron and 169 micron coal particles are shown in Figure 4.3.43 and Figure 4.3.44. Note that with the 0.5 PG swirl ratio approximately $49 \%$ of the larger coal particles are burned (Figure 4.3 .44 ) as compared to only about $18 \%$ for a zero PG swirl ratio (Figure 4.3.39). 
Figure 4.3.1 - Oxygen-Fired Burner Geometry

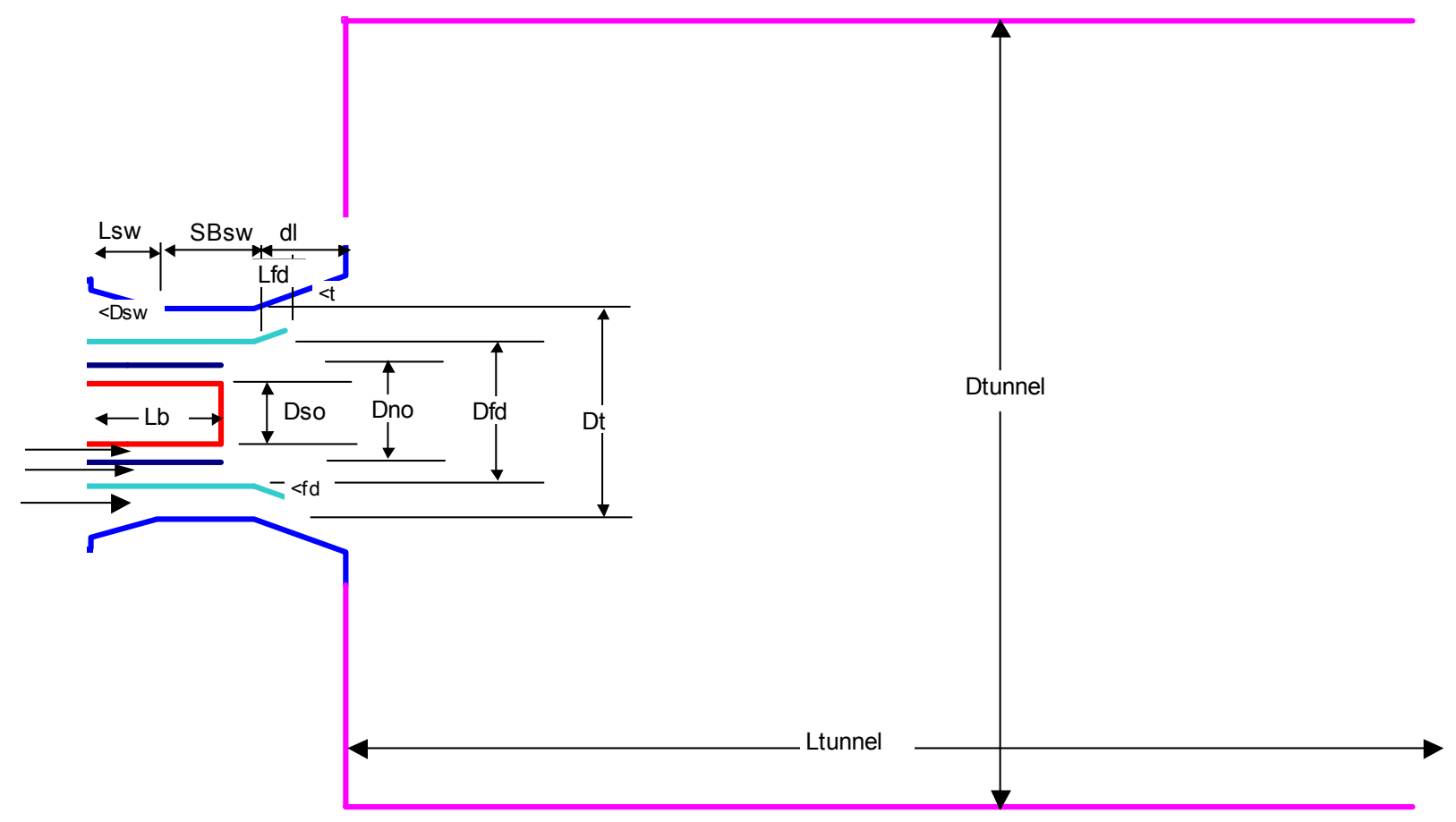

\begin{tabular}{|c|c|c|c|c|c|}
\cline { 3 - 5 } \multicolumn{2}{c|}{} & \multicolumn{2}{c|}{$65 \%$ Flue Gas Recycle } & \multicolumn{2}{c|}{$56 \%$ Flue Gas Recycle } \\
\cline { 3 - 6 } \multicolumn{2}{c|}{} & No OFG & $20 \%$ OFG & No OFG & $20 \%$ OFG \\
\hline Dt & in. & 32 & 29 & 29 & 25 \\
Dfd & in. & 22.25 & 21 & 21 & 19 \\
SBsw & in. & 13 & 12 & 11.875 & 11.875 \\
Lsw & in. & 9 & 8.375 & 8.375 & 8.375 \\
<Dsw & deg. & 18 & 18 & 18 & 18 \\
Lfd & in. & 4 & 4 & 4 & 4 \\
<fd & deg. & 22.5 & 22.5 & 22.5 & 22.5 \\
dl & in. & 12 & 11 & 11.25 & 11.25 \\
<t & deg. & 22.5 & 22.5 & 22.5 & 22.5 \\
Dno & in. & 15.5 & 15.5 & 15.5 & 15.5 \\
Dso & in. & 10 & 10 & 10 & 10 \\
Lb & in. & 20 & 20 & 20 & 20 \\
Dtunnel & in. & 120 & 120 & 120 & 120 \\
Ltunnel & in. & 144 & 144 & 144 & 144 \\
\hline
\end{tabular}


Figure 4.3.2 - Computational Model of Oxygen-Fired Burner

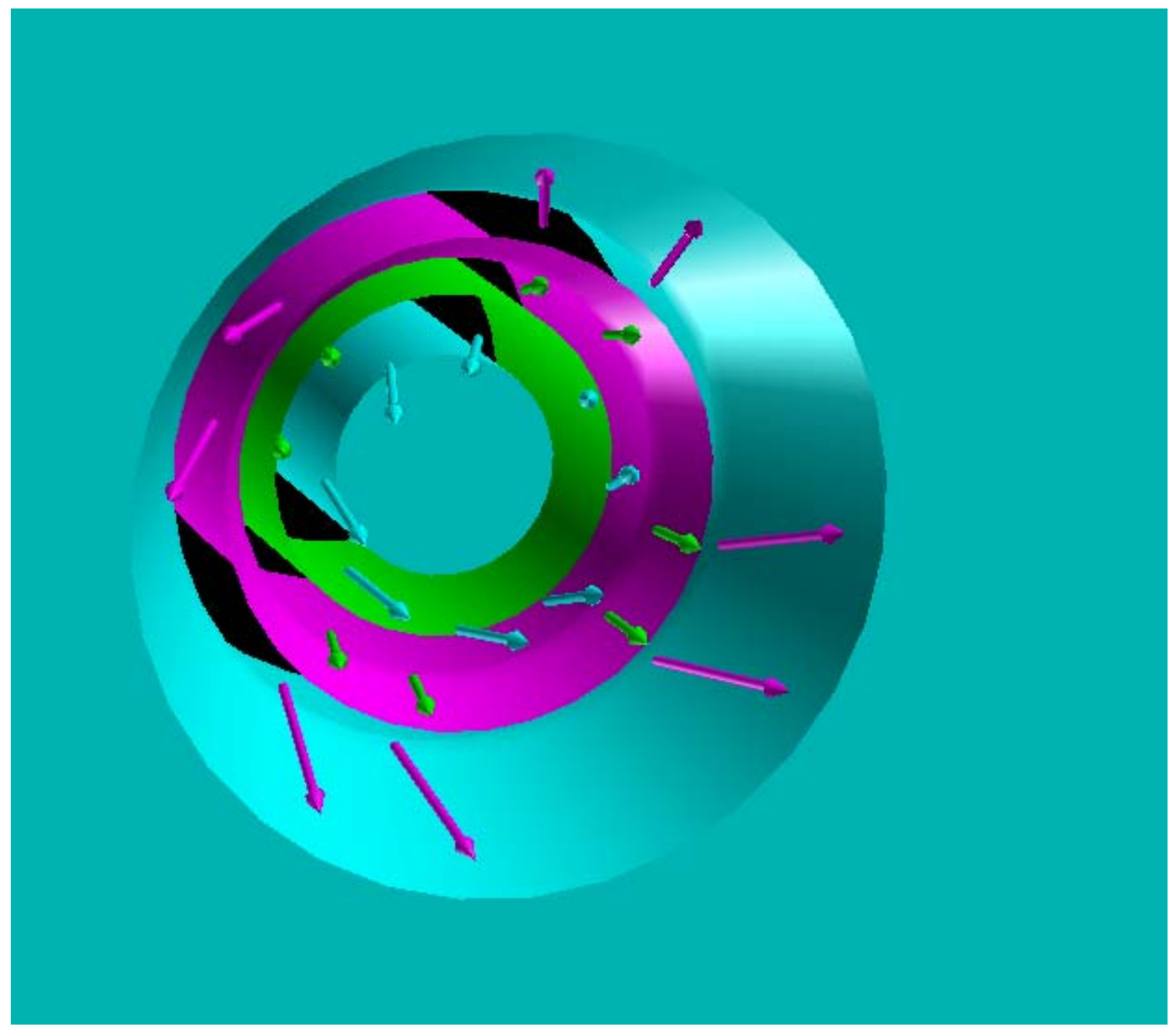

Vector Key

Outer Secondary Gas

Inner Secondary Gas

Primary Gas 
Table 4.3.1 - Coal Properties

\begin{tabular}{|r|c|c|} 
Coal Size Distribution & & \\
$<75$ micron & $\%$ & 85 \\
$<150$ micron & $\%$ & 99 \\
Size (micron) & & \\
10.7 & $\mathrm{lb} / \mathrm{hr}$ & 3,540 \\
33.7 & $\mathrm{lb} / \mathrm{hr}$ & 4,580 \\
69.3 & $\mathrm{lb} / \mathrm{hr}$ & 3,106 \\
118.2 & $\mathrm{lb} / \mathrm{hr}$ & 654 \\
169.2 & $\mathrm{lb} / \mathrm{hr}$ & 120 \\
\hline Total & $\mathrm{lb} / \mathrm{hr}$ & 12,000 \\
Ash & $\%$ & $9.99 \%$ \\
$\mathrm{~S}$ & $\%$ & $2.51 \%$ \\
$\mathrm{H}$ & $\%$ & $4.50 \%$ \\
$\mathrm{C}$ & $\%$ & $63.75 \%$ \\
$\mathrm{H} 2 \mathrm{O}$ & $\%$ & $11.12 \%$ \\
$\mathrm{~N}$ & $\%$ & $1.25 \%$ \\
$\mathrm{O}$ & $\%$ & $6.88 \%$ \\
\hline Total & $\%$ & $100.00 \%$ \\
& & \\
Voal Ultimate Analysis & $\%$ & $44.35 \%$ \\
$\mathrm{HHV}$, as received & $\mathrm{Otu} / \mathrm{lb}$ & 11,666 \\
\hline & &
\end{tabular}


Table 4.3.2 -Model Boundary Conditions

\begin{tabular}{|c|c|c|c|c|c|c|}
\hline & & & & & $20^{\circ}$ & FG \\
\hline & & Primary & Inner Sec. & Outer Sec. & Inner Sec. & Outer Sec. \\
\hline \multicolumn{7}{|l|}{ Flow Area } \\
\hline Inlet & in2 & 110.2 & 157.7 & 585.3 & 94.8 & 444.3 \\
\hline Outlet & in2 & 110.2 & 157.7 & 314.2 & 94.8 & 207.3 \\
\hline Total Mass Flow Rate & $\mathrm{lb} / \mathrm{hr}$ & 530,000 & 276,433 & $1,105,732$ & 201,383 & 805,533 \\
\hline No. of Burners & & 24 & 24 & 24 & 24 & 24 \\
\hline OFG & & & $0.0 \%$ & $0.0 \%$ & $20.0 \%$ & $20.0 \%$ \\
\hline Mass Flow Rate & $\mathrm{lb} / \mathrm{hr}$ & 22,083 & 11,518 & 46,072 & 8,391 & 33,564 \\
\hline Temperature & $\mathrm{F}$ & 216 & 580 & 580 & 580 & 580 \\
\hline Molecular weight & lb/lb-mol & 38.82 & 36.08 & 36.08 & 36.08 & 36.08 \\
\hline Density & $\mathrm{lb} / \mathrm{ft} 3$ & 0.080 & 0.049 & 0.049 & 0.049 & 0.049 \\
\hline \multicolumn{7}{|l|}{ Velocity } \\
\hline Inlet & $\mathrm{ft} / \mathrm{sec}$ & 99.8 & 60.2 & 64.9 & 72.9 & 62.3 \\
\hline Outlet & $\mathrm{ft} / \mathrm{sec}$ & 99.8 & 60.2 & 120.9 & 72.9 & 133.5 \\
\hline \multirow{2}{*}{\multicolumn{7}{|c|}{ Composition, by Vol. }} \\
\hline & & & & & & \\
\hline $\mathrm{H} 2 \mathrm{O}$ & $\%$ & $18.80 \%$ & $3.70 \%$ & $3.70 \%$ & $3.70 \%$ & $3.70 \%$ \\
\hline $\mathrm{O} 2$ & $\%$ & $3.10 \%$ & $58.30 \%$ & $58.30 \%$ & $58.30 \%$ & $58.30 \%$ \\
\hline $\mathrm{N} 2$ & $\%$ & $0.70 \%$ & $0.30 \%$ & $0.30 \%$ & $0.30 \%$ & $0.30 \%$ \\
\hline $\mathrm{AR}$ & $\%$ & $0.40 \%$ & $0.50 \%$ & $0.50 \%$ & $0.50 \%$ & $0.50 \%$ \\
\hline $\mathrm{CO} 2$ & $\%$ & $75.90 \%$ & $36.60 \%$ & $36.60 \%$ & $36.60 \%$ & $36.60 \%$ \\
\hline $\mathrm{sO} 2$ & $\%$ & $1.00 \%$ & $0.50 \%$ & $0.50 \%$ & $0.50 \%$ & $0.50 \%$ \\
\hline SO3 & $\%$ & $0.10 \%$ & $0.10 \%$ & $0.10 \%$ & $0.10 \%$ & $0.10 \%$ \\
\hline Total & $\%$ & $100.00 \%$ & $100.00 \%$ & $100.00 \%$ & $100.00 \%$ & $100.00 \%$ \\
\hline Coal Flow Rate & $\mathrm{lb} / \mathrm{hr}$ & 12,000 & 0 & 0 & 0 & 0 \\
\hline
\end{tabular}

\section{$56 \%$ Recycle}

\begin{tabular}{|c|c|c|c|c|c|c|}
\hline & & & & & $20^{\circ}$ & $\overline{\mathrm{DFG}}$ \\
\hline & & Primary & Inner Sec. & Outer Sec. & Inner Sec. & Outer Sec. \\
\hline Flow Area & & & & & & \\
\hline Inlet & in2 & 110.2 & 200.1 & 736.3 & 157.7 & 585.3 \\
\hline Outlet & in2 & 110.2 & 200.1 & 415.4 & 157.7 & 314.2 \\
\hline Mass Flow Rate & $\mathrm{lb} / \mathrm{hr}$ & 22,083 & 16,600 & 66,400 & 12,458 & 49,833 \\
\hline Temperature & $\mathrm{F}$ & 228 & 640 & 640 & 640 & 640 \\
\hline Molecular weight & $\mathrm{lb} / \mathrm{lb}-\mathrm{mol}$ & 39.05 & 37.97 & 37.97 & 37.97 & 37.97 \\
\hline Density & $\mathrm{lb} / \mathrm{ft} 3$ & 0.078 & 0.047 & 0.047 & 0.047 & 0.047 \\
\hline Velocity & & & & & & \\
\hline Inlet & $\mathrm{ft} / \mathrm{sec}$ & 103.1 & 70.1 & 76.3 & 66.8 & 72.0 \\
\hline Outlet & $\mathrm{ft} / \mathrm{sec}$ & 103.1 & 70.1 & 135.1 & 66.8 & 134.1 \\
\hline Swirl Ratio & & $0.0,0.5$ & 0.0 & 1.00 & 0.0 & 1.00 \\
\hline Composition, by Mass & & & & & & \\
\hline $\mathrm{H} 2 \mathrm{O}$ & $\%$ & $8.48 \%$ & $1.99 \%$ & $1.99 \%$ & $1.99 \%$ & $1.99 \%$ \\
\hline $\mathrm{O} 2$ & $\%$ & $2.38 \%$ & $35.31 \%$ & $35.31 \%$ & $35.31 \%$ & $35.31 \%$ \\
\hline $\mathrm{N} 2$ & $\%$ & $0.50 \%$ & $0.29 \%$ & $0.29 \%$ & $0.29 \%$ & $0.29 \%$ \\
\hline$A R$ & $\%$ & $0.82 \%$ & $0.84 \%$ & $0.84 \%$ & $0.84 \%$ & $0.84 \%$ \\
\hline $\mathrm{CO} 2$ & $\%$ & $86.08 \%$ & $60.49 \%$ & $60.49 \%$ & $60.49 \%$ & $60.49 \%$ \\
\hline $\mathrm{sO} 2$ & $\%$ & $1.64 \%$ & $1.18 \%$ & $1.18 \%$ & $1.18 \%$ & $1.18 \%$ \\
\hline $\mathrm{SO} 3$ & $\%$ & $0.13 \%$ & $0.13 \%$ & $0.13 \%$ & $0.13 \%$ & $0.13 \%$ \\
\hline Total & $\%$ & $100.03 \%$ & $100.24 \%$ & $100.24 \%$ & $100.24 \%$ & $100.24 \%$ \\
\hline Coal Flow Rate & $\mathrm{lb} / \mathrm{hr}$ & 12,000 & 0 & 0 & 0 & 0 \\
\hline
\end{tabular}


Table 4.3.3 - Summary of Fluent Burner Modeling Results

\begin{tabular}{|c|c|c|c|c|c|c|c|c|c|}
\hline \multirow[b]{3}{*}{ Results at Outlet } & & \multicolumn{4}{|c|}{$65 \%$ Flue Gas Recycle } & \multicolumn{4}{|c|}{ 56\% Flue Gas Recycle } \\
\hline & & \multicolumn{2}{|c|}{$\mathrm{O} \%$ OFG } & \multicolumn{2}{|c|}{$20 \%$ OFG } & \multicolumn{2}{|c|}{ O\% OFG } & \multicolumn{2}{|c|}{$20 \%$ OFG } \\
\hline & & 0.0 PG Swirl & 0.5 PG Swirl & 0.0 PG Swirl & 0.5 PG Swirl & 0.0 PG Swirl & 0.5 PG Swirl & 0.0 PG Swirl & 0.5 PG Swir \\
\hline Burnout & $\%$ & 0.61 & 0.85 & 0.61 & 0.71 & 0.67 & 0.79 & 0.59 & 0.73 \\
\hline $\mathrm{O} 2$ & $\%$ & 20.4 & 11.2 & 15.0 & 11.4 & 23.4 & 19.3 & 18.8 & 14.2 \\
\hline $\mathrm{NOx}$ & ppmvw & 230 & 459 & 320 & 360 & 666 & 754 & 427 & 820 \\
\hline NOx/Burnout & ppmvw & 376 & 541 & 526 & 507 & 1000 & 960 & 726 & 1123 \\
\hline Temperature & $\mathrm{F}$ & 2140 & 3300 & 2590 & 2920 & 2918 & 3093 & 2943 & 3148 \\
\hline
\end{tabular}


Figure 4.3.3 - Burnout and NOx/burnout vs. Primary gas Swirl for 65\% Recycle, No OFG

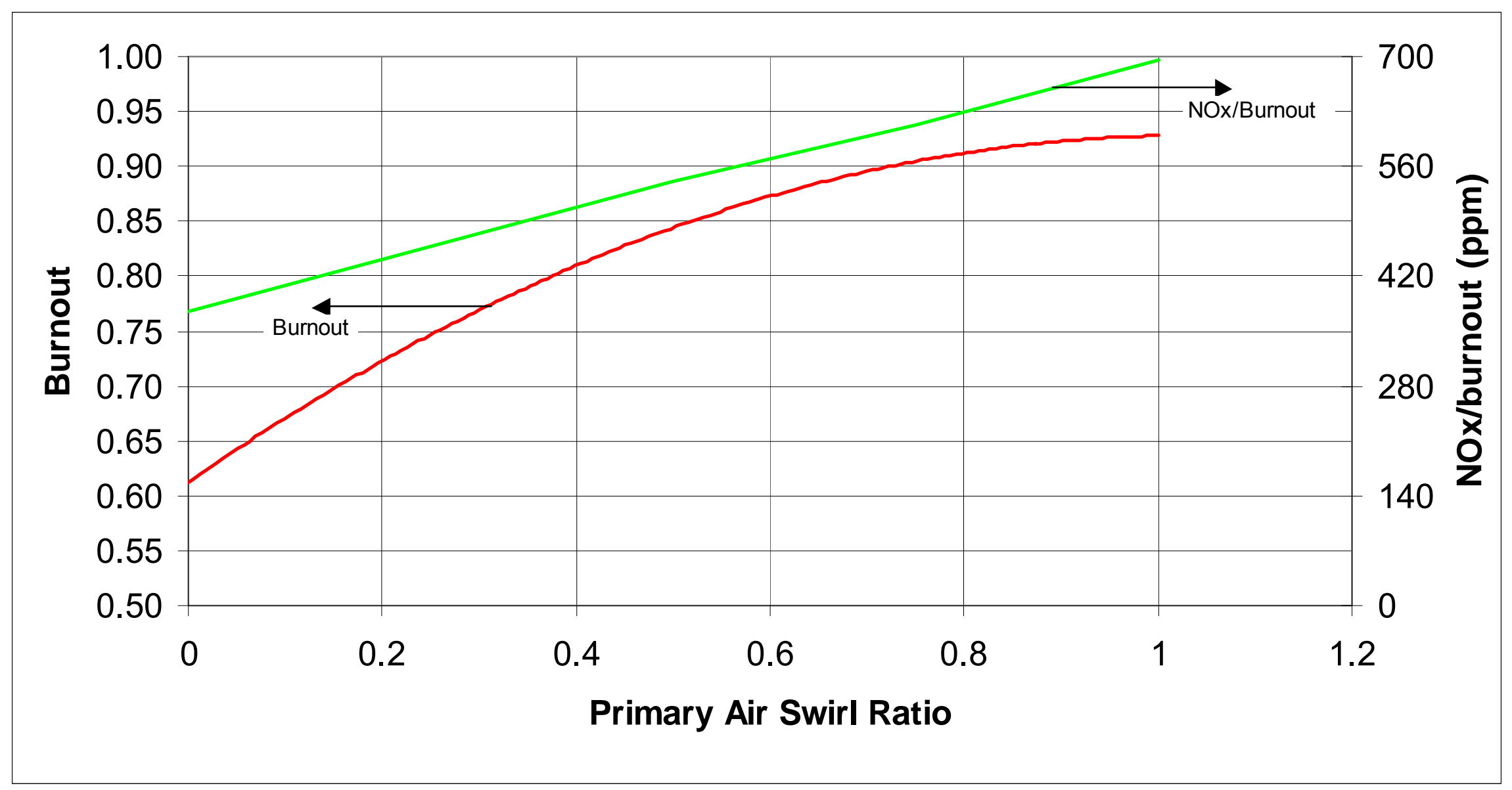


Figure 4.3.4 - Gas Velocity for 65\% Recycle, No OFG, 0.0 PG Swirl

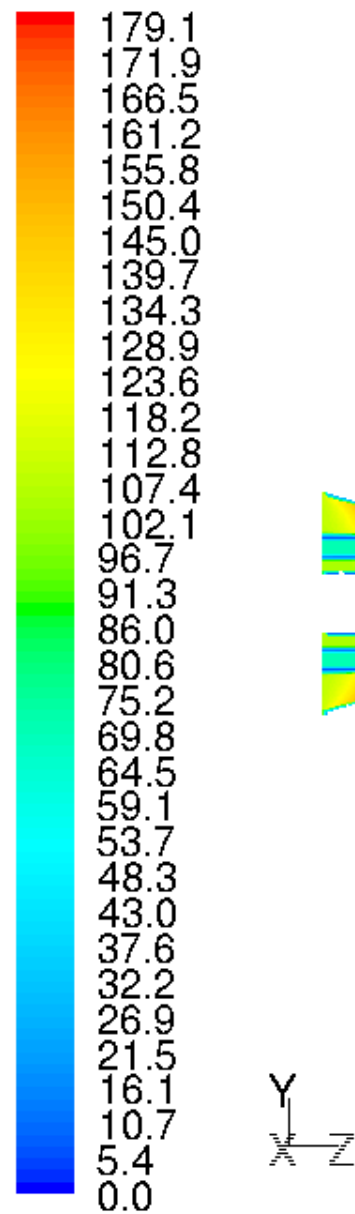

Contours of Velocity Magnitude (ft/s)

Apr 27, 2005 FLUENT 6.2 (3d, segregated, pdf13, ske) 
Figure 4.3.5 - Gas Temperature for 65\% Recycle, No OFG, 0.0 PG Swirl

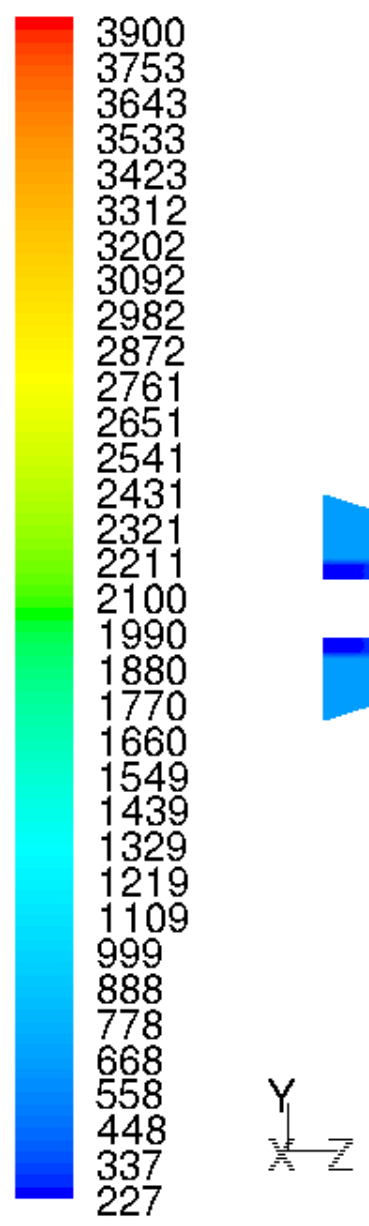

Contours of Static Temperature ( $f$ )

May 10, 2005 FLUENT 6.2 (3d, segregated, pdf13, ske) 
Figure 4.3.6 $-\mathrm{O}_{2}$ Mole Fraction for 65\% Recycle, No OFG, 0.0 PG Swirl

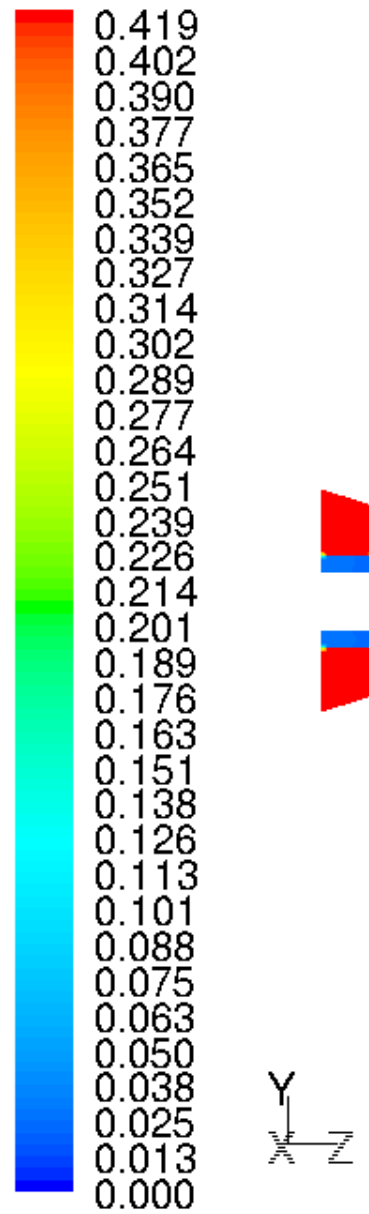

Contours of Mole fraction of 02

Apr 27, 2005 FLUENT 6.2 (3d, segregated, pdf13, ske) 


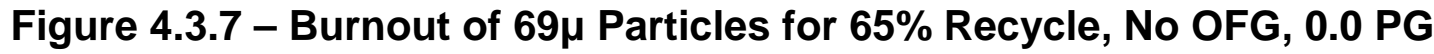
Swirl
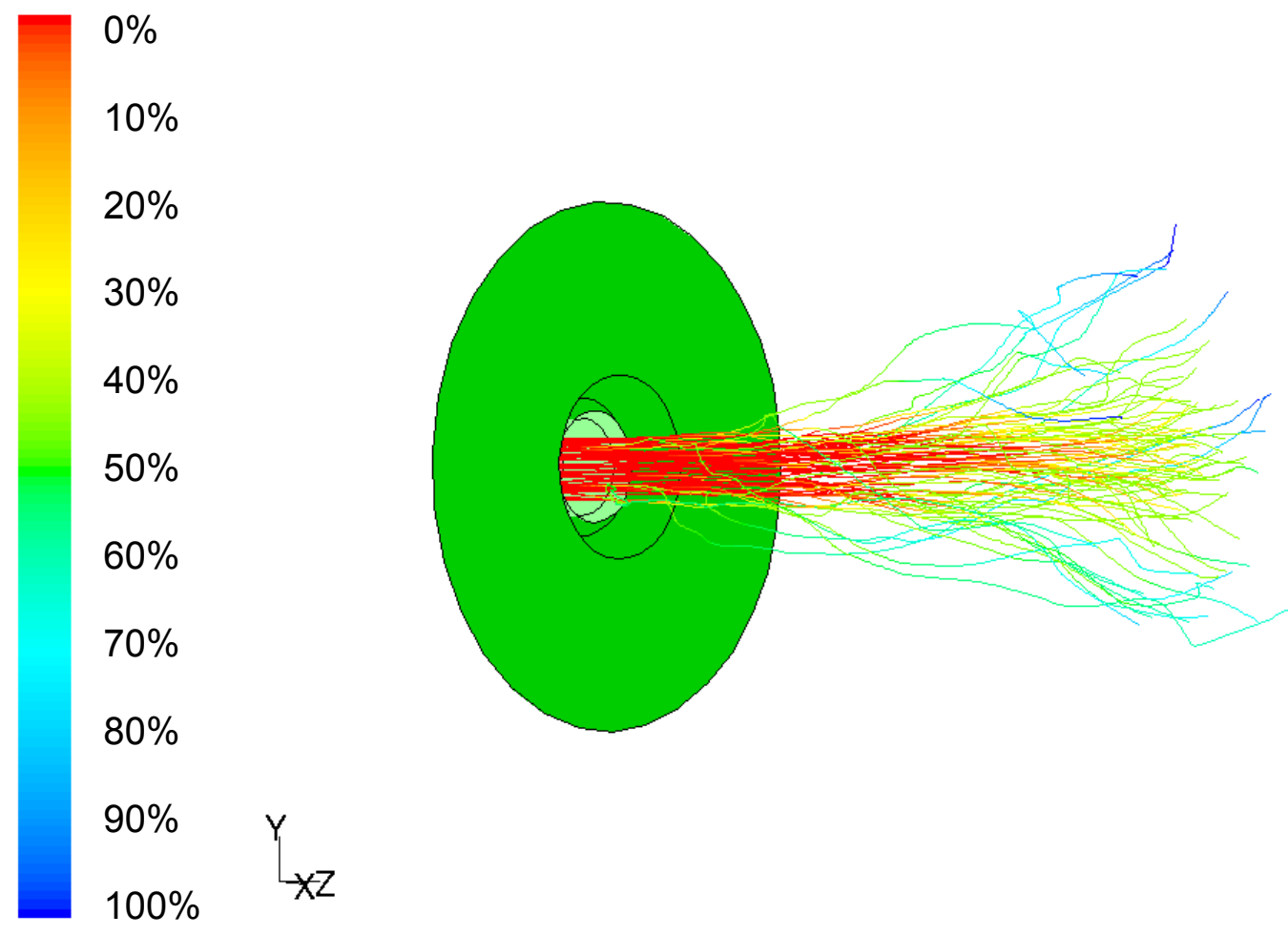

Particle Traces Colored by Particle Mass

Apr 28, 2005

FLUENT 6.2 (3d, segregated, pdf13, ske) 
Figure 4.3.8 - Burnout of 169 $\mu$ Particles for 65\% Recycle, No OFG, 0 PG Swirl
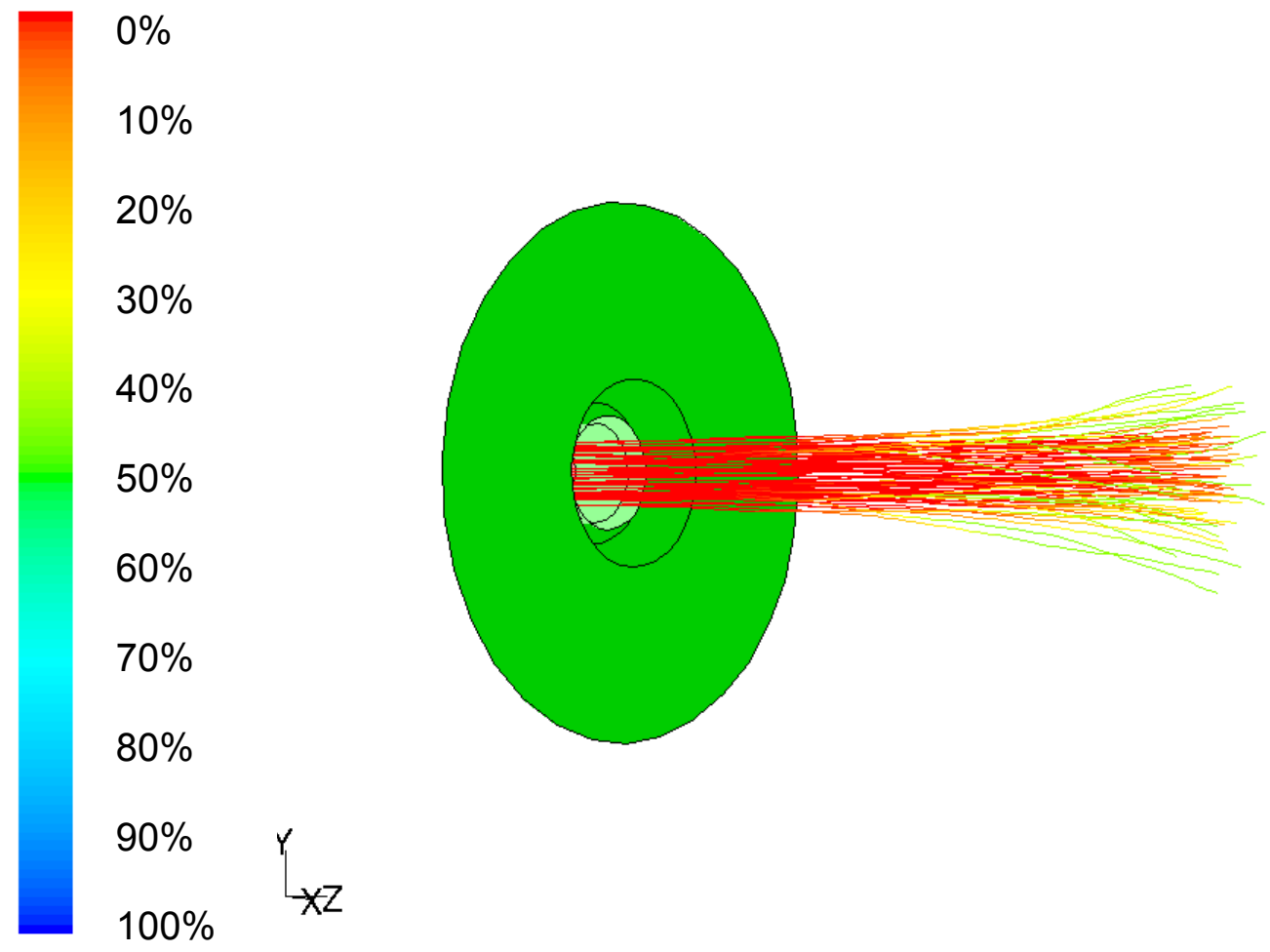

Particle Traces Colored by Particle Mass

Apr 28, 2005 FLUENT 6.2 (3d, segregated, pdf13, ske) 
Figure 4.3.9 - Gas Velocity for 65\% Recycle, No OFG, 0.5 PG Swirl
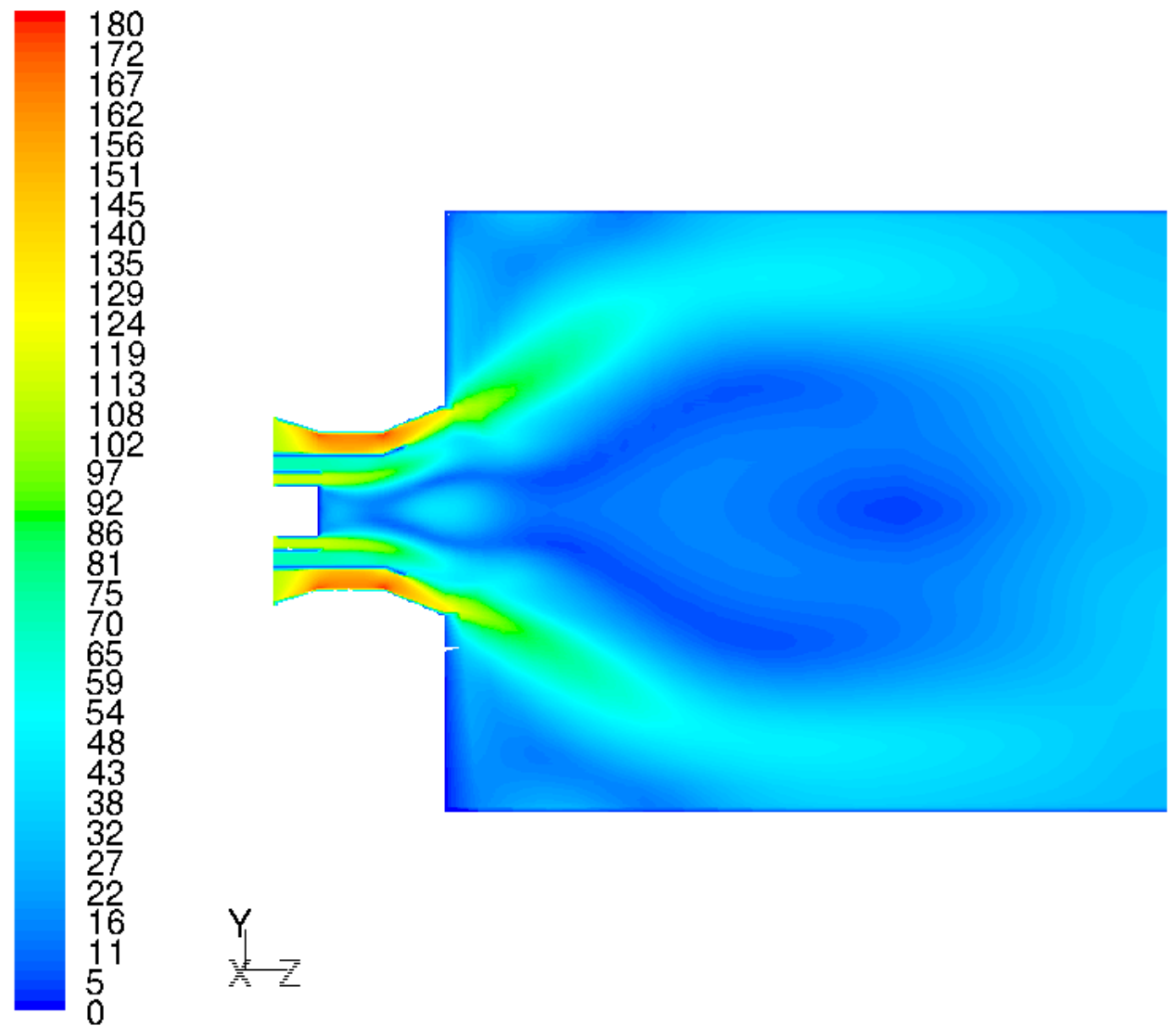

Contours of Velocity Magnitude (ft/s)

Apr 27, 2005 FLUENT 6.2 (3d, segregated, pdf13, ske) 
Figure 4.3.10 - Gas Temperature for 65\% Recycle, No OFG, 0.5 PG Swirl

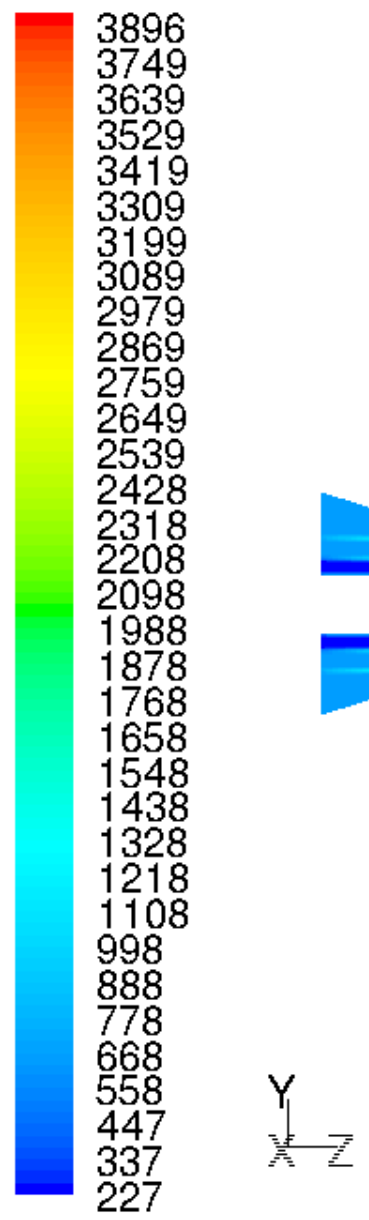

Contours of Static Temperature ( $f$ )

Apr 27, 2005 FLUENT 6.2 (3d, segregated, pdf13, ske) 
Figure 4.3.11 $-\mathrm{O}_{2}$ Mole Fraction for 65\% Recycle, No OFG, 0.5 PG Swirl
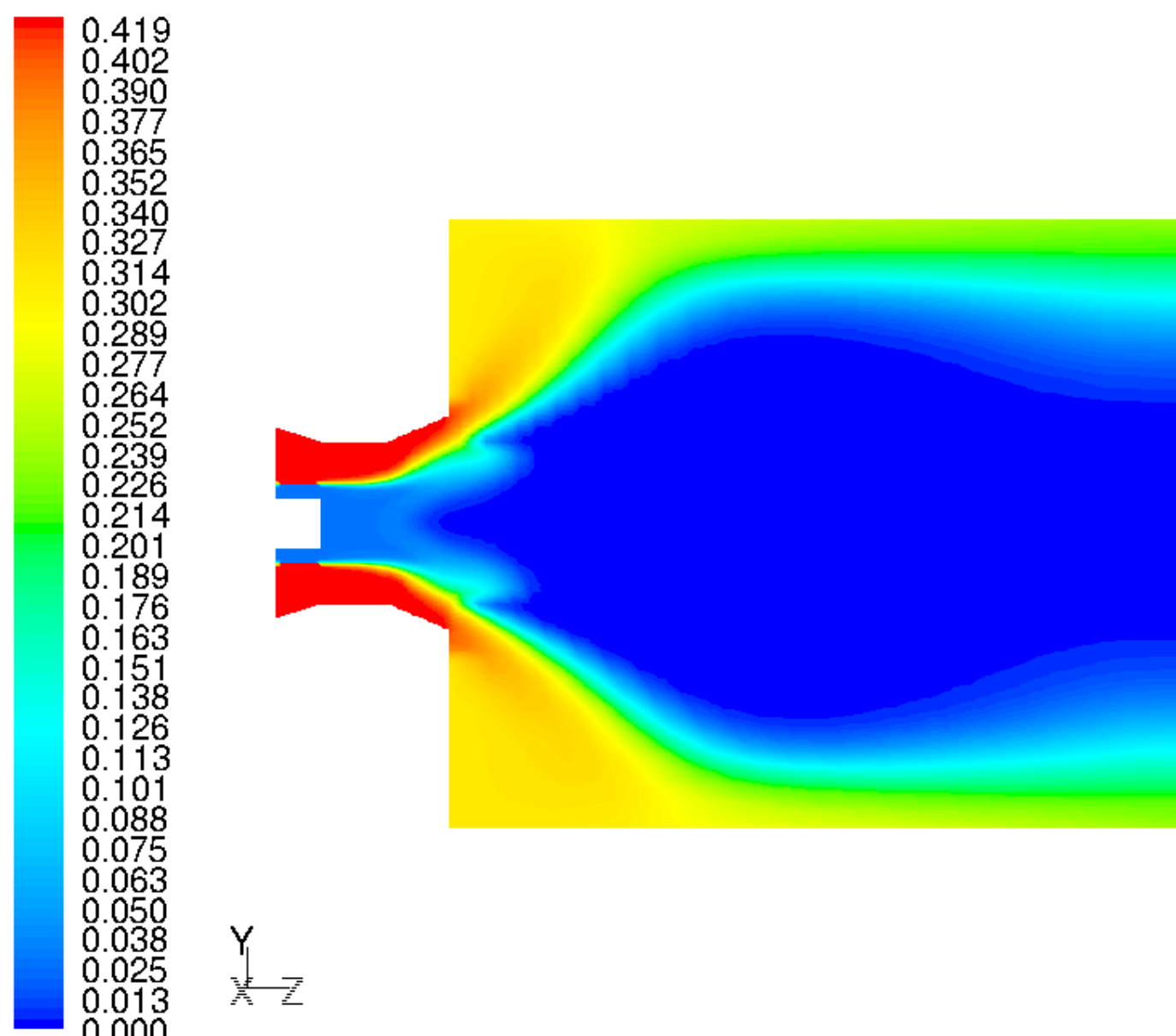

Contours of Mole fraction of 02

Apr 27, 2005 FLUENT 6.2 (3d, segregated, pdf13, ske) 
Figure 4.3.12 - Velocity Vectors Colored by Axial Velocity (ft/sec) for $65 \%$ Recycle, No OFG, 0.5 PG Swirl

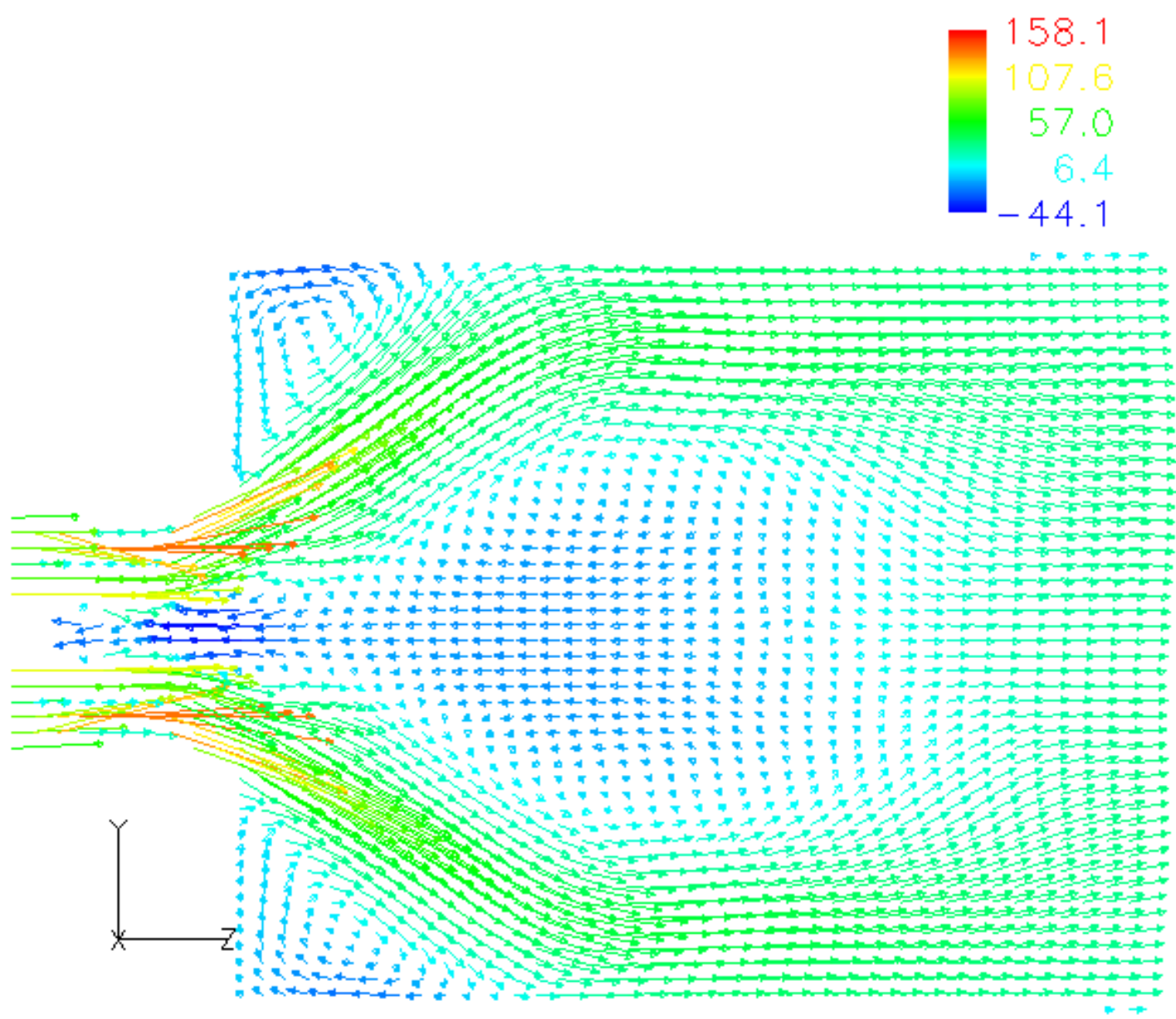


Figure 4.3.13 - Burnout of 69 $\mu$ Particles for 65\% Recycle, No OFG, 0.0 PG Swirl
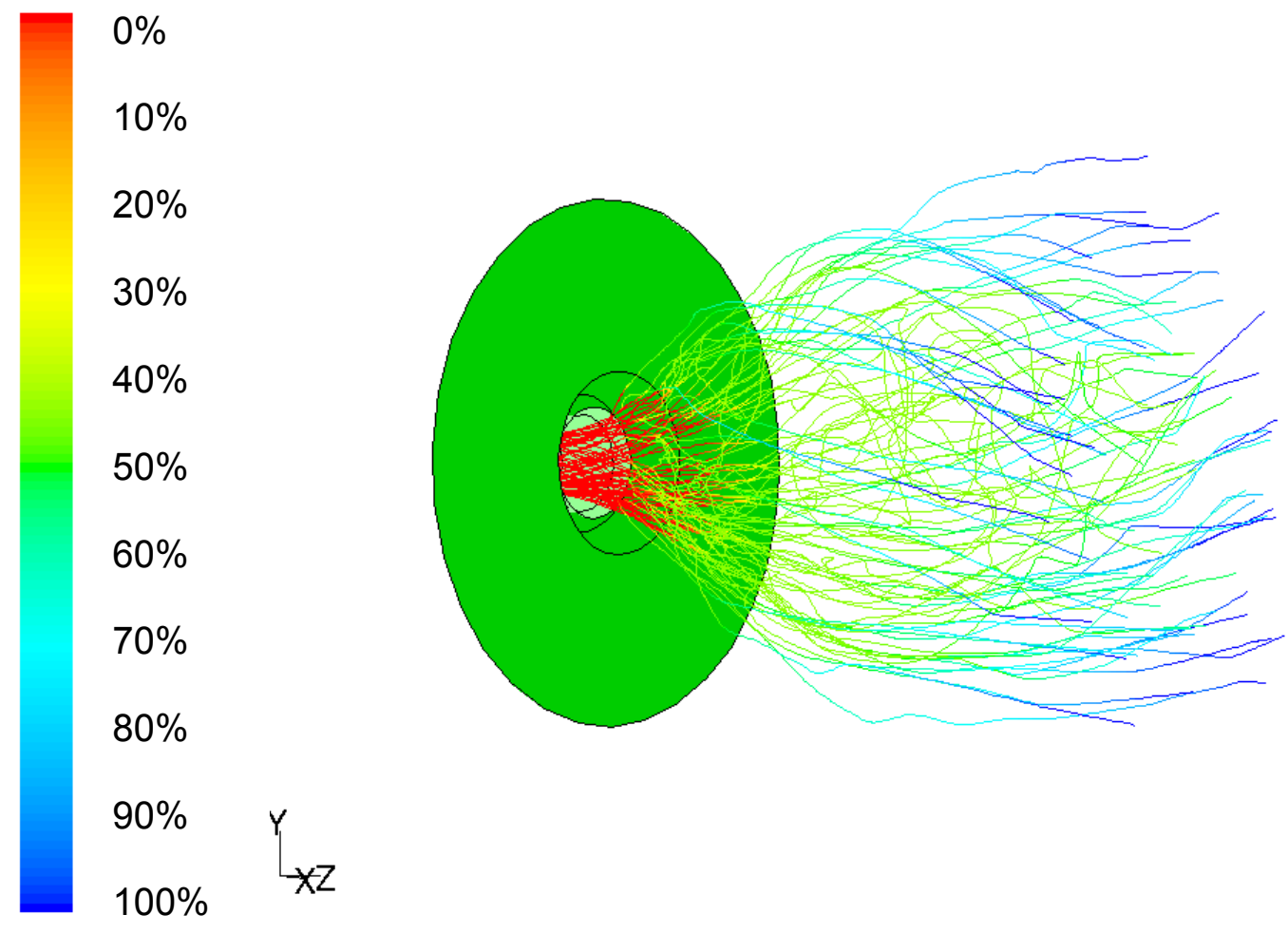

Particle Traces Colored by Particle Mass

Apr 28, 2005

FLUENT 6.2 (3d, segregated, pdf13, ske) 
Figure 4.3.14 - Burnout of $169 \mu$ Particles for 65\% Recycle, No OFG, 0 PG Swirl

\begin{tabular}{l}
$0 \%$ \\
$10 \%$ \\
$20 \%$ \\
$30 \%$ \\
$40 \%$ \\
$50 \%$ \\
$60 \%$ \\
$70 \%$ \\
$80 \%$ \\
$90 \%$ \\
$100 \% \quad Y_{X Z}$ \\
\hline
\end{tabular}

Particle Traces Colored by Particle Mass

Apr 28, 2005 FLUENT 6.2 (3d, segregated, pdf13, ske) 
Figure 4.3.15 - Gas Velocity for 65\% Recycle, 20\% OFG, 0.0 PG Swirl

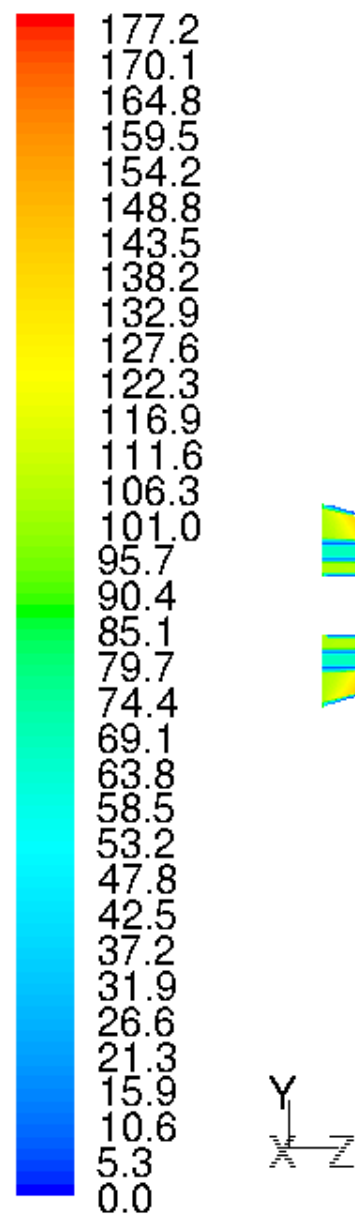

Contours of Velocity Magnitude (ft/s)

FLUENT 6.2 (3d, segregated, pdf13, ske) 
Figure 4.3.16 - Gas Temperature for 65\% Recycle, 20\% OFG, 0.0 PG Swirl

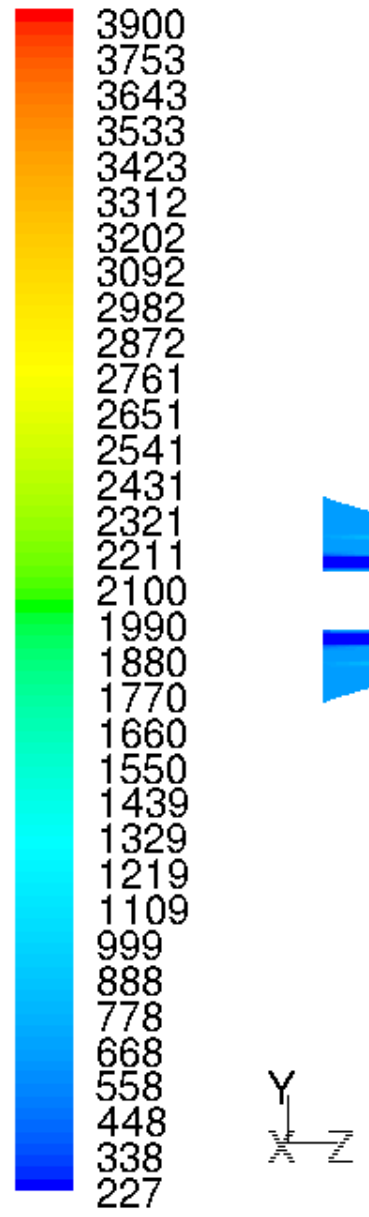

Contours of Static Temperature $(f)$

May 10, 2005 FLUENT 6.2 (3d, segregated, pdf13, ske) 
Figure 4.3.17 - 02 Mole Fraction for 65\% Recycle, 20\% OFG, 0.0PG Swirl

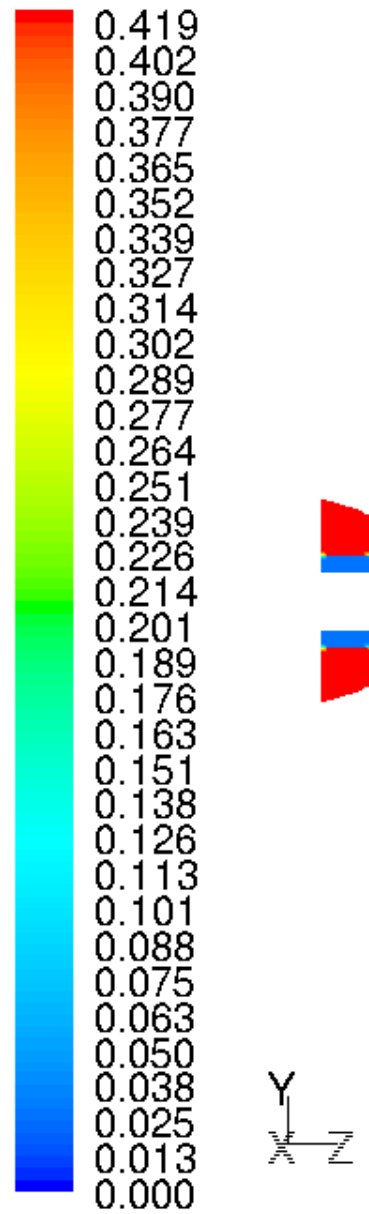

Contours of Mole fraction of 02

Apr 28, 2005 FLUENT 6.2 (3d, segregated, pdf13, ske) 
Figure 4.3.18 - Burnout of 69 $\mu$ Particles for 65\% Recycle, 20\% OFG, 0 PG Swirl
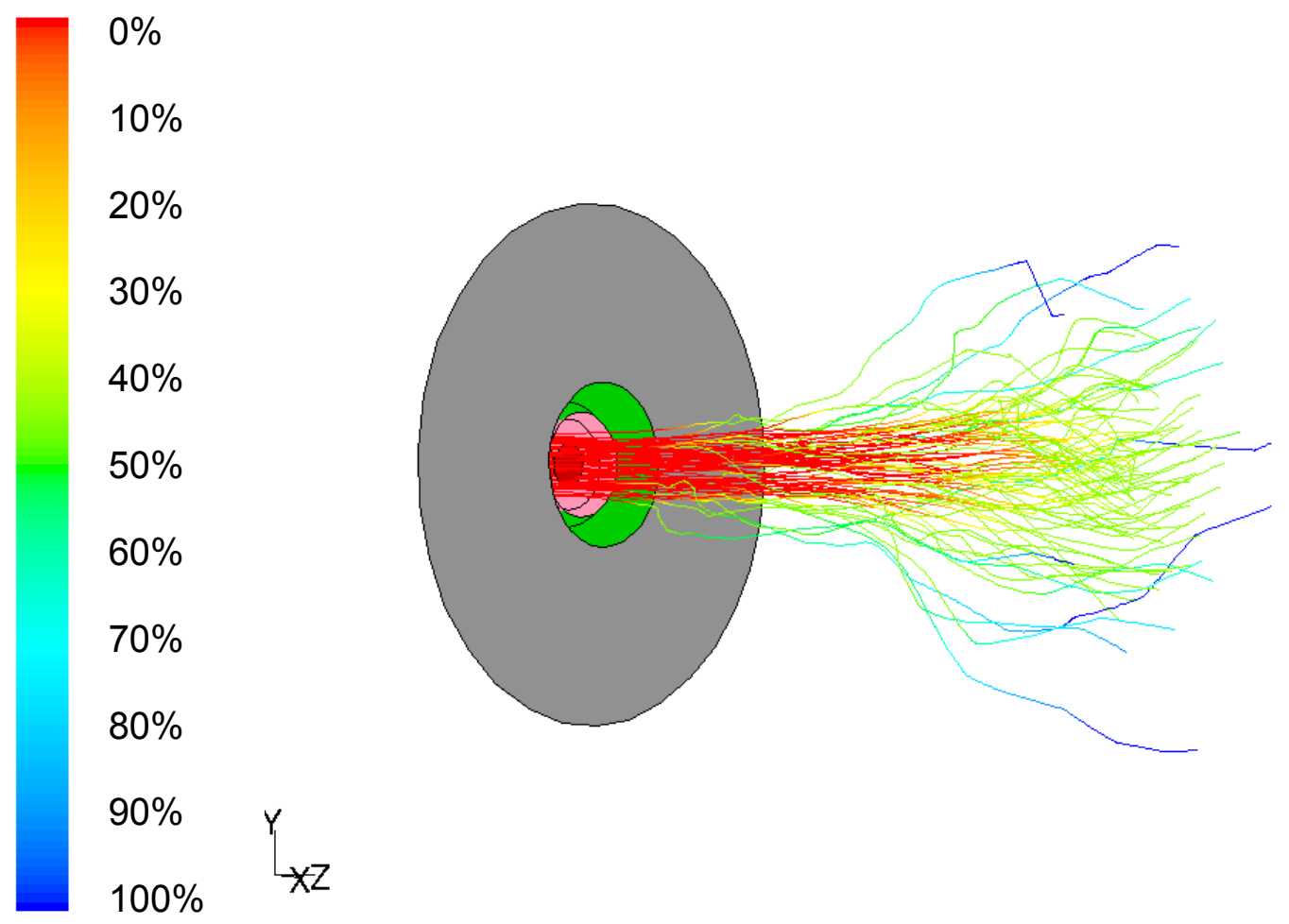

Particle Traces Colored by Particle Mass

Apr 28, 2005

FLUENT 6.2 (3d, segregated, pdf13, ske) 
Figure 4.3.19 - Burnout of 169 $\mu$ Particles for 65\% Recycle, 20\% OFG, 0 PG Swirl
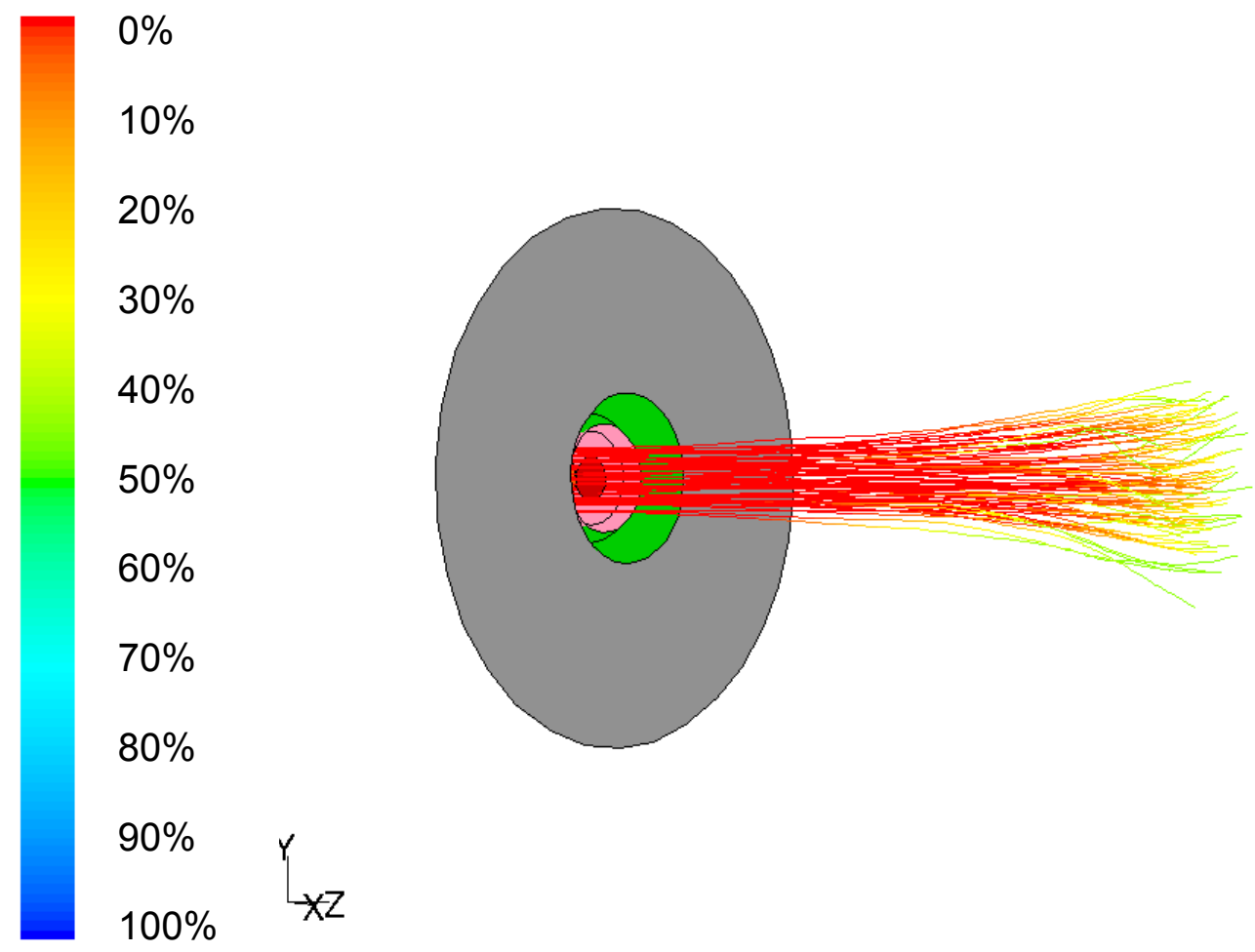

Particle Traces Colored by Particle Mass

Apr 28, 2005 FLUENT 6.2 (3d, segregated, pdf13, ske) 
Figure 4.3.20 - Gas Velocity for 65\% Recycle, 20\% OFG, 0.5 PG Swirl

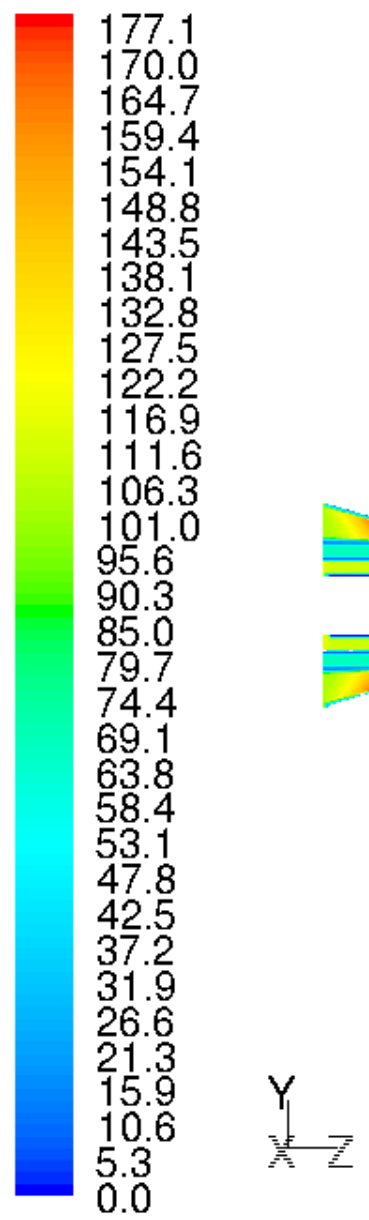

Contours of Velocity Magnitude (ft/s) FLUENT 6.2 (3d, segregated, pdf13, ske) 
Figure 4.3.21 - Gas Temperature for 65\% Recycle, 20\% OFG, 0.5 PG Swirl

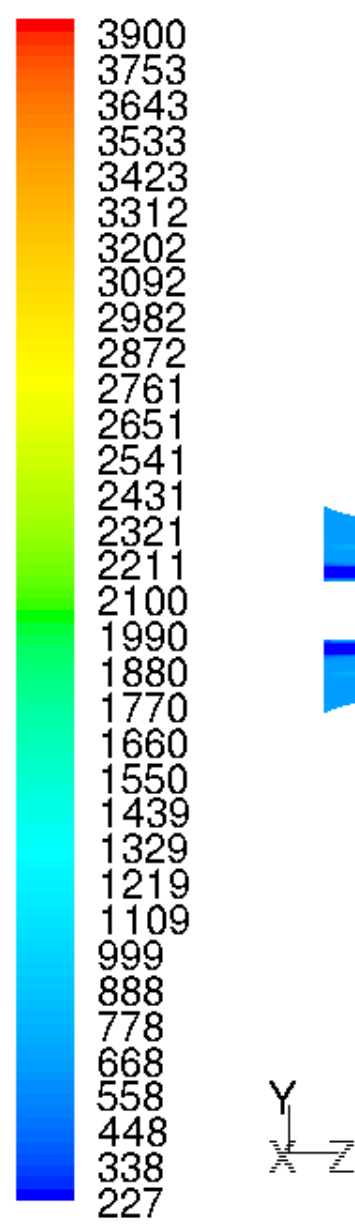

Contours of Static Temperature $(f)$

May 10,2005 FLUENT 6.2 (3d, segregated, pdf13, ske) 
Figure 4.3.22 - 02 Mole Fraction for 65\% Recycle, 20\% OFG, 0.5 PG Swirl
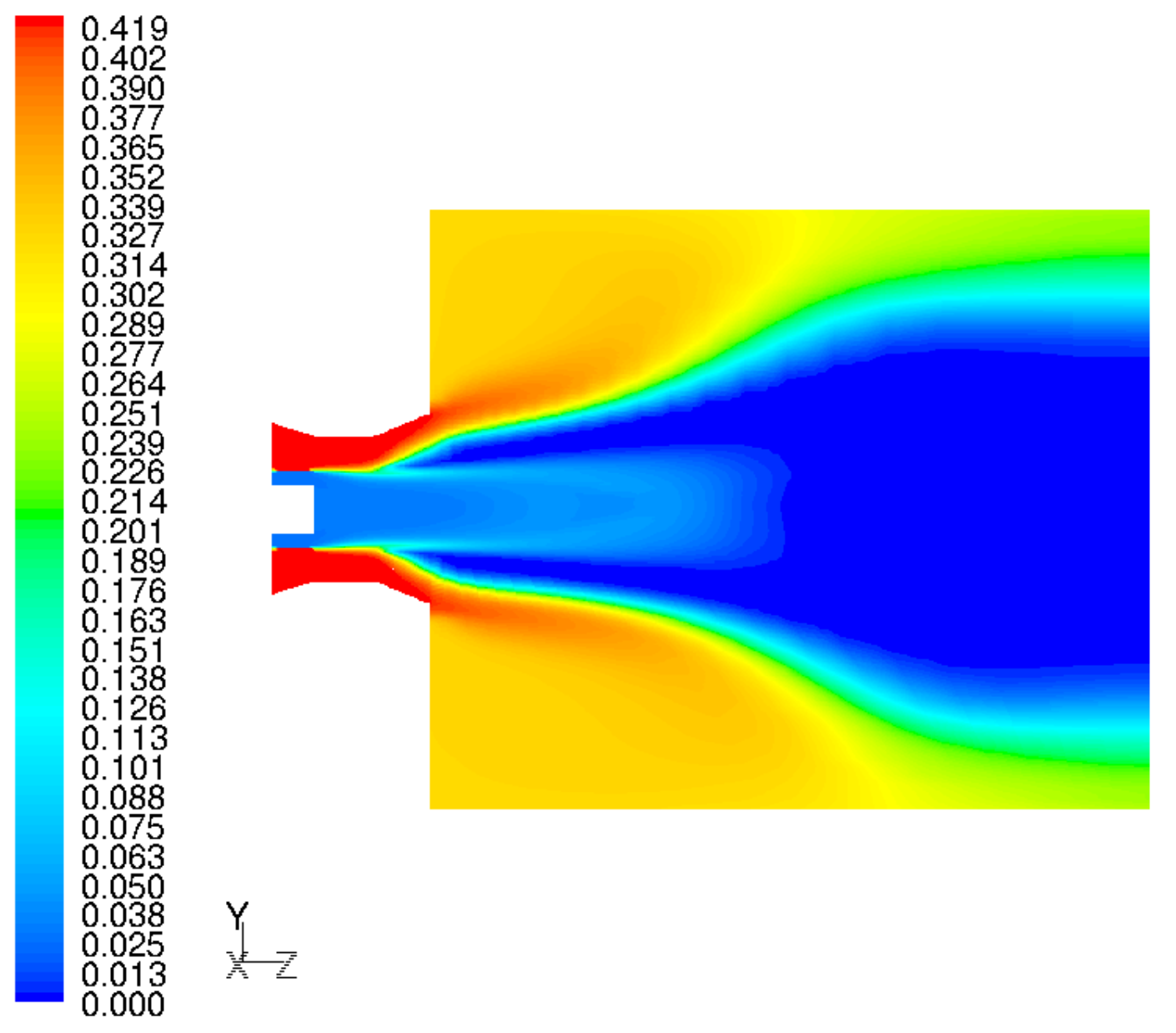

Contours of Mole fraction of 02

Apr 28, 2005 FLUENT 6.2 (3d, segregated, pdf13, ske) 
Figure 4.3.23 - Burnout of 69 $\mu$ Particles for 65\% Recycle, 20\% OFG, 0.5 PG Swirl

$0 \%$
$10 \%$
$20 \%$
$30 \%$
$40 \%$
$50 \%$
$60 \%$
$70 \%$
$80 \%$
$90 \% \quad Y_{X Z}$
$100 \% \quad$

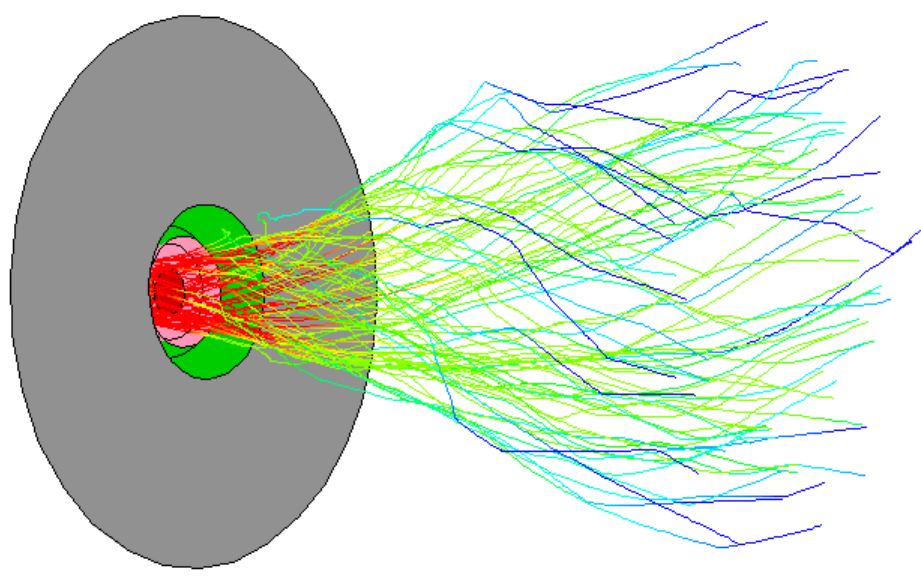

Particle Traces Colored by Particle Mass (lbm)

Apr 28, 2005

FLUENT 6.2 (3d, segregated, pdf13, ske) 
Figure 4.3.24 - Burnout of 169 $\mu$ Particles for 65\% Recycle, 20\% OFG, 0.5 PG Swirl

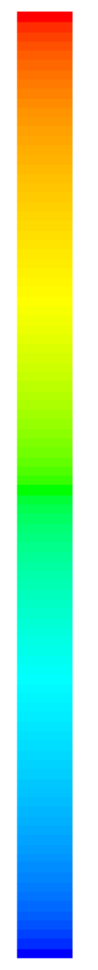

$0 \%$

$10 \%$

$20 \%$

$30 \%$

$40 \%$

$50 \%$

$60 \%$

$70 \%$

$80 \%$

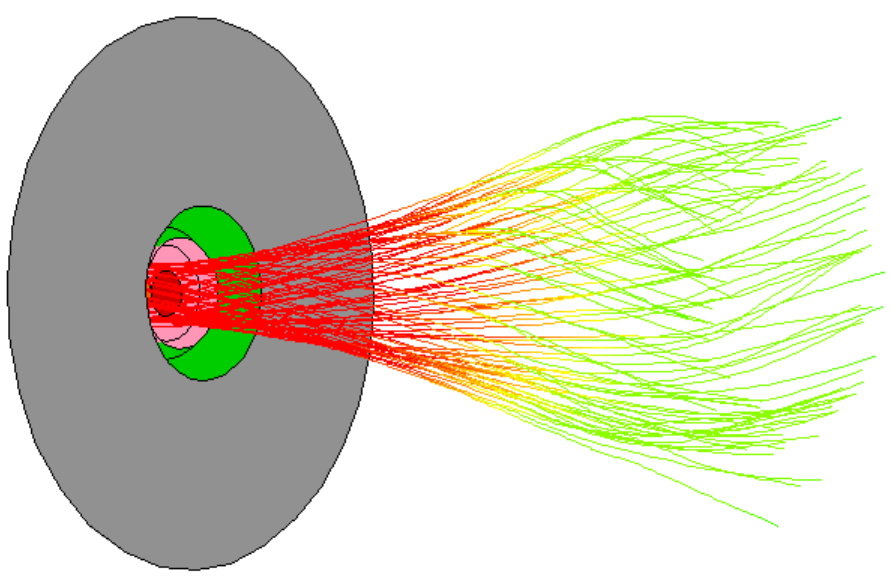

$90 \%$

$100 \%$

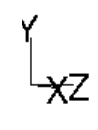

Apr 28, 2005

Particle Traces Colored by Particle Mass

FLUENT 6.2 (3d, segregated, pdf13, ske) 
Figure 4.3.25 - Gas Velocity for 56\% Recycle, 0\% OFG, 0.0 PG Swirl

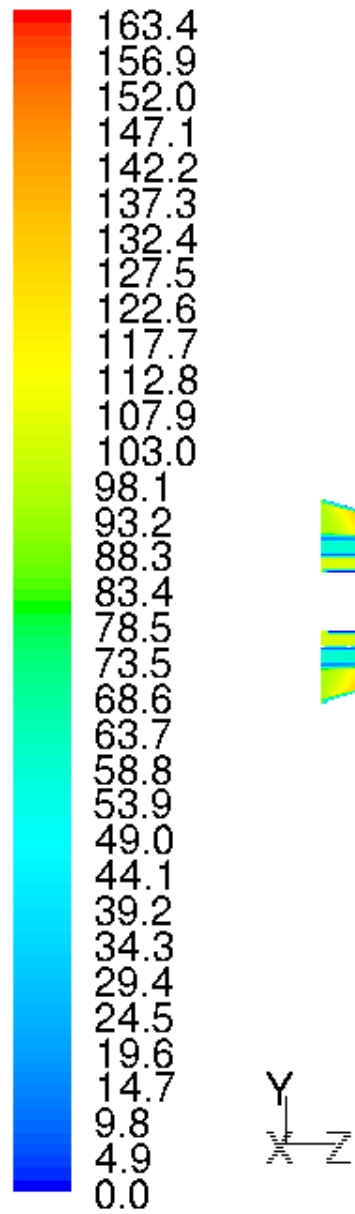

Contours of Velocity Magnitude (ft/s)

Apr 28, 2005 FLUENT 6.2 (3d, segregated, pdf13, ske) 
Figure 4.3.26 - Gas Temperature for 56\% Recycle, 0\% OFG, 0.0 PG Swirl

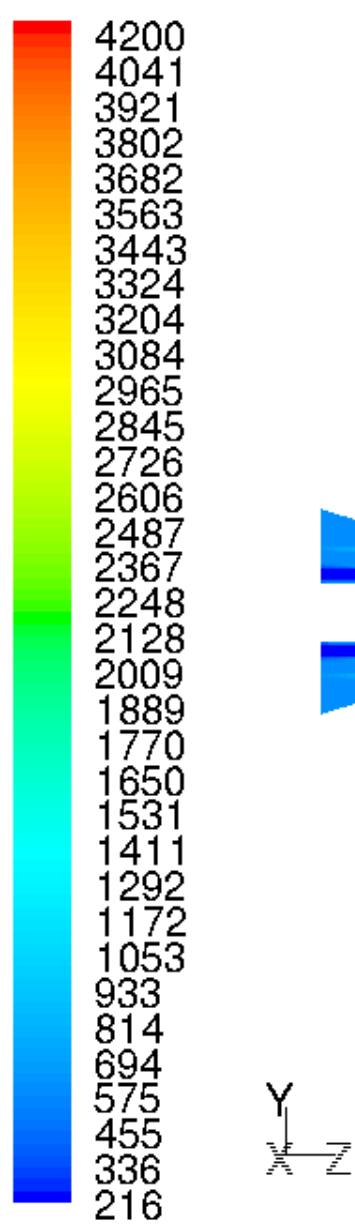

Contours of Static Temperature $(f)$

May 10, 2005 FLUENT 6.2 (3d, segregated, pdf13, ske) 
Figure 4.3.27 - 02 Mole Fraction for 56\% Recycle, 0\% OFG, 0.0 PG Swirl

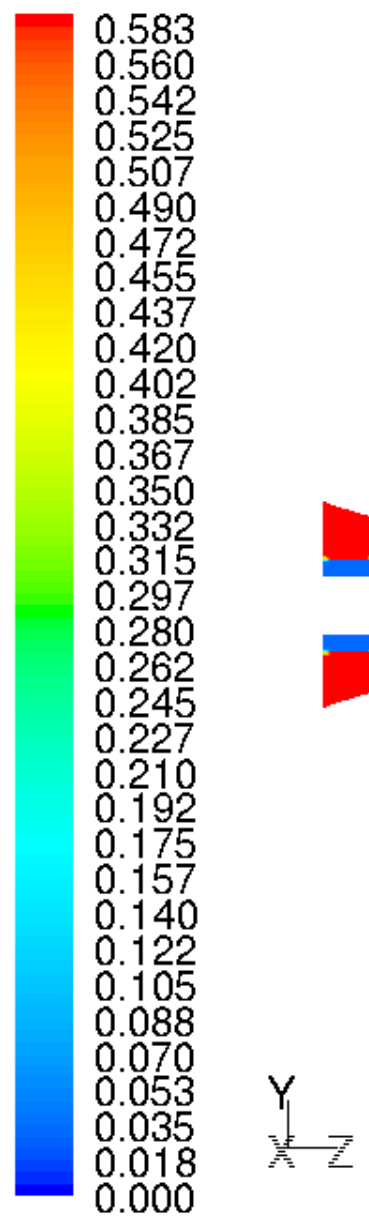

Contours of Mole fraction of 02

Apr 28, 2005 FLUENT 6.2 (3d, segregated, pdf13, ske) 


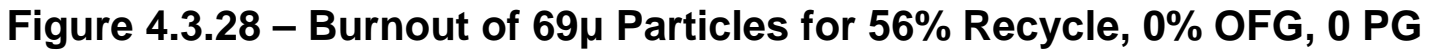
Swirl

$0 \%$
$10 \%$
$20 \%$
$30 \%$
$40 \%$
$50 \%$
$60 \%$
$70 \%$
$80 \%$
$90 \%$
$100 \%$

Particle Traces Colored by Particle Mass

Apr 28, 2005 FLUENT 6.2 (3d, segregated, pdf13, ske) 
Figure 4.3.29 - Burnout of 169 $\mu$ Particles for 56\% Recycle, 0\% OFG, 0 PG Swirl

\begin{tabular}{l}
$0 \%$ \\
$10 \%$ \\
$20 \%$ \\
$30 \%$ \\
$40 \%$ \\
$50 \%$ \\
$60 \%$ \\
$70 \%$ \\
$80 \%$ \\
$90 \%$ \\
$100 \%$ \\
\hline$\ngtr$
\end{tabular}

Particle Traces Colored by Particle Mass

Apr 28, 2005 FLUENT 6.2 (3d, segregated, pdf13, ske) 
Figure 4.3.30 - Gas Velocity for 56\% Recycle, 0\% OFG, 0.5 PG Swirl

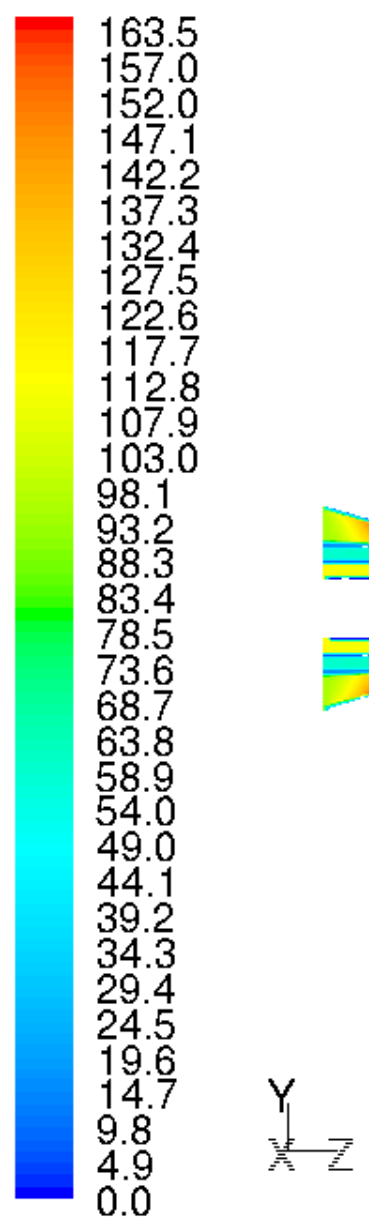

Contours of Velocity Magnitude (ft/s)

FLUENT 6.2 (3d, segregated, pdf13, ske) 
Figure 4.3.31 - Gas Temperature for 56\% Recycle, 0\% OFG, 0.5 PG Swirl

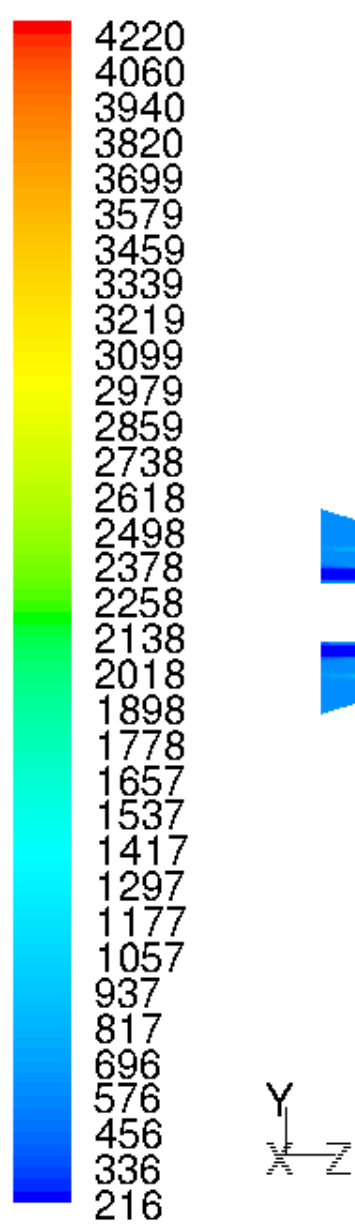

Contours of Static Temperature $(f)$

Apr 28, 2005 FLUENT 6.2 (3d, segregated, pdf13, ske) 
Figure 4.3.32 - 02 Mole Fraction for 56\% Recycle, 0\% OFG, 0.5 PG Swirl
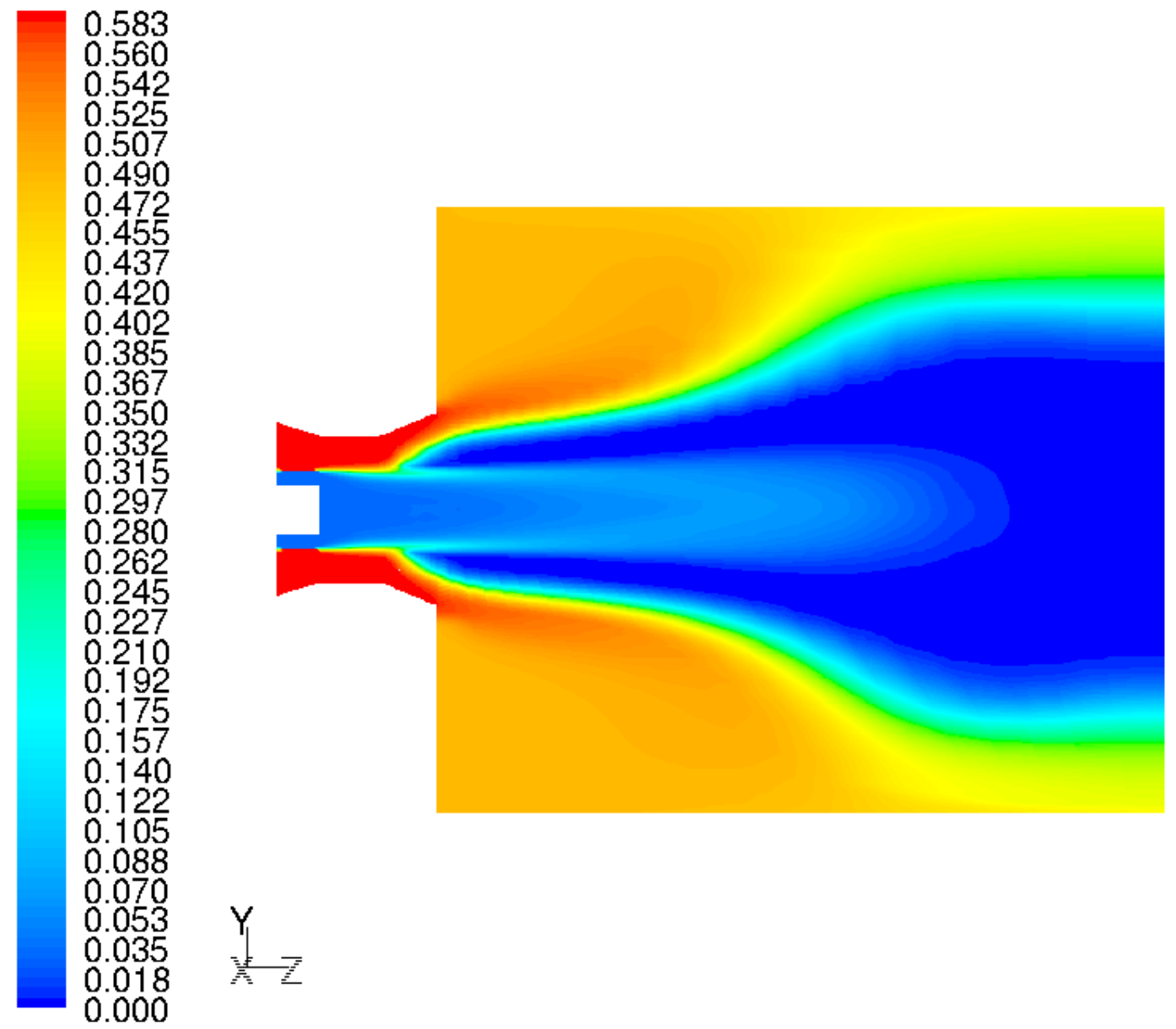

Contours of Mole fraction of 02

Apr 28, 2005 FLUENT 6.2 (3d, segregated, pdf13, ske) 
Figure 4.3.33 - Burnout of 69 $\mu$ Particles for 56\% Recycle, 0\% OFG, 0.5 PG Swirl

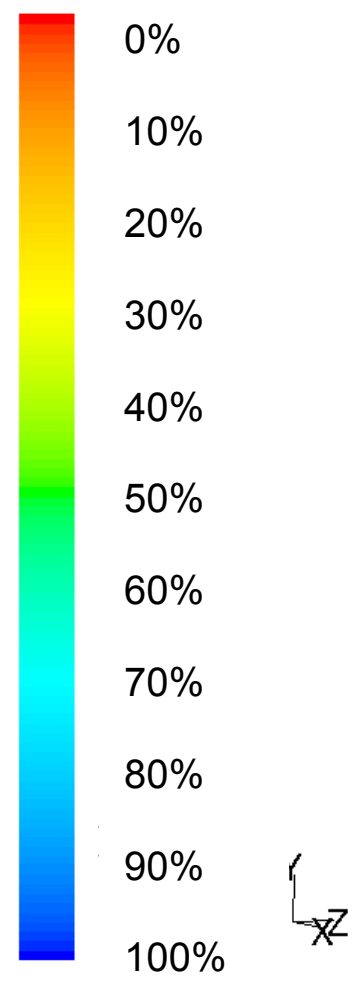

Particle Traces Colored by Particle Mass

Apr 28, 2005

FLUENT 6.2 (3d, segregated, pdf13, ske) 
Figure 4.3.34 - Burnout of $169 \mu$ Particles for 56\% Recycle, 0\% OFG, 0.5 PG Swirl

\begin{tabular}{l}
$0 \%$ \\
$10 \%$ \\
$20 \%$ \\
$30 \%$ \\
$40 \%$ \\
$50 \%$ \\
$60 \%$ \\
$70 \%$ \\
$80 \%$ \\
$90 \%$ \\
$100 \% \quad Y_{X Z}$ \\
\hline
\end{tabular}

Particle Traces Colored by Particle Mass

Apr 28, 2005 FLUENT 6.2 (3d, segregated, pdf13, ske) 
Figure 4.3.35 - Gas Velocity for 56\% Recycle, 20\% OFG, 0. PG Swirl

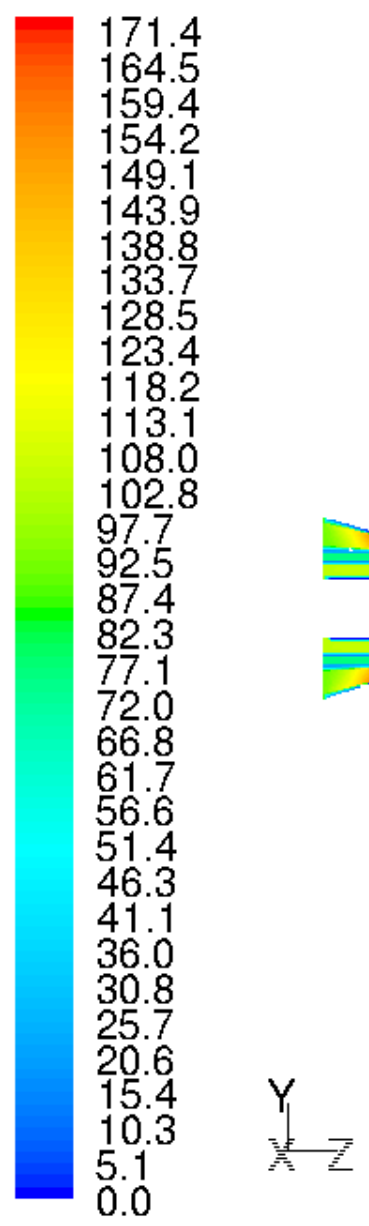

Contours of Velocity Magnitude (ft/s) FLUENT 6.2 (3d, segregated, pdf13, ske) 
Figure 4.3.36 - Gas Temperature for 56\% Recycle, 20\% OFG, 0. PG Swirl

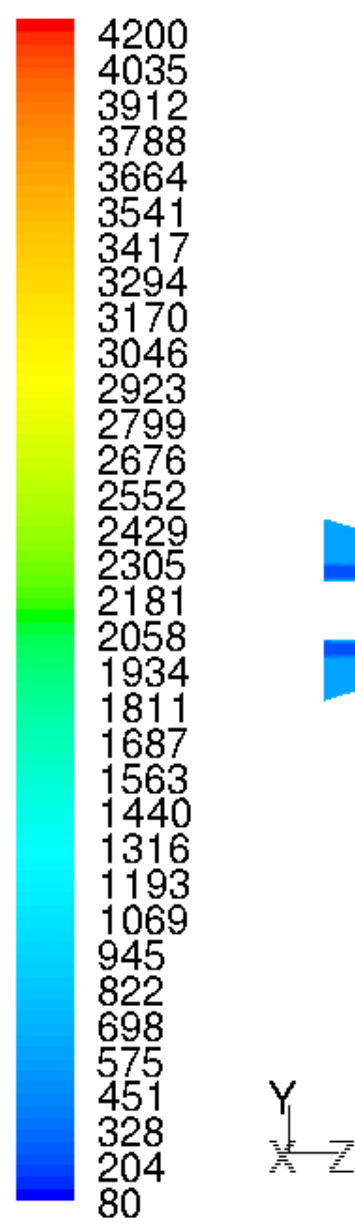

Contours of Static Temperature $(f)$

May 10, 2005 FLUENT 6.2 (3d, segregated, pdf13, ske) 
Figure 4.3.37 - 02 Mole Fraction for 56\% Recycle, 20\% OFG, 0. PG Swirl
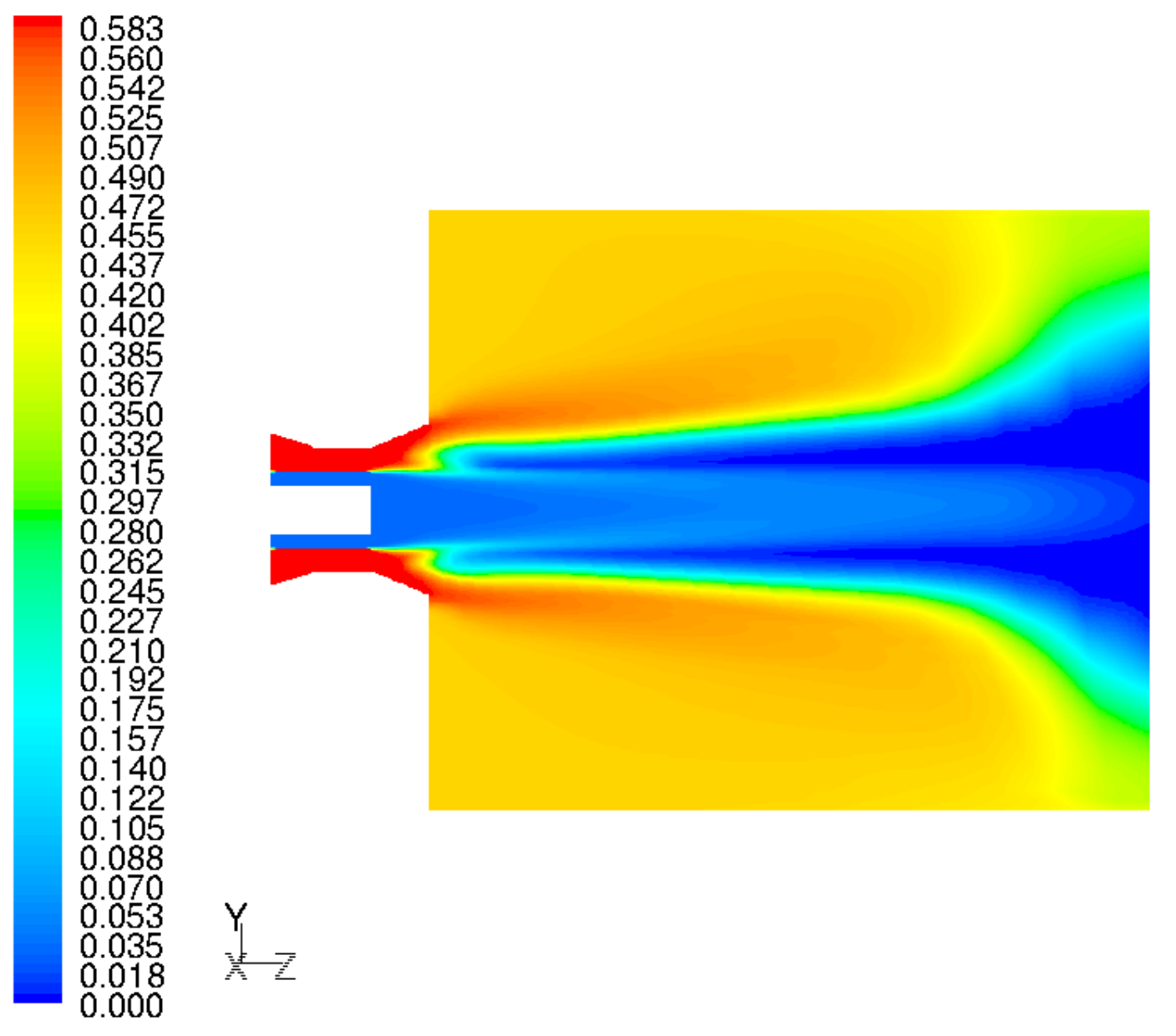

Contours of Mole fraction of o2

May 10, 2005 FLUENT 6.2 (3d, segregated, pdf13, ske) 
Figure 4.3.38 - Burnout of $69 \mu$ Particles for 56\% Recycle, 20\% OFG, 0. PG Swirl
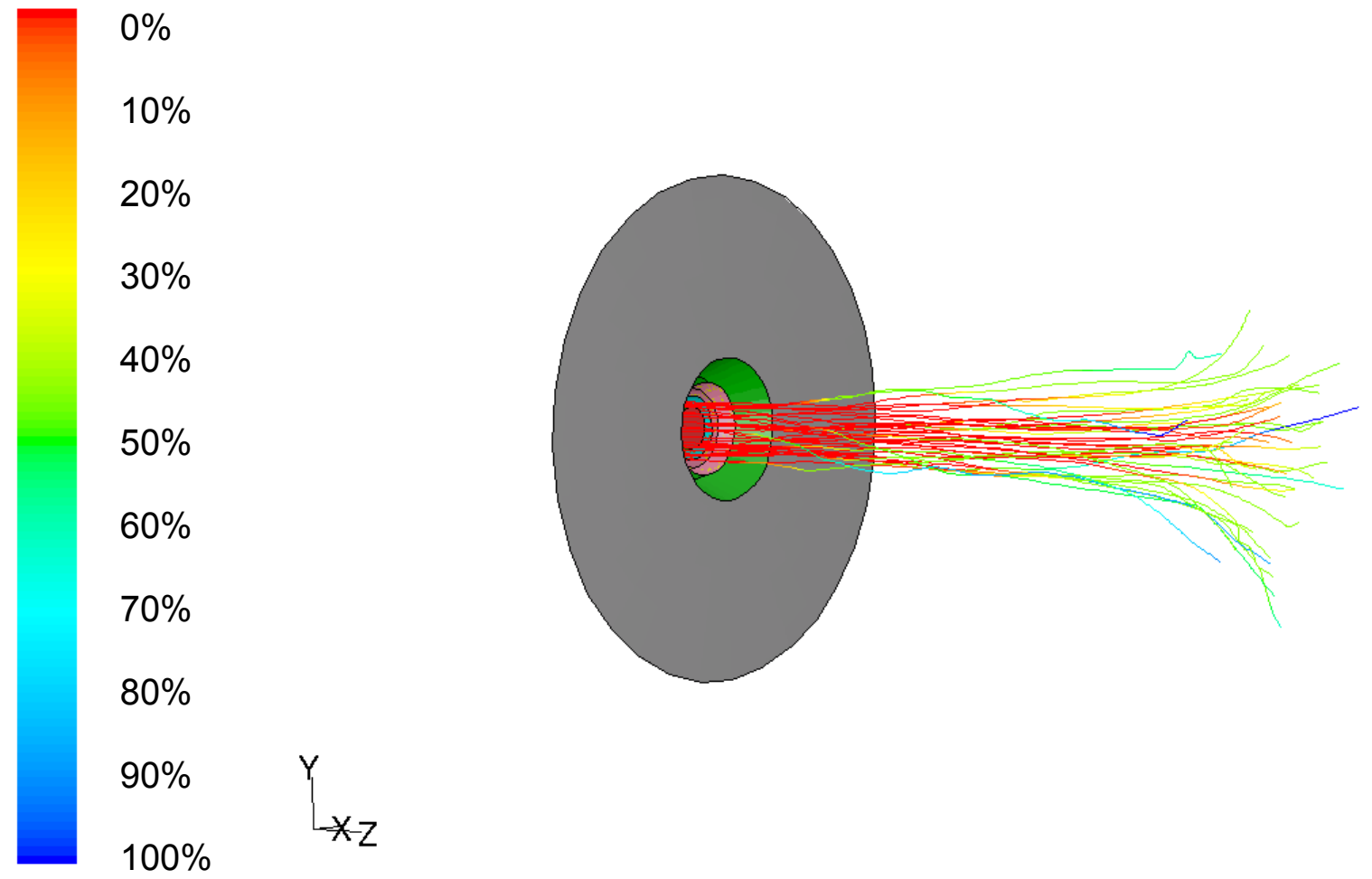
Figure 4.3.39 - Burnout of $169 \mu$ Particles for $56 \%$ Recycle, 20\% OFG, 0. PG Swirl

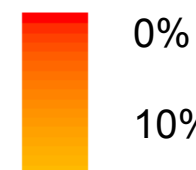

$20 \%$
$30 \%$
$40 \%$
$50 \%$
$60 \%$
$70 \%$
$80 \%$
$90 \%$
$100 \% \quad L_{X Z}$

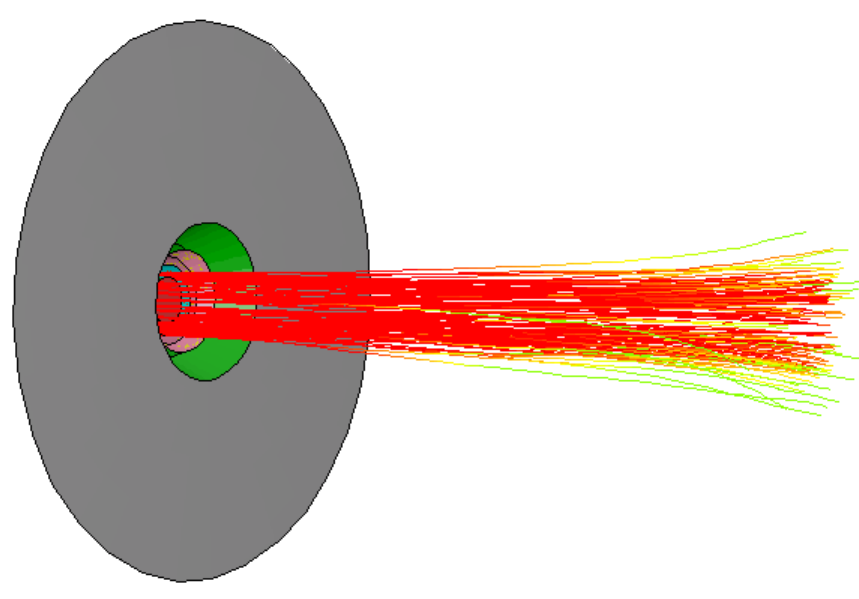


Figure 4.3.40 - Gas Velocity for 56\% Recycle, 20\% OFG, 0.5 PG Swirl

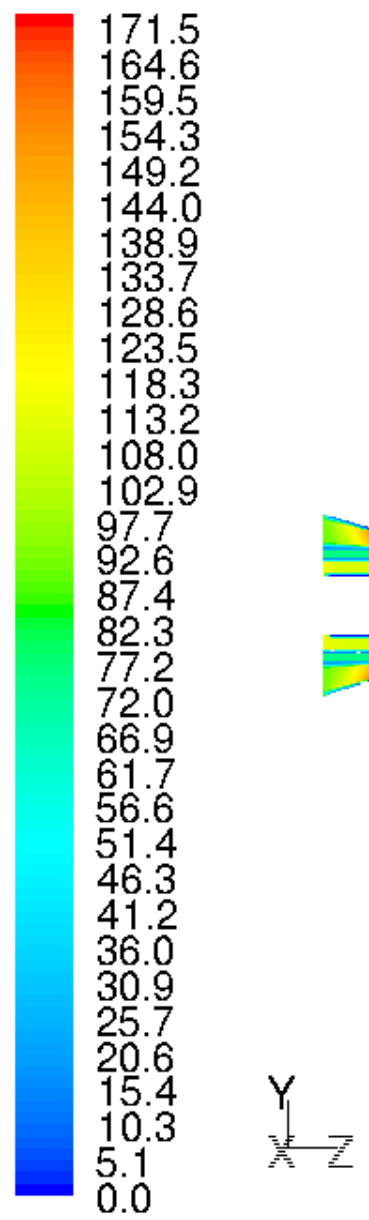

Contours of Velocity Magnitude (ft/s)

May 05, 2005 FLUENT 6.2 (3d, segregated, pdf13, ske) 
Figure 4.3.41 - Gas Temperature for 56\% Recycle, 20\% OFG, 0.5 PG Swirl
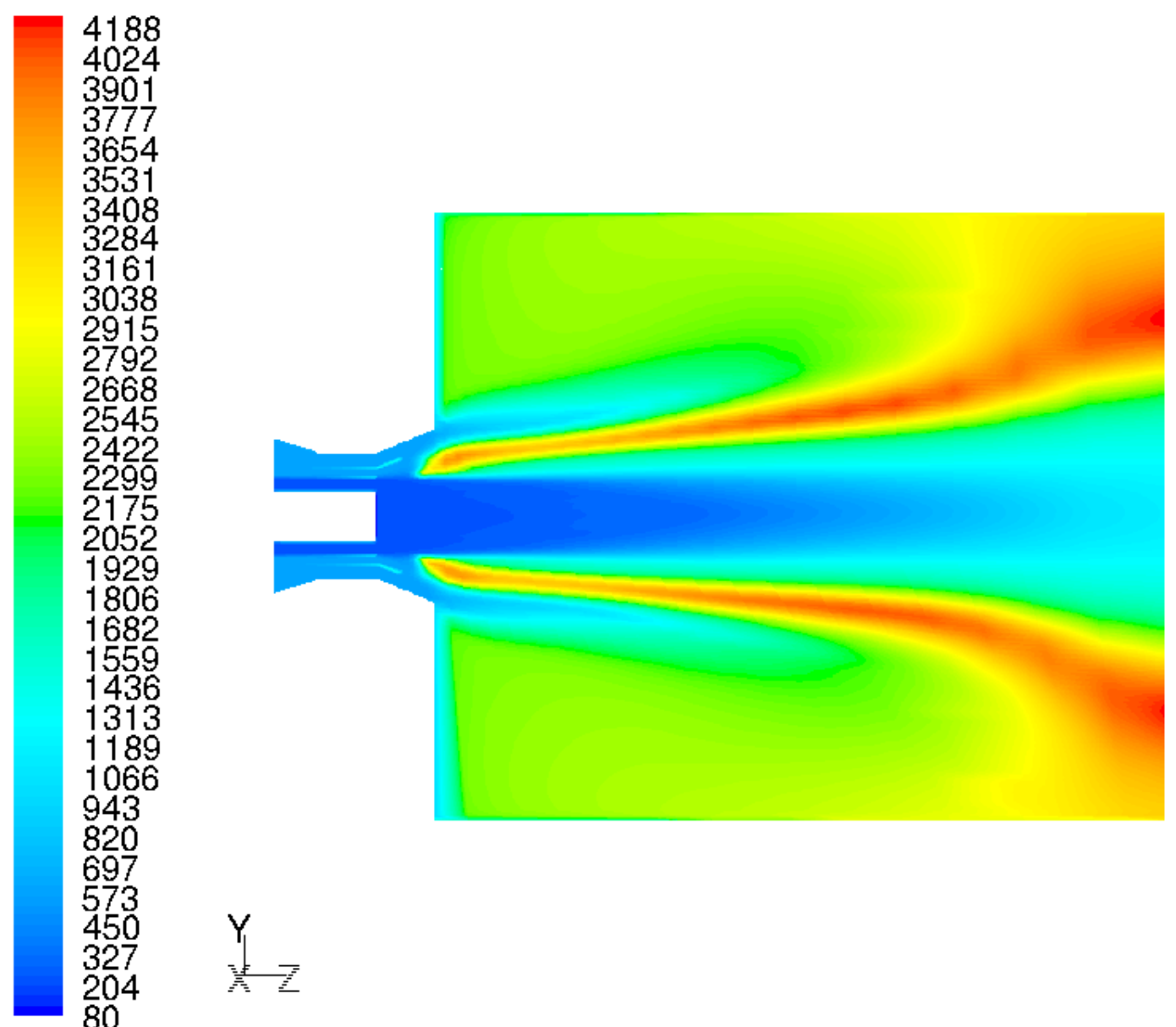

820

697

573

327

80

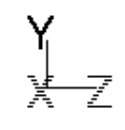

Contours of Static Temperature (f)

May 06, 2005 FLUENT 6.2 (3d, segregated, pdf13, ske) 
Figure 4.3.42 - 02 Mole Fraction for 56\% Recycle, 20\% OFG, 0.5 PG Swirl
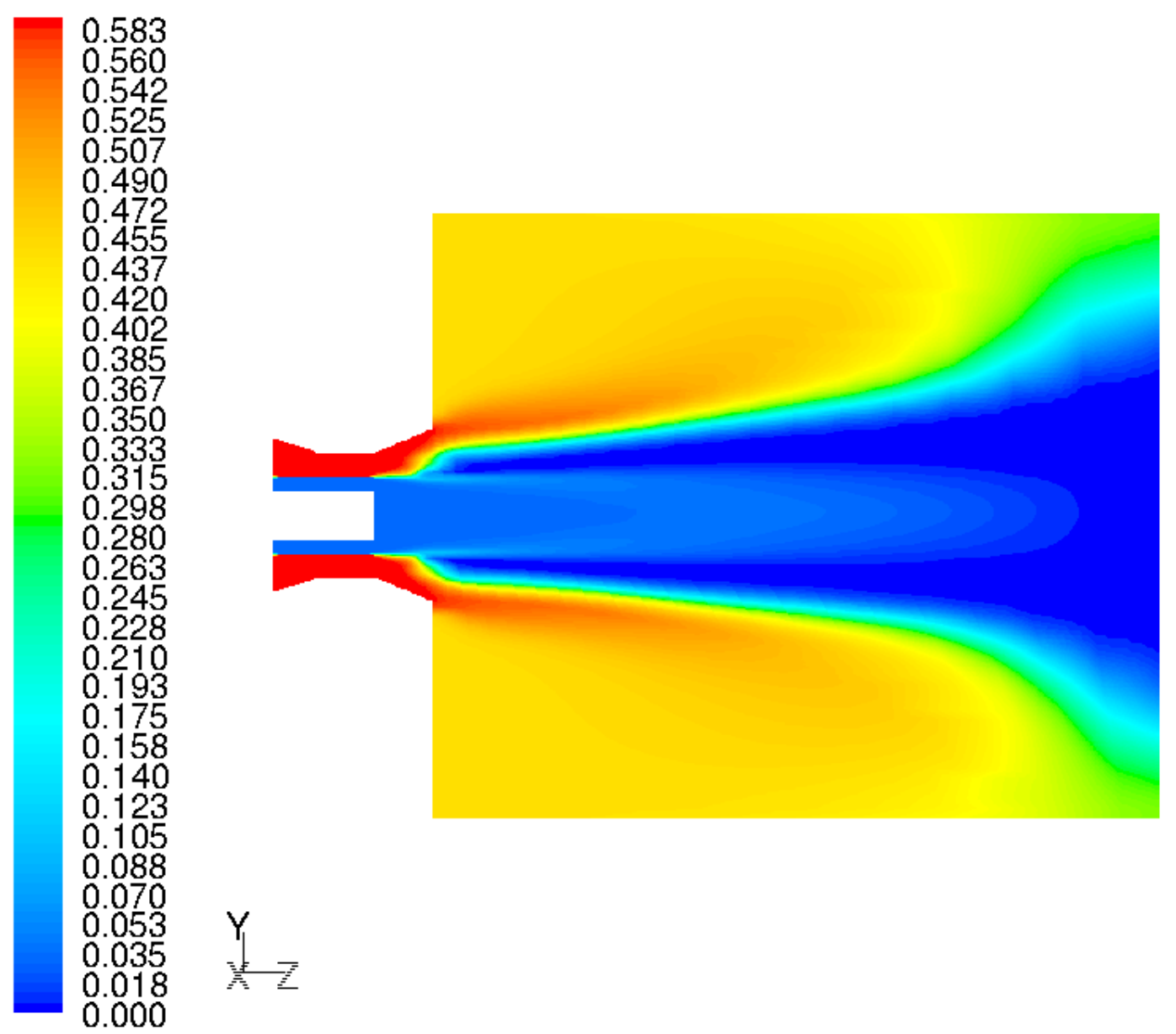

Contours of Mole fraction of o2

May 05, 2005 FLUENT 6.2 (3d, segregated, pdf13, ske) 
Figure 4.3.43 - Burnout of 69 $\mu$ Particles for 56\% Recycle, 20\% OFG, 0.5 PG Swirl

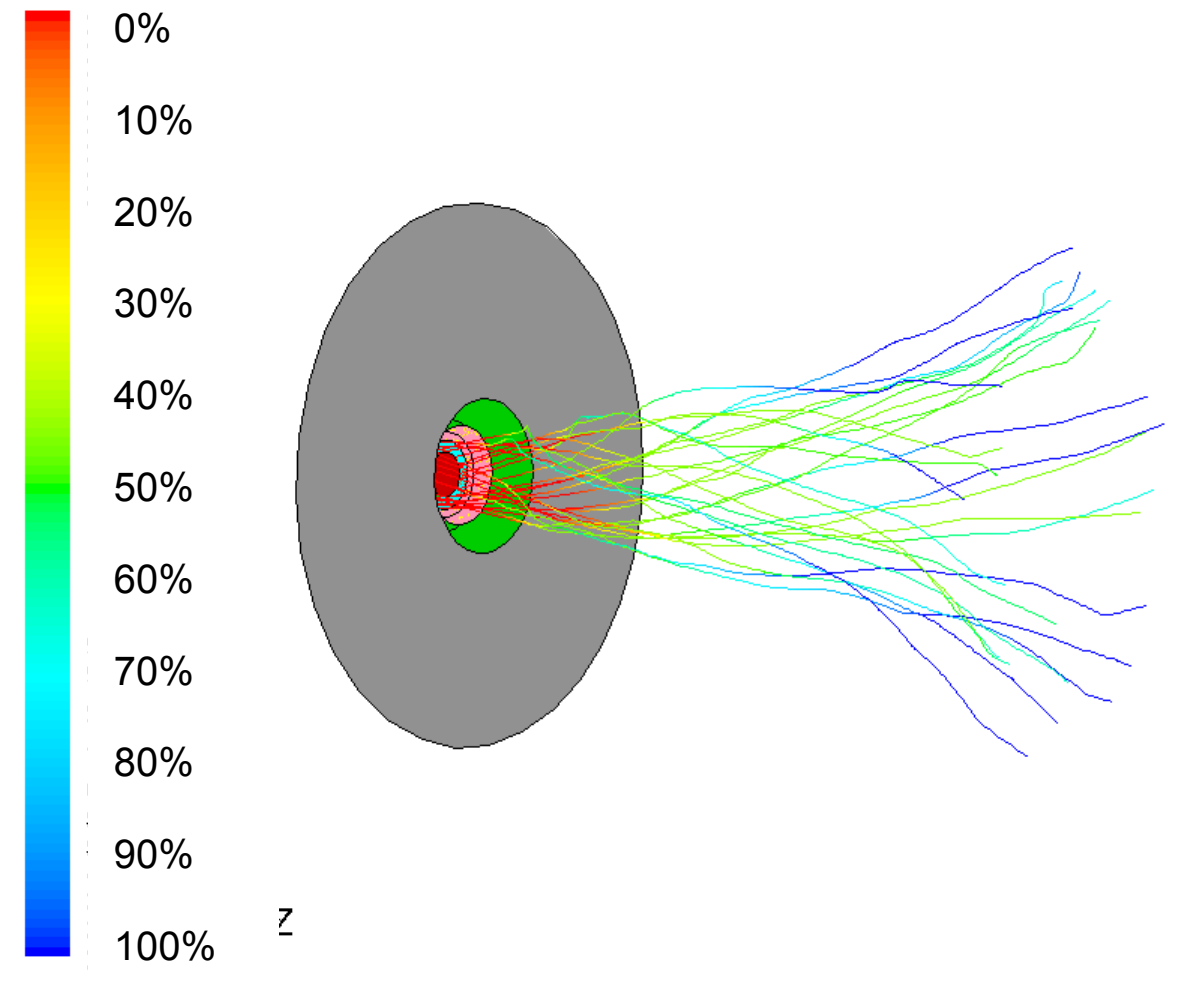

Particle Traces Colored by Particle Mass

May 05, 2005

FLUENT 6.2 (3d, segregated, pdf13, ske) 
Figure 4.3.44 - Burnout of 169 $\mu$ Particles for 56\% Recycle, 20\% OFG, 0.5 PG Swirl

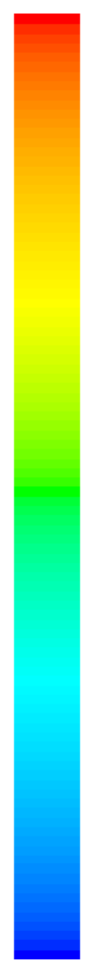

$0 \%$

$10 \%$

$20 \%$

$30 \%$

$40 \%$

$50 \%$

$60 \%$

$70 \%$

$80 \%$

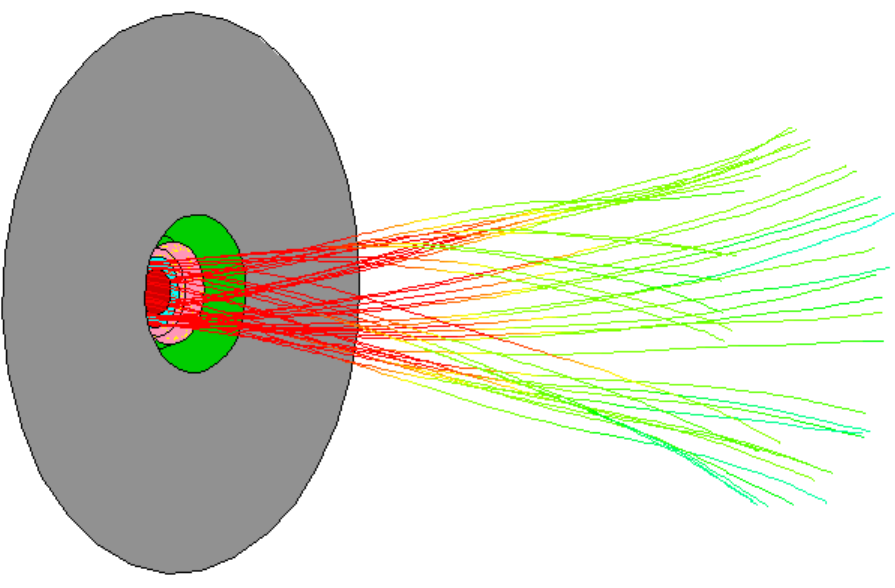

$90 \%$

$100 \%$

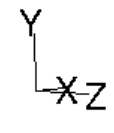




\subsection{Furnace and HRA Design and Analysis}

\subsubsection{Furnace Design and Analysis}

\subsubsection{FW-FIRE Computer Program Description}

FW-FIRE (Fossil fuel, Water-walled Furnace Integrated Reaction and Emission Simulation) simulates furnace combustion, heat transfer and pollutant formation based on fundamental principles of mass, momentum, and energy conservation [21]. FW-FIRE is an extended and enhanced version of PCGC-3, which was developed over a period of ten years by the Advanced Combustion Engineering Research Center (ACERC), operated jointly by Brigham Young University and the University of Utah. The FW-FIRE computer program incorporates the latest state-of-art coal combustion/gasification, pollutant formation, and physical analysis techniques based on extensive empirical research.

The FW-FIRE code performs general three dimensional multiphase gas combustion steady state analysis of reactive fluid flows. The program is fully capable of analyzing gas-fired and coal-fired boilers although FW-FIRE was initially tailored for pulverized coal combustion and gasification.

The FW-FIRE program models the gas flow field as a three dimensional (Cartesian or cylindrical) turbulent reacting continuum that is described locally by the Newtonian form of the Navier-Stokes equations coupled with the energy equation and other appropriate constitutive equations. These equations are solved in Eulerian framework to predict gas properties such as pressure, temperature, velocity, and pollutants and other species concentrations.

The Reynolds stress terms, which result from Favre-averaging of the conservation equations, are approximated using the Boussinesq assumption and effective eddy viscosity. The value of the eddy viscosity and subsequent closure of the turbulence equations is made using either a linear or non-linear k- $\varepsilon$ twoequation model. The effects of turbulence of the flow field on the combustion reactions are included.

The turbulent flow field is also coupled with the combustion chemistry. Since gaseous reactions are limited by mixing rates and not reaction kinetics, the process chemistry is calculated using locally instantaneous equilibrium based on the degree of mixing of the species. Rate constants for processes such as devolatilization (two step process) and char oxidation are built-in to the program based on empirical testing.

A Lagrangian model of the particle conservation equations is used to predict particle transport by characterizing the particle field as a series of discrete particle trajectories through the gas continuum. Particles interact with the gas 
field via mass, momentum, and energy exchange. Particle properties such as burnout, velocities, temperatures, and particle component compositions are obtained by integrating the governing equations along the trajectory paths. The program possesses the capability to input a particle size distribution and chemical composition.

In a pulverized coal flame, the radiation field is a multi-component, non-uniform, emitting, absorbing, gas-particle system. The coal particles cause anisotropic and multiple scattering, and the flame is surrounded by non-uniform, emitting, reflecting, absorbing surfaces. The radiation field calculations are based on an energy balance on a beam of radiation passing through a volume element containing the absorbing-reflecting-emitting medium. An Eulerian framework using a discrete-ordinates approach is used to model this process. Heat transfer via radiation and convection to waterwall and tube banks is determined by specifying a local wall temperature and emissivity.

The set of non-linear differential equations is discretized and combined by a upwind and weighted central-differencing scheme. The resulting gas flow field finite difference equations are solved using variations of the SIMPLE/SIMPER algorithm.

FW-FIRE contains a sub-model for the prediction of nitrogen pollutant emissions. This sub-model has the capability of predicting both fuel and thermal NOx formation. Fuel $\mathrm{NO}$ formation can proceed directly to $\mathrm{N}_{2}$ and $\mathrm{NO}$ (such as in the case of char) or through $\mathrm{HCN}$ and $\mathrm{NH}_{3}$ which are oxidized to form $\mathrm{NO}$ and reduced to $\mathrm{N}_{2}$ (such as in the case of volatiles). Global reaction rates are based on work by de Soete and Bose. Thermal NO formation is governed by the extended Zel lovich mechanism.

\subsubsection{Model Geometry}

A simulation was made for both the reference air-fired case and for the oxygenfired case. The FW-FIRE model simulates the furnace, in height from the bottom of the hopper to the roof, in depth from the front wall to the rear wall, and in width from the left side wall to the right side wall. Furnace partial division walls are also included in the model. Finer meshes are used to model the burners and over-fire air (OFA) ports. The air-fired model contains 528,840 (117x113x40) nodes and is shown in Figure 4.4.1. Two oxygen-fired models were constructed: one with no OFG ports and the second with OFG ports. The oxygen-fired model without OFG ports contains $364,320(132 \times 69 \times 40)$ and is shown in Figure 4.4.2. The oxygenfired model with OFG ports contains $484,160(136 \times 89 \times 40)$ nodes and is shown in Figure 4.4.3. 


\subsubsection{Boundary Conditions}

Boundary conditions are based on ASPEN simulations of the power plant (Section 4.2). The air-fired and oxygen-fired ASPEN reference cycle diagrams are presented in Figure 4.2.1 and Figure 4.2.25, respectively The input data required by FW-FIRE include fuel analysis, coal particle size distribution (mass percentage for each size bin), waterwall fluid temperatures, and the velocities, flow rates and temperatures of primary and secondary gas streams. Boundary conditions are detailed in Table 4.4.1 and Table 4.4.2.

The waterwalls of the furnace are assumed to be gray and diffusive. The wall temperature at each location is calculated based on the fluid temperature and the heat flux at the wall cell. For the waterwalls, a fluid saturation temperature of $680^{\circ} \mathrm{F}$ corresponding to a pressure of 2700 psia is applied. For the partial division walls, a steam inlet temperature of $712^{\circ} \mathrm{F}$ and a steam outlet temperature of $848^{\circ} \mathrm{F}$ are applied.

For coal devolatilization kinetic properties, Ubhayakar rate parameters were employed for bituminous coal. For bituminous char oxidation, Sandia kinetic and burning mode parameters were applied for Illinois \#6 coal.

\subsubsection{Air-Fired Reference Case}

The general layout drawing of the air-fired reference case is shown in Figure 4.4.4. The furnace has a total 24 opposed wall-fired burners (3 vertical $\times 4$ horizontal $\times 2$ walls) and 10 overfire air ports. $30 \%$ of the total combustion air is injected through the over-fire air ports located at one burner pitch above the top burner row. The radiant heat transfer surface consists of 2.75" OD tube waterwalls and five 2.0" OD tube partial divisional wall panels. Water is circulated in the furnace by natural circulation.

The boundary conditions were applied to the computational model and FW-FIRE was run until steady state conditions were achieved. The modeling results are summarized in Table 4.4.3. The coal burnout shown in the table is the percentage of dry ash-free based coal burned. The furnace exit gas temperature (FEGT) shown in the table is the average temperature of flue gas before the platen superheaters (vertical plane above the nose). The energy absorption listed is the total energy absorbed by water walls and partial division walls prior to the vertical plane above the nose. Total furnace absorption and FEGT predicted by FW-FIRE and ASPEN match closely.

Figure 4.4.5 is a plot of the flue gas velocity magnitude in a vertical plane through the second burner column. It can be seen that the gas velocity near the burners accelerates to greater than $150 \mathrm{ft} / \mathrm{s}$ due to the reduced gas density after particle ignition. Figure 4.4.6 presents a plot of gas temperature in a vertical plane through the second burner column. The maximum flue gas temperature is 
approximately $3300^{\circ} \mathrm{F}$. The mole fraction of $\mathrm{O}_{2}$ through the second burner column is presented in Figure 4.4.7.

The heat flux at the furnace water wall is shown in Figure 4.4.8. The maximum heat flux is approximately $70,000 \mathrm{Btu} / \mathrm{hr}^{-\mathrm{ft}^{2}}$ and is located on the side wall at the top of the burner zone. The total heat absorbed by the furnace walls before the furnace exit is $1840 \mathrm{MM} \mathrm{Btu/hr}$. Figure 4.4.9 displays temperatures of the furnace walls and roof. The maximum temperature of the waterwalls is approximately $800^{\circ} \mathrm{F}$ and of the division walls is approximately $875^{\circ} \mathrm{F}$. Figure 4.4 .10 presents the $\mathrm{CO}$ concentration at the wall, peaks at approximately $10 \%$ due to the substoichiometric conditions of the lower furnace (without overfire air the wall CO would be below $2 \%$ ).

The trajectories of the 72-micron particles are plotted in Figure 4.4.11 with colors in each trajectory representing the mass fraction of char in the particle. Char is formed from devolatilization and consumed by oxidation. The maximum char mass fraction is usually less than the mass fraction of fixed carbon in a proximate analysis. Figure 4.4 .11 shows that all of the 72 -micron particles are completely burned before the furnace exit. The trajectories of 176-micron particles are plotted in Figure 4.4.12. It can be observed from Figure 4.4.12 that some particles are not completely burned at the exit of the furnace, causing unburned carbon in the fly ash. Total burnout of all particle sizes is $99.66 \%(2.61 \% \mathrm{LOI})$.

Average NOx concentration at the furnace outlet is $227 \mathrm{ppmvw}(0.34 \mathrm{lb} / \mathrm{MMBtu})$. A series of runs were made to determine the furnace average outlet NOx as a function of over-fire air flow. Figure 4.4.13 presents the NOx concentration at the furnace outlet as a function of OFA flow. Increasing OFA can have a negative effect on fuel burnout. Figure 4.4.14 presents the fuel burnout versus OFA flow.

\subsubsection{Oxygen-Fired Design Case}

The preliminary size of the furnace heat transfer area was based on a calculation of average wall heat flux using the Foster Wheeler computer program, EMISS [23]. The EMISS computer program calculates radiative heat flux of $\mathrm{CO}_{2}$ and $\mathrm{H}_{2} \mathrm{O}$ gases. A three dimensional CFD run was then made using FW-FIRE to more accurately determine the total heat absorption. Based on the CFD results, the height of the furnace model was adjusted until the total heat absorption approximately matched that required in the ASPEN oxygen-fired design case. Figure 4.4.15 shows a comparison between the sizes of the resultant oxygenfired furnace and the air-fired reference furnace. Compared to the air-fired furnace, the oxygen furnace has only approximately $65 \%$ of the surface area and approximately $45 \%$ of the volume. Figure 4.4 .16 presents the oxygen-fired design general layout drawing.

The oxygen-fired furnace has a total 24 opposed wall-fired burners (4 vertical $\times 3$ horizontal $\times 2$ walls) and 8 overfire gas ports. The burner designs (including 0.5 
primary gas swirl) are based on the Low NOx Burner Design Task (see Section 4.3). The radiant heat transfer surface consists of 2.75 " OD tube waterwalls and ten 2.0" OD tube partial divisional wall panels. Water is circulated in the furnace by natural circulation.

Two designs were simulated: 1) without over-fire air and 2) with over-fire air. Since it is somewhat unknown how much NOx will be tolerated in the liquid $\mathrm{CO}_{2}$ effluent stream, a case with no OFG and a case with $20 \%$ OFG were run.

The modeling results are summarized in Table 4.4.3. The coal burnout for the oxygen-fired case is $100 \%$ due to the high furnace temperature and high concentration of $\mathrm{O}_{2}$. Total furnace absorption and FEGT predicted by FW-FIRE and ASPEN match well. NOx is 333 ppmvw for the no OFG case and 257 ppmvw for the $20 \%$ OFG case. Thus, the injection of $20 \%$ OFG results in a NOx reduction of $23 \%$. Although the average NOx concentration at the furnace outlet is similar on a volume basis for both air-fired and $\mathrm{O}_{2}$-fired $\mathrm{PC}$, it is substantially less on a mass basis for the $\mathrm{O}_{2}$-fired $\mathrm{PC}$ due to the substantially lower volumetric flue gas flow rate of the $\mathrm{O}_{2}$-fired $\mathrm{PC}$.

\subsection{No OFG Case}

Figure 4.4.17 is a plot of the flue gas velocity magnitude in a vertical plane through the middle burner column. It can be seen that the gas velocity near the burners accelerates to nearly $150 \mathrm{ft} / \mathrm{s}$ due to the reduced gas density after particle ignition. Figure 4.4.18 presents a plot of gas temperature in a vertical plane through the middle burner column. The maximum flue gas temperature is approximately $3900^{\circ} \mathrm{F}$. The mole fraction of $\mathrm{O}_{2}$ through the middle burner column is presented in Figure 4.4.19. The mixed primary/secondary gas $\mathrm{O}_{2}$ content (before combustion) is $42 \%$.

The heat flux at the furnace water wall is shown in Figure 4.4.20. The maximum heat flux is approximately $175,000 \mathrm{Btu} / \mathrm{hr}^{-\mathrm{ft}^{2}}$ and is located on the side wall at the top of the burner zone. This maximum heat flux is approximately 2.5 times the air-fired case due to the higher flame temperature and higher $\mathrm{H}_{2} \mathrm{O}$ and $\mathrm{CO}_{2}$ concentrations. The total heat absorbed by the furnace walls before the furnace exit is $2287 \mathrm{MM} \mathrm{Btu/hr}$. Figure 4.4.21 displays temperatures of the furnace walls and roof. The maximum temperature of the waterwalls is approximately $935^{\circ} \mathrm{F}$ and of the division walls is approximately $945^{\circ} \mathrm{F}$. Because of the higher temperature of the oxygen-fired case compared to the air-fired case, furnace water wall material was upgraded from 0.285 " thick carbon steel (SA-210C) to 0.240" thick SA-213-T91. Figure 4.4.22 presents the CO concentration at the wall, which is significantly greater than for the air-fired case (Figure 4.4.10) and its effects on corrosion will need to be studied in future work.

The trajectories of the 69-micron particles are plotted in Figure 4.4.23 with colors in each trajectory representing the mass fraction of char in the particle. Figure 4.4.23 shows that all of the 69-micron particles are completely burned before the 
furnace exit. The trajectories of 169-micron particles are plotted in Figure 4.4.24. Note that due to the higher temperature and $\mathrm{O}_{2}$ concentration all the 169-micron particles are completely burned as compared to the air-fired case (Figure 4.4.12) where there is some residual unburned char at the outlet. Figure 4.4 .25 shows the trajectories of 169-micron particles without primary gas swirl (this case was run prior to the finalization of the burner design analysis). Comparing Figure 4.4.24 with Figure 4.4.25 demonstrates that primary gas swirl achieves an earlier burnout of the large coal particles.

\subsection{0\% OFG Case}

Figure 4.4.26 is a plot of the flue gas velocity magnitude in a vertical plane through the middle burner column. It can be seen that the gas velocity near the burners accelerates to nearly $150 \mathrm{ft} / \mathrm{s}$ due to the reduced gas density after particle ignition. Figure 4.4.27 presents a plot of gas temperature in a vertical plane through the middle burner column. The maximum flue gas temperature is approximately $3750^{\circ} \mathrm{F}$. The mole fraction of $\mathrm{O}_{2}$ through the middle burner column is presented in Figure 4.4.28. The mixed primary/secondary gas $\mathrm{O}_{2}$ content (before combustion) is $42 \%$.

The heat flux at the furnace water wall is shown in Figure 4.4.29. The maximum heat flux is approximately $165,000 \mathrm{Btu} / \mathrm{hr}^{-\mathrm{ft}^{2}}$ and is located on the side wall at the above the over-fire ports. This maximum heat flux is approximately 2.4 times the air-fired case due to the higher flame temperature and higher $\mathrm{H}_{2} \mathrm{O}$ and $\mathrm{CO}_{2}$ concentrations. The total heat absorbed by the furnace walls before the furnace exit is $2186 \mathrm{MM} \mathrm{Btu/hr}$. Figure 4.4.30 displays temperatures of the furnace walls and roof. The maximum temperature of the waterwalls is approximately $930^{\circ} \mathrm{F}$ and of the division walls is approximately $945^{\circ} \mathrm{F}$. Because of the higher temperature of the oxygen-fired case compared to the air-fired case, furnace water wall material was upgraded from 0.285 " thick carbon steel (SA-210C) to 0.240" thick SA-213-T91. Figure 4.4.31 presents the CO concentration at the wall, which is significantly greater than for the air-fired case (Figure 4.4.10) and its effects on corrosion will need to be studied in future work.

The trajectories of the 69-micron particles are plotted in Figure 4.4.32 with colors in each trajectory representing the mass fraction of char in the particle. Figure 4.4.32 shows that all of the 69-micron particles are completely burned before the furnace exit. The trajectories of 169-micron particles are plotted in Figure 4.4.33. Note that due to the higher temperature and $\mathrm{O}_{2}$ concentration all the 169-micron particles are completely burned as compared to the air-fired case (Figure 4.4.12) where there is some residual unburned char at the outlet. Figure 4.4.34 shows the trajectories of 169-micron particles without primary gas swirl (this case was run prior to the finalization of the burner design analysis). Comparing Figure 4.4.33 with Figure 4.4.34 demonstrates that primary gas swirl achieves an earlier burnout of the large coal particles. 


\subsubsection{Heat Recovery Area Design and Analysis}

\subsubsection{HEATEX Program Description}

HEATEX [22] is a Foster Wheeler general-purpose program for thermal/hydraulic analysis of tube banks. The program performs heat transfer calculations on a local basis by dividing the tube bundle into a number of small heat transfer elements.

\subsubsection{Air-Fired Reference Case}

HEATEX was used to determine the heat recovery area (HRA) design of the convective tube banks between the furnace exit and the SCR/air heater. These tube banks include the finishing superheater, finishing reheater, primary superheater, primary reheater, upper economizer, and lower economizer. Flue gas exits the furnace at $2135^{\circ} \mathrm{F}$ and flows over the finishing superheater and finishing reheater tube bundles where it heats the main steam and reheat steam to $1000^{\circ} \mathrm{F}$ and $1005^{\circ} \mathrm{F}$, respectively. The gas flow is then split into two parallel flows: one passing over the primary reheater and the other passing over the primary superheater and upper economizer. The gas split is controlled by dampers to achieve the proper reheater outlet temperature. Attemperating spray is used to control superheat temperature. The flue gas is combined downstream of the dampers and flows over the lower economizer, which receives water from the last feedwater heater stage. Flue gas exits the lower economizer at $720^{\circ} \mathrm{F}$ and is sent to the SCR and then to the air heater. Figure 4.2.1 presents the heat transfer requirements of the HRA banks. Table 4.4.4 presents the corresponding design of the HRA banks. Total surface area of all convective banks is 294,111 $\mathrm{ft}^{2}$. The performance of HRA tube banks is shown Table 4.4.5. The total heat transferred to the water/steam is $1354 \mathrm{MM} \mathrm{Btu/hr}$ as $3.88 \mathrm{MM} \mathrm{lb} / \mathrm{hr}$ of flue gas is cooled from $2135^{\circ} \mathrm{F}$ to $720^{\circ} \mathrm{F}$.

\subsubsection{Oxygen-Fired Case}

Due to the $40 \%$ lower flue gas flow rate of the oxygen-fired case versus the airfired case, the cross sectional area of the HRA is reduced to maintain the same gas side velocity (and pressure drop). HEATEX was used to determine the heat recovery area design of the convective tube banks between the furnace exit and the gas recuperator. These tube banks include the finishing superheater, finishing reheater, primary superheater, primary reheater, and lower economizer. Flue gas exits the furnace at $2350^{\circ} \mathrm{F}$ and flows over the finishing superheater and finishing reheater tube bundles where it heats the main steam and reheat steam to $1000^{\circ} \mathrm{F}$ and $1005^{\circ} \mathrm{F}$, respectively. The gas flow is then split into two parallel flows: one passing over the primary reheater and the other passing over the primary superheater. The gas split is controlled by dampers to achieve the proper reheater outlet temperature. Attemperating spray is used to control superheat 
temperature. The flue gas is combined downstream of the dampers and flows over the lower economizer, which receives water from the last feedwater heater stage. Flue gas exits the lower economizer at $650^{\circ} \mathrm{F}$ and is sent to the gas recuperator.

Figure 4.2.25 presents the heat transfer requirements of the HRA banks. Table 4.4.4 presents the corresponding design of the HRA banks. Total surface area of all convective banks is $215,700 \mathrm{ft}^{2}$. The performance of HRA tube banks is shown in Table 4.4.5. The total heat transferred to the water/steam is $1096 \mathrm{MM}$ $\mathrm{Btu} / \mathrm{hr}$ as $2.20 \mathrm{MM} \mathrm{lb} / \mathrm{hr}$ of flue gas is cooled from $2350^{\circ} \mathrm{F}$ to $650^{\circ} \mathrm{F}$. The total heat transfer surface required in the oxygen-fired HRA is $25 \%$ less than the air-fired HRA due to the following main reasons:

1. More heat is absorbed in the oxygen-fired furnace (2264 MM Btu/hr) than the air-fired furnace (1894 MM Btu/hr) due to the higher adiabatic temperature and greater the specific heat of the oxygen-fired furnace flue gas. This requires less heat transfer duty in the HRA (as a consequence the upper economizer is not needed)

2. A higher heat transfer coefficient can be achieved in the oxygen-fired HRA than the air-fired HRA for the same flue gas pressure loss due to greater molecular weight (38 mol/lb-mol vs. $29 \mathrm{~mol} / \mathrm{lb}-\mathrm{mol})$ of the oxygen-fired flue gas.

The HRA tube materials and wall thickness are practically the same for the airfired and oxygen-fired design since the flue gas and water/steam temperature profiles encountered by the heat transfer banks are very similar. 
Figure 4.4.1- Computational Model of Air-Fired Furnace (with right side wall removed)

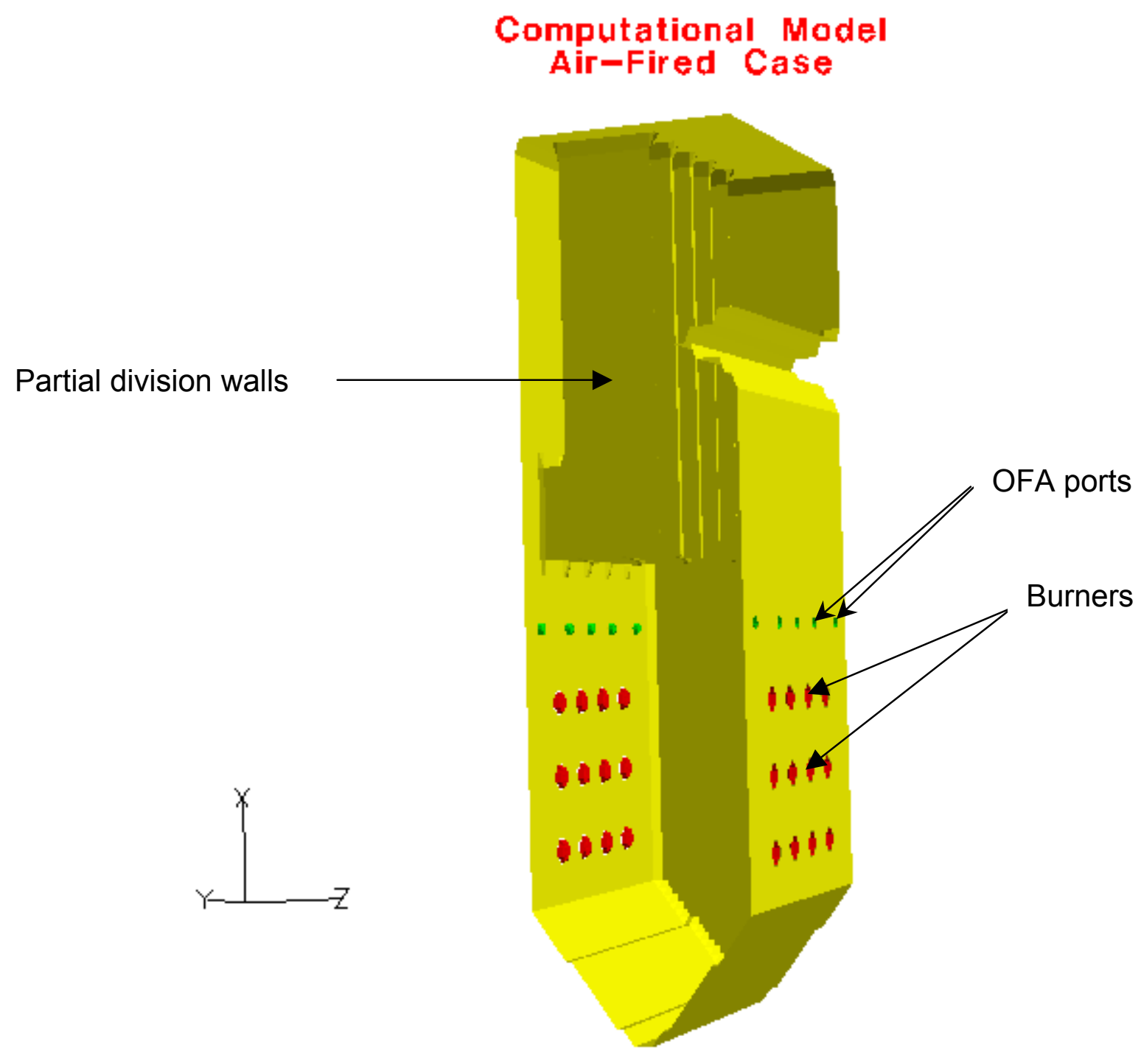


Figure 4.4.2 - Computational Model of Oxygen-Fired Furnace Without OFG

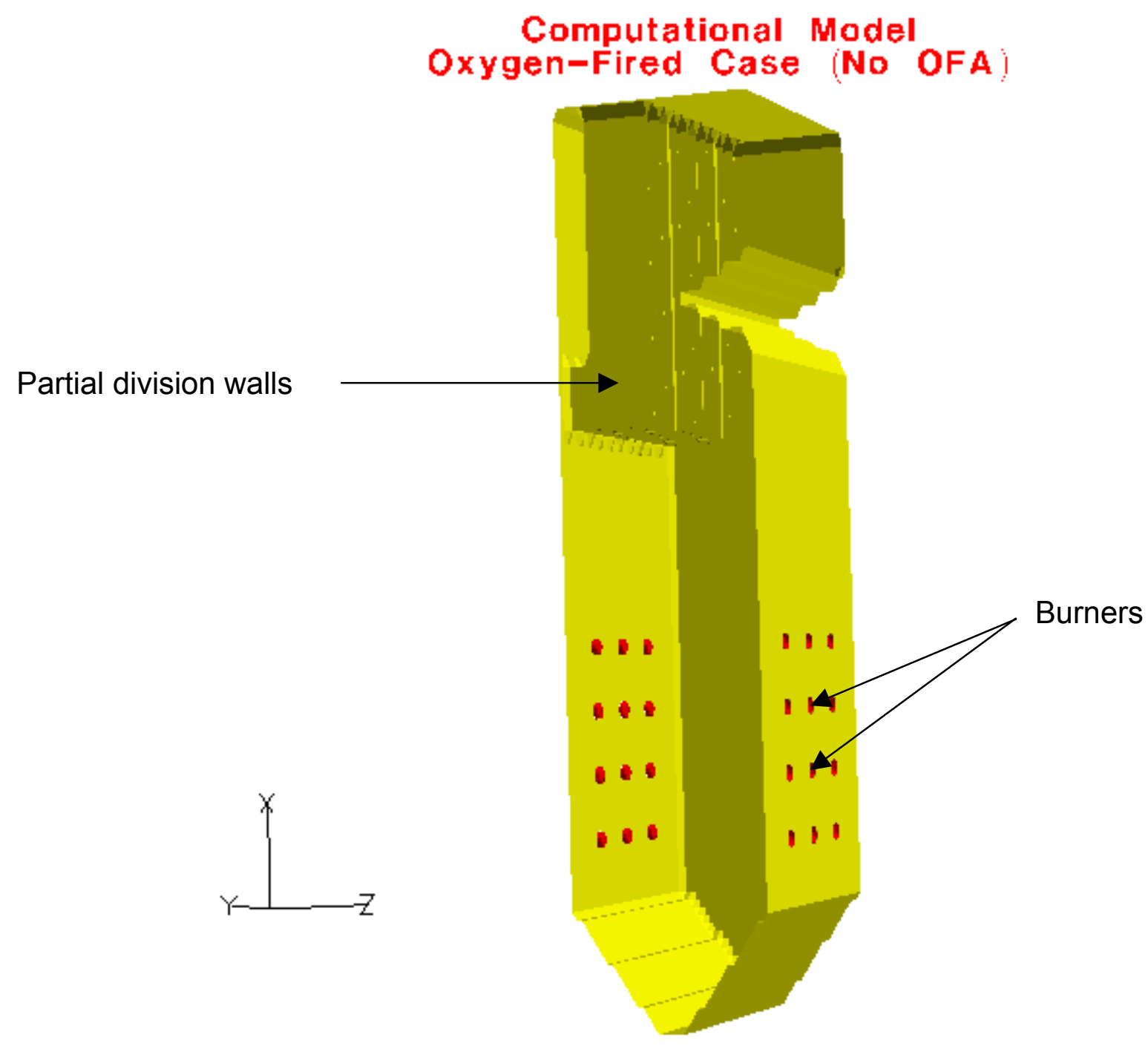


Figure 4.4.3 - Computational Model of Oxygen-Fired Furnace With OFG

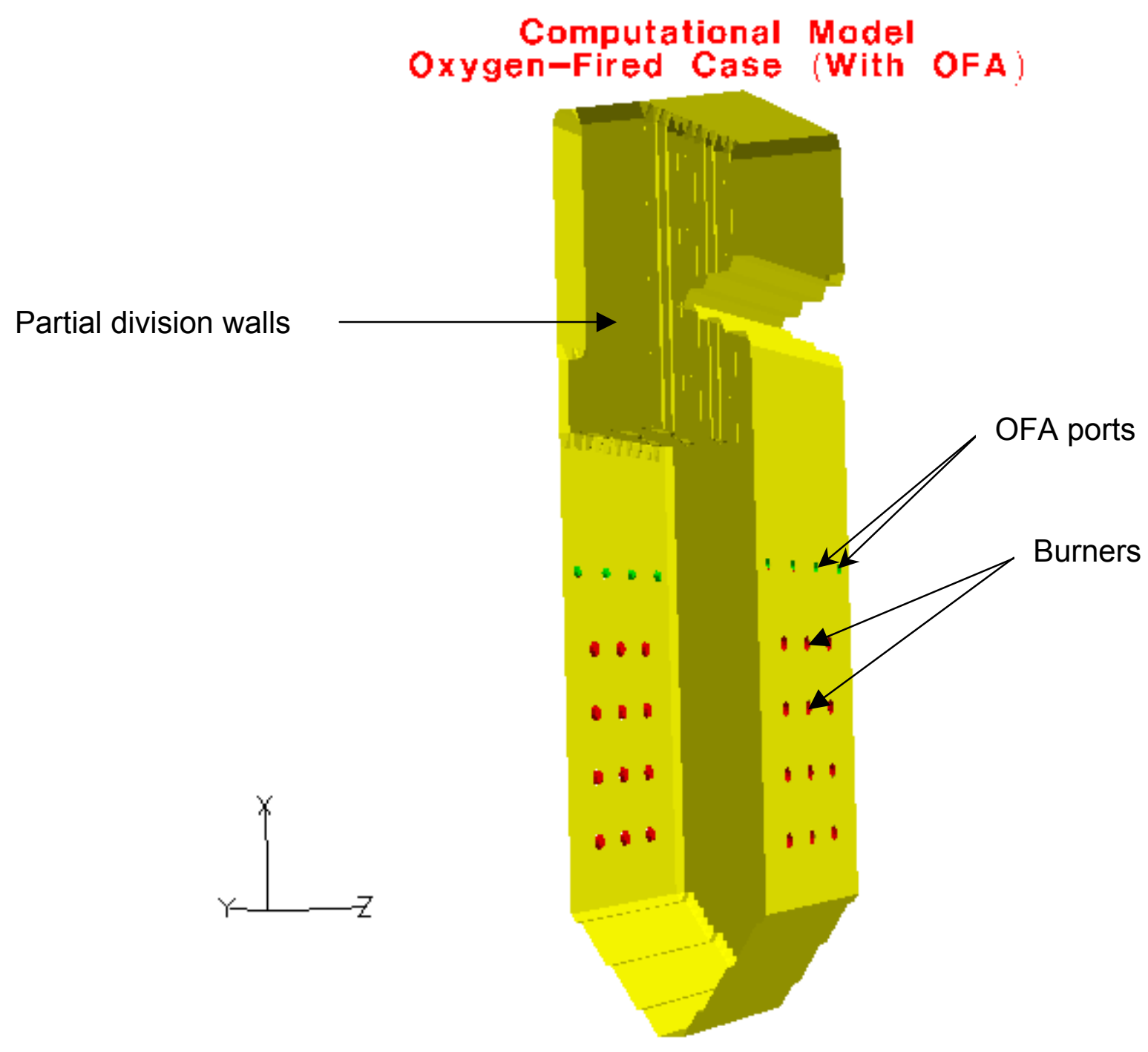


Table 4.4.1 - Air-Fired Boundary Conditions

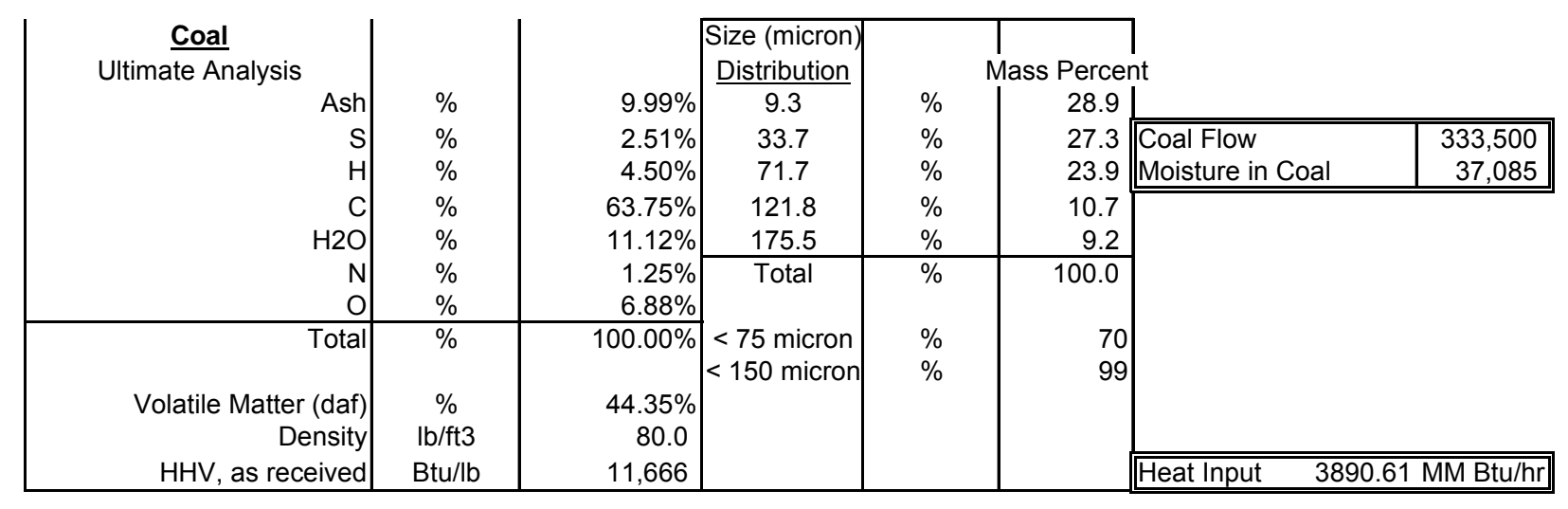

\begin{tabular}{|c|c|c|c|c|c|}
\hline TCA & $\mathrm{Ib} / \mathrm{hr}$ & $3,428,000$ & Divwall & Temp (F) & Temp (K) \\
\hline Excess $\mathrm{O} 2$ & $\%$ & 11.0 & Inlet & 712 & 651 \\
\hline Drum Pressure & psia & 2700 & Outlet & 848 & 726 \\
\hline OFA & $\%$ & $30.0 \%$ & Average & 780 & 689 \\
\hline
\end{tabular}

\begin{tabular}{|c|c|c|c|c|c|c|c|c|c|c|c|c|}
\hline & \multicolumn{2}{|c|}{ Flow Rate } & \multirow{2}{*}{$\begin{array}{c}\text { Temperature } \\
\mathrm{F}\end{array}$} & \multirow{2}{*}{$\begin{array}{l}\text { Density } \\
\text { lb/ft3 }\end{array}$} & \multirow{2}{*}{$\begin{array}{l}\text { Inner Diam. } \\
\text { in }\end{array}$} & \multirow{2}{*}{$\begin{array}{c}\text { Outer Diam. } \\
\text { in }\end{array}$} & \multirow{2}{*}{\begin{tabular}{|c|} 
Area per Port \\
ft2
\end{tabular}} & \multirow[t]{2}{*}{ No. of Ports } & \multirow{2}{*}{$\begin{array}{c}\text { Axial Velocity } \\
\mathrm{ft} / \mathrm{sec}\end{array}$} & \multirow{2}{*}{$\begin{array}{c}\text { Tan./Axial } \\
\text { Velocity }\end{array}$} & \multirow{2}{*}{$\begin{array}{c}\text { Rad./Axial } \\
\text { Velocity }\end{array}$} & \multirow{2}{*}{\begin{tabular}{|c} 
Coal Flow \\
lb/hr
\end{tabular}} \\
\hline & $\mathrm{lb} / \mathrm{hr}$ & $\%$ & & & & & & & & & & \\
\hline Primary & 685,600 & 19.8 & 258 & 0.056 & 13.100 & 22.750 & 1.887 & 24 & 75.2 & 0.00 & 0.00 & 296,415 \\
\hline Inner Sec. Air & 350,217 & 10.1 & 590 & 0.038 & 23.750 & 33.375 & 2.999 & 24 & 35.4 & 0.00 & 0.21 & \\
\hline Outer Sec. Air & $1,400,868$ & 40.4 & 590 & 0.038 & 33.875 & 49.000 & 6.837 & 24 & 62.0 & 0.41 & 0.41 & \\
\hline Tertiary Air & 0 & 0.0 & 590 & 0.038 & 0.000 & 12.100 & 0.799 & 24 & 0.0 & 0.00 & 0.00 & \\
\hline Overfire Air - Inner & 523,075 & 15.1 & 590 & 0.038 & 0.000 & 19.000 & 1.969 & 10 & 193.1 & 0.00 & 0.00 & \\
\hline Overfire Air - Outer & 505,325 & 14.6 & 590 & 0.038 & 19.500 & 27.000 & 1.902 & 10 & 193.1 & 0.00 & 0.21 & \\
\hline
\end{tabular}


Table 4.4.2 - Oxygen-Fired Boundary Conditions

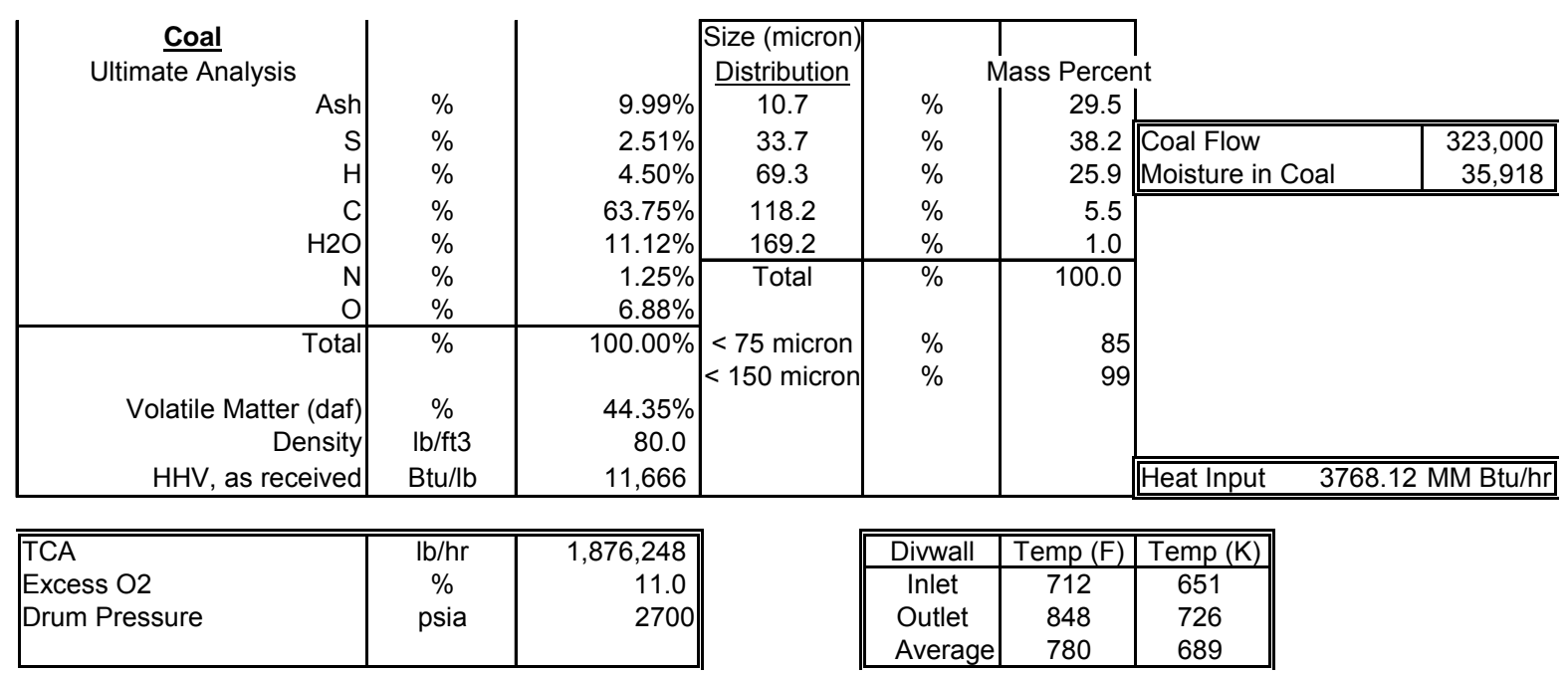

\section{No OFG}

\begin{tabular}{|c|c|c|c|c|c|c|c|c|c|c|c|c|}
\hline & \multicolumn{2}{|c|}{ Flow Rate } & \multirow{2}{*}{$\begin{array}{c}\text { Temperature } \\
\text { F }\end{array}$} & \multirow{2}{*}{$\begin{array}{l}\text { Density } \\
\mathrm{lb} / \mathrm{ft} 3\end{array}$} & \multirow{2}{*}{$\begin{array}{l}\text { Inner Diam. } \\
\text { in }\end{array}$} & \multirow{2}{*}{$\begin{array}{c}\text { Outer Diam. } \\
\text { in }\end{array}$} & \multirow{2}{*}{$\begin{array}{c}\text { Area per Port } \\
\mathrm{ft} 2\end{array}$} & \multirow{2}{*}{ No. of Ports } & \multirow{2}{*}{$\begin{array}{c}\text { Axial Velocity } \\
\mathrm{ft} / \mathrm{sec}\end{array}$} & \multirow{2}{*}{$\begin{array}{c}\text { Tan./Axial } \\
\text { Velocity }\end{array}$} & \multirow{2}{*}{\begin{tabular}{|c|} 
Rad./Axial \\
Velocity
\end{tabular}} & \multirow{2}{*}{$\begin{array}{c}\text { Coal Flow } \\
\text { lb/hr }\end{array}$} \\
\hline & $\mathrm{lb} / \mathrm{hr}$ & $\%$ & & & & & & & & & & \\
\hline Primary & 530,000 & 27.7 & 216 & 0.079 & 9.500 & 15.000 & 0.735 & 24 & 106.2 & 0.50 & 0.00 & 287,082 \\
\hline Inner Sec. Air & 276,433 & 14.5 & 580 & 0.049 & 16.000 & 22.000 & 1.244 & 24 & 52.9 & 0.00 & 0.21 & \\
\hline Outer Sec. Air & $1,105,732$ & 57.8 & 580 & 0.049 & 22.500 & 32.000 & 2.824 & 24 & 93.1 & 0.41 & 0.41 & \\
\hline Tertiary Air & 0 & 0.0 & 580 & 0.049 & 0.000 & 8.500 & 0.394 & 24 & 0.0 & 0.00 & 0.00 & \\
\hline Overfire Air - Inner & 0 & 0.0 & 580 & 0.049 & 0.000 & 23.500 & 3.012 & 12 & 0.0 & 0.00 & 0.00 & \\
\hline Overfire Air - Outer & 0 & 0.0 & 580 & 0.049 & 24.000 & 35.000 & 3.540 & 12 & 0.0 & 0.00 & 0.21 & \\
\hline
\end{tabular}

\section{$20 \%$ OFG}

\begin{tabular}{|c|c|c|c|c|c|c|c|c|c|c|c|c|}
\hline & $\begin{array}{l}\text { Flon } \\
\mathrm{lb} / \mathrm{hr}\end{array}$ & $\%$ & $\begin{array}{c}\text { Temperature } \\
\mathrm{F}\end{array}$ & $\begin{array}{l}\text { Density } \\
\mathrm{lb} / \mathrm{ft} 3\end{array}$ & $\begin{array}{l}\text { Inner Diam. } \\
\text { in }\end{array}$ & $\begin{array}{c}\text { Outer Diam. } \\
\text { in }\end{array}$ & $\begin{array}{c}\text { Area per Port } \\
\mathrm{ft} 2\end{array}$ & No. of Ports & $\begin{array}{c}\text { Axial Velocity } \\
\mathrm{ft} / \mathrm{sec}\end{array}$ & $\begin{array}{c}\text { Tan./Axial } \\
\text { Velocity }\end{array}$ & \begin{tabular}{|c|} 
Rad./Axial \\
Velocity
\end{tabular} & $\begin{array}{c}\text { Coal Flow } \\
\mathrm{lb} / \mathrm{hr}\end{array}$ \\
\hline Primary & 530,000 & 27.7 & 216 & 0.079 & 9.500 & 15.000 & 0.735 & 24 & 106.2 & 0.50 & \begin{tabular}{|l|}
0.00 \\
\end{tabular} & 287,082 \\
\hline Inner Sec. Air & 201,383 & 10.5 & 580 & 0.049 & 16.000 & 20.750 & 0.952 & 24 & 50.3 & 0.00 & 0.21 & \\
\hline Outer Sec. Air & 805,533 & 42.1 & 580 & 0.049 & 21.750 & 29.000 & 2.007 & 24 & 95.4 & 0.41 & 0.41 & \\
\hline Tertiary Air & & 0.0 & 580 & 0.049 & 0.000 & 8.500 & 0.394 & 24 & 0.0 & 0.00 & 0.00 & \\
\hline Overfire Air - Inner & 177,060 & 9.3 & 580 & 0.049 & 0.000 & 13.500 & 0.994 & 8 & 127.1 & 0.00 & 0.00 & \\
\hline Overfire Air - Outer & 198,190 & 10.4 & 580 & 0.049 & 14.000 & 20.000 & 1.113 & 8 & 127.1 & 0.00 & 0.21 & \\
\hline
\end{tabular}


Figure 4.4.4 - Air-Fired Boiler Design

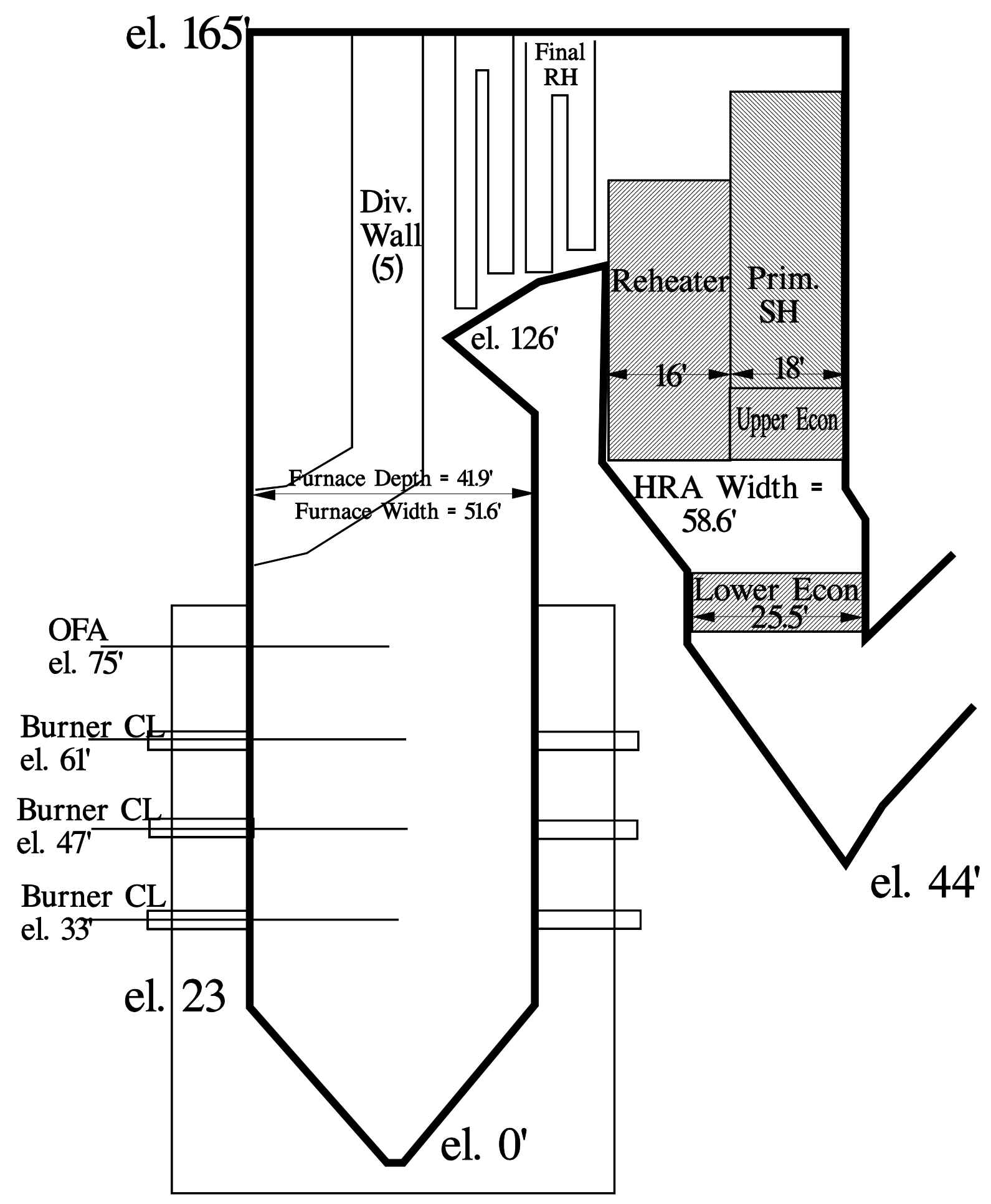


Table 4.4.3 - Summary of FW-FIRE Furnace Modeling Results

\section{Air-Fired}

\begin{tabular}{|r|c|r|r|}
\hline & & FW-FIRE & ASPEN \\
\cline { 3 - 4 } Burnout & $\%$ & 99.66 & 99.0 \\
LOI & $\%$ & 2.61 & 7.32 \\
Total Furnace Absorption & $\mathrm{M} \mathrm{Btu/hr}$ & 1840 & 1838 \\
Division Wall Absorption & 0.0 & 494 & 451 \\
FEGT & $\mathrm{F}$ & 2101 & 2135 \\
NOx & ppmvw & 227 & \\
& Ib/MMBtu & 0.34 & \\
\hline
\end{tabular}

\section{Oxygen-Fired (No OFG)}

\begin{tabular}{|r|c|r|r|}
\hline & & FW-FIRE & ASPEN \\
\cline { 3 - 4 } Burnout & $\%$ & 100.0 & 99.5 \\
LOI & $\%$ & 0.00 & 3.80 \\
Total Furnace Absorption & $\mathrm{M} \mathrm{Btu/hr}$ & 2287 & 2264 \\
Division Wall Absorption & $\mathrm{M} \mathrm{Btu} / \mathrm{hr}$ & 499 & 573 \\
FEGT & $\mathrm{F}$ & 2190 & 2350 \\
NOx & $\mathrm{ppmvw}$ & 333 & \\
& $\mathrm{lb} / \mathrm{MMBtu}$ & 0.23 & \\
\hline
\end{tabular}

\section{Oxygen-Fired (20\% OFG)}

\begin{tabular}{|r|c|r|r|}
\hline & & FW-FIRE & ASPEN \\
\cline { 3 - 4 } Burnout & $\%$ & 100.0 & 99.5 \\
LOI & $\%$ & 0.00 & 3.80 \\
Total Furnace Absorption & $\mathrm{M} \mathrm{Btu} / \mathrm{hr}$ & 2186 & 2264 \\
Division Wall Absorption & $\mathrm{M} \mathrm{Btu} / \mathrm{hr}$ & 550 & 573 \\
FEGT & $\mathrm{F}$ & 2262 & 2350 \\
NOx & $\mathrm{ppmvw}$ & 257 & \\
& lb/MMBtu & 0.18 & \\
\hline
\end{tabular}


Figure 4.4.5 - Gas Velocity for Air-Fired Case
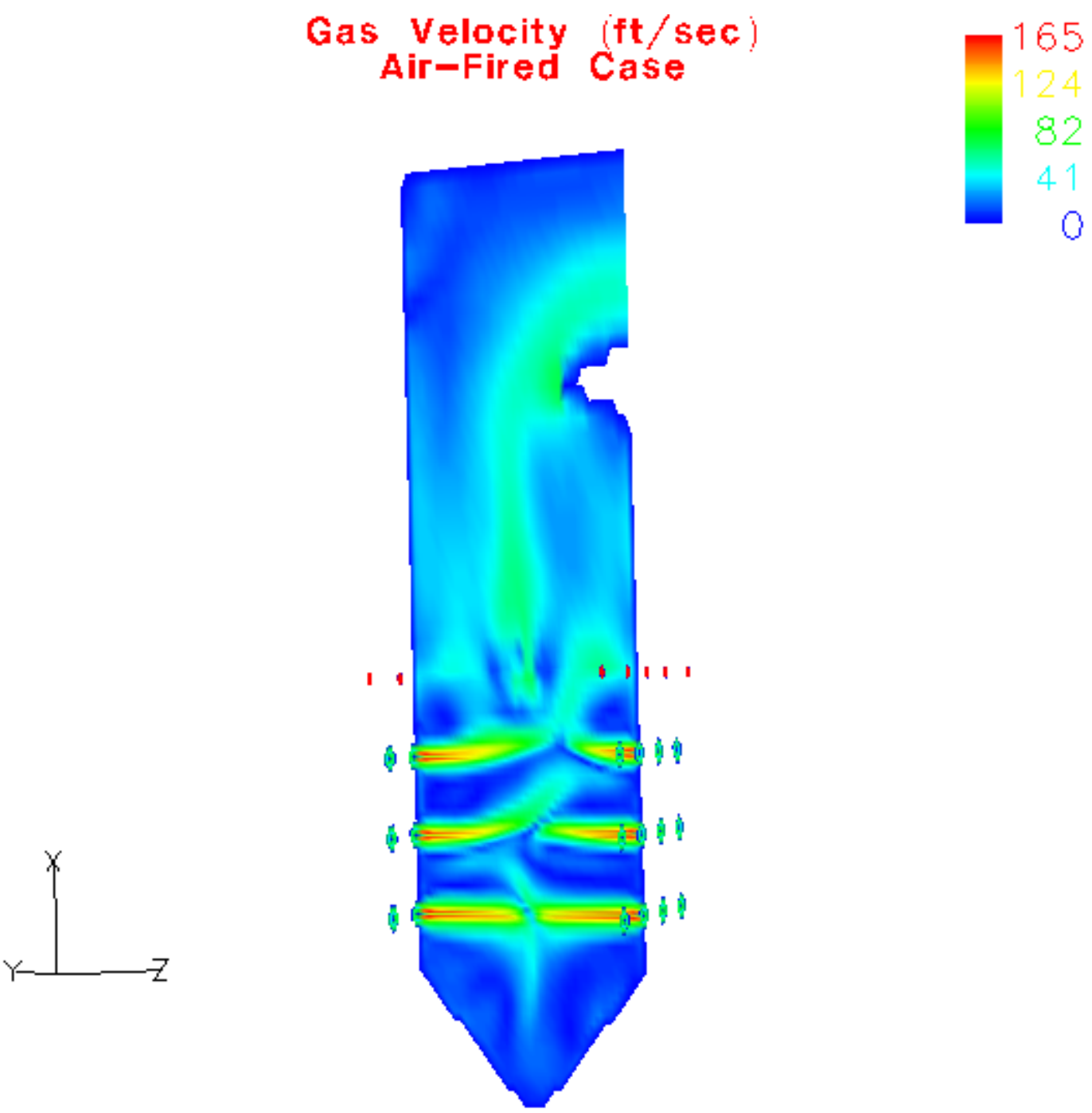
Figure 4.4.6 - Gas Temperature for Air-Fired Case Gas Temperature (F)

Air-Fired Case
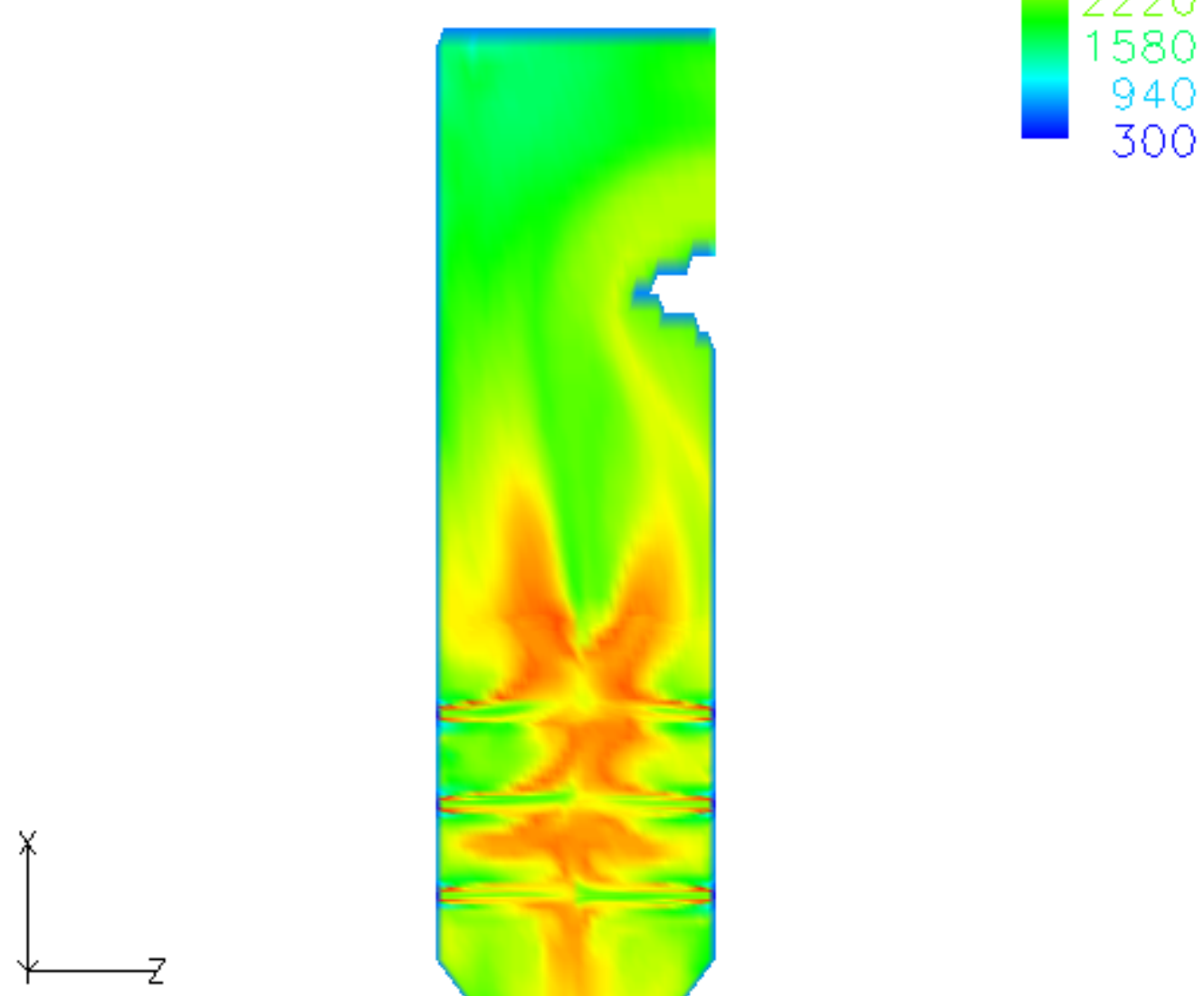
Figure 4.4.7 $-\mathrm{O}_{2}$ Mole Fraction for Air-Fired Case

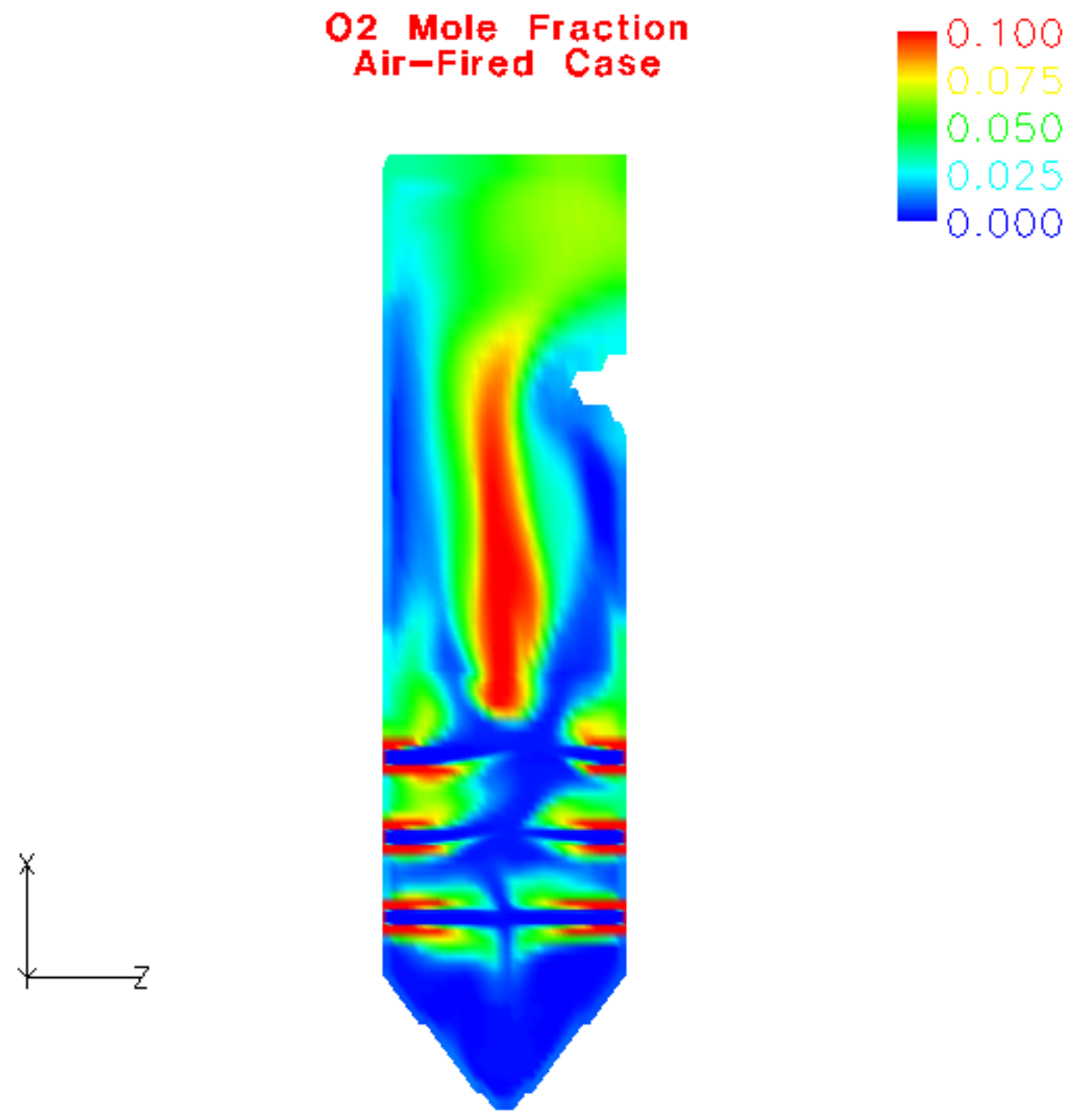


Figure 4.4.8 - Wall Heat Flux for Air-Fired Case Wall Heat Flux Btu/hr-ft2) Air-Fired Case
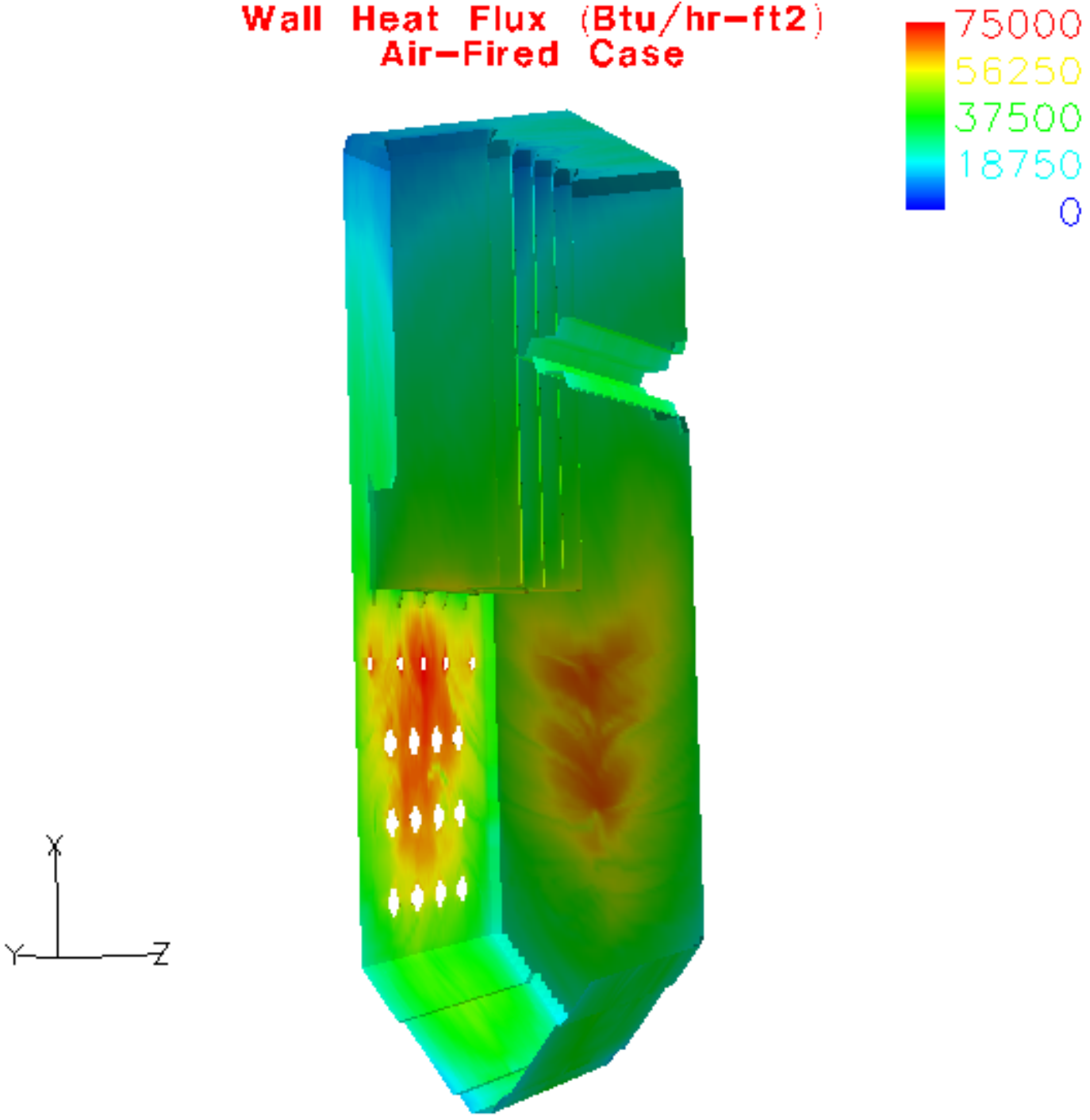
Figure 4.4.9 - Wall Temperature for Air-Fired Case

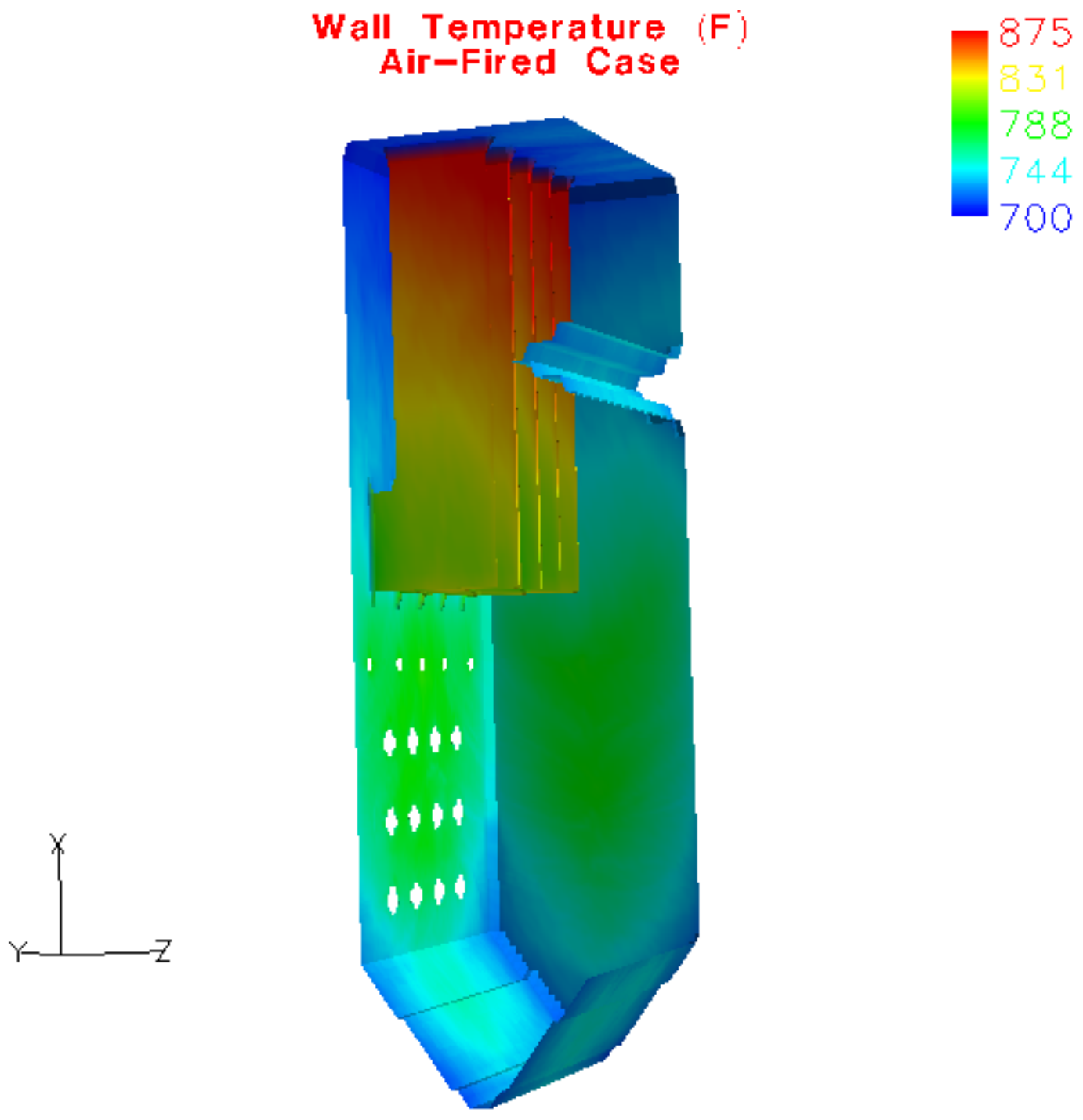


Figure 4.4.10 - Wall CO for Air-Fired Case

Co Concentration

Air-Fired Case

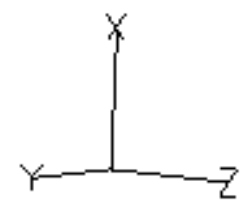

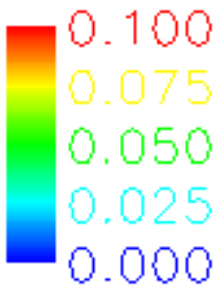

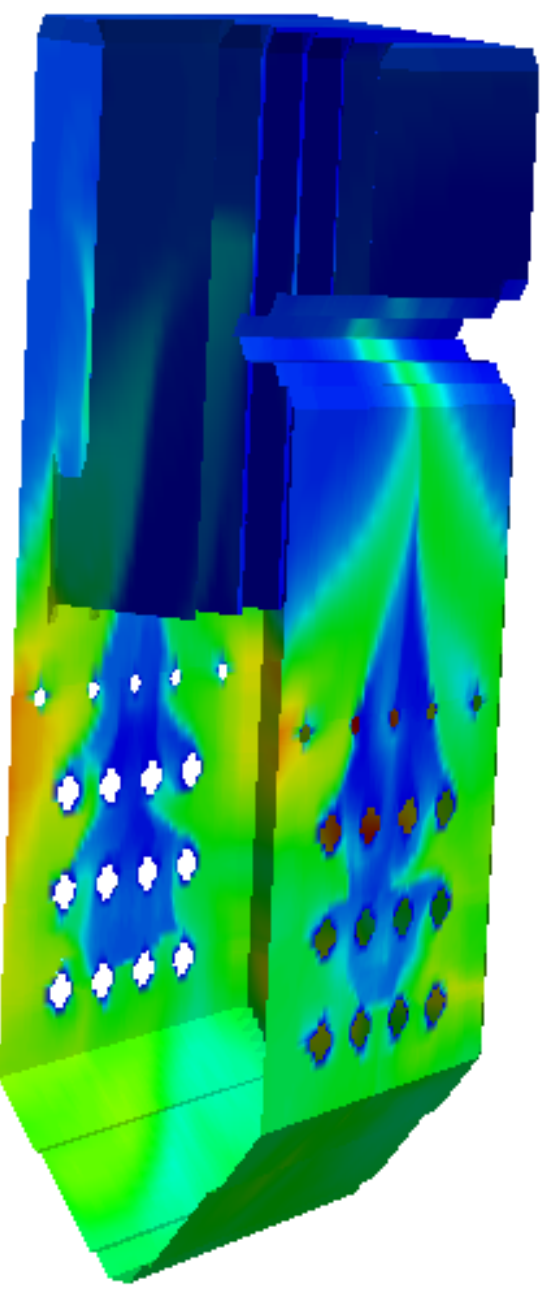


Figure 4.4.11 - Char Mass Fraction (72 microns) for Air-Fired Case

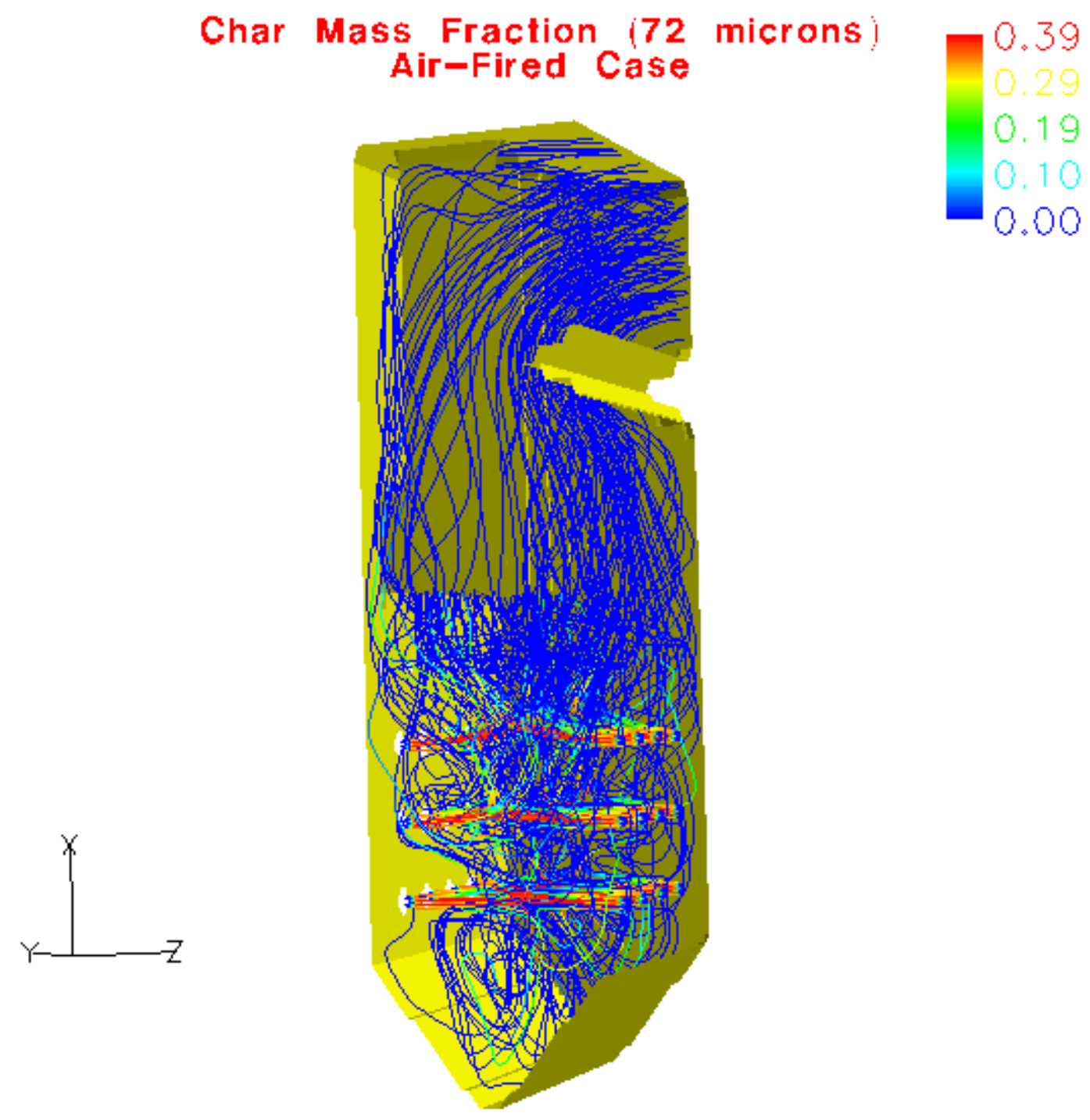


Figure 4.4.12 - Char Mass Fraction (176 microns) for Air-Fired Case

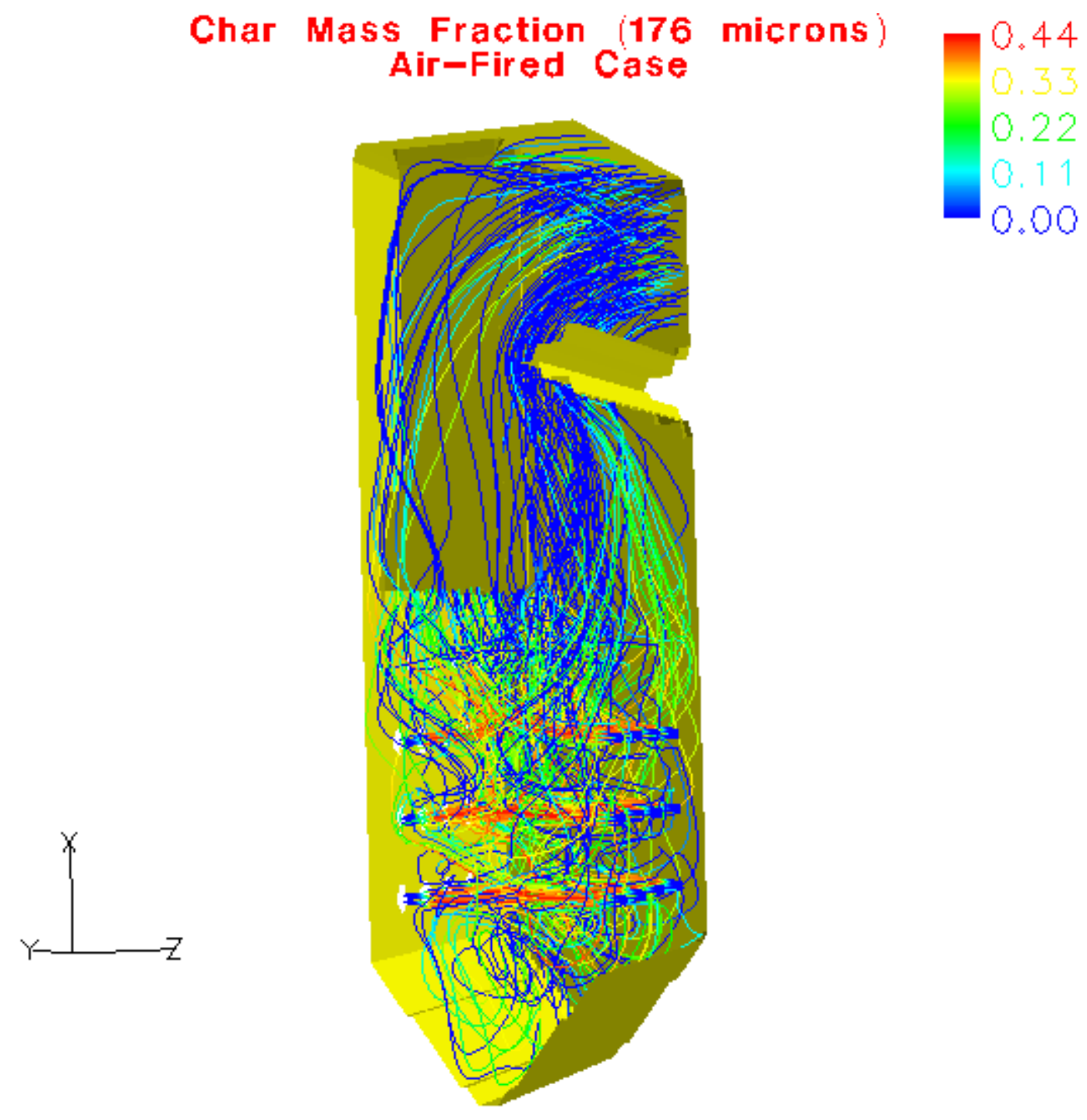


Figure 4.4.13 - Outlet NOx Versus OFA Flow Rate for Air-Fired Furnace

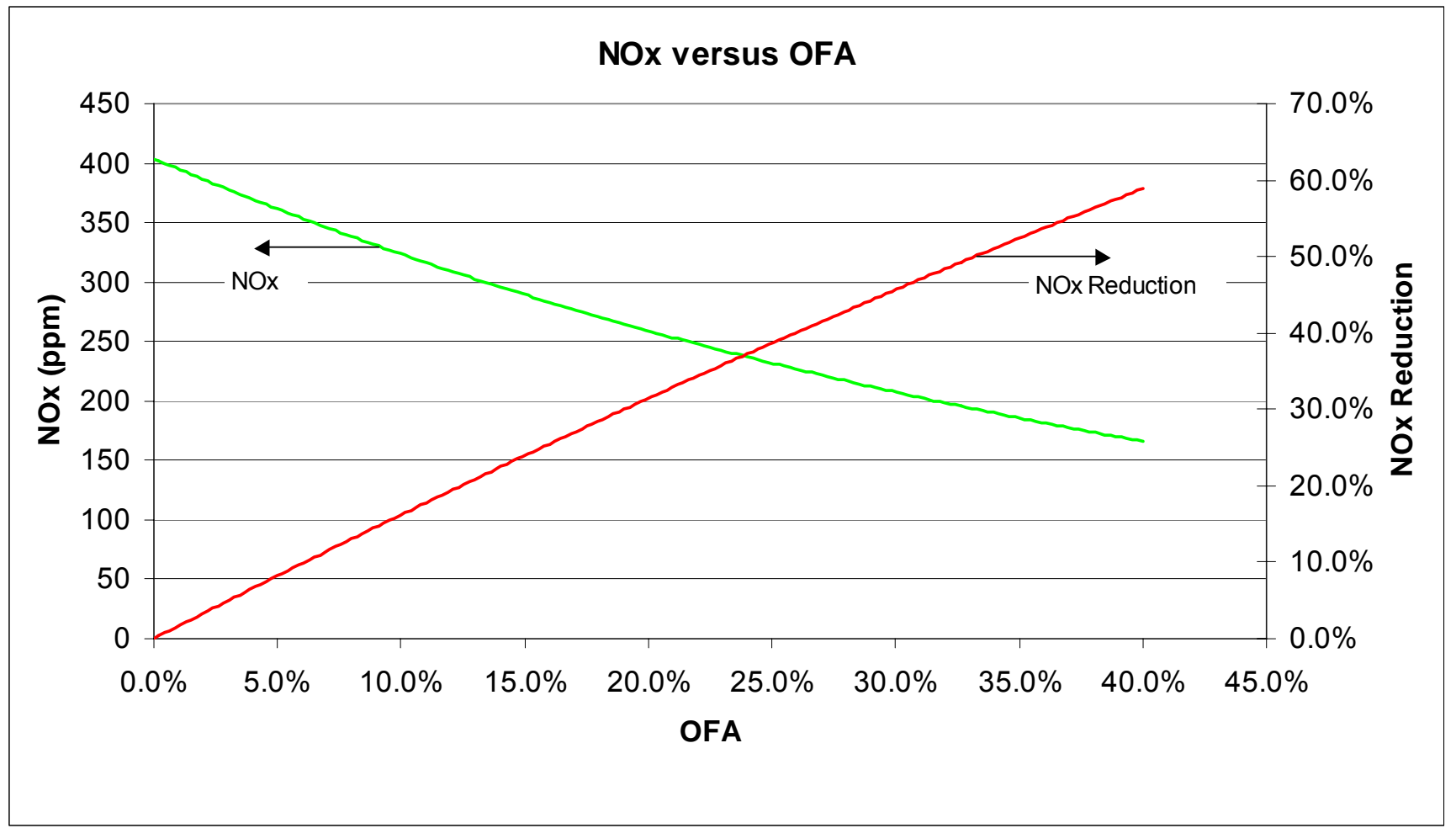

Figure 4.4.14 - Coal Burnout Versus OFA Flow Rate for Air-Fired Furnace

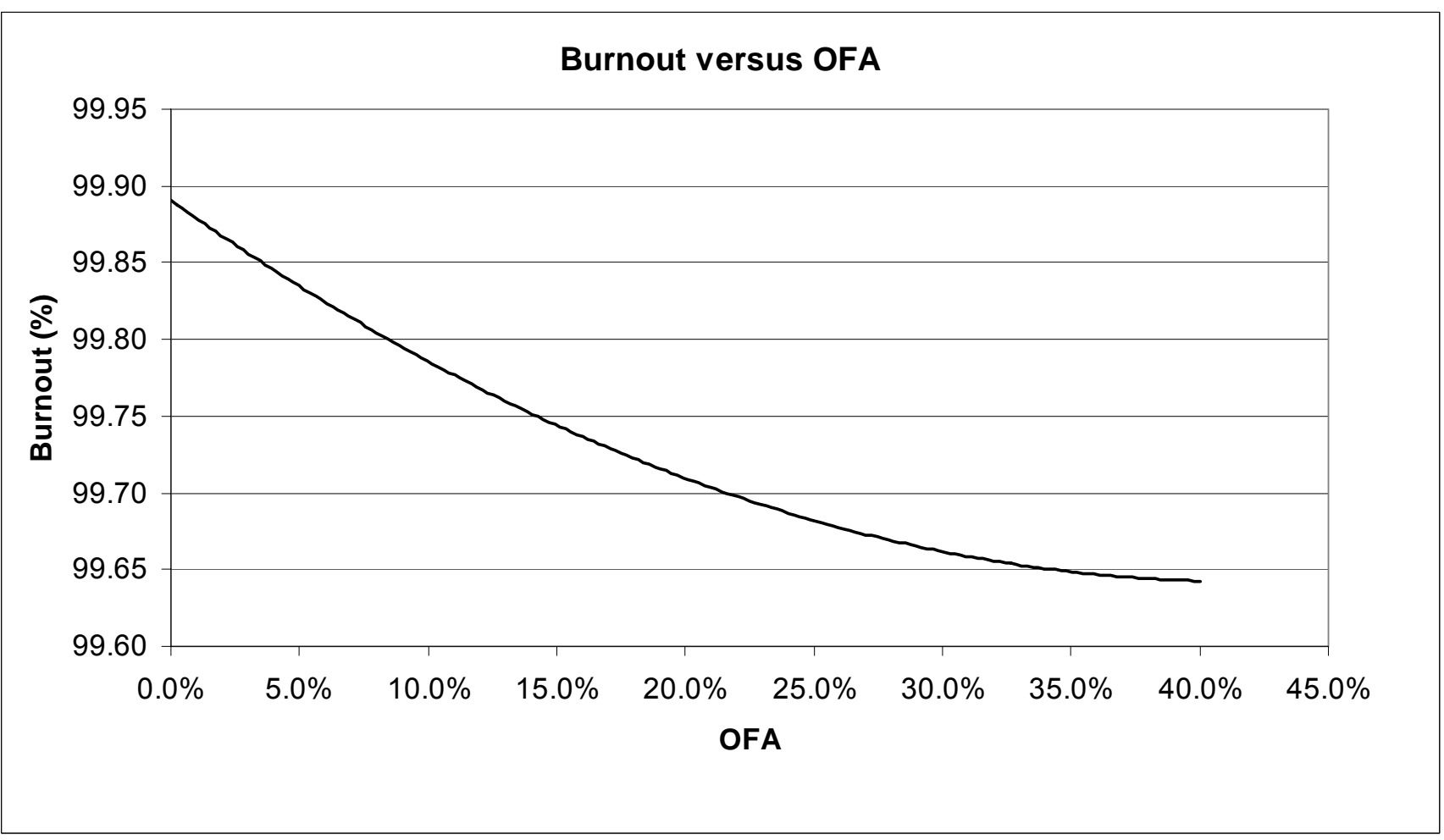


Figure 4.4.15 - Air-Fired and Oxygen-Fired Boiler Outlines $($ Black $=$ Air-Fired, Red $=$ Oxygen Fired $)$

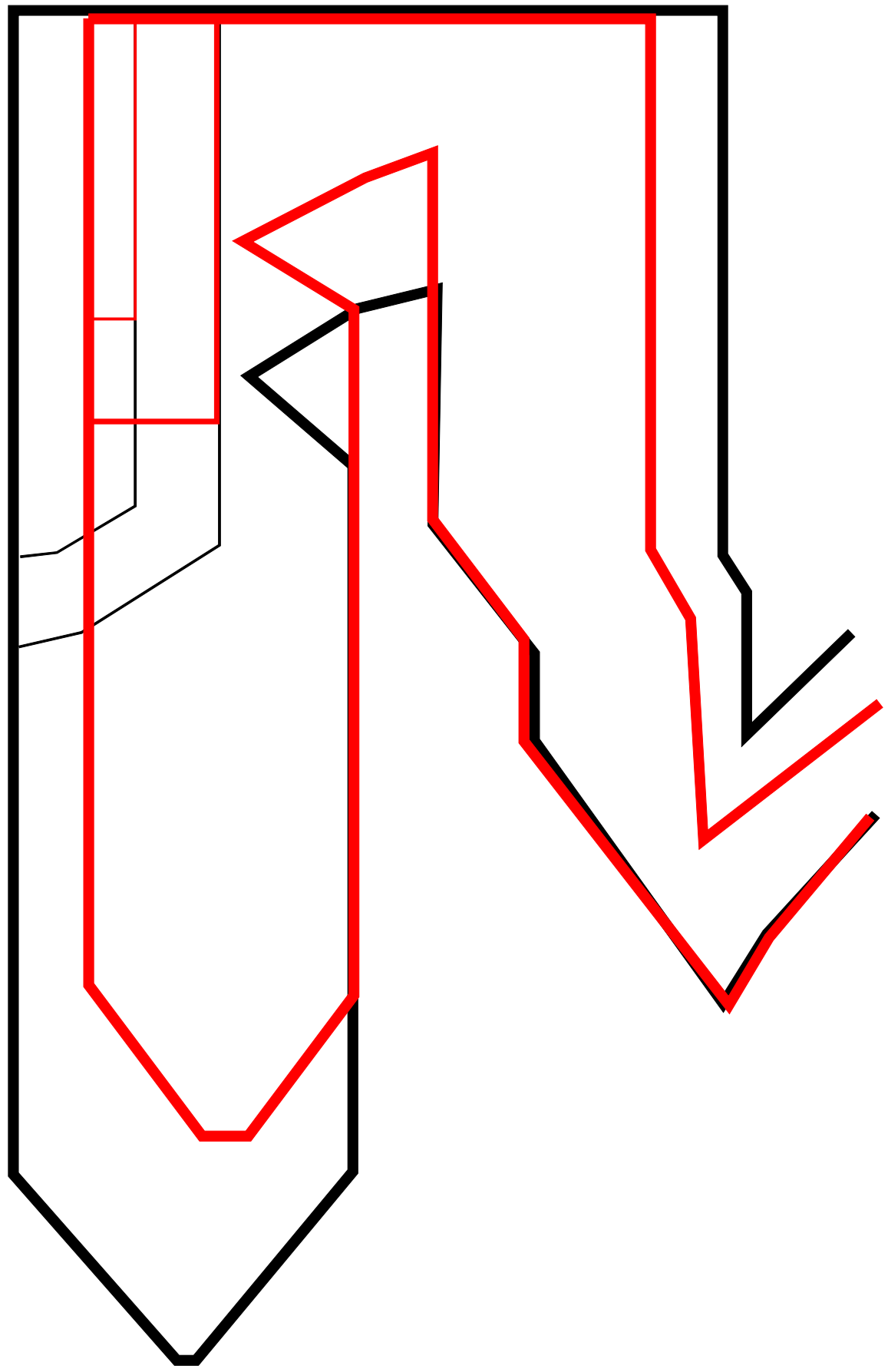


Figure 4.4.16 - Oxygen-Fired Boiler Design

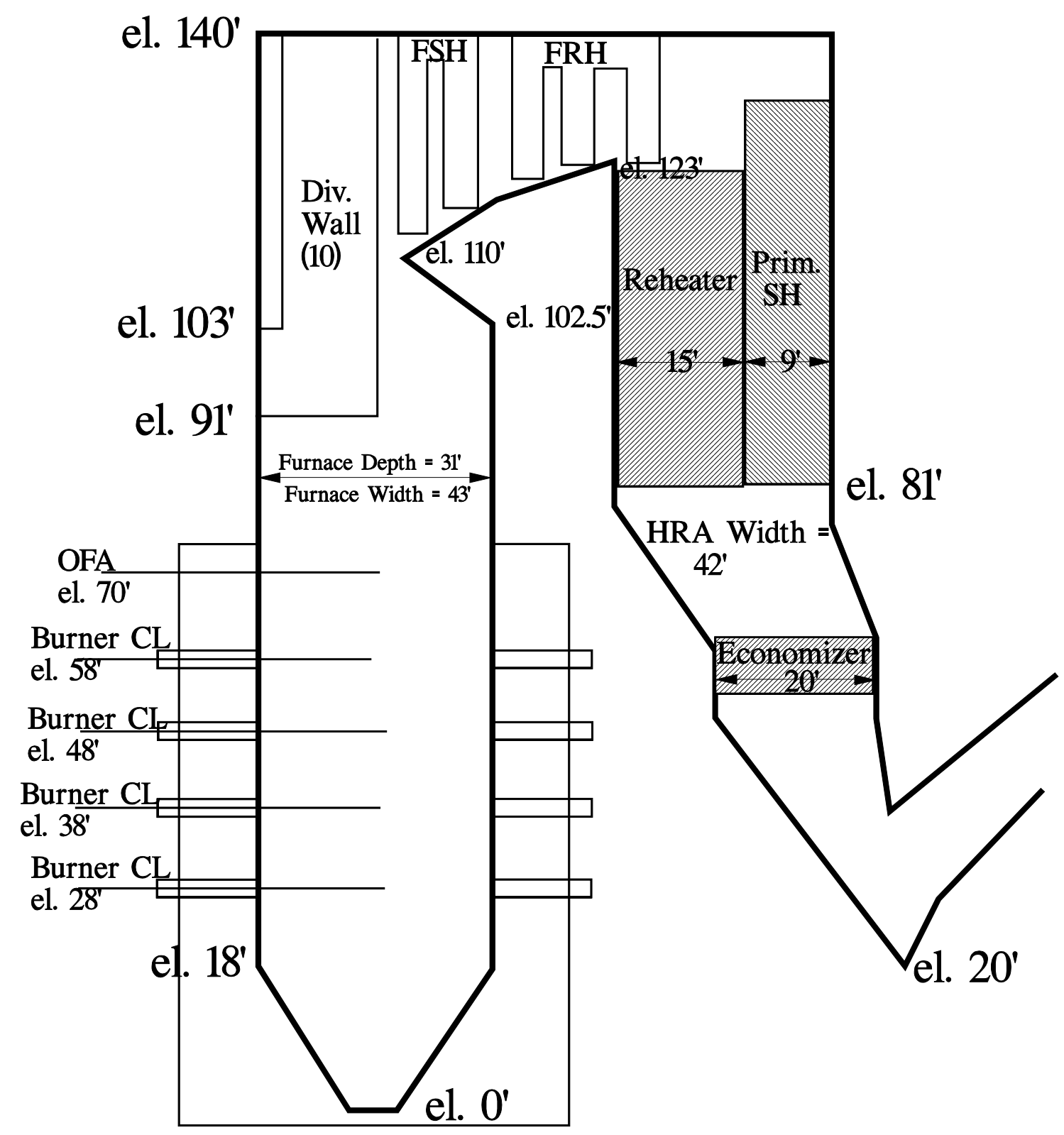


Figure 4.4.17 - Gas Velocity for $\mathrm{O}_{2}$-Fired Case Without OFG

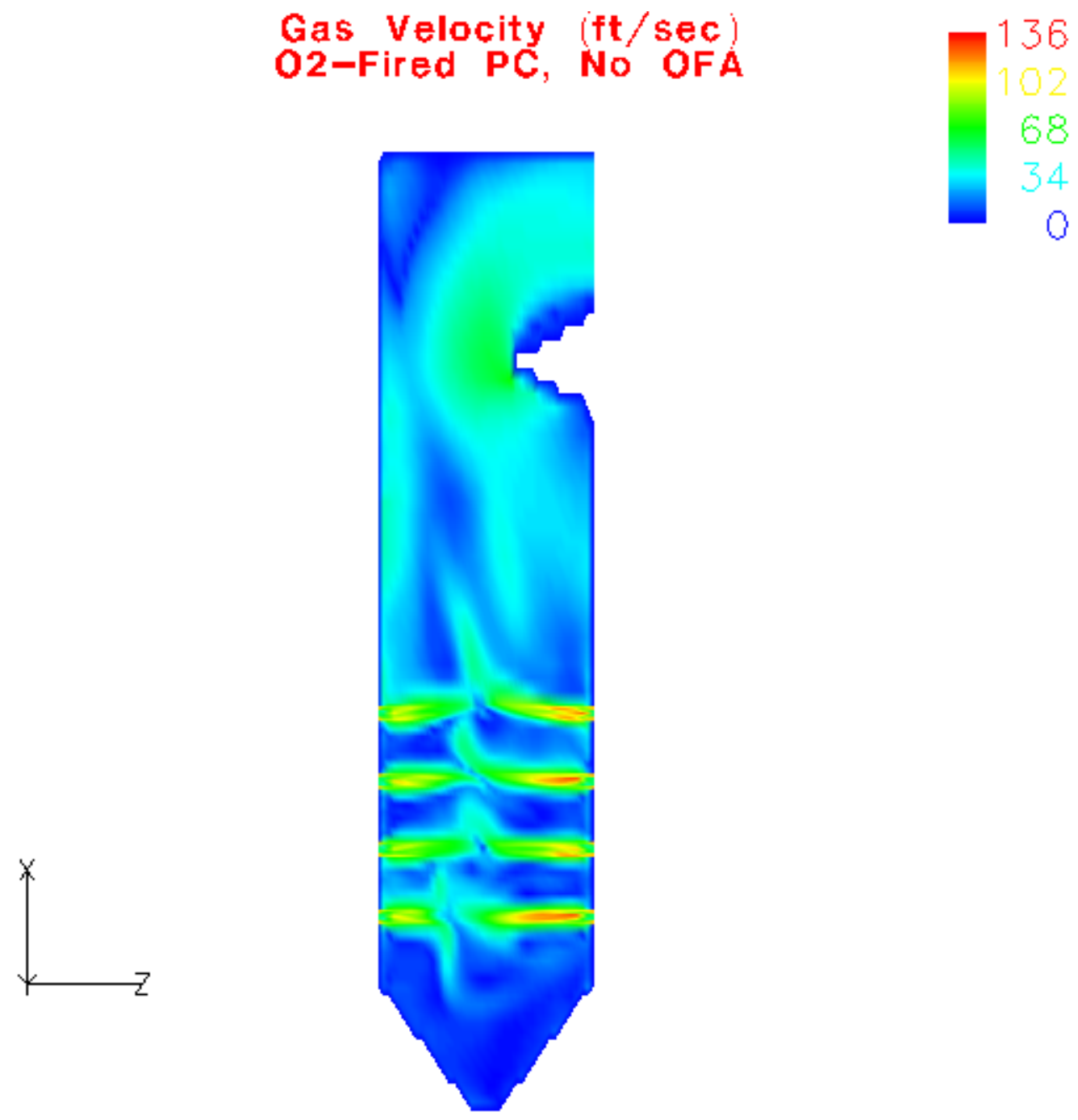


Figure 4.4.18 - Gas Temperature for $\mathrm{O}_{2}$-Fired Case Without OFG

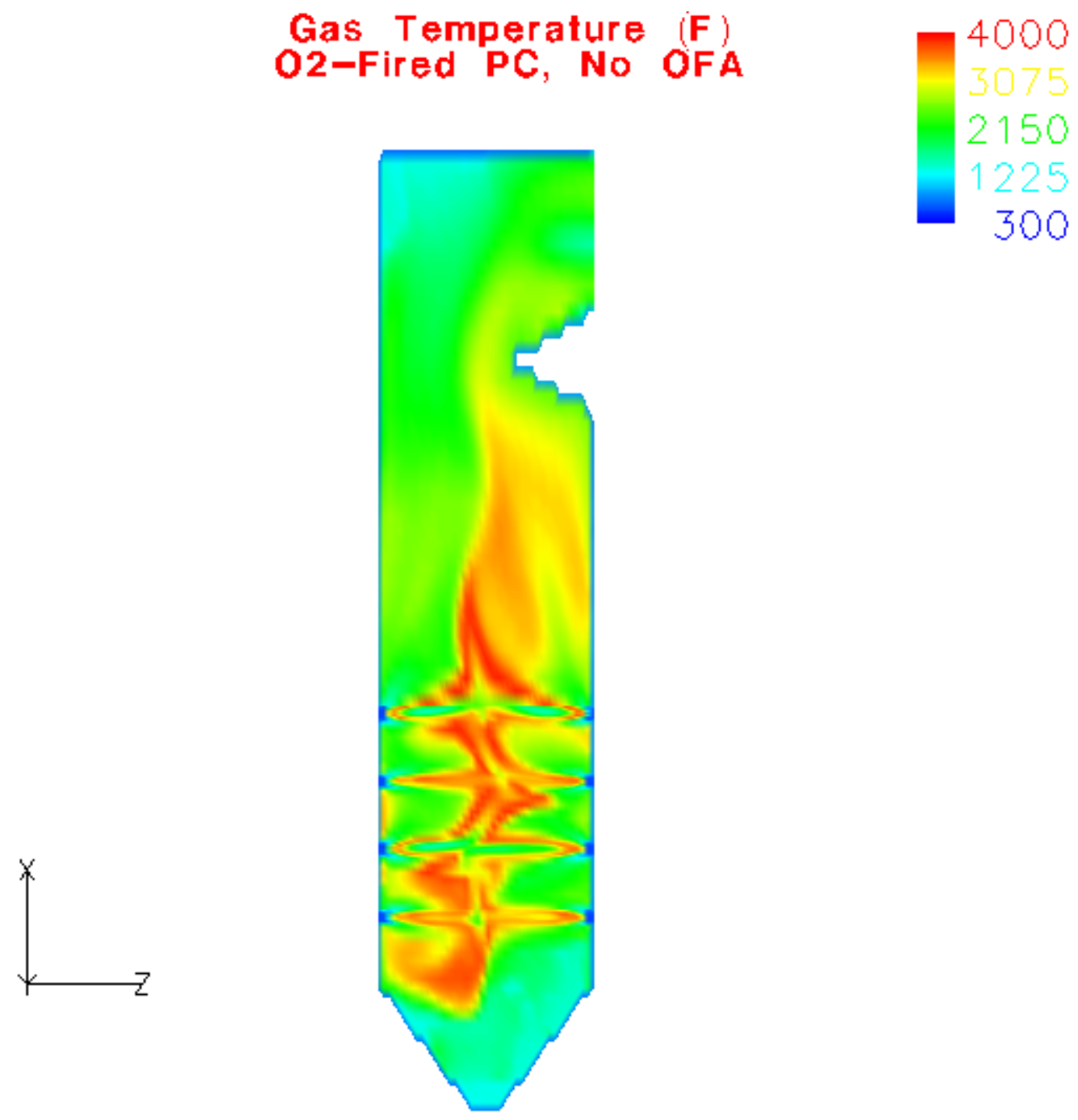


Figure 4.4.19 $-\mathrm{O}_{2}$ Mole Fraction for $\mathrm{O}_{2}$-Fired Case Without OFG

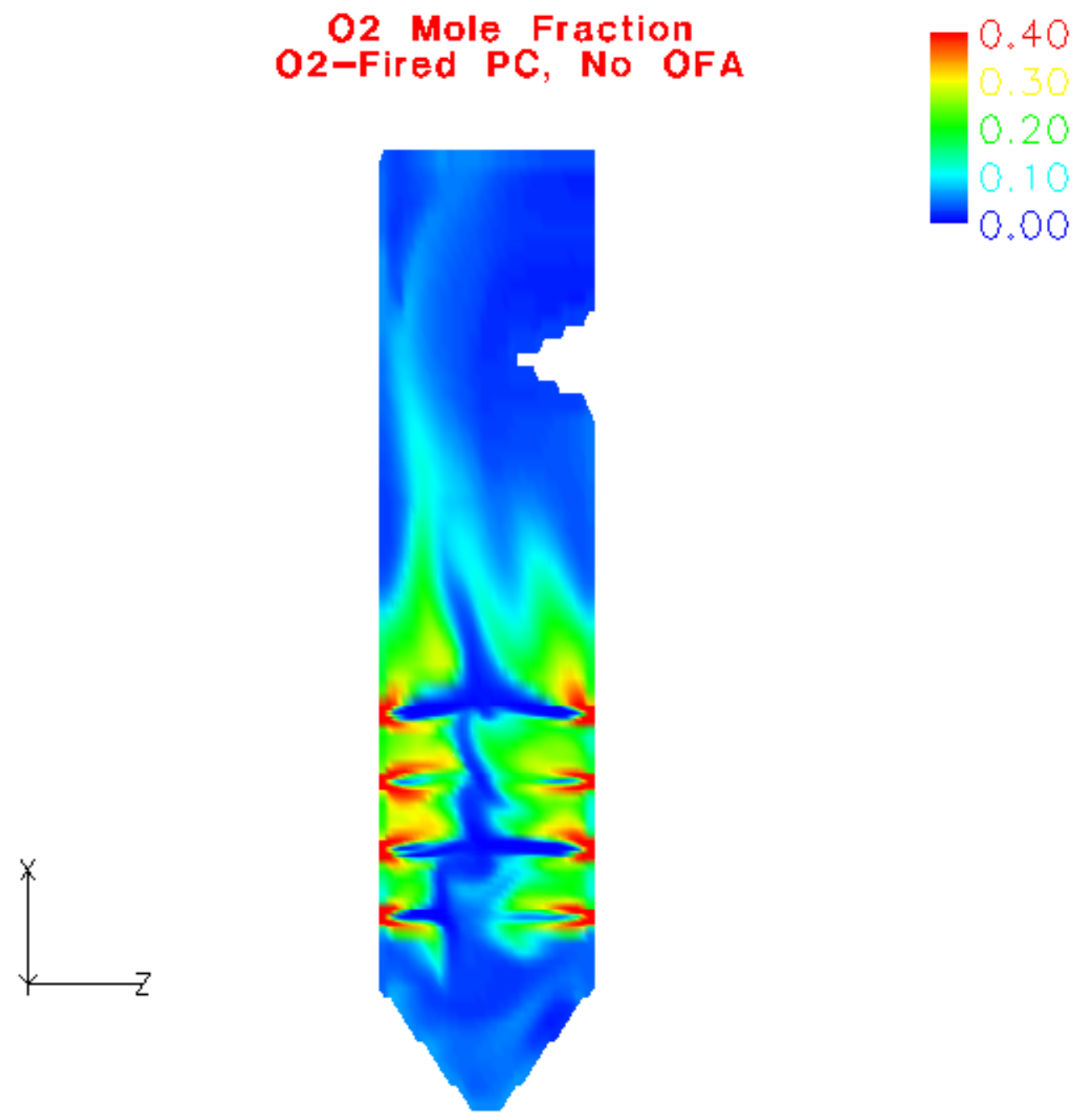


Figure 4.4.20 - Wall Heat Flux for $\mathrm{O}_{2}$-Fired Case Without OFG

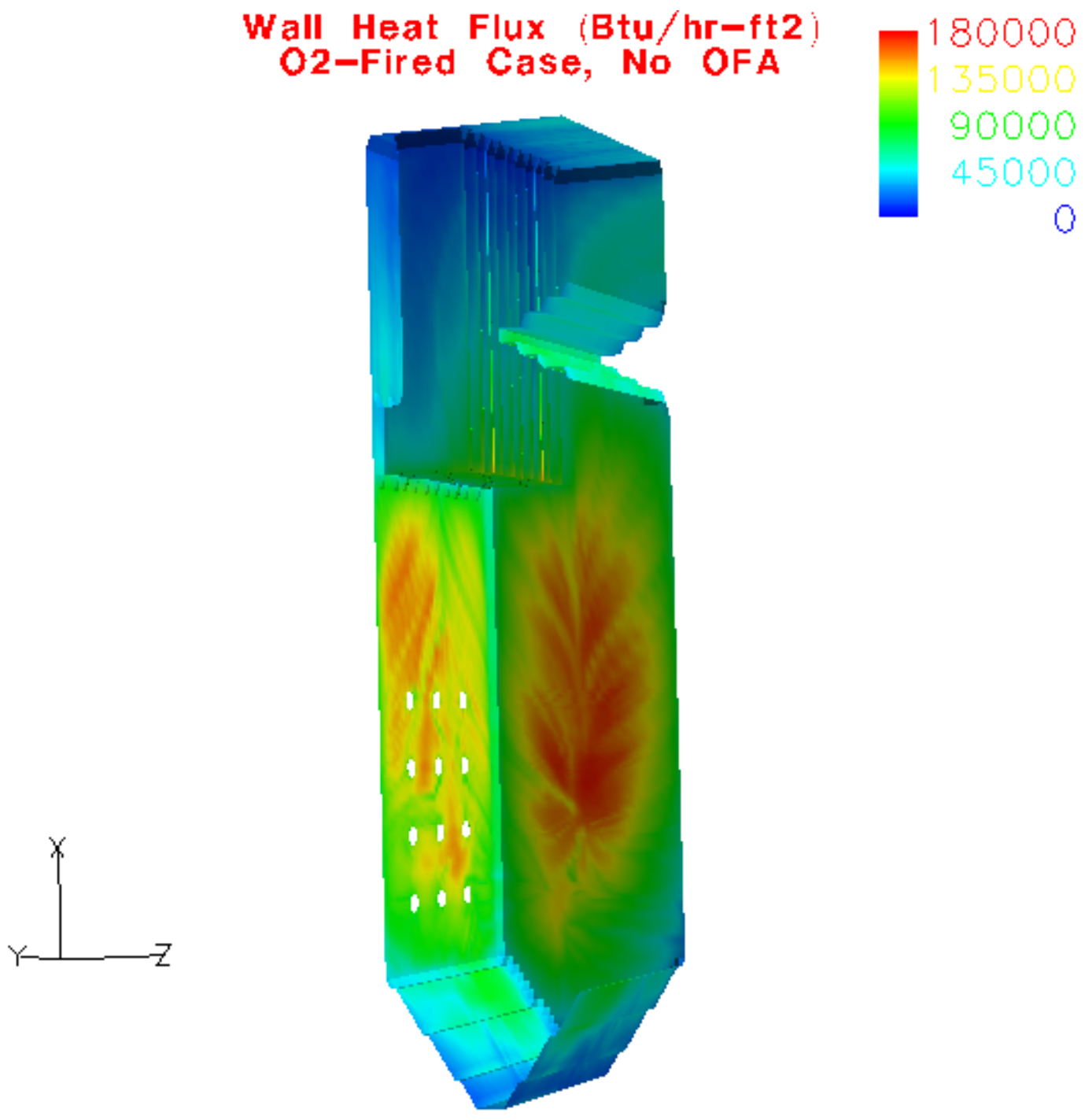


Figure 4.4.21 - Wall Temperature for $\mathrm{O}_{2}$-Fired Case Without OFG

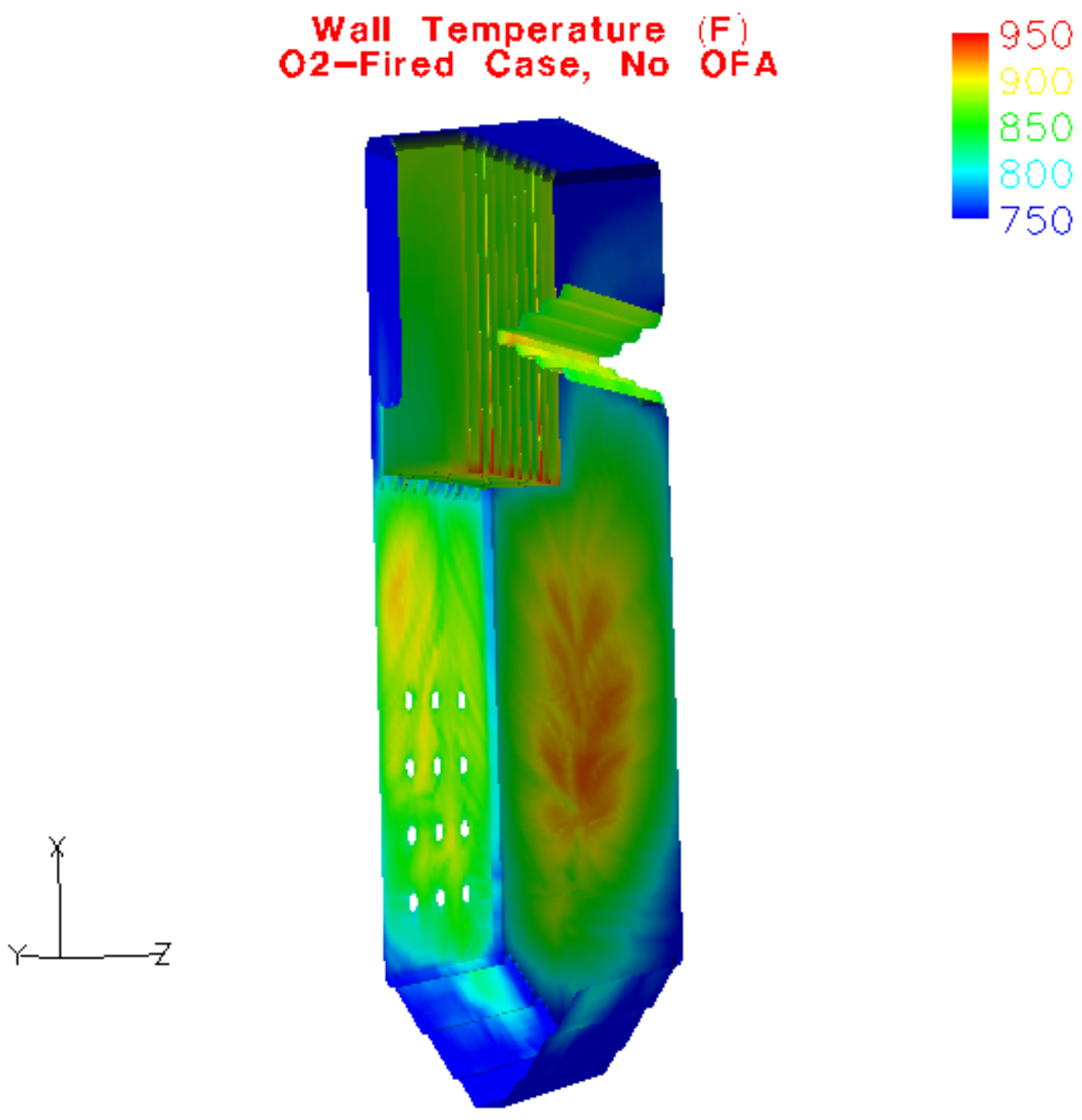


Figure 4.4.22 - Wall $\mathrm{CO}$ for $\mathrm{O}_{2}$-Fired Case Without OFG Co Concentration O2-Fired Case, $0 \%$ OFA
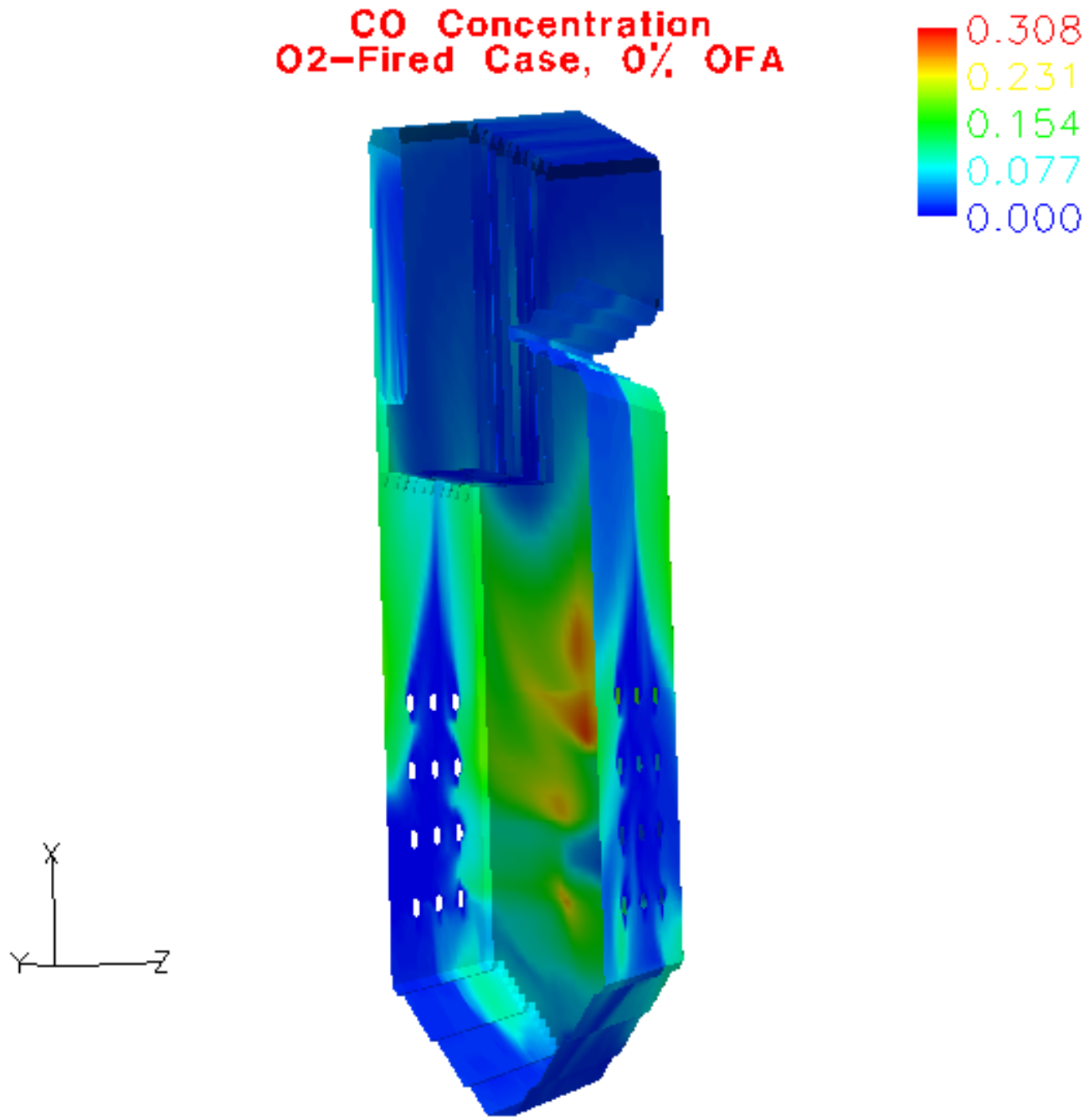
Figure 4.4.23 - Char Mass Fraction (69 micron) for $\mathrm{O}_{2}$-Fired Case, No OFG Char Mass Fraction (69 micron) 0.45 O2-Fired Case, No OFA
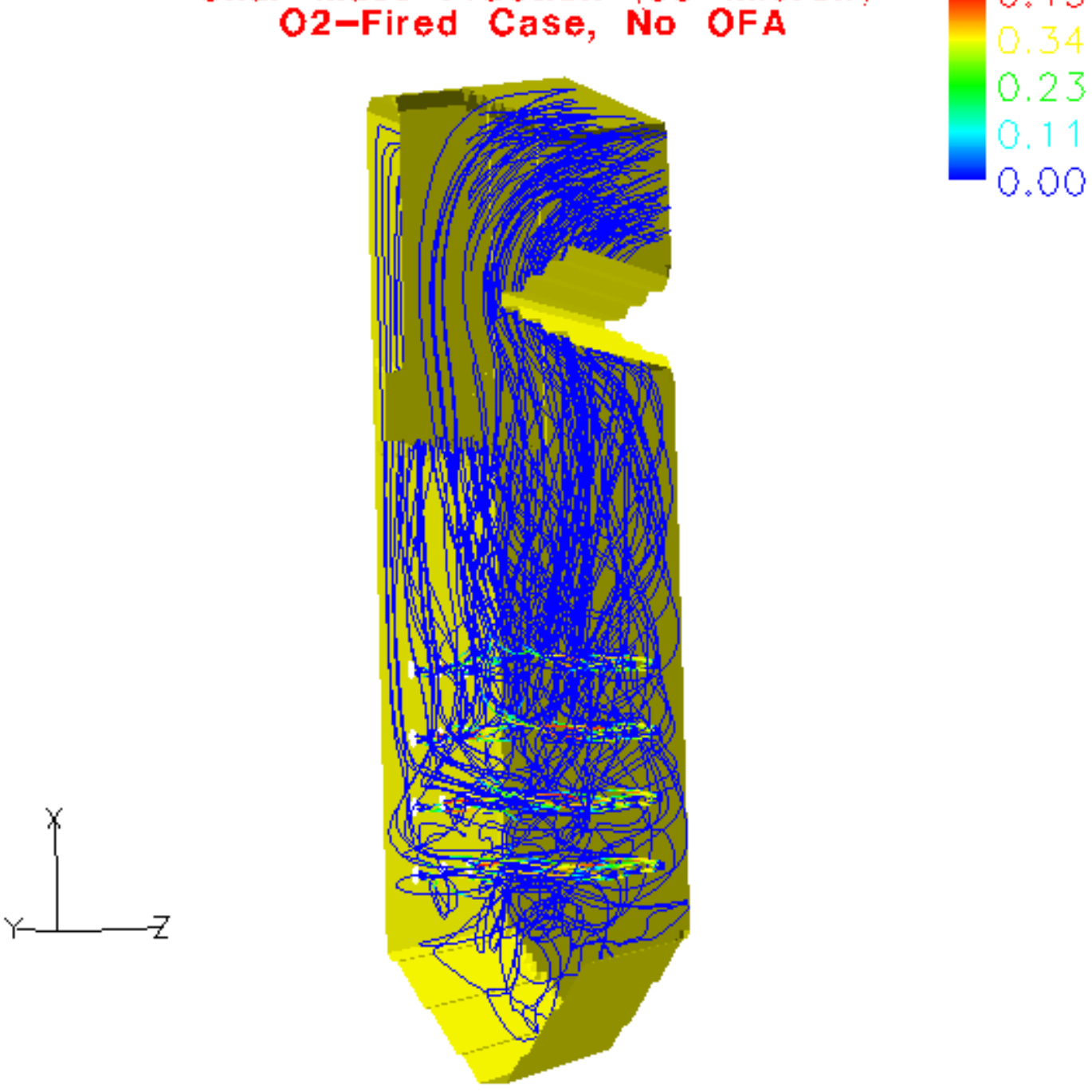
Figure 4.4.24 - Char Mass Fraction (169 micron) for $\mathrm{O}_{2}$-Fired Case, No OFG Char Mass Fraction (169 micron) 0.44 O2-Fired Case, No OFA
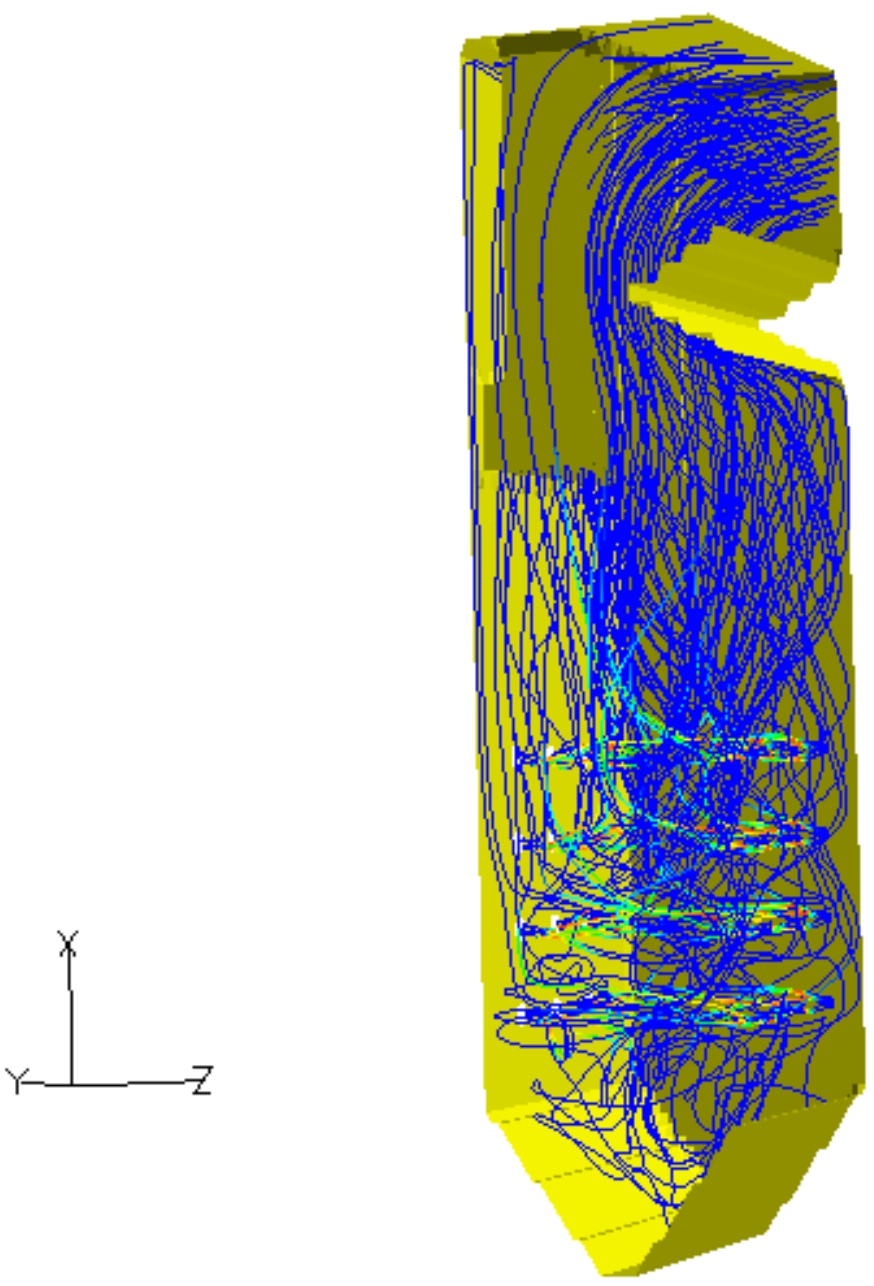

0.22

0.11 0.00 
Figure 4.4.25 - Char Mass Fraction (169 micron) for $\mathrm{O}_{2}$-Fired Case, No OFG, Without Primary gas Swirl

\section{Char Mass Fraction i169 micron? O2-Fired Case, No OFA}
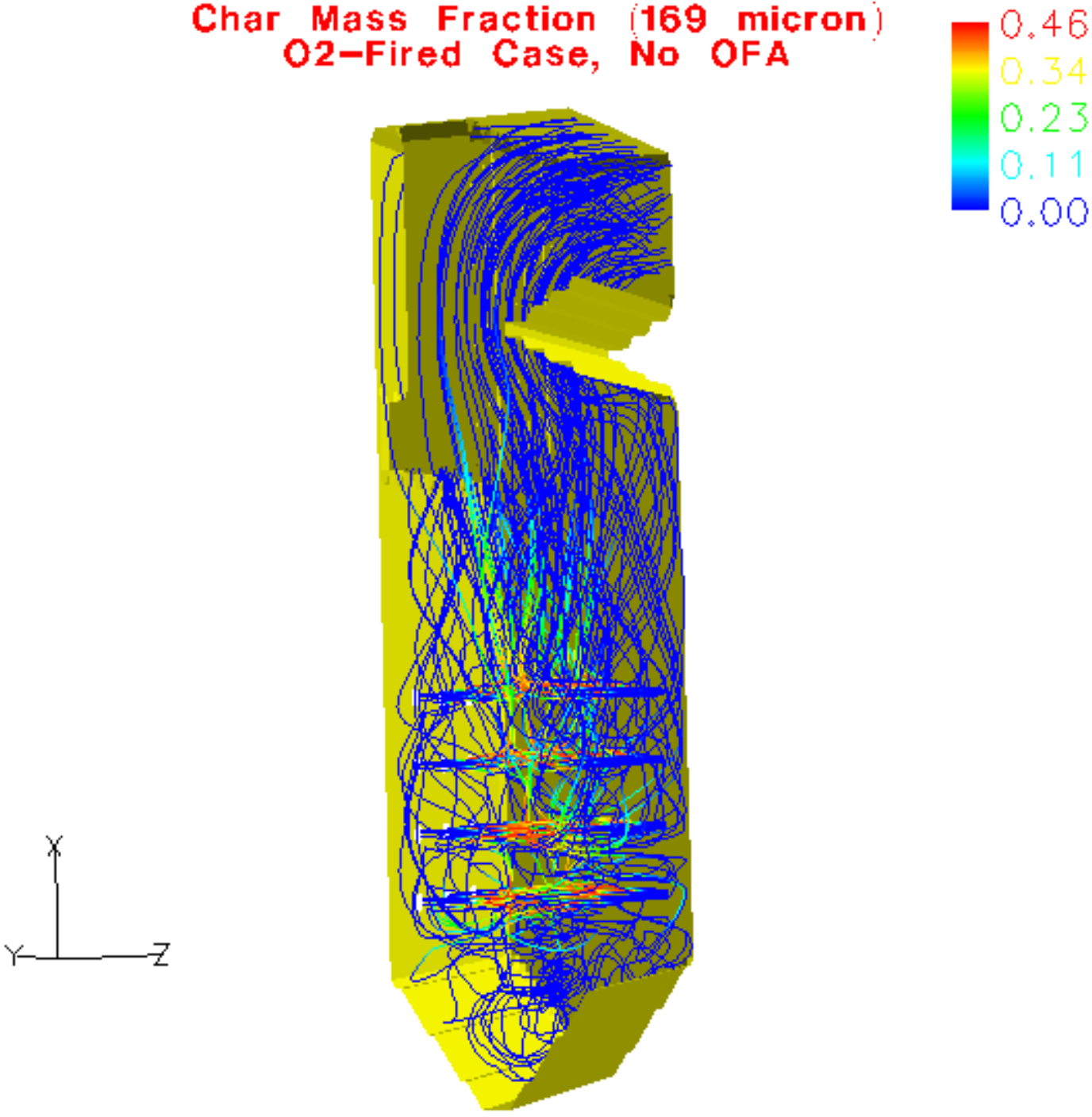
Figure 4.4.26 - Gas Velocity for $\mathrm{O}_{2}$-Fired Case With 20\% OFG

$$
\text { Gas Velocity (ft/sec) }
$$

O2-Fired PC, 20\% OFA
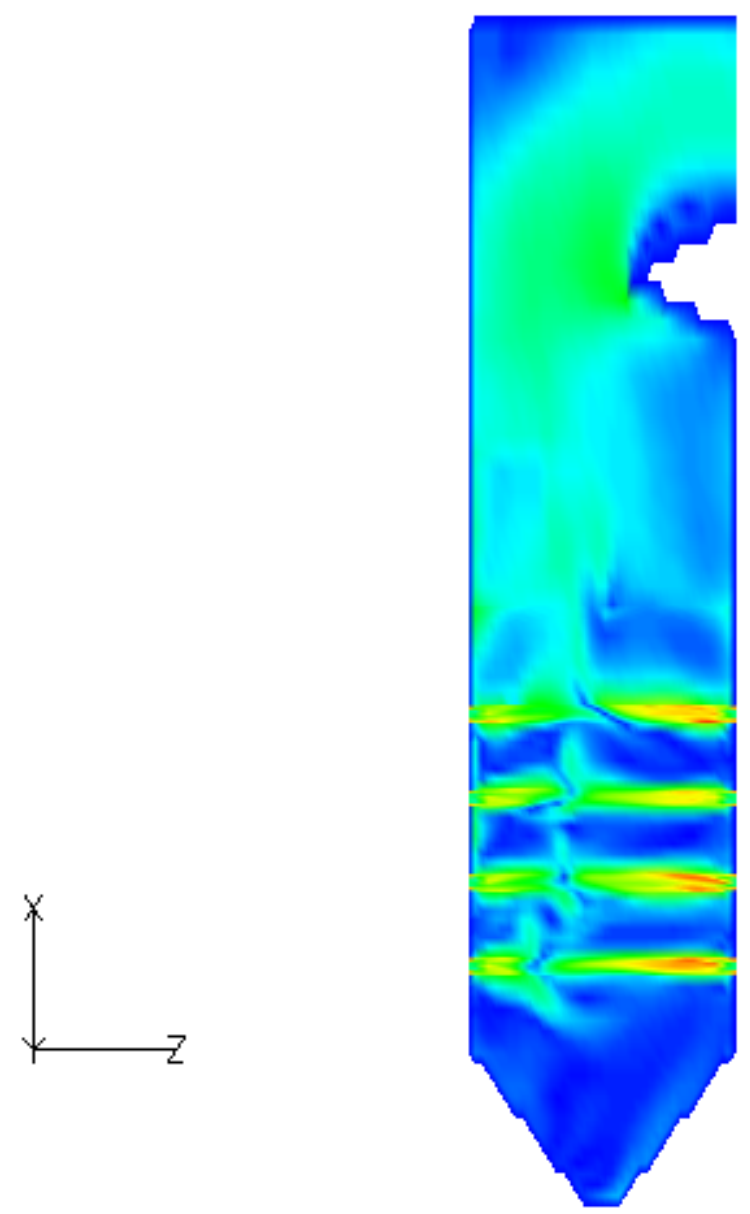

136
102
68
34
0 
Figure 4.4.27 - Gas Temperature for $\mathrm{O}_{2}$-Fired Case With 20\% OFG
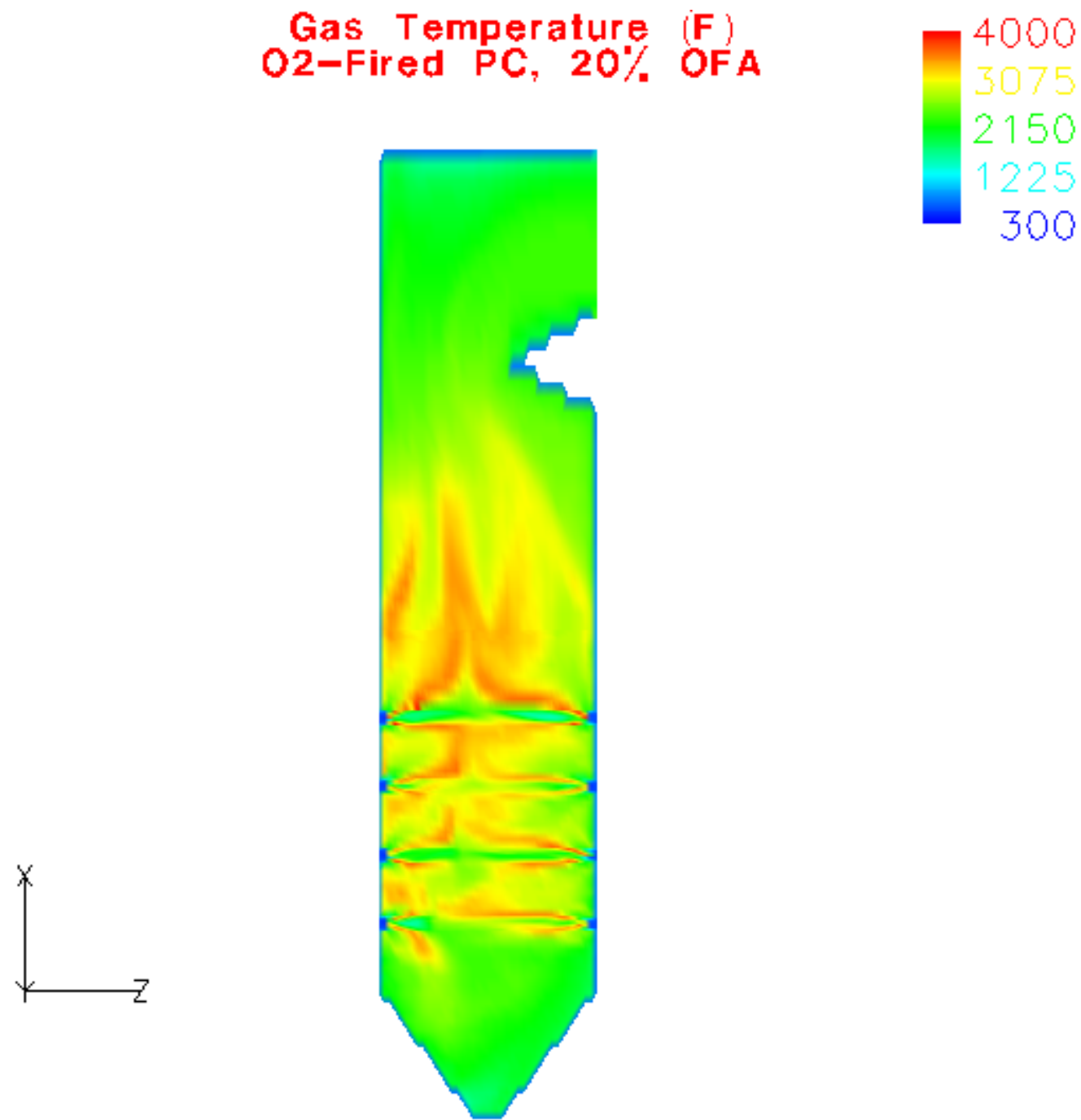
Figure 4.4.28 $-\mathrm{O}_{2}$ Mole Fraction for $\mathrm{O}_{2}$-Fired Case With 20\% OFG

$$
\begin{aligned}
& \text { O2 Mole Fraction } \\
& \text { O2-Fired PC, } 20 \% \text { OF A }
\end{aligned}
$$
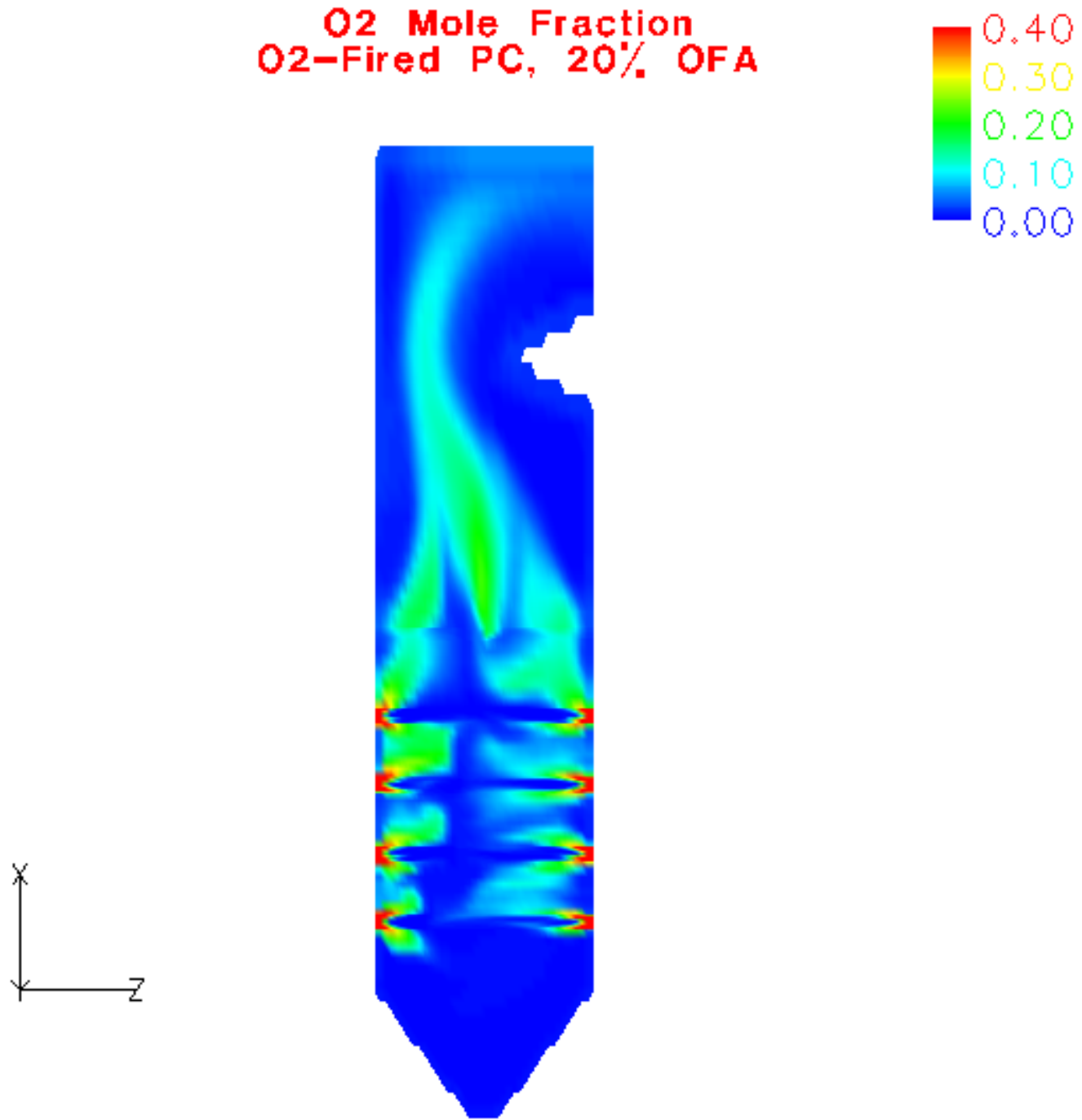
Figure 4.4.29 - Wall Heat Flux for $\mathrm{O}_{2}$-Fired Case With 20\% OFG Wall Heat Flux Btu/hr-ft2 O2-Fired Case, 20\% OFA

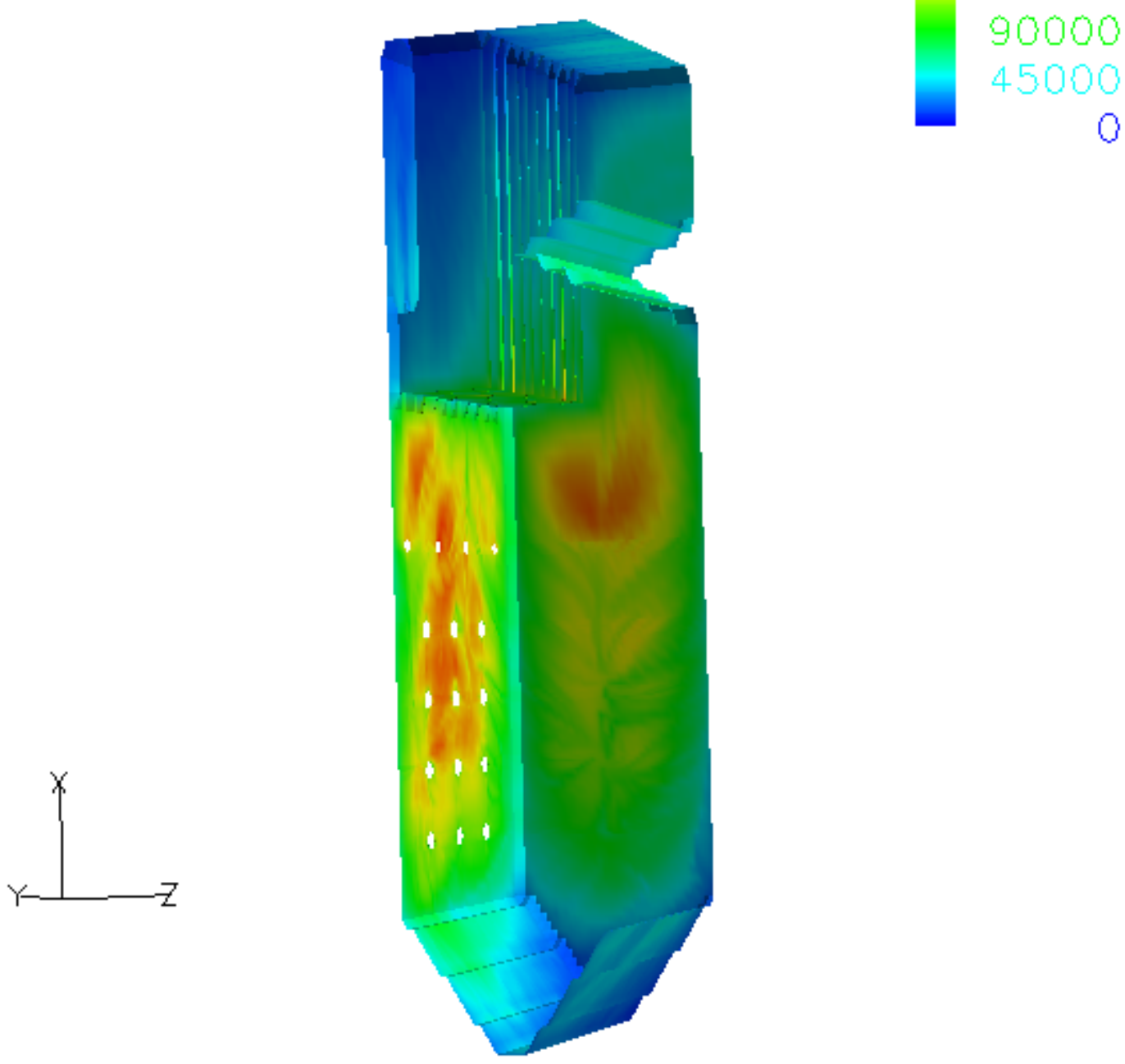


Figure 4.4.30 - Wall Temperature for $\mathrm{O}_{2}$-Fired Case With 20\% OFG

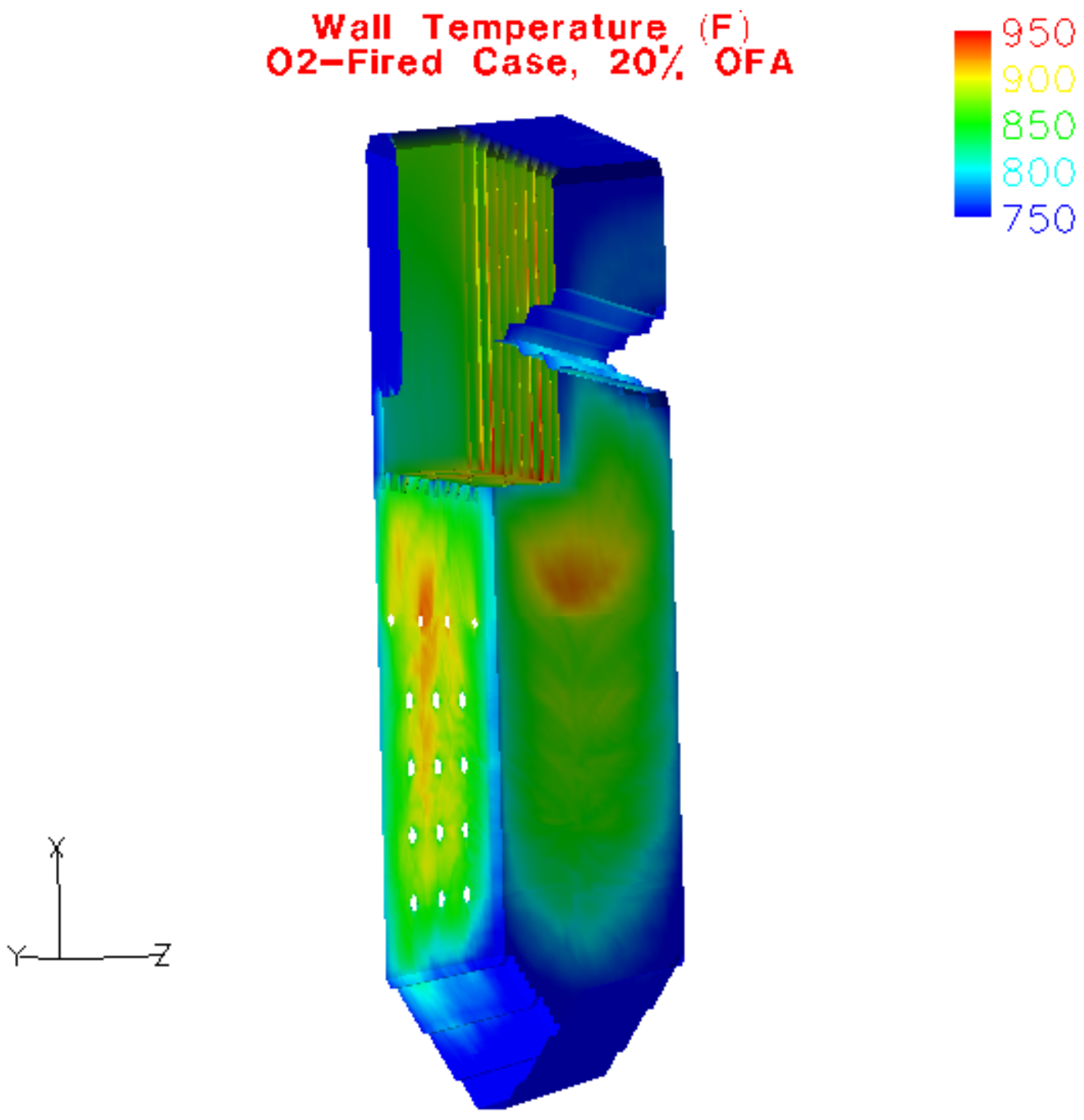


Figure 4.4.31 - Wall CO for $\mathrm{O}_{2}$-Fired Case With 20\% OFG
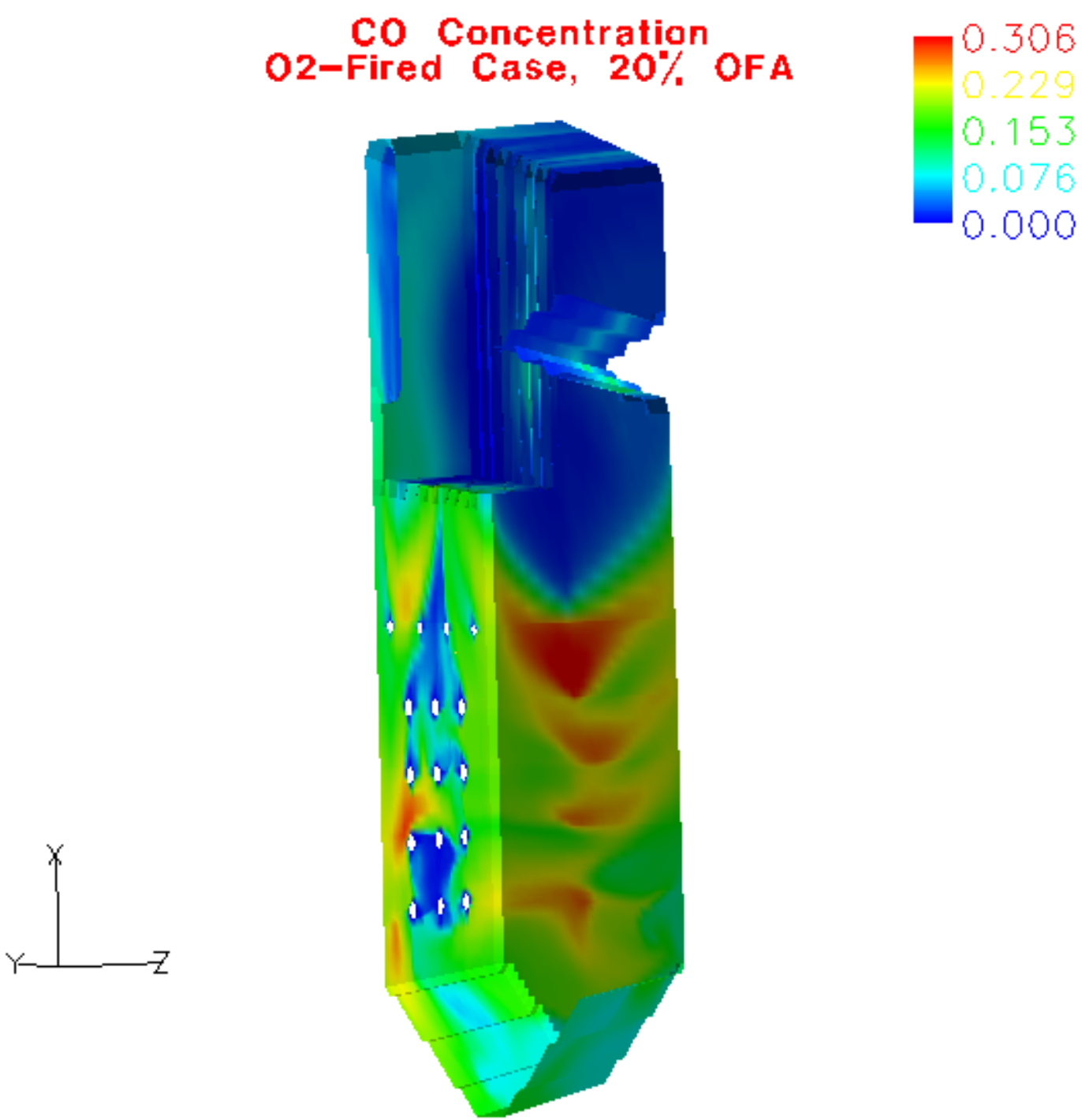
Figure 4.4.32 - Char Mass Fraction (69 micron) for $\mathrm{O}_{2}$-Fired Case, $20 \%$ OFG Char Mass Fraction (69 micron) 0.46 O2-Fired Case, 20\% OFA
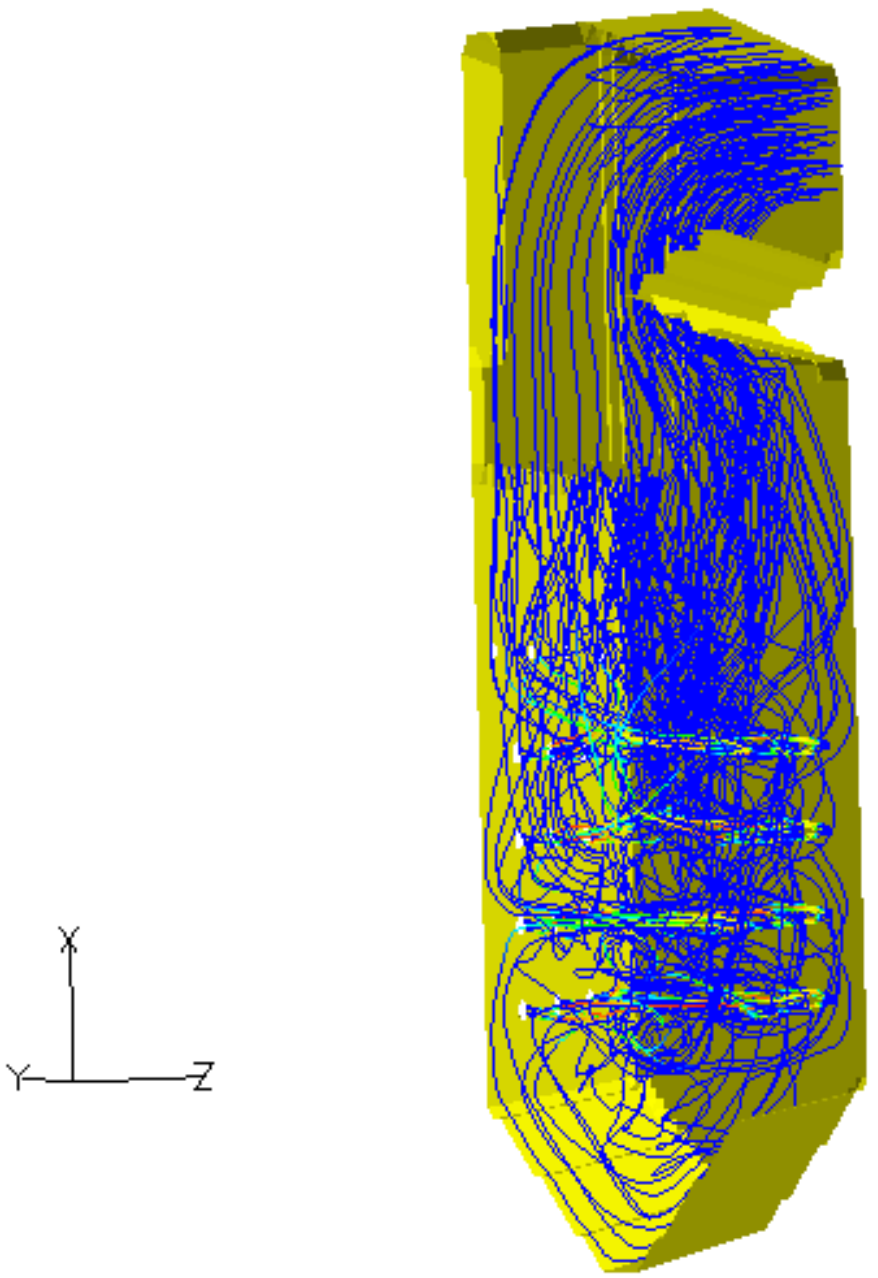
Figure 4.4.33 - Char Mass Fraction (169 micron) for $\mathrm{O}_{2}$-Fired Case, 20\% OFG

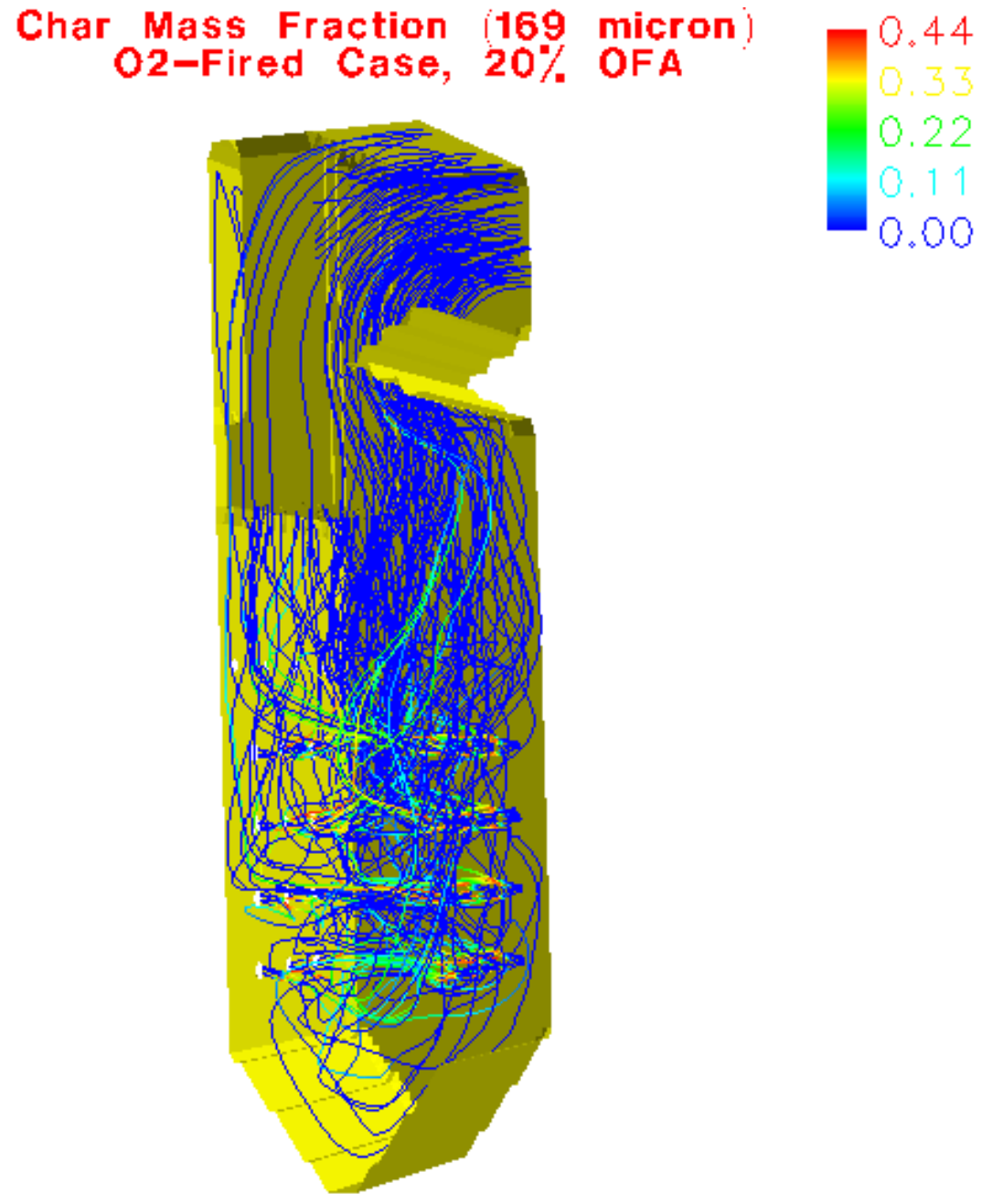


Figure 4.4.34 - Char Mass Fraction (169 micron) for $\mathrm{O}_{2}$-Fired Case, 20\% OFG, Without Primary gas Swirl

Char Mass Fraction 169 micron) 0.46 02-Fired Case, 20\% OFA
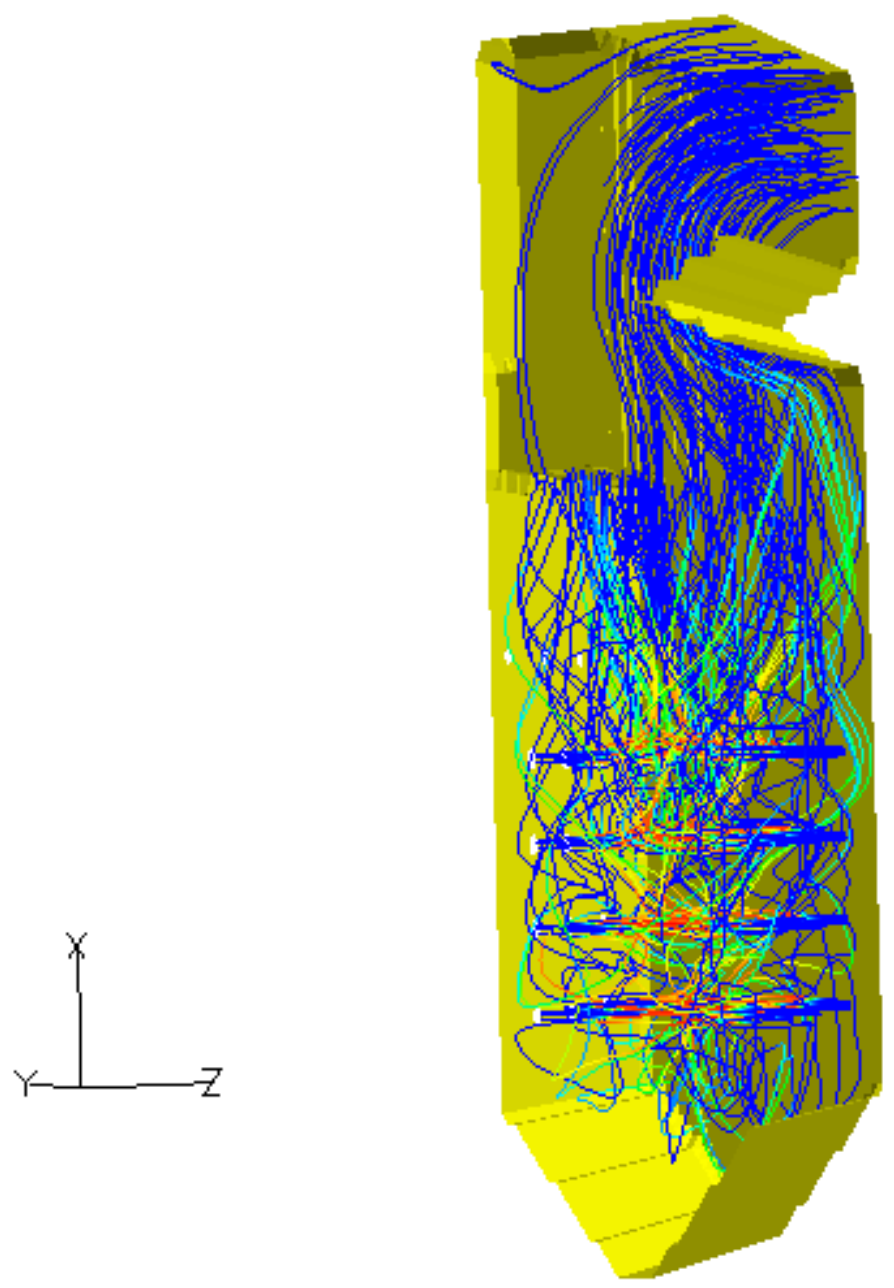
Table 4.4.4 - HRA Tube Bank Design

\begin{tabular}{|c|c|c|c|}
\hline & & Springerville & O2 PC \\
\hline \multicolumn{4}{|l|}{ Finishing Superheater } \\
\hline Length & $\mathrm{ft}$ & 38.0 & 24.0 \\
\hline No. of Tubes Deep & & 48 & 48 \\
\hline No. of Tubes Wide & & 30 & 32 \\
\hline Total Number of Tubes & & 1,440 & 1,536 \\
\hline Tube Outside Diameter & in & 2.000 & 2.000 \\
\hline Tube Thickness & in & 0.266 & 0.266 \\
\hline Tube Material & & SA-213-T91 & SA-213-T91 \\
\hline Total Surface Area & $\mathrm{ft} 2$ & 28,839 & 20,587 \\
\hline \multicolumn{4}{|l|}{ Vertical Reheater } \\
\hline Length & $\mathrm{ft}$ & 30.5 & 20.0 \\
\hline No. of Tubes Deep & & 30 & 50 \\
\hline No. of Tubes Wide & & 63 & 51 \\
\hline Total Number of Tubes & & 1,890 & 2,550 \\
\hline Tube Outside Diameter & in & 2.250 & 2.250 \\
\hline Tube Thickness & in & 0.165 & 0.165 \\
\hline Tube Material & & SA-213-T91 & SA-213-T91 \\
\hline Total Surface Area & $\mathrm{ft} 2$ & 33,926 & 30,042 \\
\hline \multicolumn{4}{|l|}{ Primary Superheater } \\
\hline Length & $\mathrm{ft}$ & 18.0 & 9.0 \\
\hline No. of Tubes Deep & & 96 & 162 \\
\hline No. of Tubes Wide & & 63 & 54 \\
\hline Total Number of Tubes & & 6,048 & 8,748 \\
\hline Tube Outside Diameter & in & 2.250 & 2.250 \\
\hline Tube Thickness & in & 0.23 & 0.23 \\
\hline Tube Material & & $\mathrm{T} 12 / \mathrm{T} 2 / \mathrm{CS}$ & $\mathrm{T} 12 / \mathrm{T} 2 / \mathrm{CS}$ \\
\hline Total Surface Area & $\mathrm{ft} 2$ & 67,231 & 48,440 \\
\hline \multicolumn{4}{|l|}{ Horizontal Reheater } \\
\hline Length & $\mathrm{ft}$ & 16.0 & 15.0 \\
\hline No. of Tubes Deep & & 65 & 100 \\
\hline No. of Tubes Wide & & 126 & 90 \\
\hline Total Number of Tubes & & 8,190 & 9,000 \\
\hline Tube Outside Diameter & in & 2.250 & 2.250 \\
\hline Tube Thickness & in & 0.165 & 0.165 \\
\hline Tube Material & & T91/T22/T2/CS & T91/T22/T2/CS \\
\hline Total Surface Area & $\mathrm{ft} 2$ & 81,952 & 84,821 \\
\hline \multicolumn{4}{|l|}{ Upper Economizer } \\
\hline$\overline{\text { Length }}$ & $\mathrm{ft}$ & 18.0 & \\
\hline No. of Tubes Deep & & 24 & \\
\hline No. of Tubes Wide & & 126 & \\
\hline Total Number of Tubes & & 3,024 & \\
\hline Tube Outside Diameter & in & 2.250 & \\
\hline Tube Thickness & in & 0.205 & \\
\hline Tube Material & & SA-210-A1 & \\
\hline Total Surface Area & $\mathrm{ft} 2$ & 32,064 & 0 \\
\hline \multicolumn{4}{|l|}{ Lower Economizer } \\
\hline Length & $\mathrm{ft}$ & 25.5 & 20.0 \\
\hline No. of Tubes Deep & & 27 & 30 \\
\hline No. of Tubes Wide & & 126 & 90 \\
\hline Total Number of Tubes & & 3,402 & 2,700 \\
\hline Tube Outside Diameter & in & 2.250 & 2.250 \\
\hline Tube Thickness & in & 0.205 & 0.205 \\
\hline Tube Material & & SA-210-A1 & SA-210-A1 \\
\hline Total Surface Area & $\mathrm{ft} 2$ & 50,099 & 31,810 \\
\hline
\end{tabular}


Table 4.4.5 - HRA Tube Bank Performance

\begin{tabular}{|c|c|c|c|c|c|c|}
\hline & Bank & $\begin{array}{l}\text { Surface } \\
\text { Area } \\
\text { (ft2) }\end{array}$ & $\begin{array}{l}\text { Heat Trans. } \\
\text { Coeff. } \\
\text { (Btu/hr-ft2-F) }\end{array}$ & $\begin{array}{c}\text { Mean Temp. } \\
\text { Diff. } \\
(\mathrm{F}) \\
\end{array}$ & $\begin{array}{c}\text { Heat } \\
\text { Transfer } \\
(\mathrm{MM} \mathrm{Btu/hr})\end{array}$ & $\begin{array}{c}\text { Gas } \\
\text { Press. Drop } \\
\text { (in H2O) }\end{array}$ \\
\hline Air PC & Finishing Superheater & 28,839 & 11.7 & 1080 & 364 & 0.14 \\
\hline $\mathrm{O} 2 \mathrm{PC}$ & Finishing Superheater & 20,587 & 14.6 & 1172 & 353 & 0.16 \\
\hline Air PC & Primary Superheater & 67,231 & 10.1 & 437 & 295 & 0.69 \\
\hline $\mathrm{O} 2 \mathrm{PC}$ & Primary Superheater & 48,438 & 10.1 & 294 & 144 & 0.69 \\
\hline Air PC & Finishing Reheater & 33,926 & 10.6 & 785 & 281 & 0.29 \\
\hline $\mathrm{O} 2 \mathrm{PC}$ & Finishing Reheater & 30,042 & 12.4 & 728 & 271 & 0.26 \\
\hline Air PC & Primary Reheater & 81,952 & 8.3 & 403 & 274 & 0.48 \\
\hline $\mathrm{O} 2 \mathrm{PC}$ & Primary Reheater & 84,821 & 10.5 & 296 & 264 & 0.63 \\
\hline Air PC & Upper Economizer & 32,064 & 9.4 & 367 & 111 & 0.39 \\
\hline $\mathrm{O} 2 \mathrm{PC}$ & Upper Economizer & & & & & 0.00 \\
\hline Air PC & Lower Economizer & 50,099 & 10.7 & 261 & 140 & 0.46 \\
\hline $\mathrm{O} 2 \mathrm{PC}$ & Lower Economizer & 31,810 & 10.6 & 192 & 64 & 0.30 \\
\hline Air PC & Total & 294,111 & & & 1354 & 2.45 \\
\hline $\mathrm{O} 2 \mathrm{PC}$ & Total & 215,698 & & & 1096 & 2.04 \\
\hline
\end{tabular}




\subsection{Economic Analysis}

\subsubsection{Main Assumptions}

The economic analysis was carried out based on the EPRI Technical Assessment Guide (TAG) methodology. Plant capital costs were compiled under the Code of Accounts developed by EPRI and used in references [12] and [24].

The estimate basis and major assumptions are listed below:

- Total plant costs are estimated in January 2004 dollars.

- Plant book life is 20 years.

- The net power output for the reference PC plant (without $\mathrm{CO}_{2}$ sequestration) is $450 \mathrm{MWe}$ and for the $\mathrm{O}_{2} \mathrm{PC}$ plant (with sequestration) is 327 MWe.

- Capacity factor is $85 \%$. The plant will operate at $100 \%$ load at $85 \%$ of the time.

- Cost of electricity (COE) was determined on a levelized constant dollar basis.

- Average annual ambient air conditions for material balances, thermal efficiencies and other performance related parameters are at a dry bulb temperature of $60 \mathrm{deg}$. $\mathrm{F}$ and an air pressure of $14.7 \mathrm{psia}$.

- The coal is Illinois \#6 coal (see Table 4.2.1 for analysis).

- Terms used are consistent with the EPRI TAG.

\subsubsection{Plant Cost Basis}

The total plant cost (TPC), also referred to as the plant capital cost is comprised of the following elements:

1. Bare erected plant cost.

2. Overheads and fee for engineering and home office.

3. Project and process contingencies.

The $\mathrm{O}_{2}$-fired PC plant capital costs were derived in comparison to a recently constructed Foster Wheeler reference plant, which is an existing subcritical pressure, natural circulation PC plant. 
The major changes to the reference plant were:

- Redesigned boiler (boiler size, and heat transfer surface) (see Section 4.4)

- Removed air pre-heater

- Added new flue gas-to-recycle gas heat exchanger

- Reduced size of FD and ID boiler fans

- Reduced weight of primary and secondary oxidant ductwork

- Removed plant selective catalytic NOx reduction (SCR) system

- Removed plant flue gas desulfurization (FGD) system

- Replaced full size plant stack with start-up stack

- Added air separation unit

- Added $\mathrm{CO}_{2}$ compression and dehydration unit

For the modified components, the plant capital costs were calculated as cost differentials by the Foster Wheeler estimating department. These cost differentials were then added to the base cost of the reference plant.

For the new components costs were either obtained from vendor quotes and/or determined by the Foster Wheeler estimating department as follows:

- The ASU cost was obtained from Air Products and Chemicals Inc.

- The $\mathrm{CO}_{2}$ compression and de-hydration system costs were developed using internal data from a Foster Wheeler commercial project. This price was compared to a recent estimate by Nexant Inc. (Ref. 25) for confirmation.

- The flue gas-to-recycle gas heat exchanger cost was estimated by Foster Wheeler based on internal cost data for similar units.

Allowance for engineering and home office overheads and fee of $6 \%$ of the bare erected cost was added for the new components. The "bare erected cost" is the installed cost of the equipment and systems that make up the plant.

For the new plant items, project contingencies were added to account for the uncertainty based on the level of detail currently available (or lacking) in the design. Consistent with EPRI Technical Assessment Guide (TAG), a 15\% (of bare erected cost) project contingency was used for the $\mathrm{CO}_{2}$ compression and de-hydration system, and a 5\% project contingency was used for the ASU. No process contingencies were applied, since the components of the new systems (e.g. compressors, knock-out pots, etc.) are well-developed technologies.

Table 4.5.1 shows the capital cost worksheet for the $\mathrm{O}_{2}$ fired PC plant. As the table shows, a total plant cost of $\$ 668,673,700.00$, or $2106 \$ / \mathrm{kW}$ was calculated. A substantial part of the cost increase is caused by $\mathrm{CO}_{2}$ compression equipment, which must be included for any $\mathrm{CO}_{2}$ removal systems. 


\section{Table 4.5.1 - Oxygen-Fired PC Plant Capital Cost Estimate}

Base Plant: Air-Fired subcritical pressure, natural circulation PC

Base Plant Output:

$450 \mathrm{MWe}$, net

Base Plant "As bid" cost: $\quad \$ 585,000,000.00$ Includes contingencies and EPC costs

Cost differences in converting air-fired PC to the oxygen-fired PC configuration:

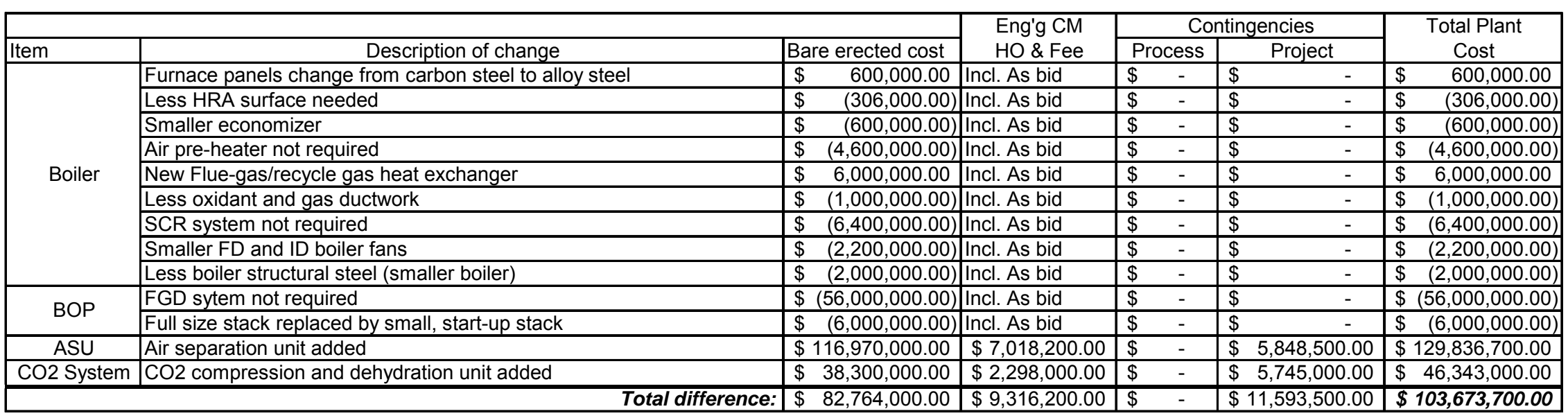

O2 PC Plant Cost:

$\$ \quad 688,673,700.00 \quad 2,106 \$ / k W$

O2 PC Plant net output:

$327 M W$ 


\subsubsection{Total Plant Investment (TPI)}

To determine the total investment required at the date of start-up, the TPC is escalated by the average interest rate over the construction period. Unlike the TPC, which assumes instantaneous construction, TPI ensures that escalation of construction costs and allowance for funds used during construction is properly taken into account. The construction period was estimated to be 4 years. Assuming uniform cash flow over the construction period, the TPI was calculated as follows:

$\mathrm{TPI}=\mathrm{TPC}\left[1+\mathrm{i}_{\text {avg }}\right]$

Where

$$
\begin{aligned}
\mathrm{i}_{\text {avg }} & =\text { Average interest rate over construction period } \\
& =(\text { Interest rate })(\text { Construction Period in Years }) / 2=10 \%
\end{aligned}
$$

The annual interest rate was taken as $5 \%$.

\subsubsection{Total Capital Requirement (TCR)}

The TCR includes all capital required to complete the project. TCR is the sum of TPI, pre-paid royalties, pre-production (start-up) costs, inventory capital, and land cost:

- Royalties costs are assumed inapplicable to the $\mathrm{CO}_{2}$ hybrid plant

- Pre-production costs cover operator training, equipment checkout, major changes in plant equipment, extra maintenance, and inefficient use of fuel and other materials during start-up. They are estimated as follows:

- 1 month of fixed operating costs, operating and maintenance labor, administrative and support labor, and maintenance materials.

- 1 month of variable operating costs at full capacity (excluding fuel) - includes chemicals, water, and other consumables and waste disposal charges.

- $\quad 25 \%$ of full capacity fuel cost for 1 month - covers inefficient operation that occurs during the start-up period.

- $\quad 2 \%$ of TPI - covers expected changes and modifications to equipment that will be needed to bring the plant up to full capacity.

- Inventory capital is the capital required for initial inventories of fuel and other consumables, which are capitalized and included in the inventory capital account. Fuel and other consumables inventory (except water) are based on full-capacity operation for 15 days. An allowance of $1 / 2$ percent of the TPC equipment cost is included for spare parts. 
- Initial catalyst and chemical charge covers the initial cost of any catalysts or chemicals that are contained in the process equipment, but not in storage. In this study, this small charge was included with the equipment capital costs and is a part of the TPC.

- Land cost is based on 60 acres at $\$ 10,000 /$ acre.

The TPI and the TCR cost components are shown on Table 4.5.5 and Table 4.5.6.

\subsubsection{Operating Costs And Expenses}

Operating costs were expressed in terms of the following categories:

- Operating Labor

- Maintenance Cost

- Maintenance labor

- Maintenance materials

- Administrative and Support Labor

- Consumables

- Fuel Cost

These values were calculated in consistence with EPRI TAG methodology. All costs were based on a first year basis with January 2004 dollars. The first year costs do not include start-up expenses, which are included in the TCR.

The cost categories listed above are calculated, on a dollars per year basis, as follows:

- Operating labor is calculated by multiplying the number of operating personnel with the average annual (burdened) compensation per person.

- Maintenance costs are estimated to be $2 \%$ of the TPC and are divided into maintenance labor and maintenance materials

- Maintenance labor is estimated to be $40 \%$ of the total maintenance cost

- Maintenance materials are estimated to be $60 \%$ of the total maintenance cost

- Administrative and support labor is estimated to be equal to $25 \%$ of the sum of operating and maintenance labor.

- Consumables are feedstock and disposal costs calculated from the annual usage at $100 \%$ load and $85 \%$ capacity factor. The costs is expressed in year 2004 dollars and levelized over 20 years on constant dollar basis. 
- Fuel cost is calculated based on the assumed net cost for delivered coal, which is $\$ 1.14 / \mathrm{MMBtu}[26]$. Fuel cost is determined on a first year basis and levelized over 20 years on a constant dollar basis. The calculation of first year fuel costs is done as follows:

Fuel (tons/day) $=($ Plant Heat Rate) $\times$ (net capacity in kW) $\times 24 \mathrm{hr} /$ day HHV x $2000 \mathrm{lb} / \mathrm{ton}$

Fuel Unit Cost (\$/ton) = HHV x $2000 \mathrm{lb} /$ ton x (Fuel Cost in $\$ /$ MMBtu) x $10^{6}$

Fuel Cost $\left(1^{\text {st }}\right.$ year $)=$ Fuel (tons/day) x Fuel Unit Cost $(\$ /$ ton $)$ x 365 day/yr x $0.85(C F)$

The operating and maintenance costs, excluding fuel and consumables, are combined and divided into two components: 1) Fixed O\&M, which is independent of power generation, and 2) Variable O\&M, which is proportional to power generation. These are calculated as follows:

Fixed O\&M (\$/yr) = Oper. Labor + Maint. Labor + Adm. and Support Labor

Fixed O\&M $(\$ / \mathrm{kW}-\mathrm{yr})=\frac{\text { Fixed O\&M }(\$ / \text { year })}{\text { Net Power }(\mathrm{kW})}$

Variable O\&M (\$/yr) = Maintenance Materials

Variable O\&M $(\$ / k W h)=\frac{\text { Variable O\&M }(\$ / y r)}{\text { Net Power }(k W) \times \text { CF x } 8760}$

Where, CF is the plant capacity factor and 8760 is the total number of hours in one year.

The operating and maintenance costs for the $\mathrm{O}_{2}$-fired PC and the air-fired reference plant are shown on Table 4.5.2. The "total production cost" shown at the bottom of the table expresses the charge of operating and maintaining the baseline plant (including fuel and consumable costs) in terms of cents per kilowatt-hour.

\subsubsection{Cost Of Electricity (COE)}

The COE value is made up of contributions from the capital cost (called the carrying charge), operating and maintenance costs, consumables, and fuel costs. The following relationship is used to calculate COE from these cost components:

COE $=$ LCC + LFOM $\times 100 /(8760 \times$ CF $)+L V O M+L C M+L F C$

LCC $=$ Levelized carrying charge, $\phi / \mathrm{kWh}$ 
LFOM = Levelized fixed O\&M, \$/kW-yr

$\mathrm{LVOM}=$ Levelized variable O\&M, $\phi / \mathrm{kWh}$

$\mathrm{LCM}=$ Levelized consumables, $\phi / \mathrm{kWh}$

LFC $=$ Levelized fuel costs, $\phi / \mathrm{kWh}$

$\mathrm{CF}=$ plant capacity factor $(0.85)$

The basis for calculating the capital investment and revenue requirements for the reference plant and the $\mathrm{O}_{2} \mathrm{PC}$ are given in Table 4.5.3 and Table 4.5.4, respectively. The capital investment and revenue requirements summary is given in Table 4.5.5 for the reference plant without $\mathrm{CO}_{2}$ sequestration and in Table 4.5.6 for the $\mathrm{O}_{2} \mathrm{PC}$.

As Table 4.5.5 and Table 4.5.6 show, the levelized COE for $85 \%$ capacity factor was calculated at $4.61 \phi / \mathrm{kWh}$ without $\mathrm{CO}_{2}$ sequestration and at $6.41 \phi / \mathrm{kWh}$ with $\mathrm{CO}_{2}$ sequestration.

\subsubsection{Comparison with Other Technologies}

An economic comparison was performed between the $\mathrm{O}_{2} \mathrm{PC}$ and other competing $\mathrm{CO}_{2}$ removal technologies. For comparison the following alternate technologies were chosen:

Air PC: $\quad$ Supercritical PC plant with post-combustion $\mathrm{CO}_{2}$ mitigation (Ref [12] case 7A).

NGCC: Natural Gas Combined Cycle with post combustion (Ref. [12] case $1 \mathrm{~A})$.

IGCC: Integrated Gasification Combined Cycle with pre-combustion $\mathrm{CO}_{2}$ mitigation (Ref. [24] case 3E).

The economics of these technologies were compared with the $\mathrm{O}_{2} \mathrm{PC}$ using both the levelized cost of electricity and the $\mathrm{CO}_{2}$ mitigation cost as indexes. The $\mathrm{CO}_{2}$ mitigation cost (MC) shows the cost impact, in dollars per tonne of $\mathrm{CO}_{2}$ that would otherwise be emitted, of a configuration that allows $\mathrm{CO}_{2}$ capture relative to the reference plant.

The MC is calculated as follows:

$$
M C=\frac{C O E_{\text {with removal }}-C O E_{\text {reference }}}{E_{\text {reference }}-E_{\text {with removal }}} \times 0.01 \$ / \phi
$$

$\mathrm{COE}=$ Cost of electricity in $\phi / \mathrm{kWh}$

$\mathrm{E}=\mathrm{CO}_{2}$ emission in tonnes $/ \mathrm{kWh}$

The COE and MC for the Air PC, NGCC, and IGCC were obtained from Ref. 12and Ref. 24. Since the economic analysis of Ref. 12 and Ref. 24 were made in 
2000 two adjustments were necessary so that the values can be compared to the results of the current $\mathrm{O}_{2} \mathrm{PC}$ economic analysis:

1. A constant inflation rate of $2 \%$ was assumed between 2000 and 2004 .

2. The 2000 natural gas fuel price was replaced with the 2004 natural gas fuel price (fuel price $=5.89$ \$/MM Btu, an increase of $118 \%$ above 2000 price).

Since the analyses of Ref. 12 and Ref. 24 were assumed at a $65 \%$ capacity factor, Figure 4.5.1 and Figure 4.5.2 present a comparison of the COE and MC using a $65 \%$ capacity factor for the $\mathrm{O}_{2} \mathrm{PC}$. Compared to the COE of the $\mathrm{O}_{2} \mathrm{PC}$, the COE for the other technologies is $17 \%$ higher for Air PC, $15 \%$ higher for NGCC, and $14 \%$ lower for IGCC. Compared to the MC of the $\mathrm{O}_{2} \mathrm{PC}$, the MC for the other technologies is $170 \%$ higher for NGCC, $100 \%$ higher for Air PC, and $9 \%$ lower for IGCC.

Since the $\mathrm{O}_{2} \mathrm{PC}$ uses reliable long-proven technology it is expected that the capacity factor of the $\mathrm{O}_{2} \mathrm{PC}$ will be close to $85 \%$. Consequently Figure 4.5 .3 and Figure 4.5.4 present a comparison of the COE and MC using an $85 \%$ capacity factor for the $\mathrm{O}_{2} \mathrm{PC}$. Compared to the COE of the $\mathrm{O}_{2} \mathrm{PC}$, the COE for the other technologies is $45 \%$ higher for Air PC, $40 \%$ higher for NGCC, and $6 \%$ higher for IGCC. Compared to the $\mathrm{MC}$ of the $\mathrm{O}_{2} \mathrm{PC}$, the $\mathrm{MC}$ for the other technologies is $250 \%$ higher for NGCC, $160 \%$ higher for Air PC, and 17\% higher for IGCC.

Note that the air-fired post combustion capture PC plant data used in Figure 4.5.1 to Figure 4.5.4 is for a supercritical unit whereas the $\mathrm{O}_{2} \mathrm{PC}$ plant operates at subcritical pressure. It is expected that the economic cost (COE and $\mathrm{MC})$ of a supercritical $\mathrm{O}_{2} \mathrm{PC}$ will be lower than a subcritical $\mathrm{O}_{2} \mathrm{PC}$. 


\section{Table 4.5.2 - Operating, Maintenance and Fuel Costs for the $\mathrm{O}_{2} \mathrm{PC}$ and the Air-fired Reference}

\author{
1) With $\mathrm{CO} 2$ Sequestration (O2 PC)

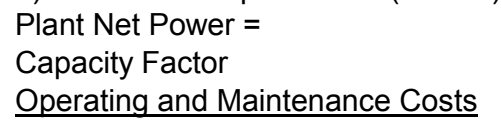 \\ $326 \mathrm{MW}$ \\ $85 \%$
}

Operating labor

Maintenance Cost

Maintenance Labor (40\%)

Maintenance Materials (60\%)

Administrative Support and Labor

$2 \%$ of TPC 60 people

Consumable Operating Costs (Except Fuel)

Water

Water Chemicals

$8080 \mathrm{kgals} /$ day

Limestone

Start-up Fuel

Startup Electricity

Ash disposal

Other Chemicals

$\underline{\text { Fuel Cost (2004 Dollars) }}$

Heat Rate $=$

11,411

$3720.11 \mathrm{MMBtus} / \mathrm{hr}$

Total Production Cost

\begin{tabular}{|c|c|c|}
\hline Unit Cost & \$lyear & \$/KW-yr \\
\hline \multirow{4}{*}{$\$ 90,000.00$} & $\$ 5,400,000.00$ & $\$ 16.56$ \\
\hline & $\$ 5,509,389.60$ & $\$ 16.90$ \\
\hline & $\$ 8,264,084.40$ & $\$ 25.35$ \\
\hline & $\$ 2,727,347.40$ & $\$ 8.37$ \\
\hline Unit Cost & \$lyear & c/KWh \\
\hline$\$ 0.80$ & $\$ 2,005,411$ & 0.070 \\
\hline \multirow[t]{2}{*}{$\$ 0.16$} & $\$ 970,619$ & 0.034 \\
\hline & $\$ 50,000.00$ & 0.002 \\
\hline$\$ 30$ & $\$ 189,000.00$ & 0.007 \\
\hline \multirow[t]{3}{*}{$\$ 10$} & $\$ 1,359,639.60$ & 0.048 \\
\hline & $\$ 330,000.00$ & 0.012 \\
\hline & & 0.160 \\
\hline \multicolumn{3}{|l|}{ Btu/kWh } \\
\hline Unit Cost & \$lyear & c/KWh \\
\hline$\$ 1.14$ & $\$ 31,577,905$ & 1.301 \\
\hline
\end{tabular}

$2.36 \mathrm{c} / \mathrm{kWh}$

2) Without CO2 Sequestration (Air-fired reference)

Plant Net Power $=$

Capacity Factor

Operating and Maintenance Costs

\begin{tabular}{|c|c|}
\hline Operating labor & 56 people \\
\hline $\begin{array}{l}\text { Maintenance Cost } \\
\text { Maintenance Labor (40\%) } \\
\text { Maintenance Materials }(60 \%)\end{array}$ & $2 \%$ of TPC \\
\hline Administrative Support and Labor & $25 \%$ of O\&M Labor \\
\hline \multicolumn{2}{|c|}{ Consumable Operating Costs (Except Fuel) } \\
\hline Water & 7906 kgals/day \\
\hline Water Chemicals & 19133 lbs/day \\
\hline Limestone & 432 tons/day \\
\hline Start-up Fuel & 5 starts/year \\
\hline Startup Electricity & $6300 \mathrm{MWh} / \mathrm{yr}$ \\
\hline Ash disposal & 52.43 ton $/ \mathrm{hr}$ \\
\hline
\end{tabular}

Fuel Cost (2004 Dollars)

Heat Rate $=$

3878.96 MMBtus/hr
9,302

$417 \mathrm{MW}$

$85 \%$

\begin{tabular}{|c|c|c|}
\hline \multirow{5}{*}{$\begin{array}{l}\text { Unit Cost } \\
\$ 90,000.00\end{array}$} & \$lyear & $\$ / K W-y r$ \\
\hline & $\$ 5,040,000.00$ & $\$ 15.46$ \\
\hline & $\$ 4,680,000.00$ & $\$ 14.36$ \\
\hline & $\$ 7,020,000.00$ & $\$ 21.53$ \\
\hline & $\$ 2,430,000.00$ & $\$ 7.45$ \\
\hline Unit Cost & \$lyear & c/KWh \\
\hline$\$ 0.80$ & $\$ 1,962,269$ & 0.054 \\
\hline$\$ 0.16$ & $\$ 949,738$ & 0.026 \\
\hline$\$ 15$ & $\$ 2,010,420$ & 0.055 \\
\hline & $\$ 50,000.00$ & 0.001 \\
\hline$\$ 30$ & $\$ 189,000.00$ & 0.005 \\
\hline$\$ 10$ & $\$ 3,903,937.80$ & 0.107 \\
\hline & & 0.248 \\
\hline Btu/kWh & & \\
\hline Unit Cost & \$lyear & c/KWh \\
\hline$\$ 1.14$ & $\$ 32,926,353$ & 1.060 \\
\hline
\end{tabular}




\section{Table 4.5.3 - Estimate Basis/Financial Criteria for Revenue Requirement Calculations: Air-fired Reference Plant}

\section{GENERAL DATA/CHARACTERISTICS}

Plant Type:

Plant Size:

Location:

Fuel: Primary/Secondary

Energy from Primary/Secondary Fuels:

Levelized Capacity Factor / Preproduction (equivalent months):

Capital Cost Year Dollars (Reference Year Dollars):

Delivered Cost of Primary/Secondary Fuel:

Design/ Construction Period:

Plant Start-up Date (1st year Dollars):

Land Area/Unit Cost:

\section{FINANCIAL CRITERIA}

Project Book Life:

Book Salvage Value:

Project Tax Life:

Tax Depreciation Method:

Inflation Rate

Property Tax Rate:

Insurance Tax Rate:

Federal Income Tax Rate:

State Income Tax Rate:

Investment Tax Credit/\% Eligible

Economic Basis:

Capital Structure

Common Equity

Preferred Stock

Debt

Weighted Cost of Capital: (after tax)
Air-fired Subcritical PC

$$
450 \mathrm{MW} \text {, net }
$$

Sea Level, Middletown USA

Illinois \#6

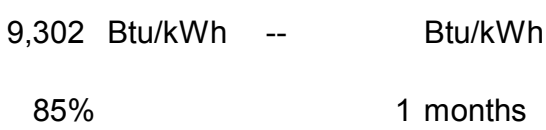

2004 (January)

1.14 \$/MBtu $\quad$-- $\quad$ \$/MBtu
4 years

2008 (January)

60 acres $\quad \$ 10,000 /$ Acre

20 years

- $\%$

20 years

Accel. Based on ACRS Class

$$
2.0 \%
$$

$1.0 \%$

$1.0 \%$

$34.0 \%$

$4.2 \%$

- $\%$ - $\%$

Over Book Constant Dollars

$\begin{array}{rrr}\text { \% of Total } & & \text { Cost(\%) } \\ 40 & & 12 \\ 0 & & 8.5 \\ 60 & 7.456 \% & 7\end{array}$




\section{Table 4.5.4 - Estimate Basis/Financial Criteria for Revenue Requirement Calculations: $\mathrm{O}_{2}$-fired Reference Plant}

\section{GENERAL DATA/CHARACTERISTICS}

Plant Type:

Plant Size:

Location:

Fuel: Primary/Secondary

Energy from Primary/Secondary Fuels:

Levelized Capacity Factor / Preproduction (equivalent months):

Capital Cost Year Dollars (Reference Year Dollars):

Delivered Cost of Primary/Secondary Fuel:

Design/ Construction Period:

Plant Start-up Date (1st year Dollars):

Land Area/Unit Cost:

\section{FINANCIAL CRITERIA}

Project Book Life:

Book Salvage Value:

Project Tax Life:

Tax Depreciation Method:

Inflation Rate:

Property Tax Rate:

Insurance Tax Rate:

Federal Income Tax Rate:

State Income Tax Rate:

Investment Tax Credit/\% Eligible

Economic Basis:

Capital Structure Common Equity Preferred Stock

Debt

Weighted Cost of Capital: (after tax)
Oxygen Fired Subcritical PC

$327 \mathrm{MW}$, net

Sea Level, Middletown USA

Illinois \#6

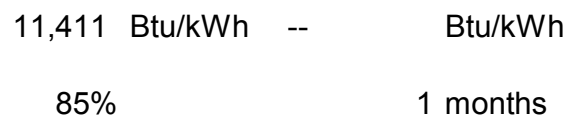

2004 (January)

1.14 \$/MBtu -- $\quad$ \$/MBtu

4 years

2008 (January)

$$
60 \text { acres } \$ 10,000 / \text { Acre }
$$

20 years

- $\%$

20 years

Accel. Based on ACRS Class

$2.0 \%$

$1.0 \%$

$1.0 \%$

$34.0 \%$

$4.2 \%$

- $\%$ - $\%$

Over Book Constant Dollars

\begin{tabular}{|c|c|}
\hline$\%$ of Total & Cost(\%) \\
\hline 40 & 12 \\
\hline 0 & 8.5 \\
\hline 60 & 7 \\
\hline
\end{tabular}




\section{Table 4.5.5 - Capital Investment and Revenue Requirement Summary: Air- fired Reference Plant}

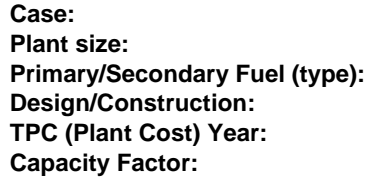

TOTAL CONSUMABLE OPERATING COST

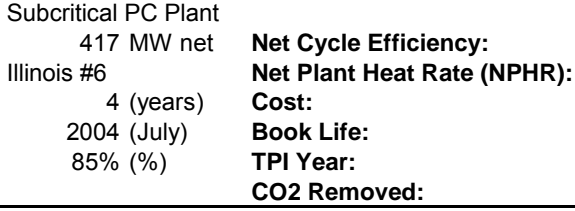

Net Plant Heat Rate (NPHR):

Cost:

Book Life:

TPI Year:

CO2 Removed:

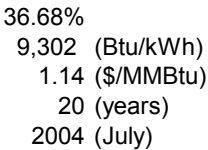

1.14 (\$/MMBtu)

20 (years)

2004 (July) (tons/year)

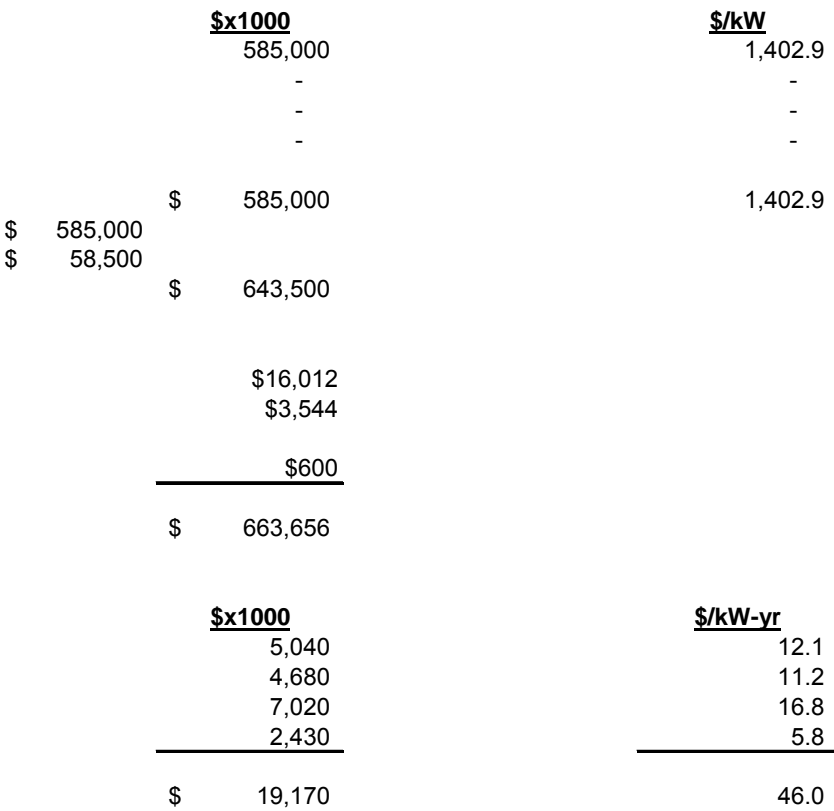

$29.14 \$ / k W-y r$

$0.23 \mathrm{c} / \mathrm{kWh}$

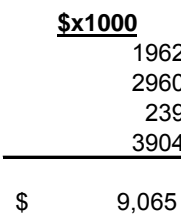

c/kWh

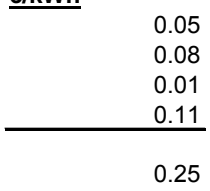

$\$ \quad 32,926$

1.06

Levelized (Over Book Life \$)

PRODUCTION COST SUMMARY

Fixed O\&M

Variable O\&M

Consumables

By-product Credit

Fuel

TOTAL PRODUCTION COST

LEVELIZED CARRYING CHARGES (Capital)

LEVELIZED (Over Book Life) BUSBAR COST OF POWER

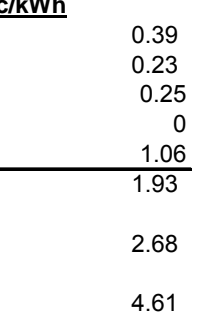


Figure 4.5.1- Comparison of Levelized Cost of Electricity Among Alternative Technologies $\left(\mathrm{O}_{2} \mathrm{PC}\right.$ with $\left.65 \% \mathrm{CF}\right)$

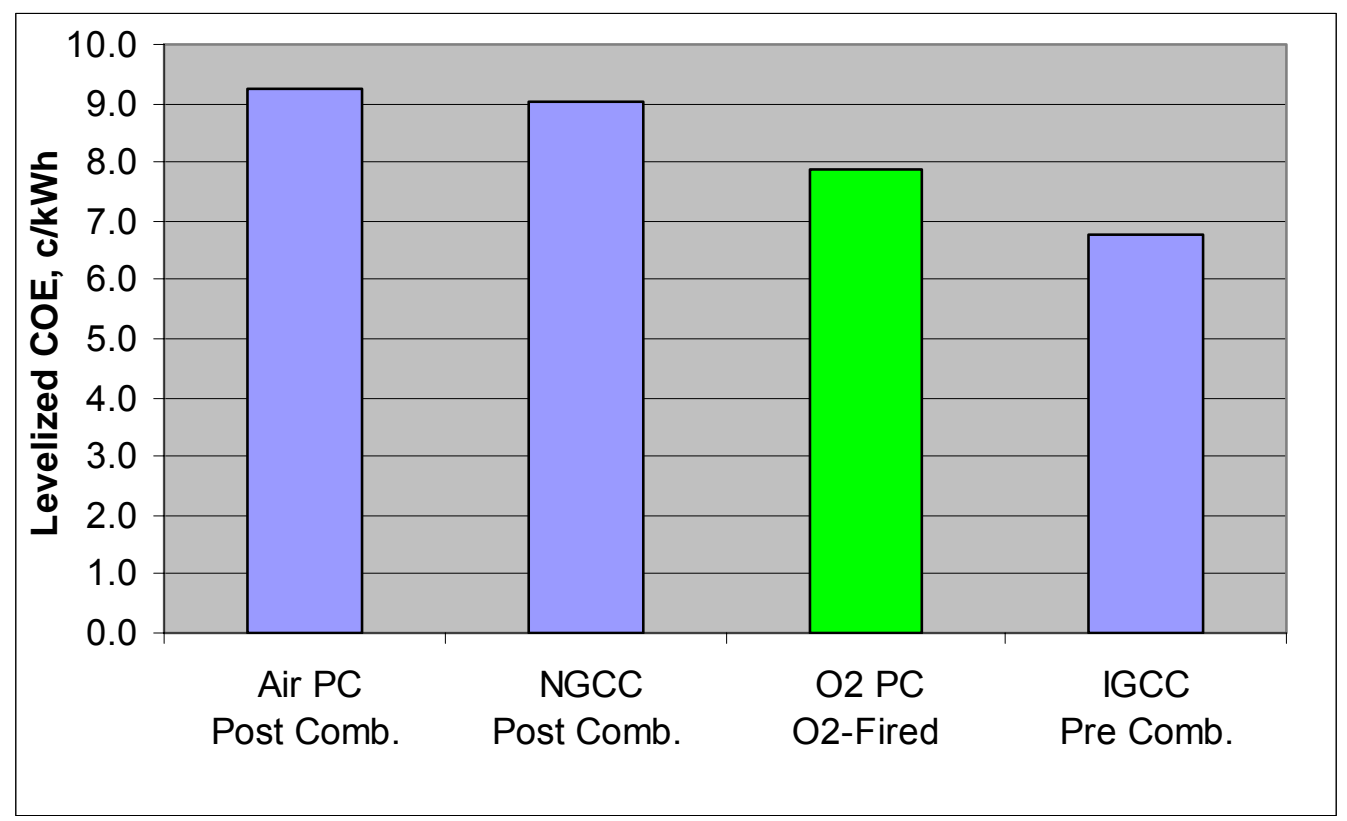

Figure 4.5.2 - Comparison of Mitigation Costs Among Alternative Technologies $\left(\mathrm{O}_{2} \mathrm{PC}\right.$ with $\left.65 \% \mathrm{CF}\right)$

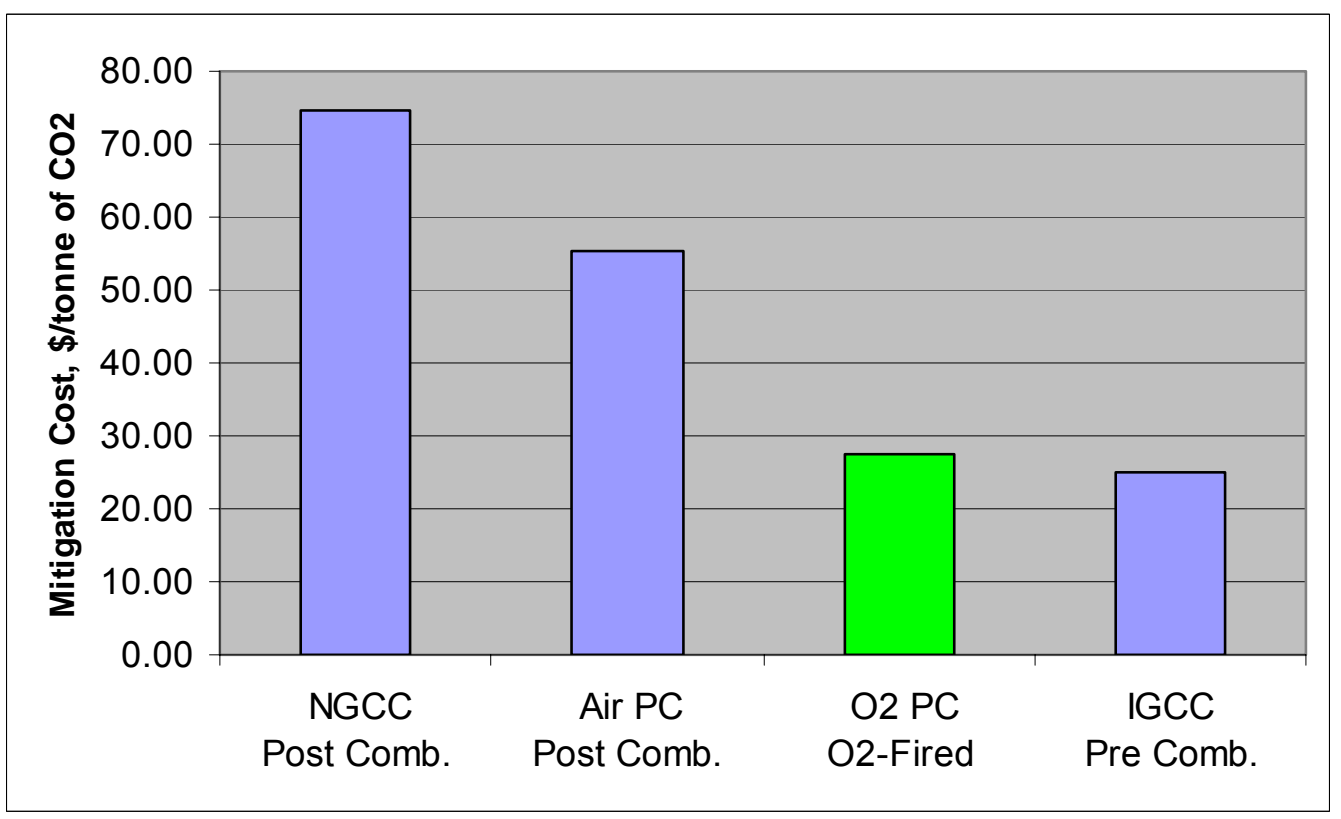


Figure 4.5.3 - Comparison of Levelized Cost of Electricity Among Alternative Technologies $\left(\mathrm{O}_{2} \mathrm{PC}\right.$ with $\left.85 \% \mathrm{CF}\right)$

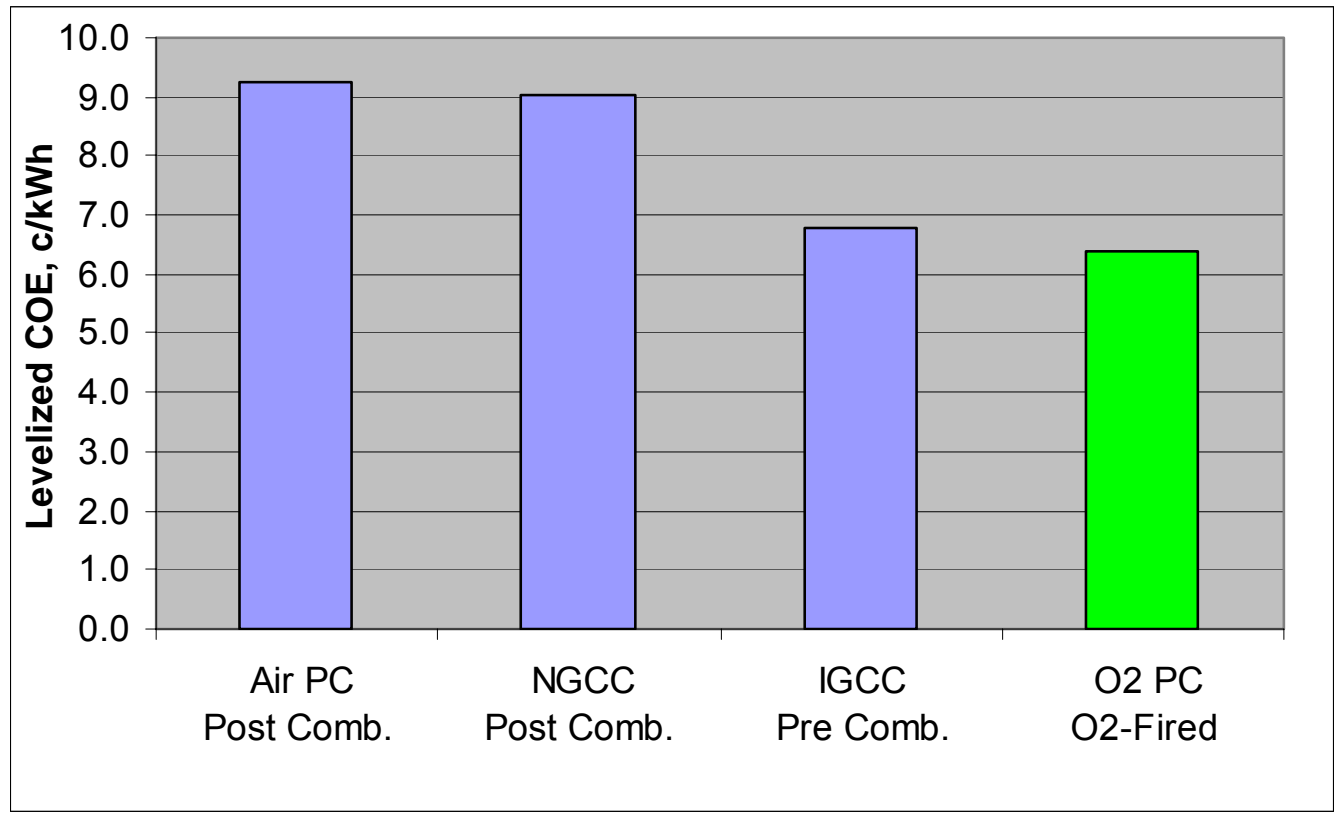

Figure 4.5.4 - Comparison of Mitigation Costs Among Alternative Technologies $\left(\mathrm{O}_{2} \mathrm{PC}\right.$ with $\left.85 \% \mathrm{CF}\right)$

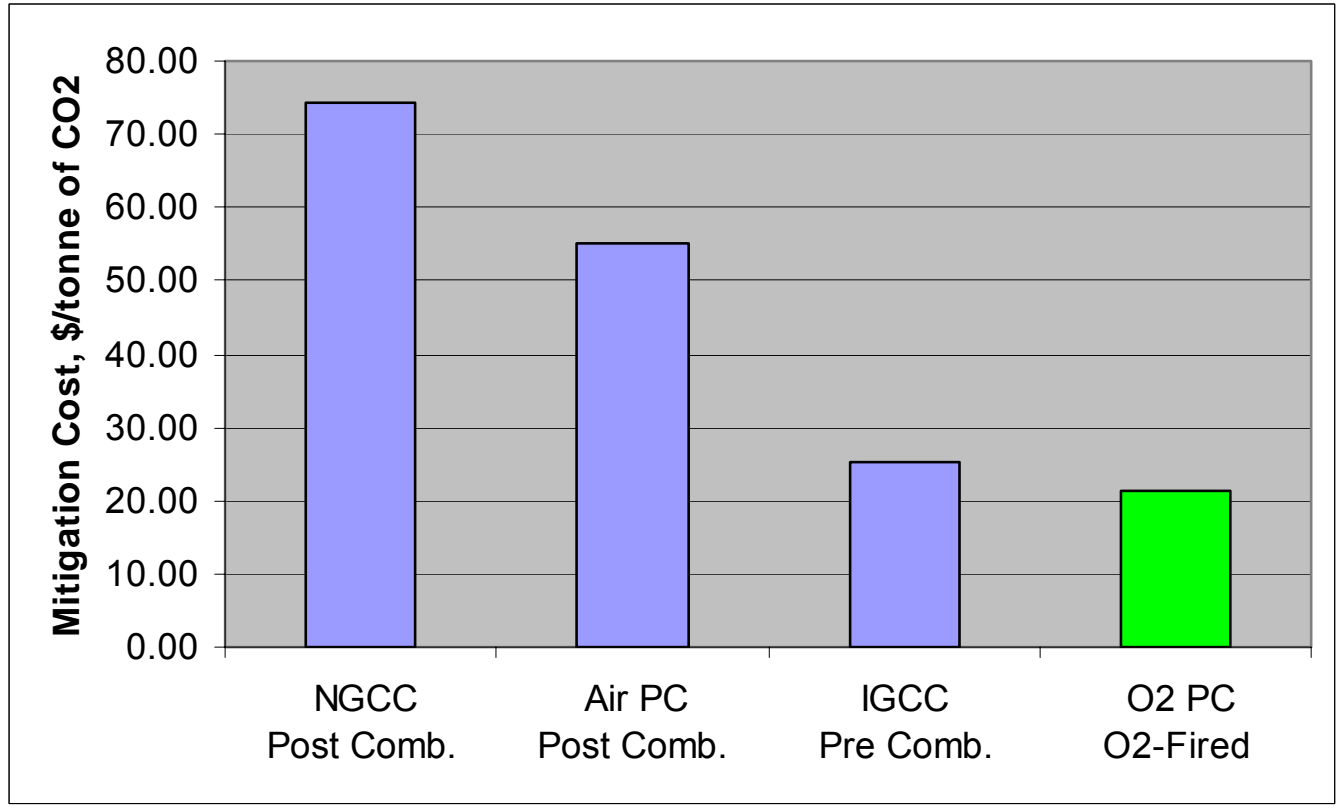




\subsection{Conclusion}

To assure continued U.S. power generation from its abundant domestic coal resources, new coal combustion technologies must be developed to meet future emissions standards, especially $\mathrm{CO}_{2}$ sequestration. Current conventional coalfired boiler plants burn coal using $15-20 \%$ excess air producing a flue gas, which is only approximately $15 \% \mathrm{CO}_{2}$. Consequently, $\mathrm{CO}_{2}$ sequestration requires noncondensable gases stripping, which is both expensive and highly powerconsumptive. Several different technologies for concentrating the $\mathrm{CO}_{2}$ by removing the non-condensable gases have been proposed including aminebased absorption and membrane gas absorption. However, these techniques require substantial energy, typically from low-pressure steam.

A new boiler is presented where the combustion air is separated into $\mathrm{O}_{2}$ and $\mathrm{N}_{2}$ and the boiler uses the $\mathrm{O}_{2}$, mixed with recycled flue gas, to combust the coal. The products of combustion are thus only $\mathrm{CO}_{2}$ and water vapor. The water vapor is easily condensed, yielding a pure $\mathrm{CO}_{2}$ stream ready for sequestration. The $\mathrm{CO}_{2}$ effluent is in a liquid form and is piped from the plant to the sequestration site. The combustion facility is thus truly a zero emission stackless plant.

The efficiency and cost-effectiveness of carbon sequestration in oxygen-firing boilers can rival competing gasification plants by specifically tailoring boiler design by appropriate surface location, combustion system design, material selection, furnace layout, and water/steam circuitry. Boiler efficiencies of near $100 \%$ can be achieved by recovery of virtually all of the flue gas exhaust sensible and latent heat. Boiler size can be substantially reduced due to higher radiative properties of $\mathrm{O}_{2}$-combustion versus air-combustion. Furthermore, a wider range of fuels can be burned due to the high oxygen content of the combustion gas and potential for high coal preheat.

A review of the published literature indicates that:

1.) It is possible to design a pulverized coal burner to operate with an oxygencarbon dioxide gas mixture rather than air; a properly designed $\mathrm{O}_{2}$ burner can yield flame temperatures and thermal profiles similar to those of an air-fired boiler while also providing improved flame stability, combustion efficiency; and NOx emissions.

2.) Plant conceptual designs and cost estimates, although differing in absolute values, indicate an $\mathrm{O}_{2}$ combustion based plant are technically feasible and, when compared to alternative existing technologies, appear to be the lowest cost way of providing a concentrated $\mathrm{CO}_{2}$ stream for sequestration. It is also expected that when for a new plant, $\mathrm{O}_{2}$ combustion will result in a more compact, less expensive boiler. Depending upon the $\mathrm{SO}_{2}$ and $\mathrm{NOx}$ levels that 
can be recirculated back to the boiler, as well as tolerated at the sequestration site, $\mathrm{O}_{2}$ can possibly result in reduced flue gas cleanup costs.

3.) Even though $\mathrm{O}_{2}$ combustion is projected to be the least expensive way of providing a concentrated $\mathrm{CO}_{2}$ stream for sequestration, significant increases in plant heat rates and costs will be experienced.

4.) Since $\mathrm{O}_{2}$ combustion eliminates the need for large, back end amine based scrubbers and, in essence, saves the boiler, it is especially attractive for retrofit applications.

5.) $\mathrm{O}_{2}$ based PC plants will require large amounts of oxygen and cryogenic air separation presently appears best suited for this application. Cryogenic units, however, are expensive and consume substantial amounts of power. It is noted that ceramic oxygen transport membranes are under development that are projected to be a lower cost, lower power consuming way to produce large quantities of oxygen. When commercial, these membranes should improve the performance and reduce the costs of the $\mathrm{O}_{2}$ based plant.

A conceptual design of a $\mathrm{CO}_{2}$ sequestration-ready oxygen-based $460 \mathrm{MWe}$ (gross) PC boiler plant was developed. The selected $\mathrm{O}_{2}$-fired design case has a system efficiency of $30.6 \%$ compared to the air-fired system efficiency of $36.7 \%$. The design $\mathrm{O}_{2}$-fired case requires T91 waterwall material and has a waterwall surface area of only $65 \%$ of the air-fired reference case.

A design and analysis of the Low NOx wall-fired burners for the proposed oxygen-fired boiler were performed. Burner designs were performed for $56 \%$ and $65 \%$ flue gas recycle for both $0 \%$ OFG and $20 \%$ OFG.

To achieve proper burnout ( $>70 \%$ by the center of the furnace) and stable ignition, a primary gas swirl ratio of 0.5 was required for all four burner designs. To achieve optimal performance the following wall-fired burner design conditions were selected as optimal:

1. Primary gas exit conditions are an axial velocity of $100 \mathrm{ft} / \mathrm{sec}$ with a tangential swirl ratio of 0.5 to achieve proper burnout and stable ignition.

2. A low velocity (60-70 ft/sec) inner secondary gas exit velocity for combustion air staging to minimize NOx formation.

3. Outer secondary gas exit conditions are an axial velocity of $120-135 \mathrm{ft} / \mathrm{sec}$ with a tangential swirl ratio of 1.0 to induce hot flue gas recirculation to the flame ignition point. 
A design and analysis of the reference air-fired boiler and the proposed oxygenfired boiler were performed. The following conclusions are made comparing the air-fired furnace with the oxygen-fired furnace design and performance:

1. The oxygen furnace has only approximately $65 \%$ of the surface area and approximately $45 \%$ of the volume of the air-fired furnace due to the higher heat flux of the oxygen-fired furnace.

2. Due to the higher $\mathrm{O}_{2}$ concentration of the oxygen-fired furnace versus the air-fired furnace $(42 \%$ vs. $21 \%)$, the maximum flame temperature of the oxygen-fired furnace is approximately $500^{\circ} \mathrm{F}$ higher.

3. Maximum wall heat flux in the oxygen-fired furnace is more than double that of the air-fired furnace $\left(165,000 \mathrm{Btu} / \mathrm{hr}^{-\mathrm{ft}^{2}} \mathrm{vs}\right.$. $\left.75,000 \mathrm{Btu} / \mathrm{hr}-\mathrm{ft}^{2}\right)$ due to the higher flame temperature and higher $\mathrm{H}_{2} \mathrm{O}$ and $\mathrm{CO}_{2}$ concentrations.

4. $100 \%$ coal burnout is achieved in the oxygen-fired furnace (compared to $99.7 \%$ burnout in the air-fired furnace) due to higher furnace temperature and higher concentration of oxygen. The burnout differential between the oxygen-fired boiler and the air-fired boiler is expected to be significantly greater when harder to burn fuels are fired.

5. The higher heat flux of the oxygen-fired furnace significantly increases the maximum waterwall temperature (from $800^{\circ} \mathrm{F}$ for the air-fired furnace to $935^{\circ} \mathrm{F}$ for the oxygen-fired furnace) requiring the material to be upgraded from carbon steel to T91.

6. The average NOx at the air-fired furnace outlet is reduced by $30 \%$ by injecting $20 \%$ OFA and by $45 \%$ by injecting $30 \%$ OFA. The average NOx at the oxygen-fired furnace outlet is reduced by $23 \%$ by injecting $20 \%$ OFG. Since it is unclear how much NOx can be tolerated by the oxygenfired furnace liquid $\mathrm{CO}_{2}$ piping system and sequestration site, the maximum permissible NOx of the oxygen-fired furnace is unknown.

7. The total heat transfer surface required in the oxygen-fired heat recovery area (HRA) is $25 \%$ less than the air-fired HRA due to more heat being absorbed in the oxygen-fired furnace and the greater molecular weight of the oxygen-fired flue gas.

8. The required HRA tube materials and wall thickness are virtually the same for the air-fired and oxygen-fired design since the flue gas and water/steam temperature profiles encountered by the heat transfer banks are very similar. 
The levelized cost of electricity (COE) was calculated to be $4.61 \phi / \mathrm{kWh}$ for the reference air-fired plant and to be $6.41 \phi / \mathrm{kWh}$ for the $\mathrm{O}_{2} \mathrm{PC}$ plant. The $\mathrm{CO}_{2}$ mitigation cost (MC) of the $\mathrm{O}_{2}-\mathrm{PC}$ plant was calculated at 21.4 \$/tonne.

Compared to the COE of the $\mathrm{O}_{2} \mathrm{PC}$, the COE for the other technologies is $45 \%$ higher for Air PC, 40\% higher for NGCC, and 6\% higher for IGCC. Compared to the $\mathrm{MC}$ of the $\mathrm{O}_{2} \mathrm{PC}$, the $\mathrm{MC}$ for the other technologies is $250 \%$ higher for NGCC, $160 \%$ higher for Air PC, and 17\% higher for IGCC.

It is expected that the $\mathrm{COE}$ and $\mathrm{MC}$ of the $\mathrm{O}_{2} \mathrm{PC}$ will be reduced by the incorporation of new lower power-consuming air separation techniques, such as membrane separation and more advanced steam cycles such as supercritical and ultra-supercritical. In DOE contract, DE-FC26-04NT42207, FW will conduct a study to improve the efficiency and cost-effectiveness of the $\mathrm{O}_{2}$-based $\mathrm{PC}$ power plant through the incorporation of a high-temperature supercritical steam cycle and advanced $\mathrm{O}_{2}$ separation techniques.

Thus $\mathrm{CO}_{2}$ sequestration with an oxygen-fired combustion plant can be performed in a proven reliable technology while maintaining a low-cost high-efficiency power plant. Of the $\mathrm{CO}_{2}$ sequestration-ready technologies, the $\mathrm{O}_{2}$-fired $\mathrm{PC}$ is the simplest, requires the least modification of existing proven designs, and requires no special chemicals for $\mathrm{CO}_{2}$ separation. As new lower power-consuming air separation techniques, such as membrane separation, become commercially available for large-scale operation in $\mathrm{O}_{2}$-fired plants, the $\mathrm{CO}_{2}$ removal power consumption and efficiency reduction will continue to decline. 


\subsection{References}

1. International Energy Agency Greenhouse Gas R\&D Programme Web Site.

2. International Energy Agency, "Key world Energy Statistics", 2003.

3. Energy Information Administration of the U.S. Department of Energy, "Annual Energy Outlook 2004", January 2004.

4. Smith, D. and Danish, K., "The Heat is On", Public Utilities Fortnightly, January 2004.

5. Bradley, J., et. al., "NOx Reduction From A 125 MW Wall-Fired Boiler Utilizing Oxygen Enhanced Combustion", 29 ${ }^{\text {th }}$ International Technical Conference on Coal Utilization and Fuel Systems, April 18-22, 2004, Clearwater, FL.

6. Haeyang, P., et. al., "Bench Scale Experiment of Pure Oxygen Pulverized Coal Combustion in High Temperature", $9^{\text {th }}$ Asian Pacific Conference on Chemical Engineering Congress, September 29, 2002, Christchurch, New Zealand.

7. Douglas, M., et. al., "Oxy-Fuel Combustion At The CANMET Vertical Combustor Research Facility", $1^{\text {st }}$ National Conference on Carbon Sequestration, May 15-17, 2001, Washington, DC.

8. Thambimuthu, K. and Croiset, E., "Enriched Oxygen Coal-Fired Combustion", Advanced Coal-Based Power and Environmental Systems Conference, July 21-23, 1998, Morgantown, W. VA.

9. Varagani, R., et. al., "Oxycombustion in Pulverized Coal-Fired Boiler; A Promising Technology for $\mathrm{CO}_{2}$ Capture", Third Annual Conference on Carbon Sequestration, May 3-6, 2004, Alexandria, VA.

10. "Greenhouse Gas Emissions from Power Stations", International Energy Agency Greenhouse Gas R\&D Programme, Report No. ISBN 189837310 8, June 1993.

11. "Carbon Dioxide Capture from Power Stations", International Energy Agency Greenhouse Gas R\&D Programme, Report No. ISBN 1898373 15G, February, 1994.

12. White, J.S., Buchanan, T.L., Schoff, R.L. (Parsons); Stiegel, G. (DOE); Holt, N.A., Booras G. (EPRI); Wolk, R. (WITS), "Evaluation of Innovative 
Fossil Fuel Power Plants with $\mathrm{CO}_{2}$ Removal", EPRI, Palo Alto, CA, U,S. Department of Energy-Office of Fossil Energy, Germantown, MD and U.S. Department of Energy/NETL, Pittsburgh, PA EPRI Report No. 1000316, December 2000.

13. Amick, A. et. al., "An Advanced IGCC Coal Power Plant", Twentieth Annual International Pittsburgh Coal Conference, Pittsburgh PA., September 15-19, 2001.

14. Holt, N. et. al., "Summary of Recent IGCC Studies of $\mathrm{CO}_{2}$ Capture for Sequestration", Gasification Technologies 2003, San Francisco CA., October12-15, 2003.

15. Steigel, G., et. al., "DOE's Gasification Industry Interviews: Survey of Market Trends, Issues, and R\&D Needs", Gasification Technologies 2001, San Francisco, CA, October 7-10, 2001.

16. Nsakala, Y., et. al., "Engineering Feasibility of $\mathrm{CO}_{2}$ Capture On An Existing US Coal-Fired Power Plant", First National Conference on Carbon Sequestration, May 15-17, 2001, Washington, DC.

17. Simbeck, D., "Overview and Insights on the Three Basic CO2 Capture Options", Third Annual Conference on Carbon Sequestration, May 3-6, 2004, Alexandria, VA.

18. Armstrong, P., et. al., "ITM Oxygen: An Enabler for IGCC", Gasification Technologies 2003, San Francisco CA., October12-15, 2003.

19. Prasad, R., et. al., "Oxygen Transport Membranes for Future IGCC Power Plants", Twentieth Annual International Pittsburgh Coal Conference, Pittsburgh PA., September 15-19, 2001.

20. Wilkinson, M.,Boden, John (BP), Panesar, R. (Mitsui Babcock), Allam, R. (Air Products), " $\mathrm{CO}_{2}$ Capture Via Oxygen Firing: Optimisation of a Retrofit Design Concept for a Refinery Power Station Boiler", First National Conference on Carbon Sequestration, May 15-17, 2001, Washington DC.

21. FW-FIRE, Fossil-fuel Water-walled Furnace Integrated Reaction Emission, Theory and User's Manual, Foster Wheeler Development Corp., 11/30/99.

22. HEATEX Computer Program, "A Program to Determine the Thermal/Hydraulic Performance of Gas-Cooled Heat Exchangers", Revision 24, Foster Wheeler Corporation. 
23. EMISS Computer Program, "A Program to Determine Gaseous Emissivity", Foster Wheeler Corporation.

24. Schoff, R.L., White, J.S., Buchanan, T.L. (Parsons); Holt, N.A., Booras G. (EPRI); Wolk, R. (WITS), "Updated Cost and Performance Estimates For Fossil Fuel Power Plants with $\mathrm{CO}_{2}$ Removal", EPRI, Palo Alto, CA, U.S. Department of Energy - Office of Fossil Energy, Germantown, MD and U.S. Department of Energy/NETL, Pittsburgh, PA: 2002. 1004483.

25. Gerard N. Choi, et al., "Cost Efficient Amine Plant Design for Post Combustion $\mathrm{CO}_{2}$ Capture from Power Plant Flue Gas", DOE/NETL 3rd Annual Conference on Carbon Sequestration, Alexandria, VA, May 3-6, 2004.

26. Energy Information Administration/Electric Power Monthly, October 2004. 


\subsection{Bibliography}

N/A 


\subsection{List of Acronyms and Abbreviations}

\begin{tabular}{ll} 
A & Absorptivity \\
$\sigma$ & Stefan-Boltzmann constant \\
$\varepsilon$ & Emissivity \\
ACI & Activated Carbon Injection \\
ASU & Air separation unit \\
CF & Capacity Factor \\
CFD & Computational fluid dynamics \\
CO $_{2}$ & Carbon Dioxide \\
COE & Cost or Electricity \\
E & Emission of CO \\
EIA & Energy Information Agency \\
EOR & Enhanced Oil Recovery \\
EPRI & Electric Power Research Institute \\
ESP & Electrostatic Precipitator \\
FD & Forced draft \\
FEGT & Furnace exit gas temperature \\
FGD & Flue Gas Desulfurization \\
FW & Foster Wheeler \\
FW-FIRE & Fossil fuel, Water-walled Furnace $\quad$ Integrated $\quad$ Reaction $\quad$ and \\
& Emission Simulation \\
GE & General Electric Company \\
$\mathrm{H}_{2} S$ & Hydrogen Sulfide \\
HHV & Higher heating value \\
HRA & Heat recovery area \\
HRSG & Heat Recovery Steam Generator \\
ID & Induced draft \\
IEA & International Energy Agency \\
IGCC & Integrated Coal Gasification Combined Cycle \\
ITM & lon Transport Membrane \\
LCC & Levelized Carrying Charge \\
LCM & Levelized Consumables \\
LFC & Levelized Fuel Costs \\
LFOM & Levelized Fixed O\&M \\
LHV & Lower heating value \\
LOI & Loss on ignition \\
LSD & Limestone Spray Dryer \\
LVOM & Levelized Variable O\&M \\
MC & Mitigation Cost (CO 2 ) \\
MEA & Monoethanolamine \\
$\mathrm{N}_{2}$ & Nitrogen \\
NGCC & Natural Gas Combined Cycle \\
NOx & Nitrogen oxides \\
O\&M & Operation and Maintenance \\
& \\
& \\
\hline
\end{tabular}




$\begin{array}{ll}\mathrm{O}_{2} & \text { Oxygen } \\ \text { OEC } & \text { Oxygen Enhanced Combustion } \\ \text { OFA } & \text { Over-fired air } \\ \text { OFG } & \text { Over-fire gas } \\ \text { OTM } & \text { Oxygen Transport Membrane } \\ \text { PA } & \text { Primary Air } \\ \text { PG } & \text { Primary Gas } \\ \text { PC } & \text { Pulverized coal } \\ \text { PDF } & \text { Probability density function } \\ \text { ppmv } & \text { Parts Per Million by Volume } \\ \text { PRB } & \text { Powder River Basin } \\ \text { Q/A } & \text { Heat Flux } \\ \text { SC } & \text { Super Critical Pressure } \\ \text { SCR } & \text { Selective catalytic reactor } \\ \text { SO } & \text { Sulfur Dioxide } \\ \text { SOx } & \text { Oxides of Sulfur } \\ \text { T } & \text { Temperature } \\ \text { TCR } & \text { Total Capital Requirement } \\ \text { TEG } & \text { Triethyleneglycol } \\ \text { TPC } & \text { Total Plant Cost } \\ \text { TPI } & \text { Total Plant Investment } \\ \text { U } & \text { Heat transfer coefficient } \\ \text { U.S. } & \text { United States } \\ \text { UBC } & \text { Unburned carbon loss } \\ \text { USC } & \text { Ultra Super Critical Pressure }\end{array}$

